\title{
ANÁLISE DO CONTEÚDO HARMÔNICO NA ENTRADA DE SUBESTAÇÕES RETIFICADORAS FERROVIÁRIAS
}

Dissertação apresentada à Escola Politécnica da Universidade de São Paulo para obtenção do título de Mestre em Ciências 


\section{ANÁLISE DO CONTEÚDO HARMÔNICO NA ENTRADA DE SUBESTAÇÕES RETIFICADORAS FERROVIÁRIAS}

Dissertação apresentada à Escola Politécnica da Universidade de São Paulo para obtenção do título de Mestre em Ciências

Área de concentração:

Sistemas de Potência

Orientador: Prof. Dr. Walter Kaiser

São Paulo 
Este exemplar foi revisado e alterado em relação à versão original, sob responsabilidade única do autor e com a anuência de seu orientador.

São Paulo, de agosto de 2012.

Assinatura do autor

Assinatura do orientador

\section{FICHA CATALOGRÁFICA}

\section{Zakowicz, Rafael}

Análise do conteúdo harmônico na entrada de subestações retificadoras ferroviárias / R. Zakowicz. -- ed.rev. -- São Paulo, 2012.

$100 p$.

Dissertação (Mestrado) - Escola Politécnica da Universidade de São Paulo. Departamento de Engenharia de Energia e Automação Elétricas.

1.Ferrovias (Sistemas) 2.Análise de desempenho 3.Simulação 4.Teoria da eletricidade I.Universidade de São Paulo. Escola Politécnica. Departamento de Engenharia de Energia e Automação Elétricas II.t. 


\section{AGRADECIMENTOS}

Ao Prof. Dr. Walter Kaiser, pela orientação e pelo constante estímulo transmitido durante todo o trabalho.

Aos professores Dr. Wilson Komatsu e Dr. Lourenço Matakas Júnior, pela colaboração e ensinamentos ao longo do curso.

Em memória do Prof. Dr. Clóvis Goldemberg, pelos ensinamentos e pelo incentivo à construção deste trabalho.

Ao Dr. Mário Leite Pereira Filho, do Instituto de Pesquisas Tecnológicas, pelo apoio e incentivo transmitidos que tornaram possível a realização deste trabalho.

Ao Dr. Cassiano Lobo Pires, da Companhia do Metrô de São Paulo, pela colaboração e ensinamentos ao longo do curso.

Aos engenheiros da CPTM José Antônio de Filippi, Durval Maggioni Finotto, Tomas Toledo Arruda e Paulo Roberto dos Santos Spinola Costa pelos dados fornecidos que tornaram possível a modelagem do estudo de caso aqui apresentado e a Luiz Carlos Bartholomeu pelo auxílio nas medições realizadas nas subestações.

Aos engenheiros do ENERQ, Centro de Estudos em Regulação e Qualidade de Energia, da USP, Dr. Sílvio Xavier Duarte e Tiago Poles de Souza, pelo auxílio nas medições.

Aos amigos Antônio Francisco Gentil Ferreira Júnior, Eduardo Berruezo, Lucas Blattner Martinho, Régis Renato Dias, Rima Yehia e Tomie Yokoji pelos conselhos que muito animaram o meu espírito.

À minha querida amiga Paulina Neyde Beltrame Romano, a Tia Neyde, pelo constante incentivo e auxílios de toda ordem para a elaboração desta dissertação.

Ao Conselho Nacional de Desenvolvimento Científico e Tecnológico, CNPq, pelo auxílio financeiro.

E a todos que de alguma forma contribuíram para a realização deste trabalho. 


\section{RESUMO}

O objetivo deste trabalho é realizar medições de distorção de tensão e corrente na entrada de subestações que alimentam sistemas ferroviários e verificar se estas atendem às normas IEEE - 519:1992 e IEC 61000-3-6:2008. Foram realizadas medições durante uma semana nas subestações retificadoras Tietê e Jaraguá, ambas da CPTM. Os resultados das medições foram comparados com simulações computacionais baseadas em um modelo simplificado do sistema de alimentação.

Palavras-chave: Eletrônica de potência. Distorções harmônicas. Tração ferroviária. 


\begin{abstract}
This study reports an experimental assessment of current and voltage distortion at the ac side of railway power supply installations and their compliance with the IEEE-519: 1992 and IEC 61000-3-6: 2008 standards. All experimental measurements were conducted using a commercially available power quality analyzer installed during a week at the CPTM rectifier substations of Tietê and Jaraguá. A simplified model was applied to computer simulations in order to calibrate the model through the comparison with experimental results.
\end{abstract}

Keywords: Power electronics. Harmonic distortions. Railway electric traction. 


\section{LISTA DE FIGURAS}

Fig. 2.1 - Esquema de um sistema de alimentação ferroviário CA/CC....................................4

Fig. 2.2 - Sistema de alimentação utilizando terceiro trilho.......................................................5

Fig. 2.3 - Detalhe do pantógrafo e da catenária.....................................................................

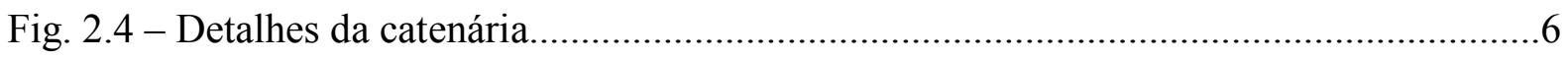

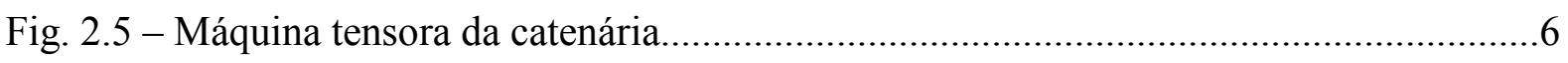

Fig. 2.6 - Arranjo típico de um sistema de alimentação ferroviário.........................................7

Fig. 2.7 - Arranjo de um retificador de 12 pulsos utilizando pontes de diodos em série...........7

Fig. 2.8 - Curva da DHTv em um período de 24 horas (PRUDENZI, 2003).........................11

Fig. 2.9 - Curva da DHTv em um período de 24 horas (GOLDEMBERG et al, 2005)...........12

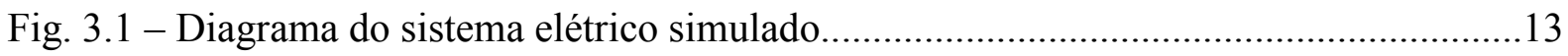

Fig. 3.2 - Modelo equivalente do transformador de potência abaixador de tensão..................14

Fig. 3.3 - Modelo equivalente do transformador de 3 enrolamentos.....................................15

Fig. 3.4 - Circuito equivalente do transformador de 3 enrolamentos.....................................15

Fig. 3.5 - Modelo utilizado para representar a linha de transmissão........................................16

Fig. 3.6 - Modelo equivalente da carga representada pelo trem com filtro LC de entrada......18

Fig. 4.1 - Diagrama de blocos do sistema elétrico da CPTM e localização do medidor RMS. .20

Fig. 4.2 - Transformador de potência abaixador $88 \mathrm{kV} / 34,5 \mathrm{kV}$ da subestação Tietê.

Fig. 4.3 - Distâncias entre as subestações (lado CA) e as estações de passageiros

(lado CC)

Fig. 4.4 - Intervalo de tempo, em minutos, entre trens (dias úteis).

Fig. 4.5 - Número de trens entre as estações de passageiros Piqueri e Jaraguá (dias úteis).....23

Fig. 4.6 - Número de trens entre as estações de passageiros Água Branca e Perus (dias úteis).

Fig. 4.7 - Registro da corrente CA ao longo da semana em Tietê.........................................24

Fig. 4.8 - Registro da DHTv ao longo da semana em Tietê..................................................25

Fig. 4.9 - Registro da tensão na entrada de Tietê na quinta-feira, 20/10/2011 ........................26

Fig. 4.10 - Registro da componente fundamental da corrente na entrada de Tietê..................27

Fig. 4.11 - Registro da DHTv na entrada de Tietê na quinta-feira, 20/10/2011_.....................27

Fig. 4.12 - Espectro da tensão do registro no instante de menor DHTv em Tietê...................28

Fig. 4.13 - Espectro da tensão do registro no instante de maior DHTv em Tietê....................28 
Fig. 4.14 - Registro das harmônicas de tensão de $5^{\mathrm{a}}$ e $7^{\mathrm{a}}$ ordens em Tietê.

Fig. 4.15 - Registro das harmônicas de tensão de ordens 11, 13, 23 e 25 em Tietê......

Fig. 4.16 - Registro das harmônicas de corrente de $5^{\mathrm{a}}$ e $7^{\mathrm{a}}$ ordens em Tietê............................30

Fig. 4.17 - Registro das harmônicas de corrente de ordens 11, 13, 23 e 25 em Tietê..............31

Fig. 4.18 - Registro da DHTi na subestação Tietê.................................................................31

Fig. 4.19 - Forma de onda e espectro da corrente na subestação Tietê às 7h00,

$20 / 10 / 2011$

Fig. 4.20 - Forma de onda e espectro da corrente na subestação Tietê às 12h00, $20 / 10 / 2011$

Fig. 4.21 - Forma de onda e espectro da corrente na subestação Tietê às 22h00, 20/10/2011.

Fig. 4.22 - Registro da DTD na entrada de Tietê.

Fig. 4.23 - Registro das componentes harmônicas não-características de corrente de $5^{\text {a }}$ e $7^{\mathrm{a}}$ ordens em porcentagem de IL na entrada de Tietê.

Fig. 4.24 - Registro das componentes harmônicas características de corrente de $11^{\mathrm{a}}, 13^{\mathrm{a}}$, $23^{\mathrm{a}}$ e $25^{\mathrm{a}}$ ordens, em porcentagem de IL, na entrada de Tietê.

Fig. 4.25 - Registro do fator de defasagem na entrada de Tietê. 36

Fig. 4.26 - Registro do fator de potência real na entrada de Tietê. 37

Fig. 4.27 - Registro da corrente CA ao longo da semana de medições em Jaraguá......

Fig. 4.28 - Registro da DHT de tensão ao longo da semana de medições em Jaraguá.. 40

Fig. 4.29 - Registro da tensão na entrada de Jaraguá na quinta-feira, 09/02/2012.

Fig. 4.30 - Registro da componente fundamental da corrente na entrada de Jaraguá. . .41

Fig. 4.31 - Registro da DHTv na entrada de Jaraguá.....

Fig. 4.32 - Espectro da tensão do registro no instante de menor DHTv em Jaraguá. .42

Fig. 4.33 - Espectro da tensão do registro no instante de maior DHTv em Jaraguá. .43

Fig. 4.34 - Registro das harmônicas de tensão de $5^{\mathrm{a}}$ e $7^{\mathrm{a}}$ ordens em Jaraguá.

Fig. 4.35 - Registro das harmônicas de tensão de ordens 11, 13, 23 e 25 em Jaraguá..

Fig. 4.36 - Registro das harmônicas de corrente de $5^{\mathrm{a}}$ e $7^{\mathrm{a}}$ ordens em Jaraguá.........................44

Fig. 4.37 - Registro das harmônicas de corrente de ordens 11, 13, 23 e 25 em Jaraguá..........45

Fig. 4.38 - Registro da DHTi na entrada de Jaraguá............................................................45

Fig. 4.39 - Forma de onda e espectro da corrente na subestação Jaraguá às 7 h00...................46

Fig. 4.40 - Forma de onda e espectro da corrente na subestação Jaraguá às $12 \mathrm{~h} 00$.................46

Fig. 4.41 - Forma de onda e espectro da corrente na subestação Jaraguá às 23 h00.................46

Fig. 4.42 - Registro da DTD na entrada de Jaraguá..................................................................47 
Fig. 4.43 - Registro das componentes harmônicas não-características de corrente de $5^{\text {a }}$ e $7^{\mathrm{a}}$ ordens em porcentagem de IL na entrada de Jaraguá.

Fig. 4.44 - Registro das componentes harmônicas características de corrente de $11^{\mathrm{a}}$,

$13^{\mathrm{a}}, 23^{\mathrm{a}}$ e $25^{\mathrm{a}}$ ordens, em porcentagem de IL, na entrada de Jaraguá..... 48

Fig. 4.45 - Resultado das medições e simulações para a $11^{\mathrm{a}}$ harmônica de tensão em Tietê...50 Fig. 4.46 - Resultado das medições e simulações para a $13^{\mathrm{a}}$ harmônica de tensão em Tietê...51 Fig. 4.47 - Resultado das medições e simulações para a 23a harmônica de tensão em Tietê...51 Fig. 4.48 - Resultado das medições e simulações para a $25^{\mathrm{a}}$ harmônica de tensão em Tietê...52 Fig. 4.49 - Resultado das medições e simulações para a $11^{\text {a }}$ harmônica de corrente em Tietê....... .52

Fig. 4.50 - Resultado das medições e simulações para a $13^{\mathrm{a}}$ harmônica de corrente em

Tietê.

Fig. 4.51 - Resultado das medições e simulações para a 23a harmônica de corrente em Tietê. .53

Fig. 4.52 - Resultado das medições e simulações para a $25^{\mathrm{a}}$ harmônica de corrente em Tietê.. .54

Fig. 4.53 - Resultado das medições e simulações para a $11^{\mathrm{a}}$ harmônica de tensão em Jaraguá.

Fig. 4.54 - Resultado das medições e simulações para a $13^{\mathrm{a}}$ harmônica de tensão em Jaraguá

Fig. 4.55 - Resultado das medições e simulações para a 23 $3^{\mathrm{a}}$ harmônica de tensão em Jaraguá... .55

Fig. 4.56 - Resultado das medições e simulações para a $25^{\mathrm{a}}$ harmônica de tensão em Jaraguá.

Fig. 4.57 - Resultado das medições e simulações para a $11^{\mathrm{a}}$ harmônica de corrente em Jaraguá. .56

Fig. 4.58 - Resultado das medições e simulações para a $13^{\mathrm{a}}$ harmônica de corrente em Jaraguá..

Fig. 4.59 - Resultado das medições e simulações para a $23^{\mathrm{a}}$ harmônica de corrente em Jaraguá

Fig. 4.60 - Resultado das medições e simulações para a 25a harmônica de corrente em

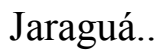
.58

Fig. C.1 - Registro da tensão de entrada em Tietê no domingo, 23/10/2011.

Fig. C.2 - Registro da corrente de entrada em Tietê no domingo, 23/10/2011... 
Fig. C.3 - Registro da DHTv na entrada de Tietê no domingo, 23/10/2011

Fig. C.4 - Espectro de tensão do registro no instante de maior DHTv em Tietê no domingo, 23/10/2011

Fig. C.5 - Espectro de tensão do registro no instante de menor DHTv em Tietê no domingo, $23 / 10 / 2011$ 68

Fig. C.6 - Registro das harmônicas de tensão de $5^{\mathrm{a}}$ e $7^{\mathrm{a}}$ ordens em Tietê no domingo, $23 / 10 / 2011$ .69

Fig. C.7 - Registro da 47a harmônica de tensão em Tietê no domingo, 23/10/2011. .69

Fig. C.8 - Registro da tensão de entrada em Jaraguá no domingo, 12/02/2012 ......................70

Fig. C.9 - Registro da corrente de entrada em Jaraguá no domingo, 12/02/2012 _..................70

Fig. C.10 - Registro da DHTv na entrada de Jaraguá no domingo, 12/02/2012 ....................71

Fig. C.11 - Espectro de tensão do registro no instante de maior DHTv em Jaraguá no domingo, $12 / 02 / 2012$.

Fig. C.12 - Espectro de tensão do registro no instante de menor DHT de tensão em Jaraguá no domingo, 12/02/2012.

Fig. C.13 - Registro das harmônicas de tensão de ordens 5, 7, 17 e 19 em Jaraguá no domingo, 12/02/2012

Fig. C.14 - Registro das harmônicas de tensão de ordens 11, 13, 23 e 25 em Jaraguá no domingo, $12 / 02 / 2012$ .72

Fig. D. 1 - Registro das harmônicas de corrente de $5^{\mathrm{a}}$ e $7^{\mathrm{a}}$ ordens em Tietê na terça-feira, $18 / 10 / 2011$ .73

Fig. D. 2 - Registro das harmônicas de corrente de $5^{\mathrm{a}}$ e $7^{\mathrm{a}}$ ordens em Tietê na quarta-feira, $19 / 10 / 2011$ .73

Fig. D.3 - Registro das harmônicas de corrente de $5^{\mathrm{a}}$ e $7^{\mathrm{a}}$ ordens em Tietê na quinta-feira, $20 / 10 / 2011$ .74

Fig. D. 4 - Registro das harmônicas de corrente de $5^{\mathrm{a}}$ e $7^{\mathrm{a}}$ ordens em Tietê na sexta-feira,

$21 / 10 / 2011$

Fig. D.5 - Registro das harmônicas de corrente de $5^{\mathrm{a}}$ e $7^{\mathrm{a}}$ ordens em Tietê no sábado, $22 / 10 / 2011$ .75

Fig. D.6 - Registro das harmônicas de corrente de $5^{\mathrm{a}}$ e $7^{\mathrm{a}}$ ordens em Tietê no domingo, $23 / 10 / 2011$ .75

Fig. D.7 - Registro das harmônicas de tensão de $5^{\mathrm{a}}$ e $7^{\mathrm{a}}$ ordens em Tietê na terça-feira, $18 / 10 / 2011$ 
Fig. D.8 - Registro das harmônicas de tensão de $5^{\mathrm{a}}$ e $7^{\mathrm{a}}$ ordens em Tietê na quarta-feira, $19 / 10 / 2011$

Fig. D. 9 - Registro das harmônicas de tensão de $5^{\mathrm{a}}$ e $7^{\mathrm{a}}$ ordens em Tietê na quinta-feira, $20 / 10 / 2011$

Fig. D. 10 - Registro das harmônicas de tensão de $5^{\mathrm{a}}$ e $7^{\mathrm{a}}$ ordens em Tietê na sexta-feira, $21 / 10 / 2011$

Fig. D.11 - Registro das harmônicas de tensão de $5^{\mathrm{a}}$ e $7^{\mathrm{a}}$ ordens em Tietê no sábado, $22 / 10 / 2011$ .78

Fig. D. 12 - Registro das harmônicas de tensão de $5^{\mathrm{a}}$ e $7^{\mathrm{a}}$ ordens em Tietê no domingo, $23 / 10 / 2011$

Fig. D.13 - Registro das harmônicas de corrente de $5^{\mathrm{a}}$ e $7^{\mathrm{a}}$ ordens em Jaraguá na quinta-feira, 09/02/2012

Fig. D. 14 - Registro das harmônicas de corrente de $5^{\mathrm{a}}$ e $7^{\mathrm{a}}$ ordens em Jaraguá no sábado, 11/02/2012. .79

Fig. D.15 - Registro das harmônicas de corrente de $5^{\mathrm{a}}$ e $7^{\mathrm{a}}$ ordens em Jaraguá no domingo, $12 / 02 / 2012$

Fig. D. 16 - Registro das harmônicas de corrente de $5^{\mathrm{a}}$ e $7^{\mathrm{a}}$ ordens em Jaraguá na quarta-feira, 15/02/2012.

Fig. D. 17 - Registro das harmônicas de corrente de $5^{\mathrm{a}}$ e $7^{\mathrm{a}}$ ordens em Jaraguá na quinta-feira, 16/02/2012.

Fig. D.18 - Registro das harmônicas de tensão de $5^{\mathrm{a}}$ e $7^{\mathrm{a}}$ ordens em Jaraguá na quinta-feira, 09/02/2012.

Fig. D.19 - Registro das harmônicas de tensão de $5^{\mathrm{a}}$ e $7^{\mathrm{a}}$ ordens em Jaraguá no sábado, $11 / 02 / 2012$

Fig. D.20 - Registro das harmônicas de tensão de $5^{\mathrm{a}}$ e $7^{\mathrm{a}}$ ordens em Jaraguá no domingo, $12 / 02 / 2012$ .82

Fig. D.21 - Registro das harmônicas de tensão de $5^{\mathrm{a}}$ e $7^{\mathrm{a}}$ ordens em Jaraguá na quarta-feira, 15/02/2012.

Fig. D.22 - Registro das harmônicas de tensão de $5^{\mathrm{a}}$ e $7^{\mathrm{a}}$ ordens em Jaraguá na quinta-feira, 16/02/2012 


\section{LISTA DE TABELAS}

Tabela 3.1 - Impedâncias em p.u. dos transformadores retificadores de Tietê e Jaraguá.........15

Tabela 3.2 - Impedâncias em ohms dos transformadores retificadores de Tietê e Jaraguá.......16

Tabela 3.3 - Parâmetros do cabo da linha de transmissão.......................................................17

Tabela 4.1 - Limites de amplitudes de harmônicas de corrente em porcentagem da corrente de carga para sistemas com níveis de tensão de 69 kV a 161 kV e conversores com 12 pulsos.

Tabela 4.2 - Períodos em que as harmônicas características de corrente ultrapassaram o limite recomendado pela IEEE-519 na subestação Tietê.

Tabela 4.3 - Limites de amplitudes de harmônicas de corrente em porcentagem da corrente de carga para sistemas com níveis de tensão de 120 V a 69 kV e conversores com 12 pulsos.

Tabela A1.1 - Limites de Distorção da Corrente - Distribuição $\left(120 \mathrm{~V} \leq \mathrm{V}_{\text {Nom }} \leq 69 \mathrm{kV}\right) \ldots . . .84$

Tabela A1.2 - Limites de Distorção da Corrente - Subtransmissão

$\left(69 \mathrm{kV}<\mathrm{V}_{\text {Nom }} \leq 161 \mathrm{kV}\right)$.

Tabela A1.3 - Limites de Distorção de Tensão (em porcentagem da componente fundamental de tensão)

Tabela A2.1 - Níveis de harmônicas de tensão (em porcentagem da componente fundamental de tensão) para sistemas de potência de média e alta tensão. .85

Tabela A3.1 - Valores de referência para distorções harmônicas totais de tensão

(em porcentagem da componente fundamental de tensão) . .86

Tabela A3.2 - Limites máximos para componentes harmônicas individuais de tensão (em porcentagem da tensão fundamental). 


\section{SUMÁRIO}

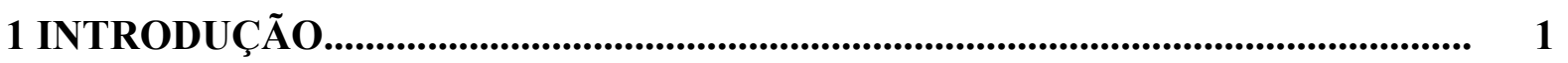

2 SISTEMA DE ALIMENTAÇÃO DE TRENS URBANOS......................................... 4

2.1 Impacto do conteúdo harmônico das subestações retificadoras na rede CA................. 8

2.2 Exemplos de medições de conteúdo harmônico em redes ferroviárias.......................... 10

3 MODELAGEM DO SISTEMA ELÉTRICO.......................................................... 13

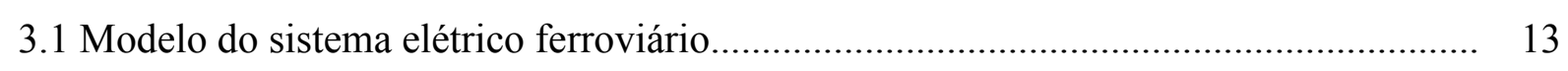

3.2 Modelo da alimentação elétrica do sistema ferroviário............................................... 14

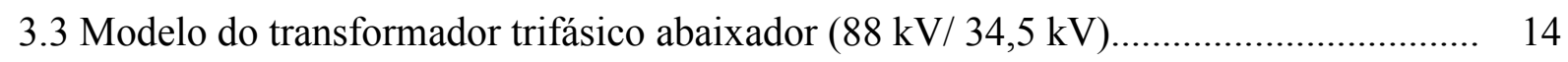

3.4 Modelo do transformador trifásico de 3 enrolamentos do retificador $(34,5 \mathrm{kV} / 1,25 \mathrm{kV}) .15$

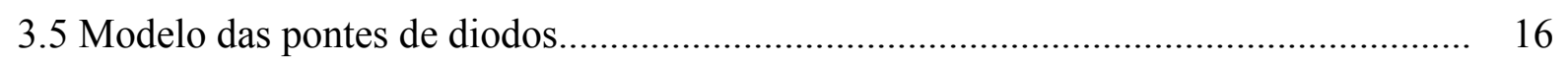

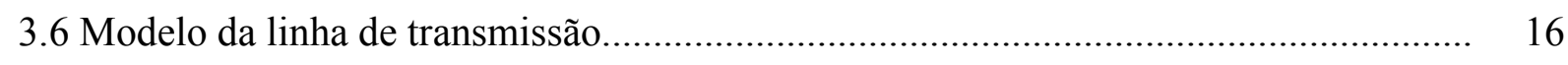

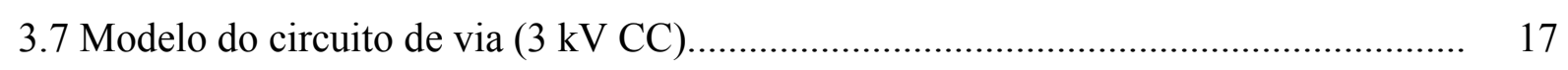

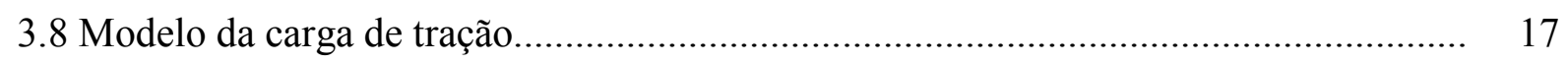

4 MEDIÇÕES E SIMULAÇÕES.................................................................................... 19

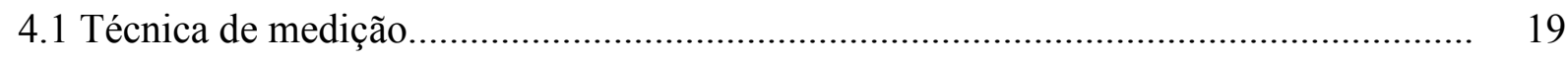

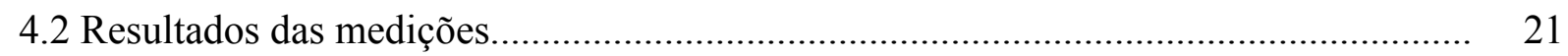

4.2.1 Registros das medições ao longo da semana em Tietê............................................ 24

4.2.2 Análises das medições na quinta-feira dia 20/10/2011 .......................................... 26

4.2.3Análise da distorção de tensão no barramento de $88 \mathrm{kV}$ (Tietê)................................ 28

4.2.4 Análise da distorção de corrente no barramento de $88 \mathrm{kV}$ (Tietê)........................... 30

4.2.5 Análise do Fator de Potência............................................................................... 36

4.2.6 Conclusões parciais de Tietê............................................................................. 38

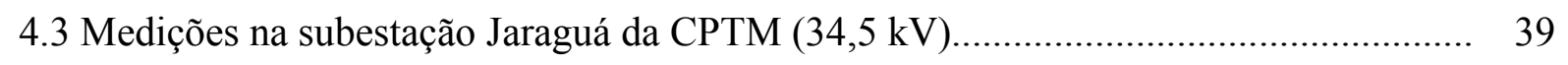

4.3.1 Análise da distorção de tensão no barramento de 34,5 kV (Jaraguá)........................ 42

4.3.2 Análise da distorção de corrente no barramento de 34,5 kV (Jaraguá)..................... 44

4.3.3 Conclusões parciais de Jaraguá............................................................................ 49

4.4 Resultados das simulações................................................................................ 50

4.4.1 Harmônicas de tensão em Tietê......................................................................... 50

4.4.2 Harmônicas de corrente em Tietê........................................................................ 52

4.4.3 Harmônicas de tensão em Jaraguá..................................................................... 54

4.4.4 Harmônicas de corrente em Jaraguá................................................................... 56 
5 CONCLUSÕES.

REFERÊNCIAS BIBLIOGRÁFICAS......................................................................... 62

APÊNDICE A - MODELO DA REDE ELÉTRICA EM MATLAB............................. 64

APÊNDICE B - DADOS DE ENTRADA PARA AS SIMULAÇÕES....................... 65

APÊNDICE C-MEDIÇÕES AOS DOMINGOS.............................................................. 67

APÊNDICE D - REGISTRO DAS MEDIÇÕES DE 5 E $7^{\mathrm{a}}$ HARMÔNICAS.......... 73

ANEXO A - NORMAS E RECOMENDAÇÕES PARA CONTEÚDO

HARMÔNICO EM REDES CA...................................................................................... 84 


\section{CAPÍTULO 1 \\ INTRODUÇÃO}

A mobilidade urbana é uma questão crucial no desenvolvimento das grandes cidades brasileiras. A demora nos deslocamentos, os longos congestionamentos e a falta de acesso ao transporte são problemas diretamente decorrentes do atual modelo de mobilidade adotado em São Paulo. O Plano Integrado de Transportes Urbanos para 2020 (PITU 2020) prevê a melhoria da acessibilidade e o aumento da mobilidade aos usuários do transporte coletivo. Dentro deste contexto, US\$ 600 milhões/ano estão sendo investidos para a recuperação e adequação da malha da Companhia Paulista de Trens Metropolitanos (CPTM), e, simultaneamente, a ampliação da malha da Companhia do Metropolitano de São Paulo (Metrô).

O transporte coletivo de passageiros na cidade de São Paulo é realizado por linhas de trem de superfície administradas pela Companhia Paulista de Trens Metropolitanos (CPTM), linhas de metrô vinculadas à Companhia do Metropolitano de São Paulo (Metrô) e frotas de ônibus geridas pela São Paulo Transporte S.A. (SPTrans) da prefeitura e pela Empresa Metropolitana de Transportes Urbanos de São Paulo (EMTU) do governo do Estado de São Paulo, esta responsável pelo transporte interurbano entre as cidades da Região Metropolitana de São Paulo.

Tanto os trens da CPTM, como os do Metrô são movidos a energia elétrica sendo não poluentes. Em ambos os casos, os trens-unidade elétricos são alimentados em corrente contínua, obtida de subestações retificadoras trifásicas ligadas em paralelo no lado CC e distribuída ao longo da via. As subestações retificadoras são alimentadas no lado CA por redes de distribuição proprietárias de cada empresa, que por sua vez são alimentadas pelo sistema de subtransmissão da concessionária de energia elétrica. Nos trens da CPTM a energia em corrente contínua é suprida através de uma rede suspensa denominada catenária, enquanto que nas linhas 1, 2 e 3 do metrô a transmissão de energia aos trens é feita através de um terceiro trilho próximo aos trilhos das vias.

Apesar das vantagens oferecidas por sistemas da tração elétrica, para as concessionárias de energia elétrica o sistema de tração é classificado como uma carga especial devido ao nível elevado de potência, por ser não linear e pelo fato de variar ao longo do dia. 
Uma vez que a corrente absorvida pelas subestações retificadoras é não senoidal, sob o ponto de vista da concessionária estas se comportam como geradores de harmônicos de corrente. Em função da sua potência elevada, a corrente de carga não senoidal provoca uma queda de tensão significativa na impedância interna da rede que pode resultar em distorções apreciáveis na tensão CA fornecida pela concessionária para outros consumidores.

Distorção harmônica é o termo usado para designar correntes e tensões distorcidas quando cargas não lineares são conectadas à rede elétrica. Cargas não lineares são aquelas que absorvem corrente não senoidal da rede. Retificadores, inversores, transformadores saturados, lâmpadas de descarga, motores de indução, controladores de velocidade programáveis, compensadores estáticos de reativos são exemplos de cargas não lineares. Essas cargas são representadas como fontes de harmônicas.

A existência de distorções harmônicas em sistemas elétricos é indesejável porque podem causar interferências em sistemas de controle computadorizados, aquecimento em máquinas rotativas reduzindo, portanto, sua vida útil, sobreaquecimento e falha de bancos de capacitores, interferência telefônica, perdas adicionais em linhas de transmissão e transformadores de potência, erros em medidores de energia etc.

Em alguns casos, determinados componentes harmônicos injetados na rede CA podem entrar em ressonância com componentes reativos da rede ou equipamentos conectados à mesma, provocando sobretensões e atuações de proteções. Este fenômeno é mais provável em instalações onde as subestações retificadoras são alimentadas por cabos subterrâneos, cujas blindagens necessárias para se obter o nível de isolação elétrica necessário tem um comportamento capacitivo.

O objetivo deste trabalho é medir o conteúdo harmônico na entrada de subestações retificadoras da CPTM, e analisar o impacto provocado na rede da concessionária com base nos critérios estabelecidos pelas normas IEC 61000-3-6:2008 e IEEE-519:1992. Além das medições, propõe-se uma modelagem em ambiente Matlab para, através de simulações computacionais, obter uma ferramenta de estimativa dos níveis harmônicos de auxílio na tomada de decisões de futuras modificações do sistema.

O texto desta dissertação está organizado em cinco capítulos.

O capítulo 1 apresenta uma introdução ao problema da determinação do conteúdo harmônico na entrada de subestações retificadoras alimentando sistemas de tração ferroviários e descreve a forma como o texto da dissertação está estruturado e organizado. 
O capítulo 2 descreve os principais componentes do sistema de alimentação de trens urbanos. São mostrados dois exemplos de medições de harmônicos no lado CA de sistemas ferroviários sendo um em Roma e o outro em São Paulo. Em ambos os casos os sistemas utilizam conversores trifásicos a diodos em ponte completa de 12 pulsos.

O capítulo 3 apresenta uma proposta de modelagem implementada em ambiente Matlab de um trecho do sistema elétrico da CPTM composto pelas subestações Tietê e Jaraguá.

O capítulo 4 descreve o método de medição para o conteúdo harmônico de tensões e correntes provenientes do sistema ferroviário modelado no capítulo 3 e apresenta os resultados obtidos das medições e das simulações desse sistema.

A conclusão do estudo é apresentada no capítulo 5, assim como sugestões para trabalhos futuros sobre o tema. 


\section{CAPÍTULO 2}

\section{SISTEMA DE ALIMENTAÇÃO DE TRENS URBANOS}

A grande maioria dos trens de transporte coletivo urbano no mundo é alimentada em corrente contínua. A energia é captada de um sistema de distribuição em corrente alternada, em geral proprietário da concessionária que opera os trens, que por sua vez é alimentado pelo sistema de subtransmissão da concessionária de energia elétrica. A conversão CA para CC é realizada em subestações retificadoras alocadas ao longo da linha e os níveis de tensão CC são estabelecidos pelas normas EN 51163 e IEC 60850. A figura 2.1 apresenta um sistema típico de alimentação ferroviária.

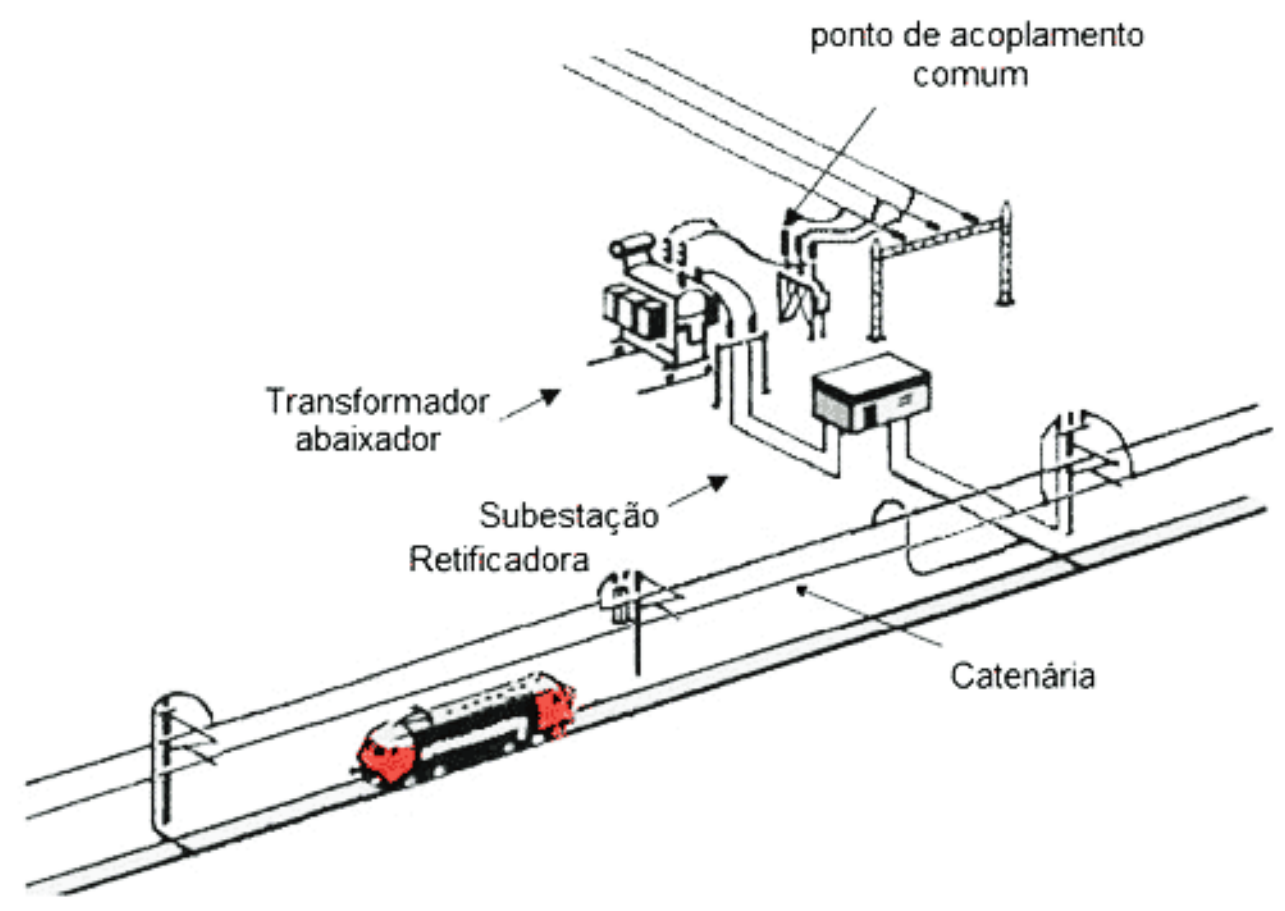

Fig. 2.1 - Esquema de um sistema de alimentação ferroviário CA/CC.

Na cidade de São Paulo a energia dos trens da CPTM e do Metrô provém de redes de distribuição próprias de $34,5 \mathrm{kV}$ e $22 \mathrm{kV}$ respectivamente, alimentadas pelo sistema em $88 \mathrm{kV}$ da concessionária de energia elétrica.

Os trens do Metrô são alimentados em 750 V CC nas linhas 1, 2 e 3, e a captação de corrente é feita por sapatas que deslizam por um terceiro trilho paralelo à via. Um sistema de alimentação pelo terceiro trilho é mostrado na figura 2.2. 


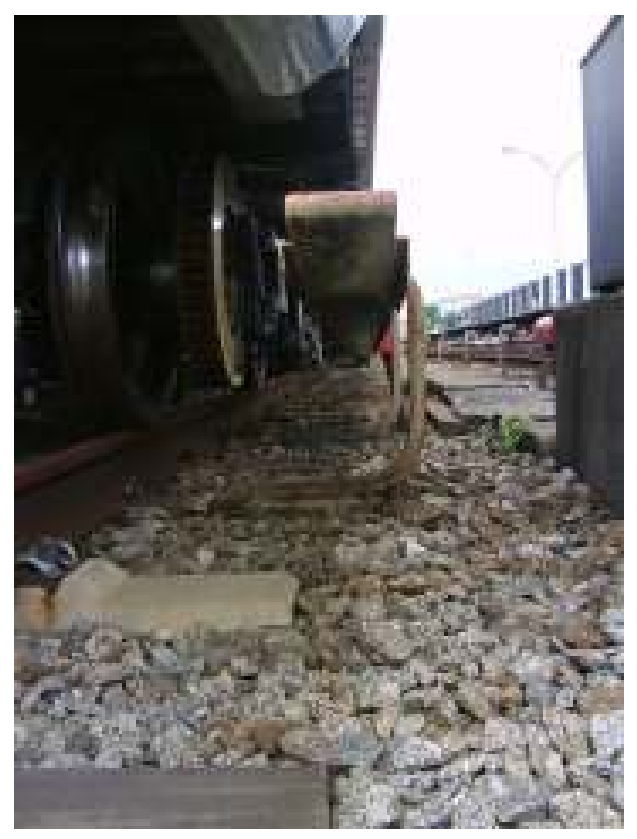

Terceiro trilho

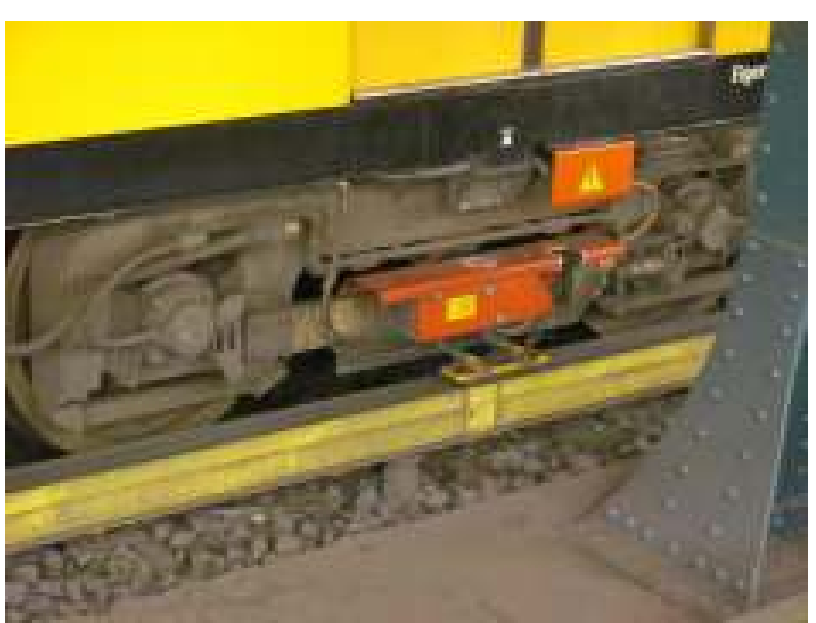

Detalhe da sapata de captação de corrente

Fig. 2.2 - Sistema de alimentação utilizando terceiro trilho.

Os trens urbanos e interurbanos da CPTM são alimentados por uma linha aérea de contato denominada catenária com tensão de $3 \mathrm{kV} \mathrm{CC}$ e a captação de corrente é feita através de pantógrafos como mostra a figura 2.3.

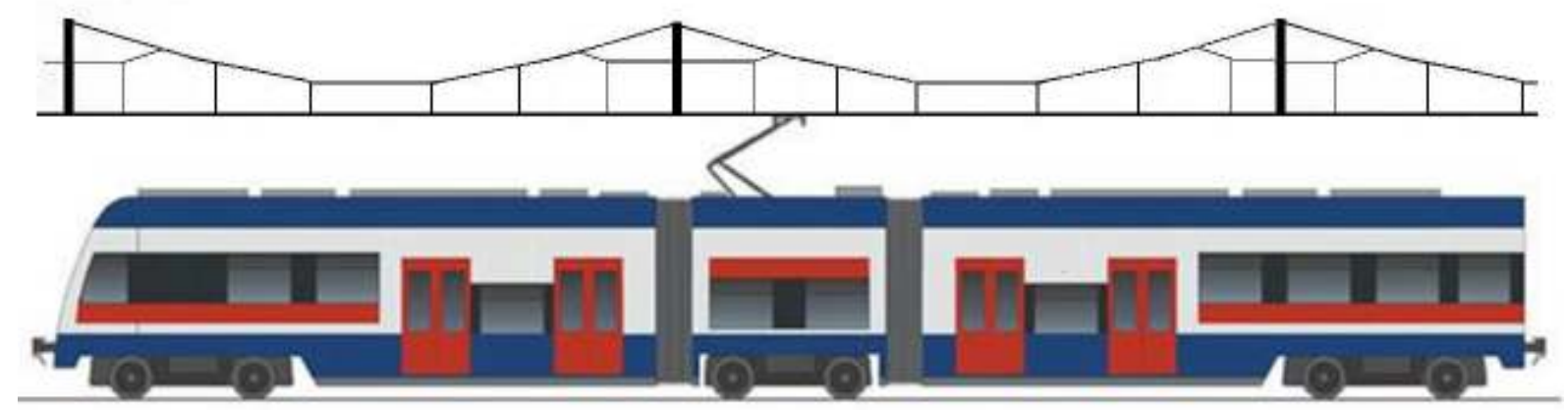

Fig. 2.3 - Detalhe do pantógrafo e da catenária.

Catenária é a designação matemática da forma geométrica que representa uma corda suspensa pelas suas extremidades e sujeita à ação da gravidade. Esta forma é bem visível nas linhas aéreas de alta tensão ou nas linhas de telefone. Os primeiros sistemas de tração elétrica alimentados por via aérea consistiam de apenas um fio devidamente suspenso em vários apoios. Porém, com o aumento da velocidade dos trens, foi necessário suspender o fio de alimentação através de um cabo mensageiro e de suspensórios (vide figura 2.4) para manter o condutor retilíneo sobre a via. O conjunto manteve o nome de catenária. 
(I) Alimentador

(II) Isoladores;

(III) Cabo do tirante

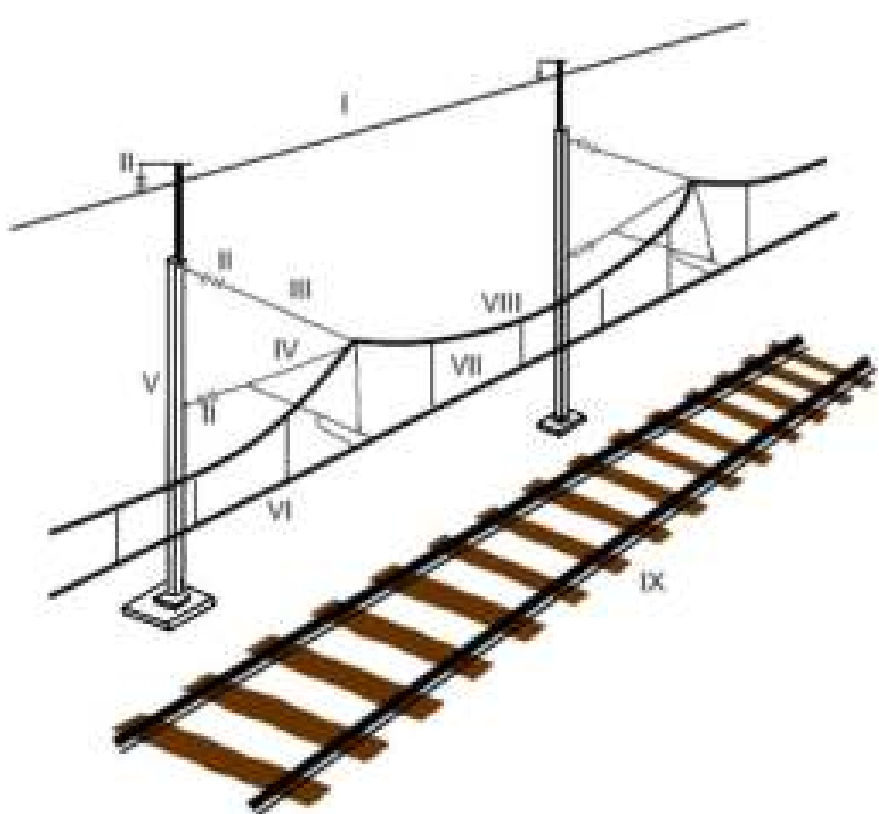

(IV) Braço do tirante;

(V) Postes;

(VI) Fio de contato;

(VII) Suspensórios;

(VIII) Cabo mensageiro;

(IX) Via de Rolamento

Para garantir uma boa conexão entre o pantógrafo e o fio de contato, este deve se manter tracionado. Porém, diferenças de temperatura registradas ao longo do ano fazem com que a flecha do fio de contato se altere. Para minimizar esse efeito, os condutores da catenária são submetidos a uma força que independe da temperatura. Para tanto é usado um sistema de pesos e roldanas mostrado na figura 2.5 nos quais os pesos sobem ou descem à medida que os fios se contraem ou dilatam. Trata-se da chamada rede aérea autocompensada, presente em algumas linhas da CPTM.

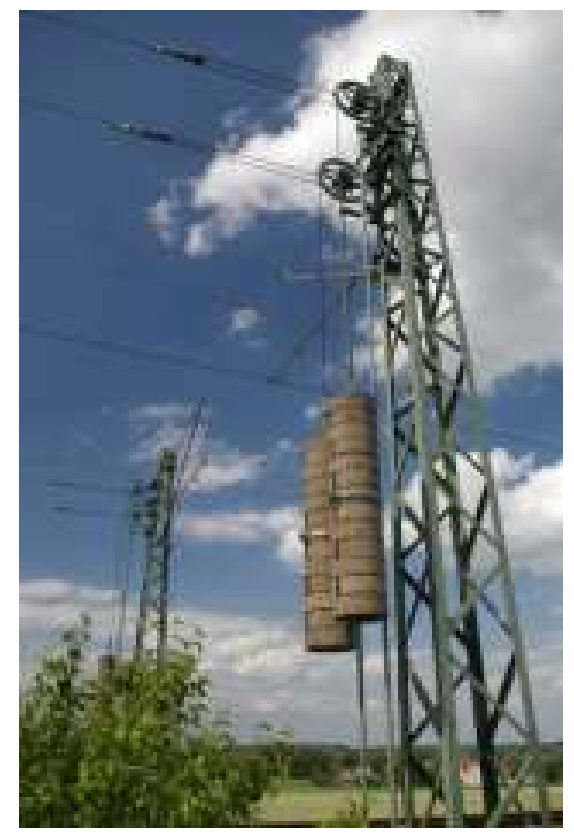

Fig. 2.5 - Máquina tensora da catenária. 
O arranjo típico de uma subestação retificadora é mostrado no diagrama unifilar da figura 2.6 (HILL, 1994). A ondulação de tensão CC é determinada pelo número de pulsos do retificador. Retificadores de 6 pulsos eram usados antigamente. A maioria dos sistemas de tração de transporte urbano utiliza retificadores de 12 pulsos, sendo que quanto maior o número de pulsos, menor será a ondulação. Existem sistemas que utilizam retificadores de 24 pulsos, embora sejam muito raros.

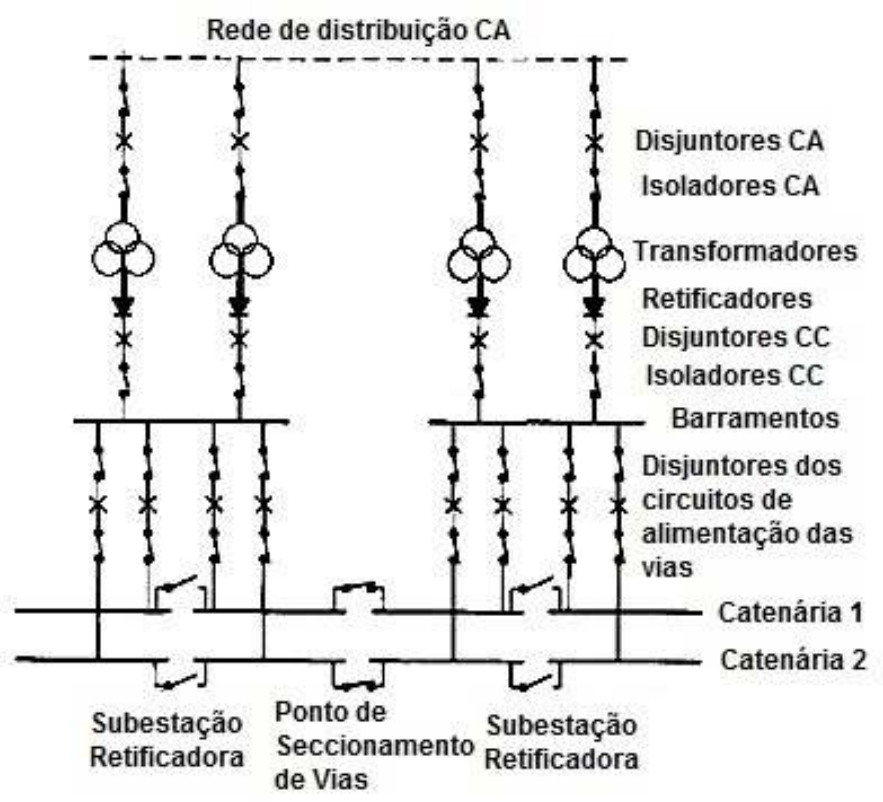

Fig. 2.6 - Arranjo típico de um sistema de alimentação ferroviário.

As subestações retificadoras da CPTM utilizam retificadores de 12 pulsos não controlados implementados através de duas pontes de Graetz a diodos de 6 pulsos ligadas em série. $\mathrm{O}$ conjunto é alimentado por um transformador de três enrolamentos, sendo um secundário ligado em delta e o outro em estrela, conforme mostrado na figura 2.7.

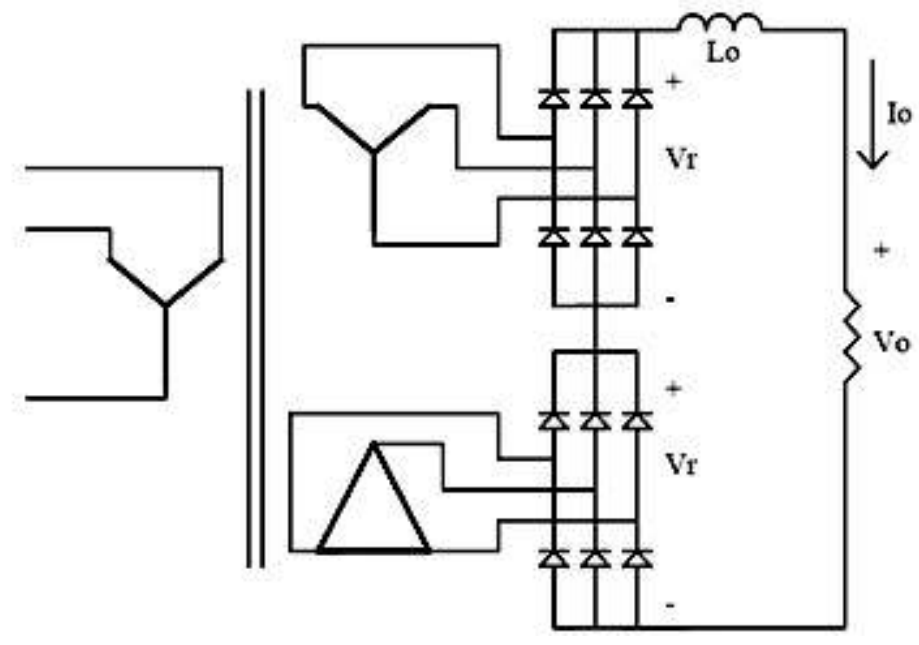

Fig. 2.7 - Arranjo de um retificador de 12 pulsos utilizando pontes de diodos em série. 
Transformadores com secundários acoplados são usados para otimizar a regulação de tensão e limitar a corrente de curto-circuito. A disposição dos enrolamentos determina a reatância de curto-circuito, e, consequentemente, a reatância de comutação e a regulação da tensão CC. A corrente no lado CC é filtrada através de um indutor de alisamento, cuja indutância é de $620 \mathrm{mH}$ nas subestações da CPTM.

As subestações retificadoras podem ser alimentadas por linhas de distribuição aéreas ou subterrâneas. As linhas subterrâneas necessitam de um investimento mais elevado em relação às linhas aéreas, porém são mais imunes às intempéries da natureza, principalmente a transitórios atmosféricos, e requerem menor manutenção. Por outro lado, a localização de faltas é mais complexa e seu reparo é mais oneroso.

\subsection{Impacto do conteúdo harmônico das subestações retificadoras na rede $\mathbf{C A}$}

As subestações retificadoras do sistema de tração são cargas não lineares de potência elevada (alguns MW) que injetam componentes harmônicas de corrente no sistema. As amplitudes das componentes harmônicas de retificadores ideais no lado CA são dadas por:

$$
\begin{gathered}
\mathrm{I}_{\mathrm{h}}=\frac{\mathrm{I}_{1}}{\mathrm{~h}} \\
\mathrm{~h}=\mathrm{n} \cdot \mathrm{p} \pm 1
\end{gathered}
$$

onde:

$\mathrm{I}_{1}$ - amplitude da componente fundamental;

h - ordem harmônica;

$\mathrm{n}$ - número inteiro positivo e;

$\mathrm{p}$ - número de pulsos do circuito retificador.

As harmônicas que seguem essa lei de formação são chamadas de harmônicas características.

No caso do retificador de 12 pulsos, as harmônicas características de corrente no lado CA são de ordem 11, 13, 23, 25, 35, 37, 47 e 49. Segundo as normas IEEE-519 e IEC 61000-3-6, harmônicas de ordens superiores à $50^{\mathrm{a}}$ ordem podem ser desprezadas. As componentes harmônicas de corrente que fluem através da impedância do sistema CA são responsáveis por harmônicos de tensão que deformam a tensão do alimentador. 
Na prática observam-se também componentes harmônicas não características em retificadores de 12 pulsos, como, por exemplo, harmônicas de $5^{\mathrm{a}}$ e $7^{\mathrm{a}}$ ordem, decorrentes de pequenos desequilíbrios nas impedâncias de cada fase do transformador.

Para quantificar o conteúdo harmônico faz-se necessária a definição de indicadores. $\mathrm{O}$ indicador mais usado para medir o conteúdo harmônico de uma forma de onda é a Distorção Harmônica Total (DHT). A DHT pode ser calculada para tensão ou para corrente e seu valor é obtido das expressões:

$$
\begin{gathered}
\operatorname{DHT}_{\mathrm{v}}=\frac{\sqrt{\sum_{\mathrm{h}=2}^{\mathrm{h}_{\text {max }}} \mathrm{V}_{\mathrm{h}}^{2}}}{\mathrm{~V}_{1}} \\
\mathrm{DHT}_{\mathrm{i}}=\frac{\sqrt{\sum_{\mathrm{h}=2}^{\mathrm{h}_{\mathrm{max}} \mathrm{I}_{\mathrm{h}}^{2}}}}{\mathrm{I}_{1}}
\end{gathered}
$$

onde:

h - número inteiro e representa a ordem harmônica;

$V_{h}$ - valor eficaz da componente de tensão harmônica $h$;

$\mathrm{V}_{1}$ - valor eficaz da tensão fundamental;

$I_{h} \quad$ - valor eficaz da componente de corrente harmônica h;

$I_{1} \quad$ - valor eficaz da corrente fundamental.

A norma IEC 61000-3-6 admite distorções harmônicas totais de tensão máximas de 3,0\% e de $6,5 \%$ em sistemas com tensão nominal entre $35 \mathrm{kV}$ e $230 \mathrm{kV}$, e entre $1 \mathrm{kV}$ e $35 \mathrm{kV}$, respectivamente. A IEEE-519 estabelece os limites de 2,5\% para distorções harmônicas totais de tensão em sistemas com tensão nominal entre $69 \mathrm{kV}$ e $161 \mathrm{kV}$, e de $5,0 \%$ para sistemas com tensão nominal menor que $69 \mathrm{kV}$.

A Distorção Total de Demanda (DTD) é utilizada para quantificar a distorção harmônica de corrente em relação à máxima demanda de 15 ou 30 minutos de corrente da carga. O DTD é definido matematicamente da seguinte forma:

$$
\mathrm{DTD}=\frac{\sqrt{\sum_{\mathrm{h}=2}^{\mathrm{h}_{\text {máx }} \mathrm{I}_{\mathrm{h}}^{2}}}}{\mathrm{I}_{\mathrm{L}}}
$$

onde:

$I_{L}$ é o valor da corrente de máxima demanda na frequência fundamental;

$I_{h}$ é o valor eficaz da componente de corrente harmônica h. 
Em sistemas já existentes, $I_{L}$ pode ser calculada como a média da máxima demanda de corrente para os últimos 12 meses. Em novos sistemas, deve-se estimar $I_{L}$ baseado em previsões de curvas de carga.

A diferença entre esse índice e o DHTi é que o DHTi calcula a distorção total de corrente em relação à corrente fundamental, enquanto que o DTD calcula a distorção total de corrente em relação à corrente de máxima demanda de carga.

O anexo A apresenta detalhes sobre os limites estabelecidos pelas normas.

\subsection{Exemplos de medições de conteúdo harmônico em redes ferroviárias}

O real impacto de um sistema de alimentação ferroviário e/ou metroviário na rede CA somente pode ser avaliado através de medições. Simulações computacionais fornecem uma boa aproximação, porém os modelos necessitam de um refinamento adicional para incorporar não idealidades existentes na rede real.

$\mathrm{Na}$ literatura encontram-se poucos estudos que trazem medições em redes ferroviárias e/ou metroviárias.

(PRUDENZI, 2003) apresenta medições em uma rede de distribuição em 20 kV que alimenta o sistema de transporte urbano ferroviário de Roma e adjacências, com $40 \mathrm{~km}$ de via. Esta rede encontra-se ligada através de cinco pontos a uma linha de transmissão de $150 \mathrm{kV}$ da concessionária e alimenta 14 subestações retificadoras responsáveis pelo suprimento de energia em 3,0 kV CC para os trens.

A demanda total do sistema varia de $20 \mathrm{MW}$ a $24 \mathrm{MW}$. Cada subestação retificadora é equipada com dois conversores trifásicos a diodos em ponte completa de 12 pulsos $(1,5 \mathrm{kV}$ e 3,5 MW) e dispõe ainda de 2 transformadores $(20 \mathrm{kV} / 400 \mathrm{~V})$ para alimentação de cargas auxiliares tais como iluminação, bombas, elevadores e escadas rolantes.

Os autores efetuaram medições durante períodos de 24 horas em dias úteis (operação normal dos trens) e em finais de semana para identificar componentes harmônicas que não provinham da carga de tração. Constatou-se que a curva de carga diária é fortemente influenciada pela lotação dos trens e pelo intervalo de tempo entre trens (headway).

As medições de DHTv mostram valores de 4\% a 5\% durante um dia útil no barramento de $150 \mathrm{kV}$ (potência de curto-circuito de $4150 \mathrm{MVA}$ ), conforme mostrado na figura 2.8. 
Esses valores encontram-se acima do limite máximo permitido pela IEEE-519 para este nível de tensão, que é de 2,5\%. Uma explicação para estes valores elevados é a presença de ressonância harmônica devido à alta capacitância dos cabos (PRUDENZI, 2003).

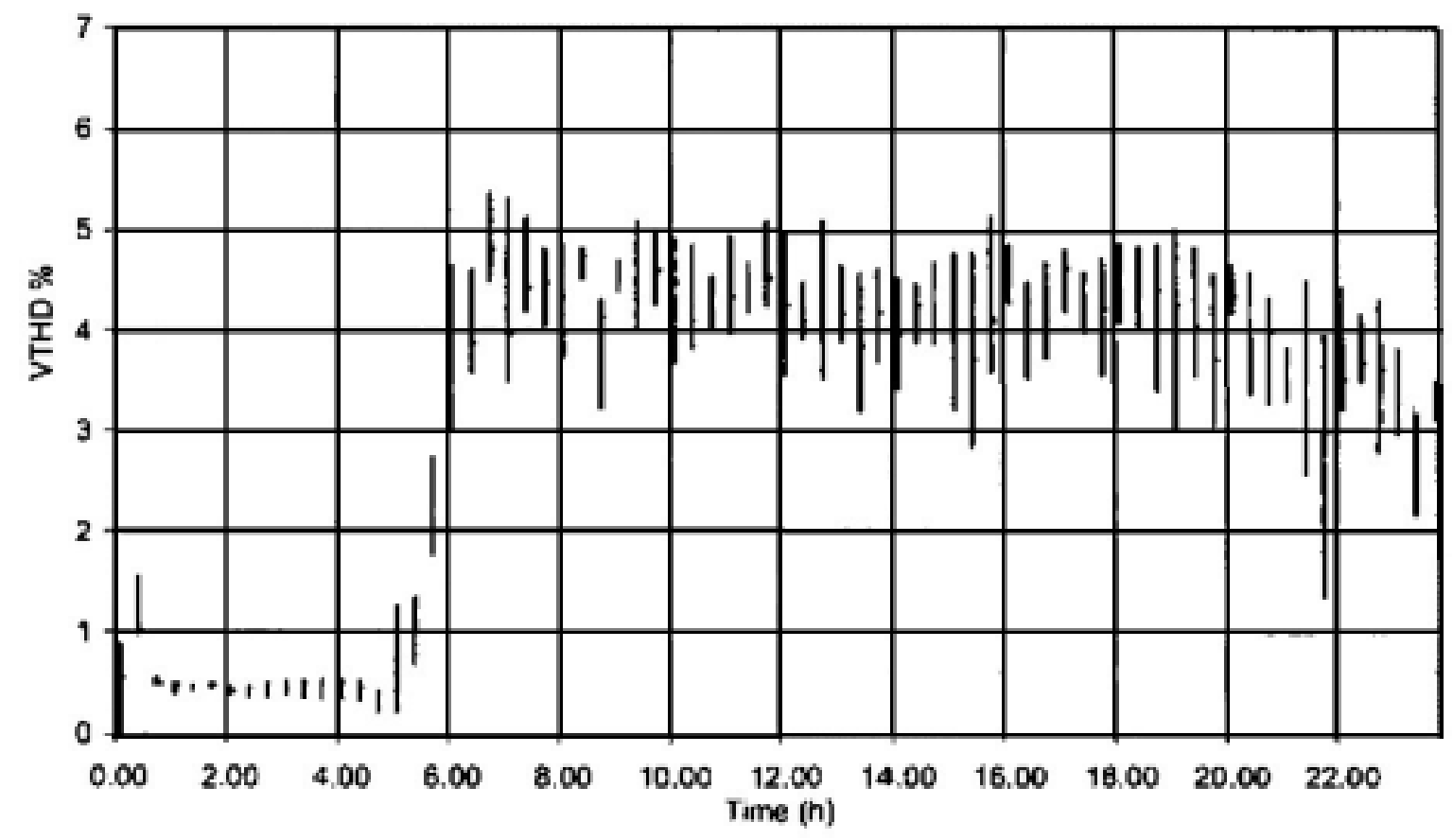

Fig. 2.8 - Curva da DHTv em um período de 24 horas (PRUDENZI, 2003).

Para determinação da distorção de tensão no ponto de acoplamento são necessárias medições durante intervalos de tempo em que não haja circulação de trens para se obter a contribuição de outros consumidores não relacionados com o sistema ferroviário.

Entre os dias 12 e 13 de abril de 2005, (GOLDEMBERG et al., 2005) realizaram medições para determinação do conteúdo harmônico na linha 2 do Metrô de São Paulo. Esta linha é composta por 8 subestações retificadoras distribuídas ao longo de aproximadamente $10 \mathrm{~km}$, suprindo os trens com tensão CC de $750 \mathrm{~V}$. O ponto de conexão com a concessionária fíca em uma subestação que possui dois transformadores 33,3 MVA e $88 \mathrm{kV} / 22 \mathrm{kV}$ ligados em paralelo. A potência de curto-circuito no primário dos transformadores é de 1470 MVA. Cada subestação retificadora é alimentada em $22 \mathrm{kV}$ e possui um conversor trifásico a diodos em ponte completa de 12 pulsos (750 V e 4,7 MVA) formado por duas pontes de Graetz de 6 pulsos ligadas em paralelo. O retificador é alimentado por um transformador de três enrolamentos, sendo um secundário ligado em delta e o outro em estrela. 
A figura 2.9 apresenta os resultados de medição no barramento de $88 \mathrm{kV}$ durante um dia útil. O instante 'zero' corresponde às 12:25:49 do dia 12/Abril/2005. Verifica-se que a distorção harmônica total de tensão varia de $0,43 \%$ a $1,93 \%$. Os valores estão em conformidade com as normas, uma vez que a IEEE-519 admite uma DHTv máxima de 2,5\% e a IEC admite uma DHTv de 3,0\% neste nível de tensão.

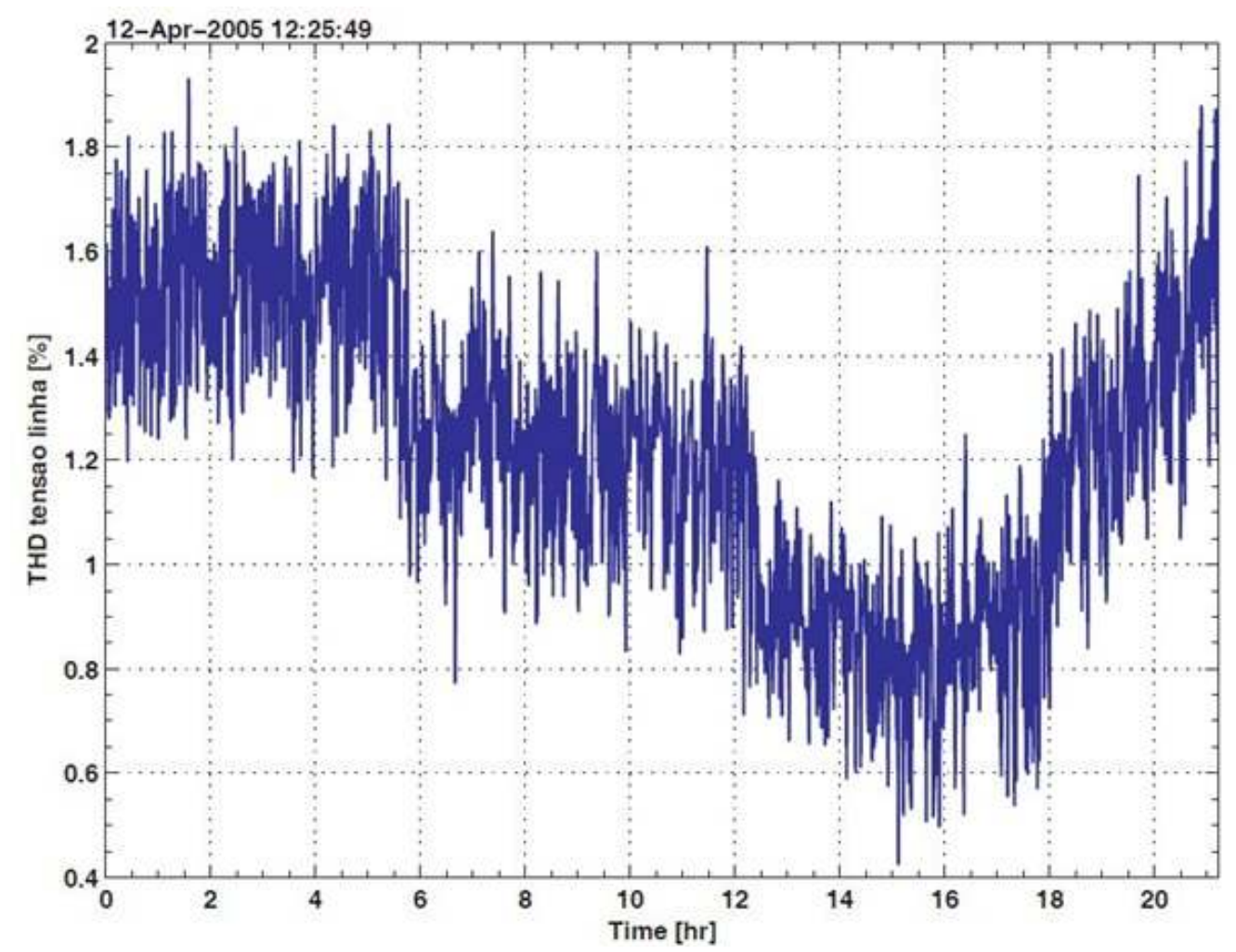

Fig. 2.9 - Curva da DHTv em um período de 24 horas (GOLDEMBERG et al, 2005).

O fato do sistema de tração apresentar uma dinâmica imposta pelo carregamento da via dificulta a avaliação do seu impacto na rede CA, tornando imprescindíveis medições durante um tempo longo. Ambas as medições mostram que a distorção harmônica de tensão é significativa e que a instalação de filtros pode se tornar necessária. 


\section{CAPÍTULO 3 \\ MODELAGEM DO SISTEMA ELÉTRICO}

\subsection{Modelo do sistema elétrico ferroviário}

O objetivo do presente estudo é modelar e simular um trecho de rede da Companhia Paulista de Trens Metropolitanos que compreende as subestações Tietê e Jaraguá. A análise é feita utilizando como ferramenta de simulação computacional o toolbox SimPowerSystems 5.1 do Matlab.

A modelagem não contempla os circuitos que alimentam os equipamentos auxiliares das estações, pois, considera-se que estes não produzem contribuições relevantes para este estudo. O modelo utilizado na simulação encontra-se no apêndice A. Os parâmetros do modelo encontram-se no apêndice B. A figura 3.1 apresenta um diagrama do trecho de rede simulado.

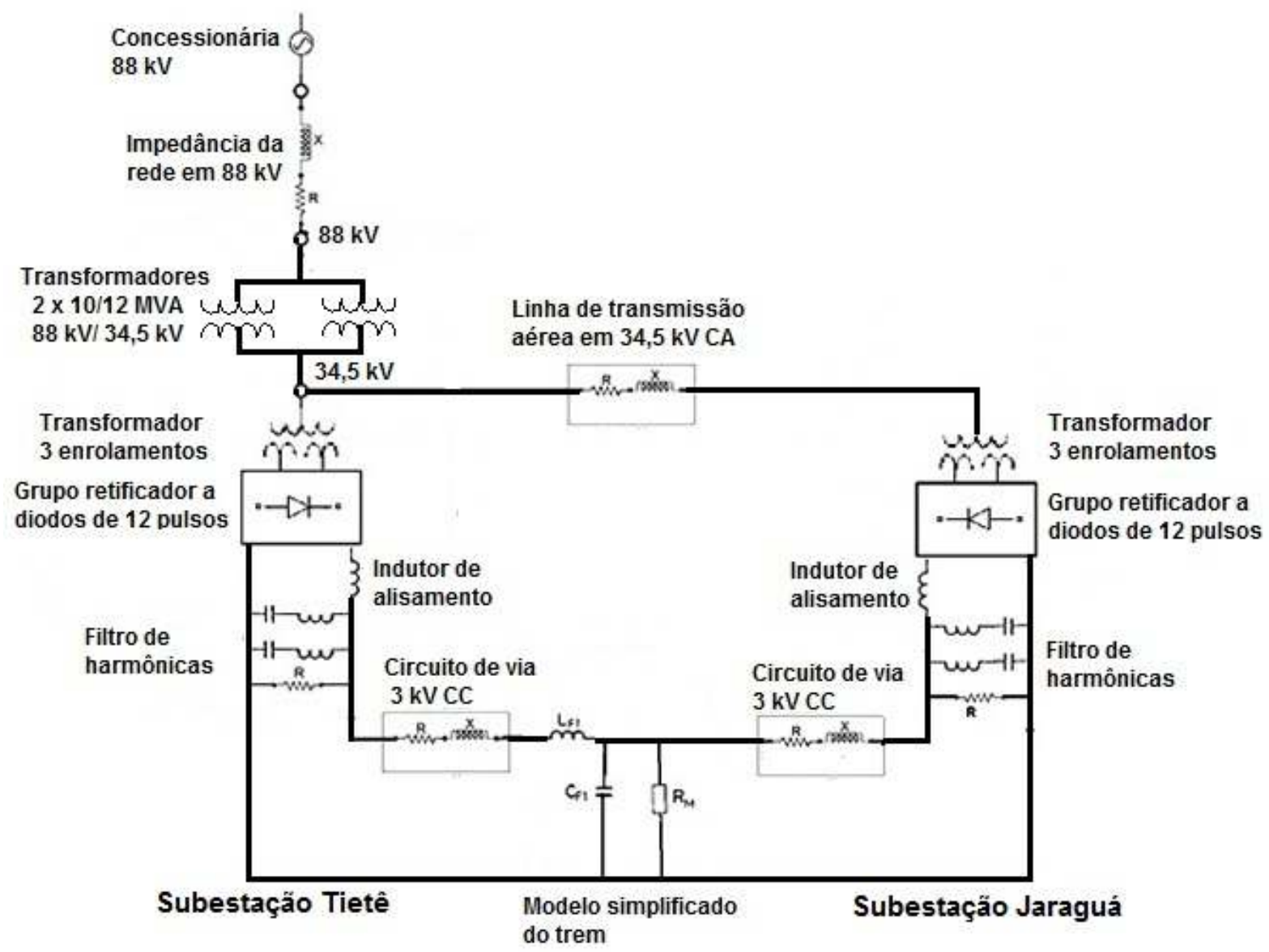

Fig. 3.1 - Diagrama do sistema elétrico simulado. 
A subestação Tietê possui três grupos retificadores de 12 pulsos ligados em paralelo, cada um com potência nominal de 4,22 MVA e formados por associação série de 2 pontes de diodos de 6 pulsos. Na subestação Jaraguá, distante $6,6 \mathrm{~km}$ de Tietê, estão instalados dois grupos retificadores de 12 pulsos ligados em paralelo, cada grupo com potência nominal de 4,22 MVA e também formados por associação em série de 2 pontes de diodos de 6 pulsos.

\subsection{Modelo da alimentação elétrica do sistema ferroviário}

A concessionária de energia elétrica é modelada através de uma fonte de tensão trifásica com uma impedância interna do tipo R-L. As três fases são conectadas em Y com neutro aterrado. São especificadas a tensão eficaz de linha, o ângulo da fase A da tensão de linha, a frequência, a potência de curto-circuito trifásica, a tensão de base e a razão Xcc/Rcc.

A reatância de curto-circuito, Xcc, é obtida a partir da potência de curto-circuito trifásico (VA), da tensão de linha de base (Vrms) e da frequência da rede:

$$
\mathrm{Xcc}=\frac{V_{\text {base }}^{2}}{\mathrm{~S}_{\mathrm{CC}}}
$$

A tensão de base, em volts rms, é usualmente a tensão nominal da rede.

\subsection{Modelo do transformador trifásico abaixador $(88 \mathrm{kV} / 34,5 \mathrm{kV})$}

O transformador trifásico abaixador com dois enrolamentos é modelado por três transformadores monofásicos. São especificadas a potência nominal e a frequência, as tensões de linha, as resistências e as indutâncias dos enrolamentos primário e secundário, e a resistência e reatância de magnetização.

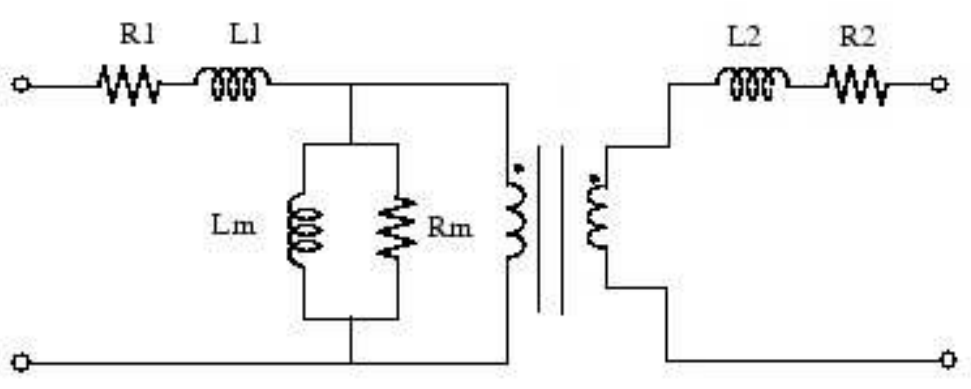

Fig. 3.2 - Modelo equivalente do transformador de potência abaixador de tensão. 


\subsection{Modelo do transformador trifásico de 3 enrolamentos do retificador}

\section{$(34,5 \mathrm{kV} / 1,25 \mathrm{kV})$}

Cada grupo retificador de 12 pulsos das subestações Tietê e Jaraguá é alimentado por um transformador trifásico de três enrolamentos, com impedância de curto-circuito de $6,33 \%$ e potência de base de $2110 \mathrm{kVA}$, cuja implementação é feita usando-se três transformadores monofásicos de três enrolamentos. A figura 3.3 mostra o modelo equivalente do transformador.
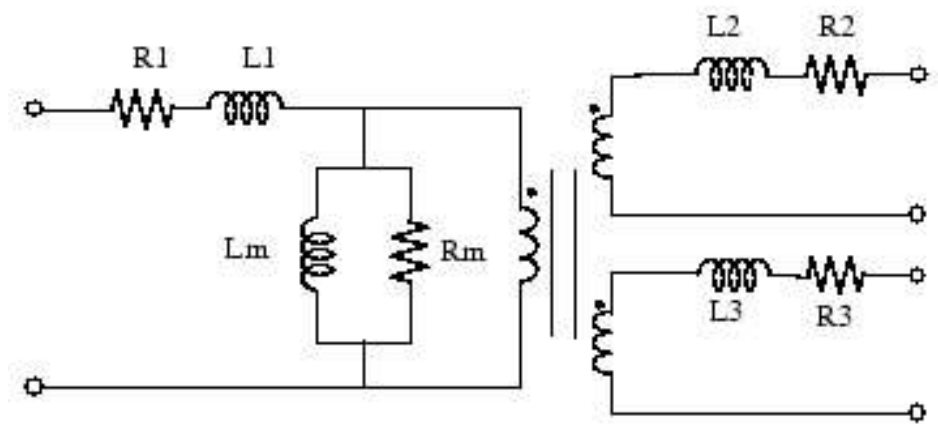

Fig. 3.3 - Modelo equivalente do transformador de 3 enrolamentos.

A figura 3.4 mostra o circuito elétrico equivalente do transformador.

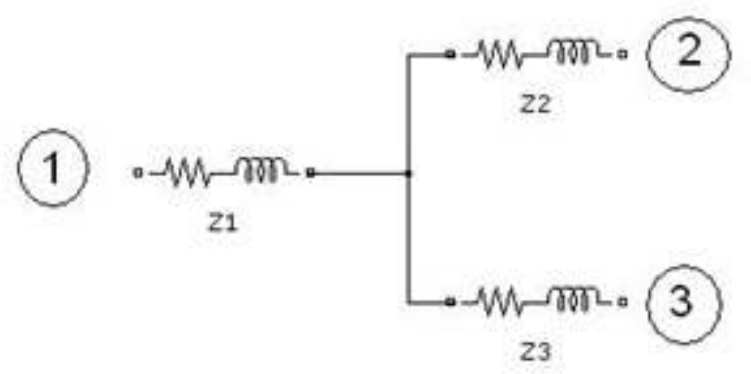

Fig. 3.4 - Circuito equivalente do transformador de 3 enrolamentos.

A tabela 3.1 apresenta os dados de placa dos transformadores de três enrolamentos das subestações Tietê e Jaraguá.

Tabela 3.1 - Impedâncias em p.u. dos transformadores retificadores de Tietê e Jaraguá.

\begin{tabular}{c|c|c|c}
\hline- & $z_{12}(\mathrm{Y}-\Delta)$ & $z_{13}(\mathrm{Y}-\mathrm{y})$ & $Z_{23}(\Delta-\mathrm{y})$ \\
\hline p.u. & $6,09 \%$ & $6,69 \%$ & $0,61 \%$ \\
\hline $\mathrm{V}_{\text {base }}(\mathrm{kV})$ & 34,5 & 34,5 & 1,25 \\
\hline $\mathrm{S}_{\text {base }}(\mathrm{MVA})$ & 2,110 & 2,110 & 2,110 \\
\hline $\mathrm{X} / \mathrm{R}$ & 11,07 & 11,07 & 11,07 \\
\hline
\end{tabular}


As impedâncias por fase refletidas para o enrolamento primário são obtidas utilizando os valores em p.u. da tabela 3.1, e as equações abaixo,:

$$
\begin{aligned}
& z_{1}=\frac{1}{2} \cdot\left(z_{12}+z_{13}-z_{23}\right) \\
& z_{2}=\frac{1}{2} \cdot\left(z_{12}+z_{23}-z_{13}\right) \\
& z_{3}=\frac{1}{2} \cdot\left(z_{13}+z_{23}-z_{12}\right)
\end{aligned}
$$

Obtém-se, portanto, $z_{1}=6,085 \% ; z_{2}=0,005 \%$ e $z_{3}=0,605 \%$.

As impedâncias de base são dadas por:

$$
\begin{gathered}
Z_{\text {base } 1}=\frac{V_{\text {base } 12}^{2}}{S_{\text {base }}}=564,099 \Omega \\
Z_{\text {base } 2}=Z_{\text {base3 }}=\frac{V_{\text {base23 }}^{2}}{S_{\text {base }}}=0,7405 \Omega
\end{gathered}
$$

Multiplicando-se os valores das impedâncias por fase em p.u. pelas respectivas impedâncias de base, obtém-se os valores das impedâncias reais, em ohms, apresentados na tabela 3.2.

Tabela 3.2 - Impedâncias em ohms dos transformadores retificadores de Tietê e Jaraguá.

\begin{tabular}{l|l|l}
\hline $\mathrm{Z} 1=34,3254 \Omega$ & $\mathrm{Z} 2=37,025 \mu \Omega$ & $\mathrm{Z} 3=4,48 \mathrm{~m} \Omega$ \\
$\mathrm{R} 1=3,088 \Omega$ & $\mathrm{R} 2=3,33108 \mu \Omega$ & $\mathrm{R} 3=0,403059 \mathrm{~m} \Omega$ \\
$\mathrm{X} 1=34,1864 \Omega$ & $\mathrm{X} 2=36,875 \mu \Omega$ & $\mathrm{X} 3=4,46186 \mathrm{~m} \Omega$ \\
\hline
\end{tabular}

\subsection{Modelo das pontes de diodos}

Os diodos foram representados por uma resistência equivalente de perdas em série com uma fonte de tensão representando a queda de tensão direta. Em paralelo com o mesmo utilizou-se um elemento RC série (snubber) que ajuda a evitar oscilações numéricas em sistemas discretos. O circuito de snubber existe fisicamente e é utilizado para suprimir o rápido crescimento de tensão sobre o diodo, protegendo-o de sobretensões.

\subsection{Modelo da linha de transmissão}

As linhas de transmissão que interligam as subestações foram modeladas através de ramos $\mathrm{RL}$, como mostra a figura 3.5, uma vez que para linhas curtas (comprimento $<80 \mathrm{~km}$ ) as capacitâncias podem ser desprezadas. 


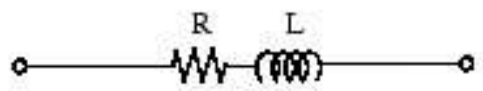

Fig. 3.5 - Modelo utilizado para representar a linha de transmissão.

A tabela 3.3 mostra os parâmetros do cabo utilizado.

Tabela 3.3 - Parâmetros do cabo da linha de transmissão.

\begin{tabular}{c}
\hline Cabo Linhas Aéreas (CPTM) \\
\hline $\mathrm{r}=0,377 \Omega / \mathrm{km}$ \\
\hline $\mathrm{x}_{\mathrm{L}}=0,662 \Omega / \mathrm{km}$ \\
\hline
\end{tabular}

\subsection{Modelo do circuito de via ( $3 \mathrm{kV} \mathrm{CC})$}

Sob o ponto de vista elétrico a via é formada por dois trilhos em paralelo, sendo a resistência por trilho de $0,02 \Omega / \mathrm{km}$, e a resistência total de rolagem igual a $0,01 \Omega / \mathrm{km}$. A linha de contato é composta de um fio e um cabo mensageiro, conforme dados recebidos da CPTM. O fio de contato e o cabo mensageiro possuem secções de $180 \mathrm{~mm}^{2}$ e $253 \mathrm{~mm}^{2}$, respectivamente, totalizando uma secção equivalente de cobre de $433 \mathrm{~mm}^{2}$. O cálculo da impedância equivalente da via foi feito a partir da aproximação de C. F. Wagner e R. D. Evans para as fórmulas de J. R. Carson. Foi utilizado o método de K. G. Markvardt e as dimensões relativas da via.

\subsection{Modelo da carga de tração}

O trecho estudado é percorrido por três tipos de trens: trens da série 1100 , trens da série 1700 e trens da série 7000 .

Os trens da série 1100 são o modelo mais antigo da frota da CPTM em atividade e foram construídos em 1957 pela extinta Mafersa (Materiais Ferroviários S/A). Cada composição é constituída por 6 carros. O sistema de tração desta série utiliza motores de corrente contínua com potência de tração de $2280 \mathrm{~kW}$.

Os trens da série 1700 foram fabricados em 1987 também pela Mafersa e são formados por 8 carros. Utilizam motor de corrente contínua e apresentam potência de tração de $4640 \mathrm{~kW}$. 
Os trens pertencentes à série 7000 são fabricados pela Construcciones y Auxiliar de Ferrocarriles - CAF, e iniciaram sua operação no ano de 2010. Cada composição é constituída por 4 carros sendo que os dois das extremidades são motorizados e os dois centrais são reboques. Estes trens utilizam motores assíncronos CA e possuem potência de tração de 4160 $\mathrm{kW}$.

Os trens são modelados por um filtro L-C de entrada e uma resistência conforme mostrado na figura 3.6. A resistência foi ajustada de acordo com a potência consumida pelo trem.

Lf1

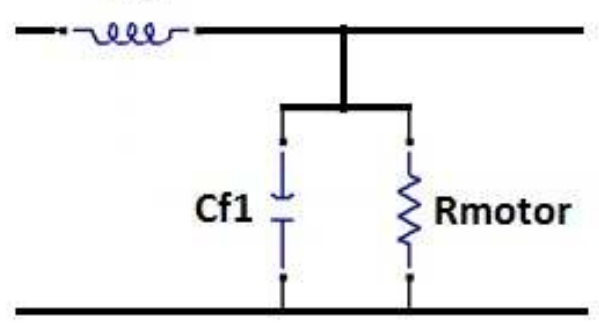

Fig. 3.6 - Modelo equivalente da carga representada pelo trem com filtro LC de entrada. 


\section{CAPÍTULO 4 MEDIÇÕES E SIMULAÇÕES}

A fim de validar o modelo apresentado no capítulo anterior, foram feitas medições nas subestações Tietê e Jaraguá da CPTM.

Por questões de ordem operacional as medições não foram realizadas simultaneamente. Os registros foram realizados durante uma semana de operação normal em cada um dos locais. Com base nos dados da operação dos trens nesses dias, obteve-se uma boa estimativa do comportamento das harmônicas de corrente e de tensão no sistema estudado.

\subsection{Técnica de medição}

Para se determinar os níveis de distorção harmônica de tensão e de corrente apresentados neste trabalho utilizou-se o registrador eletrônico de grandezas em tempo real modelo MARH-21 fabricado pela RMS Sistemas Eletrônicos do Brasil. Este equipamento possui resolução de $0,1 \%$ para as harmônicas. Os sinais foram registrados a cada intervalo de 2 minutos. A taxa de amostragem do sinal no modo de programação utilizado foi de 192 amostras por ciclo de $60 \mathrm{~Hz}$, ou seja, $11520 \mathrm{~Hz}$, e foram registradas as harmônicas de tensão e de corrente nas três fases até a $25^{\mathrm{a}}$ ordem $(1500 \mathrm{~Hz})$, além das taxas de distorção harmônica total de tensão e de corrente. Em cada intervalo o medidor registrou um ciclo de tensão e de corrente nas fases medidas.

As medições em campo foram feitas no primário do transformador abaixador de tensão $88 \mathrm{kV} / 34,5 \mathrm{kV}$ localizado na subestação retificadora Tietê, e na entrada da subestação retificadora Jaraguá conforme mostrado na figura 4.1. 


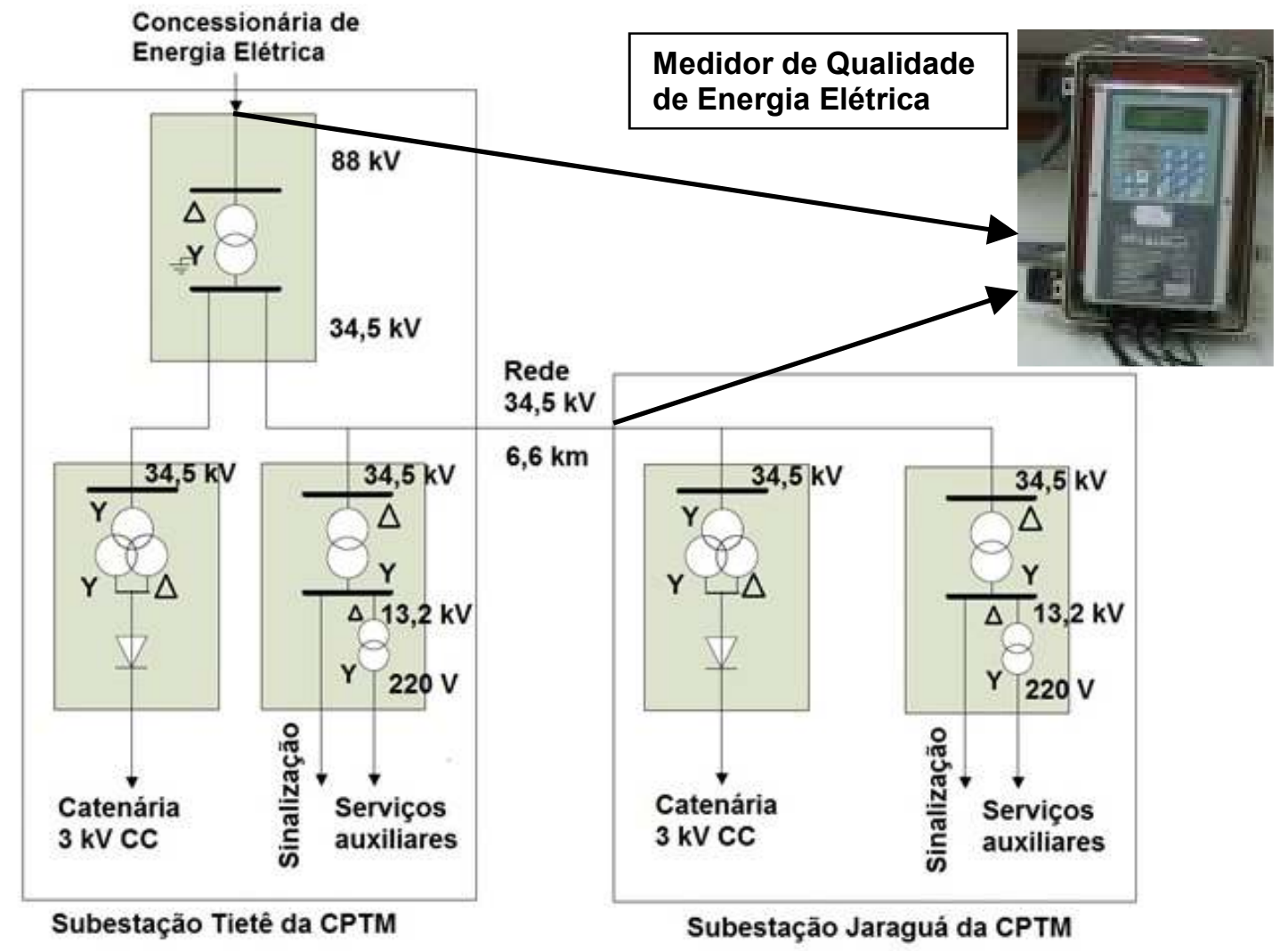

Fig. 4.1 - Diagrama de blocos do sistema elétrico da CPTM e localização do medidor RMS.

Para a medição da corrente foram utilizados alicates com núcleos metálicos de ferro-silício, com escala em 10 A e precisão de 0,1 A na faixa de frequências de $40 \mathrm{~Hz}$ a $10 \mathrm{kHz}$. Os alicates foram colocados nas saídas dos transformadores de corrente (TCs) com relação de $400 / 5$.

A medição de tensão foi feita utilizando-se garras fixadas nos secundários dos transformadores de potencial (TPs), com relação de 88000/110, em Tietê, e 33000/115, em Jaraguá.

A figura 4.2 mostra o transformador de potência abaixador de tensão de $88 \mathrm{kV}$ para $34,5 \mathrm{kV}$, localizado na subestação Tietê. 


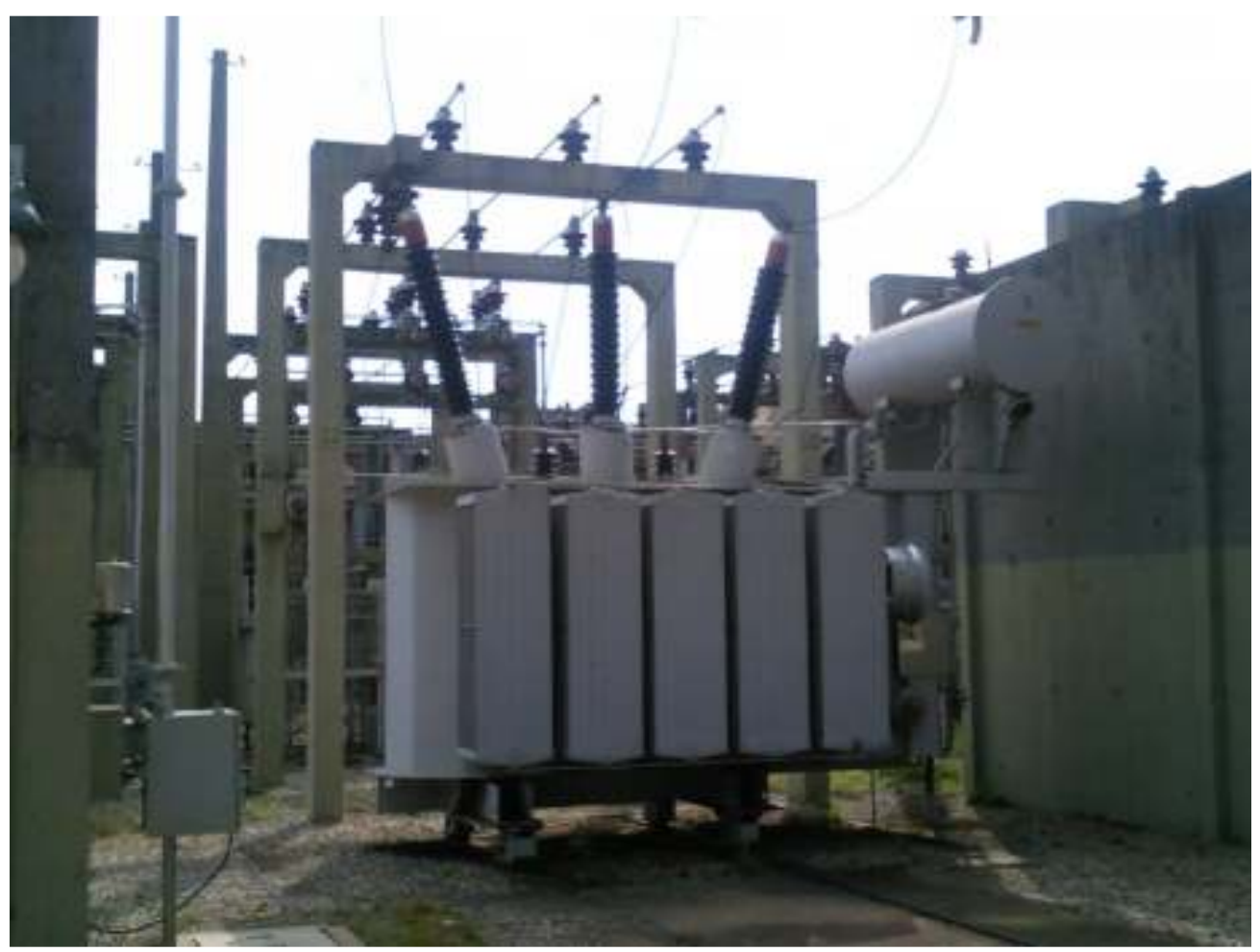

Fig. 4.2 - Transformador de potência abaixador 88 kV/34,5 kV da subestação Tietê.

\subsection{Medições na subestação Tietê da CPTM $(88$ kV)}

As medições na subestação Tietê foram realizadas no período compreendido entre os dias 18 e 23 de outubro de 2011.

São apresentados gráficos de 24 horas para: tensões e correntes eficazes, distorções harmônicas totais das tensões e das correntes e componentes individuais das harmônicas mais significativas das tensões e das correntes.

Em cada gráfico, os dados foram tratados utilizando uma linha de tendência chamada de média móvel. Esse método considera como previsão para o período futuro a média das últimas observações passadas. A média móvel para o período de tempo $t$ é dada por:

$$
x_{t}=\frac{x_{t-1}+x_{t-2}+\ldots+x_{t-n}}{n}
$$

onde $n$ representa o número de observações incluídas na média $x_{t}$.

O diagrama da figura 4.3 apresenta a distância entre as subestações Pari, Tietê, Francisco Morato, Jaraguá e Caieiras (lado CA) e as estações de passageiros Água Branca, Piqueri, Jaraguá e Perus (lado CC). 


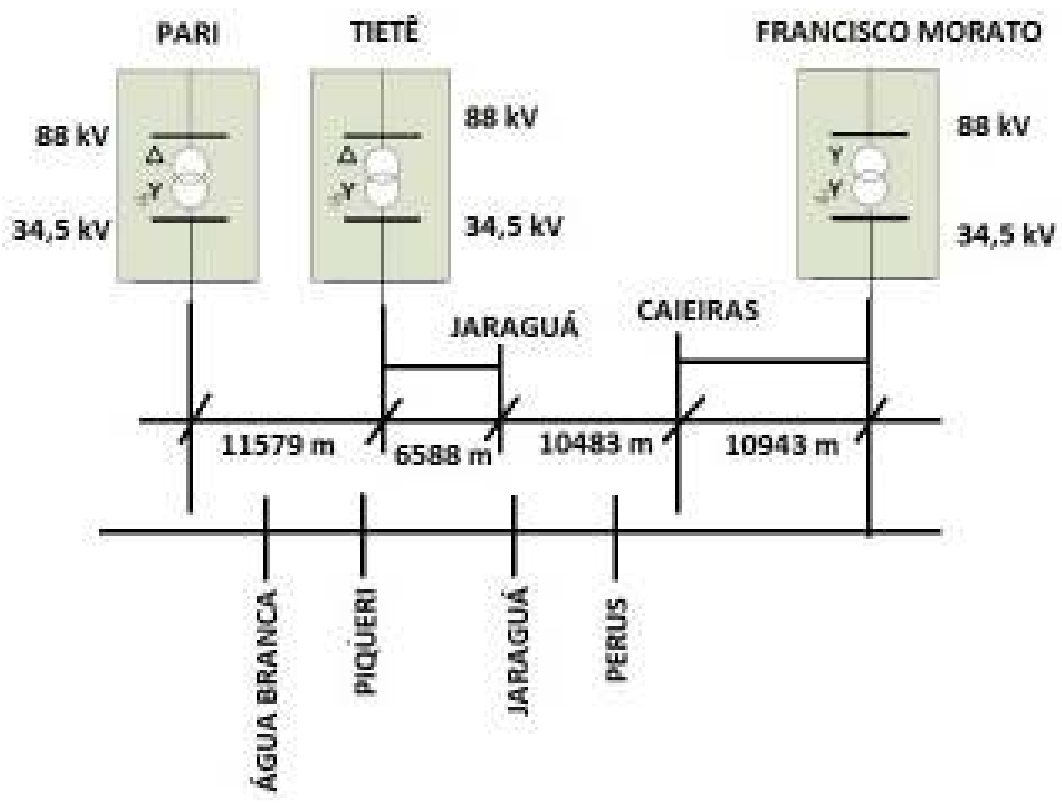

Fig. 4.3 - Distâncias entre as subestações (lado CA) e as estações de passageiros (lado CC).

A seguir são apresentados os seguintes gráficos do fluxo de trens para os dias úteis: o diagrama com o headway (vide figura 4.4), o número de trens por hora entre as estações de passageiros Piqueri e Jaraguá (vide figura 4.5) e o número de trens por hora entre as estações Água Branca e Perus (vide figura 4.6).

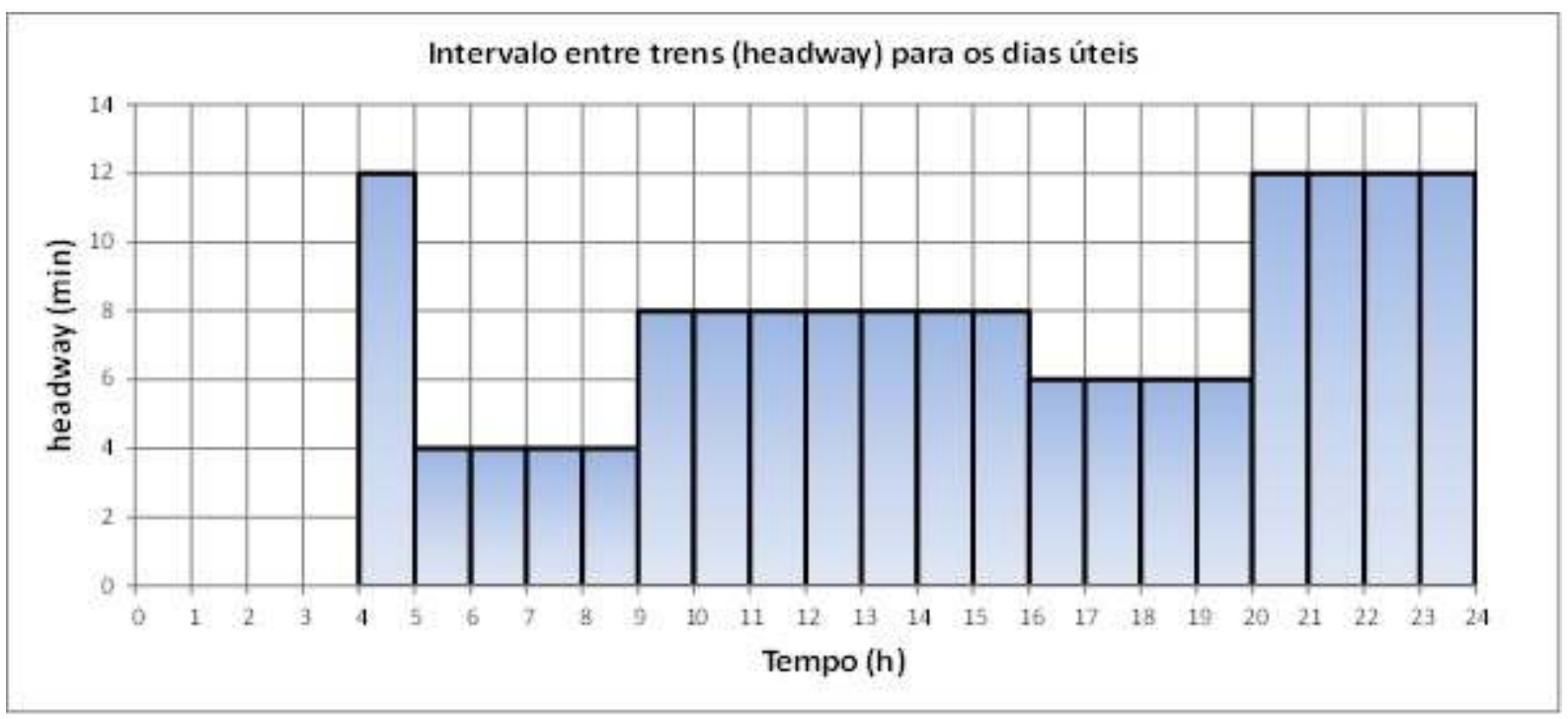

Fig. 4.4 - Intervalo de tempo, em minutos, entre trens (dias úteis). 


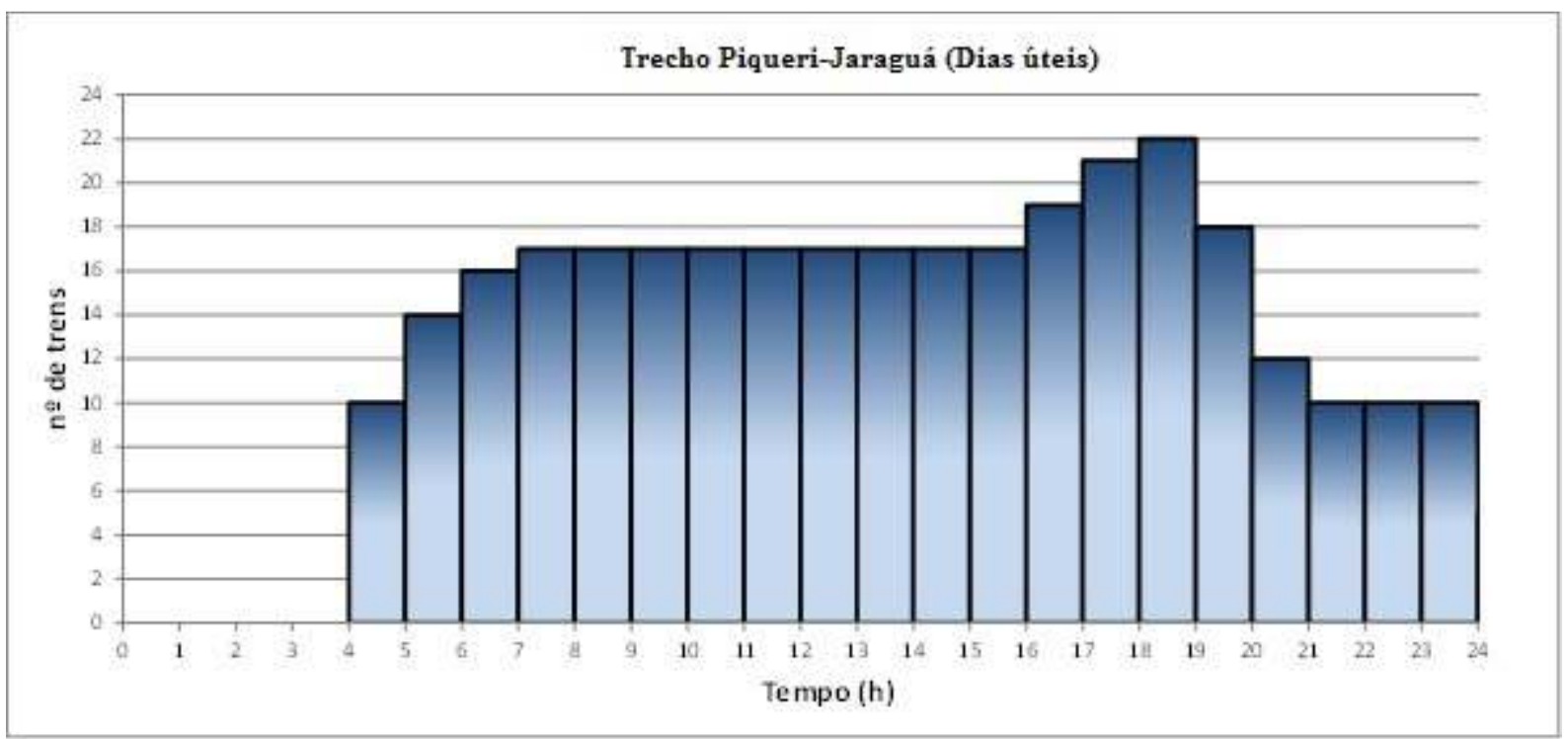

Fig. 4.5 - Número de trens entre as estações de passageiros Piqueri e Jaraguá (dias úteis).

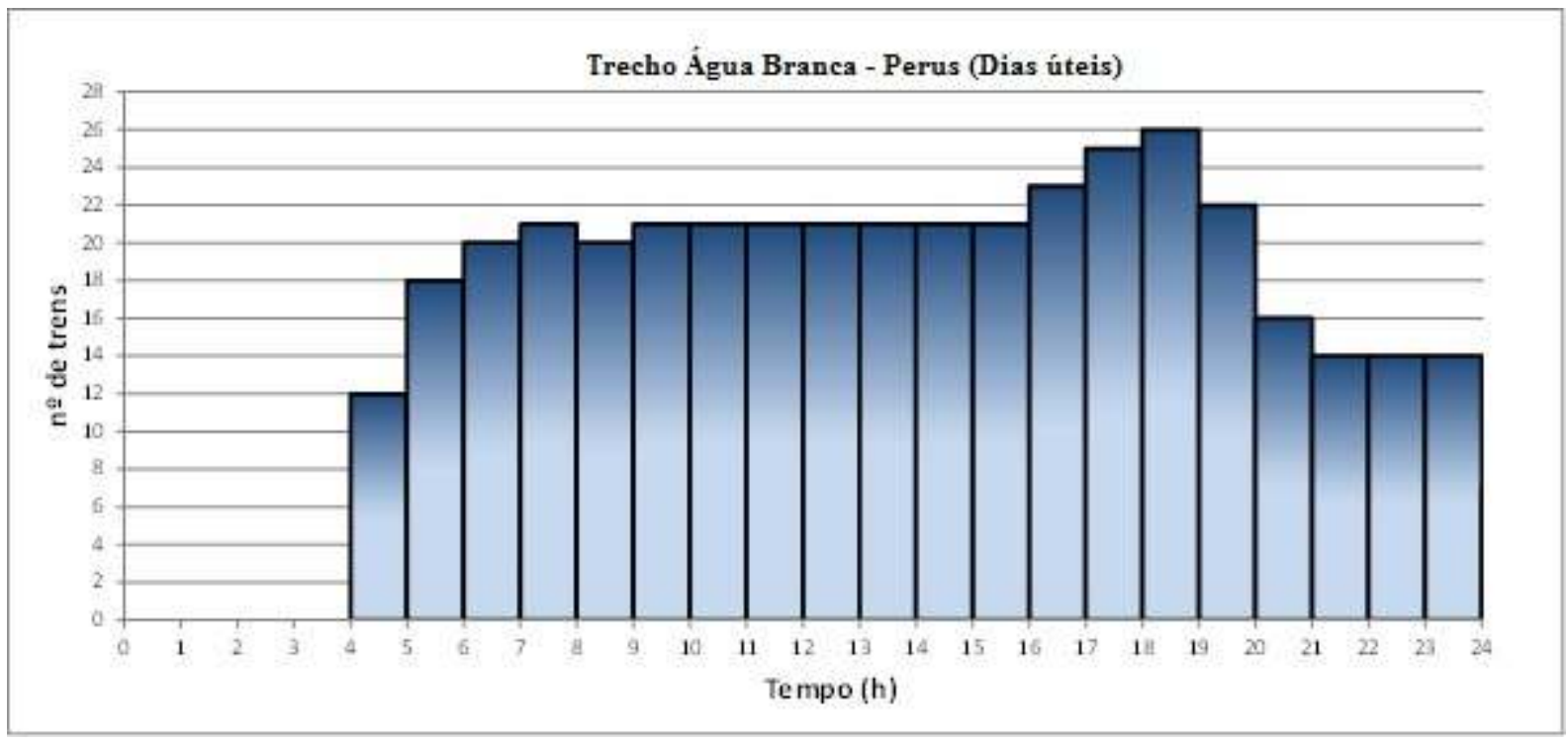

Fig. 4.6 - Número de trens entre as estações de passageiros Água Branca e Perus (dias úteis).

O headway é o intervalo de tempo entre os trens. O parâmetro é dado em minutos e relacionase diretamente com a performance operacional de uma linha de metrô ou trem de subúrbio. Considera-se que quanto menor for o valor do headway, melhor será o desempenho da linha. Um headway menor implica em uma quantidade maior de trens circulando na linha além de maior velocidade dos mesmos. Para tanto é necessário um sistema de sinalização adequado para evitar acidentes. 


\subsubsection{Registros das medições ao longo da semana em Tietê}

A entrada de energia da subestação Tietê representa o ponto de acoplamento comum entre o sistema ferroviário da CPTM e a concessionária de energia elétrica. $\mathrm{O}$ valor da corrente nominal na barra de $88 \mathrm{kV}$ é 82 A $\left(\mathrm{S}_{\text {trafo }}=12,5 \mathrm{MVA}\right)$.

A figura 4.7 apresenta os registros da corrente CA em uma fase medida ao longo da semana em Tietê. Nota-se que o sistema opera com folga, pois, em média, a corrente máxima não ultrapassa $30 \mathrm{~A}$. Observa-se que as curvas de corrente nos dias úteis apresentam um perfil diferente do perfil do sábado que, por sua vez, difere significativamente do perfil de domingo. Isso ocorre devido à operação dos trens ser diferenciada para dias úteis, sábados e domingos.

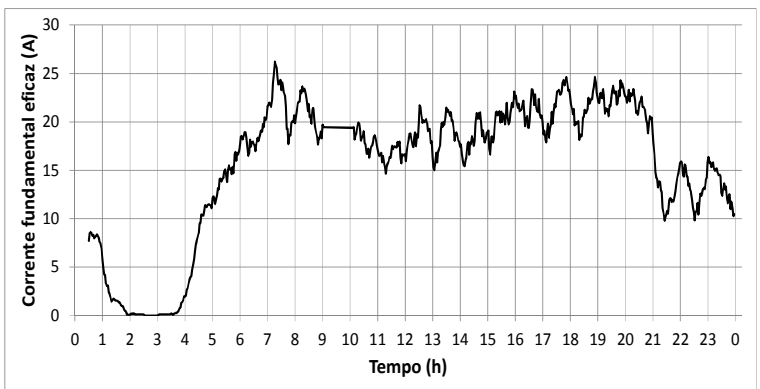

Terça-feira 18/10/2011

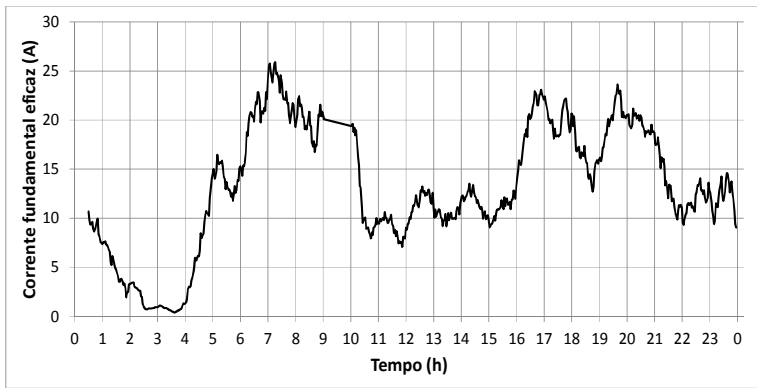

Quinta-feira 20/10/2011

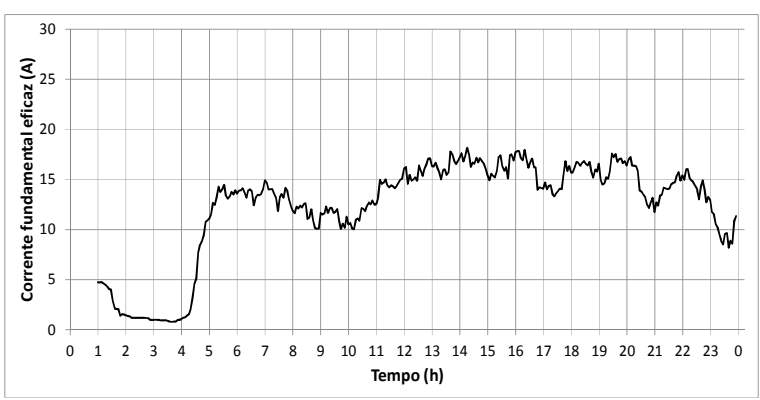

Sábado 22/10/2011

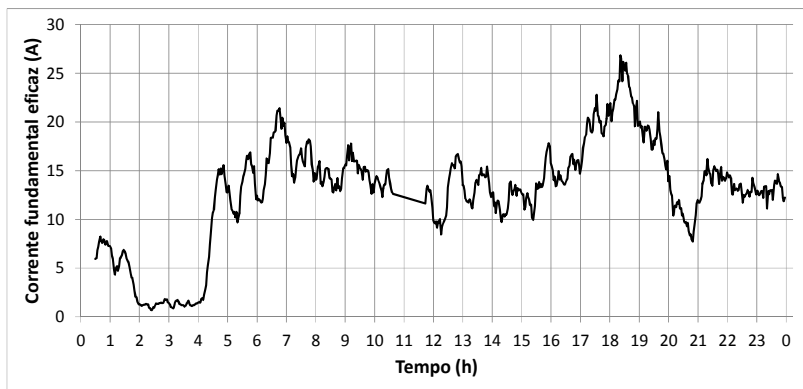

Quarta-feira 19/10/2011

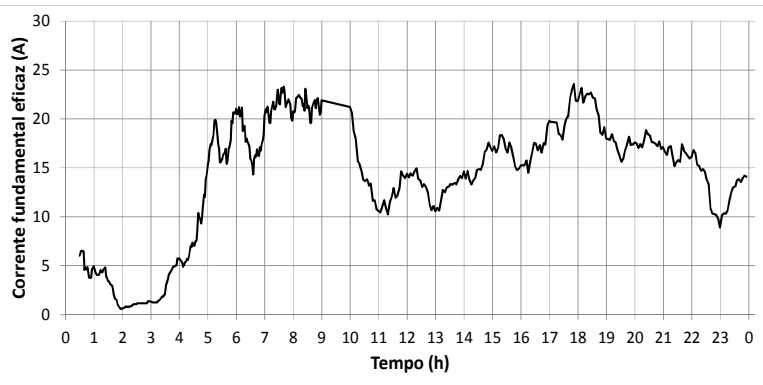

Sexta-feira $21 / 10 / 2011$

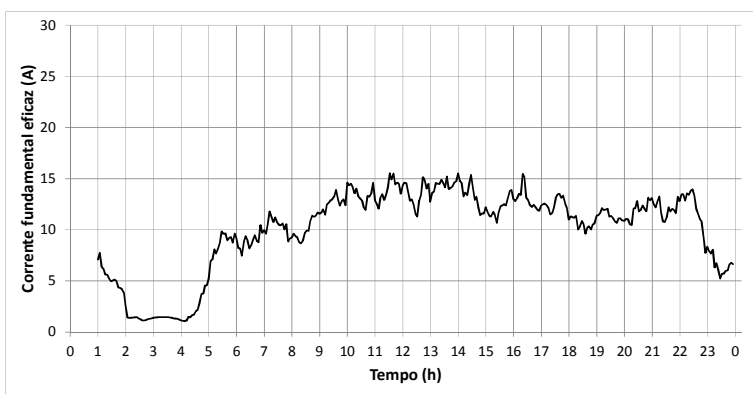

Domingo 23/10/2011

Fig. 4.7 - Registro da corrente CA ao longo da semana em Tietê. 
A figura 4.8 mostra a variação da DHTv em Tietê nesta semana.

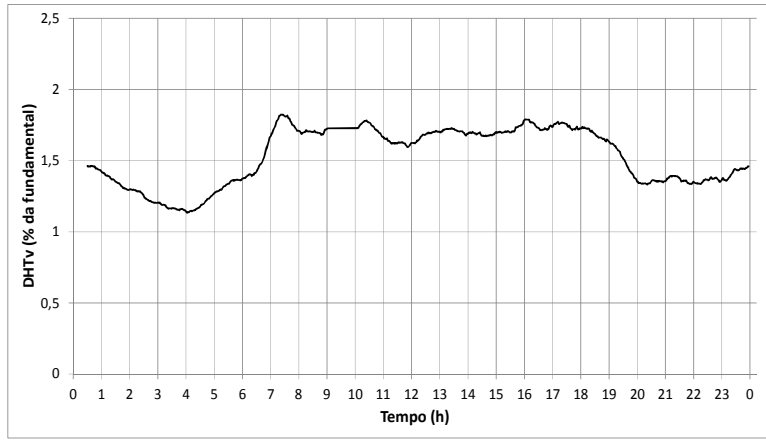

Terça-feira 18/10/2011

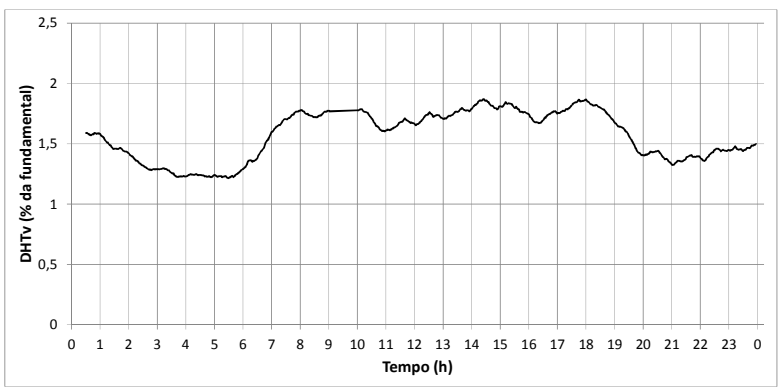

Quinta-feira 20/10/2011

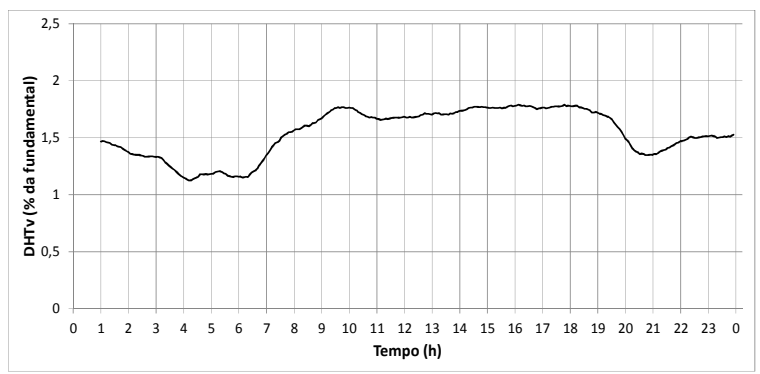

Sábado 22/10/2011

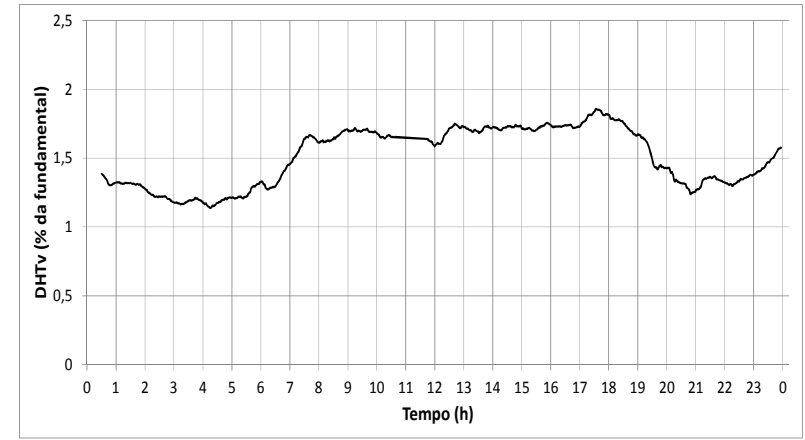

Quarta-feira 19/10/2011

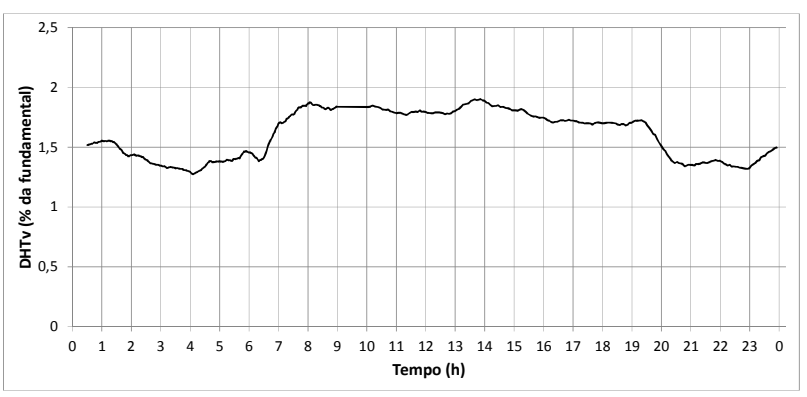

Sexta-feira 21/10/2011

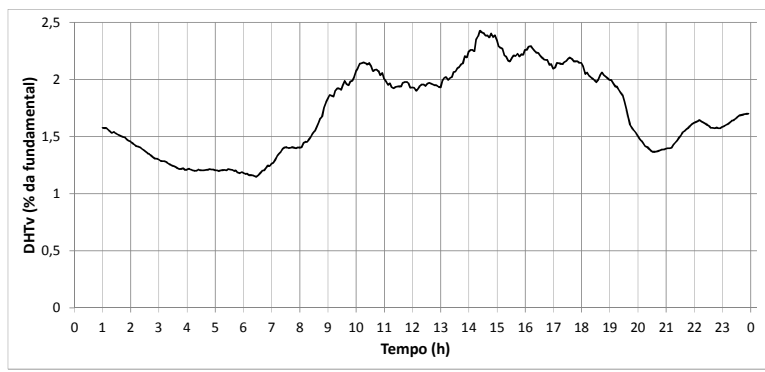

Domingo 23/10/2011

Fig. 4.8 - Registro da DHTv ao longo da semana em Tietê.

As normas IEEE-519 e IEC 61000-3-6 estabelecem, para o nível de tensão de 88 kV, os limites para DHTv de 2,5\% e de 3,0\%, respectivamente. Os limites máximos de componentes harmônicas individuais estabelecidos pelas normas encontram-se no Anexo A.

Os limites de DHTv devem ser considerados para o "pior caso" durante a condição de operação normal. Para períodos curtos, e durante condições anormais ou de partida, os limites 
podem ser excedidos em 50\%. Da figura 4.8, verifica-se que os valores de DHTv encontramse abaixo do limite estabelecido pela IEEE-519 e seu comportamento é similar durante os dias da semana.

\subsubsection{Análises das medições na quinta-feira dia 20/10/2011}

Uma vez que o comportamento das curvas durante os dias úteis é similar, optou-se por restringir a análise para um único dia útil, no caso a quinta-feira dia 20/10/2011. Esta escolha se justifica pelo fato de que os horários de pico estão mais claramente definidos neste dia do que nos demais dias da semana. Os registros no domingo representam a operação com número reduzido de trens e encontram-se no apêndice D.

A figura 4.9 apresenta o perfil da tensão de entrada da subestação Tietê. São mostradas somente as tensões das fases $\mathrm{A}$ e $\mathrm{C}$, pois nesta subestação o TP de medição para a fase $\mathrm{B}$ não estava disponível. Observa-se que a tensão é praticamente constante no período de 24 horas.

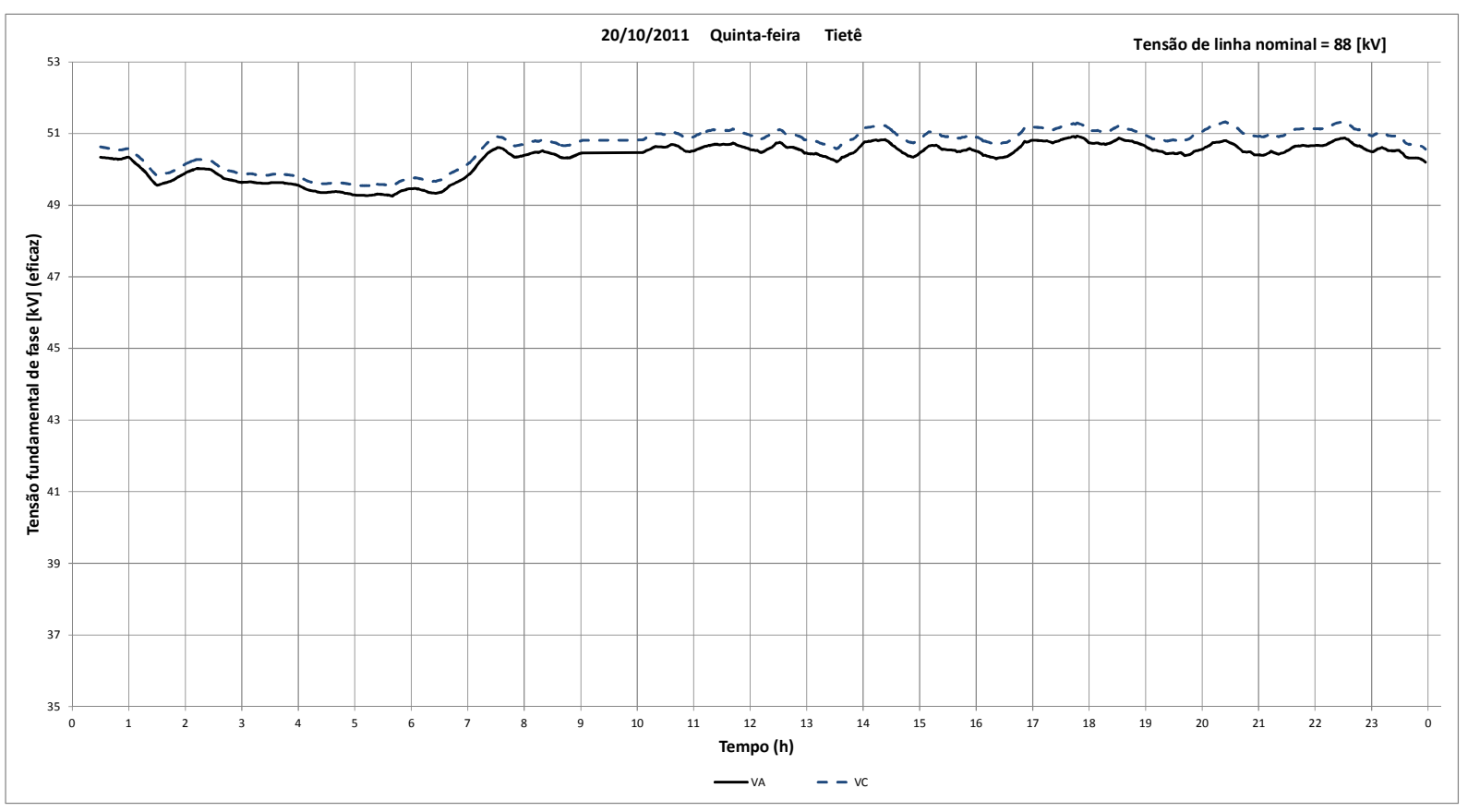

Fig. 4.9 - Registro da tensão na entrada de Tietê na quinta-feira, 20/10/2011. 
A figura 4.10 mostra os registros das componentes fundamentais das correntes nas três fases. Conforme esperado, as correntes nas fases são praticamente equilibradas.

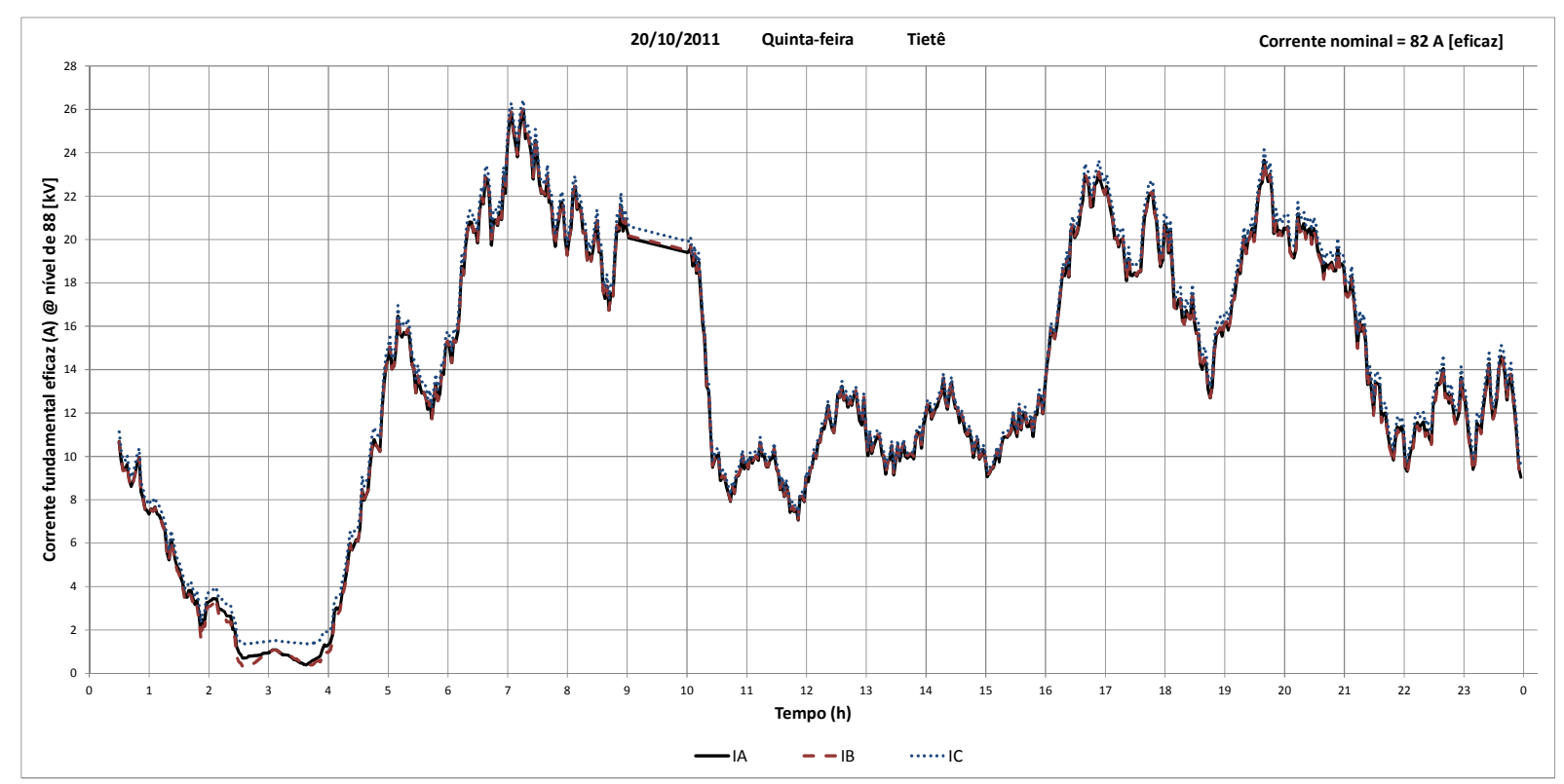

Fig. 4.10 - Registro da componente fundamental da corrente na entrada de Tietê.

Observa-se que o movimento dos trens tem início às $4 \mathrm{~h} 00 \mathrm{e}$ há dois horários de pico, um de manhã entre 5 h00 e 9 h00 e outro à tarde entre $17 \mathrm{~h} 00$ e $20 \mathrm{~h} 30$.

Os valores de DHTv são apresentados na figura 4.11. Nota-se que o comportamento de DHTv das fases $\mathrm{A}$ e $\mathrm{C}$ é semelhante ao das tensões (figura 4.9). Portanto, na sequência serão apresentados somente os registros na fase $\mathrm{A}$.

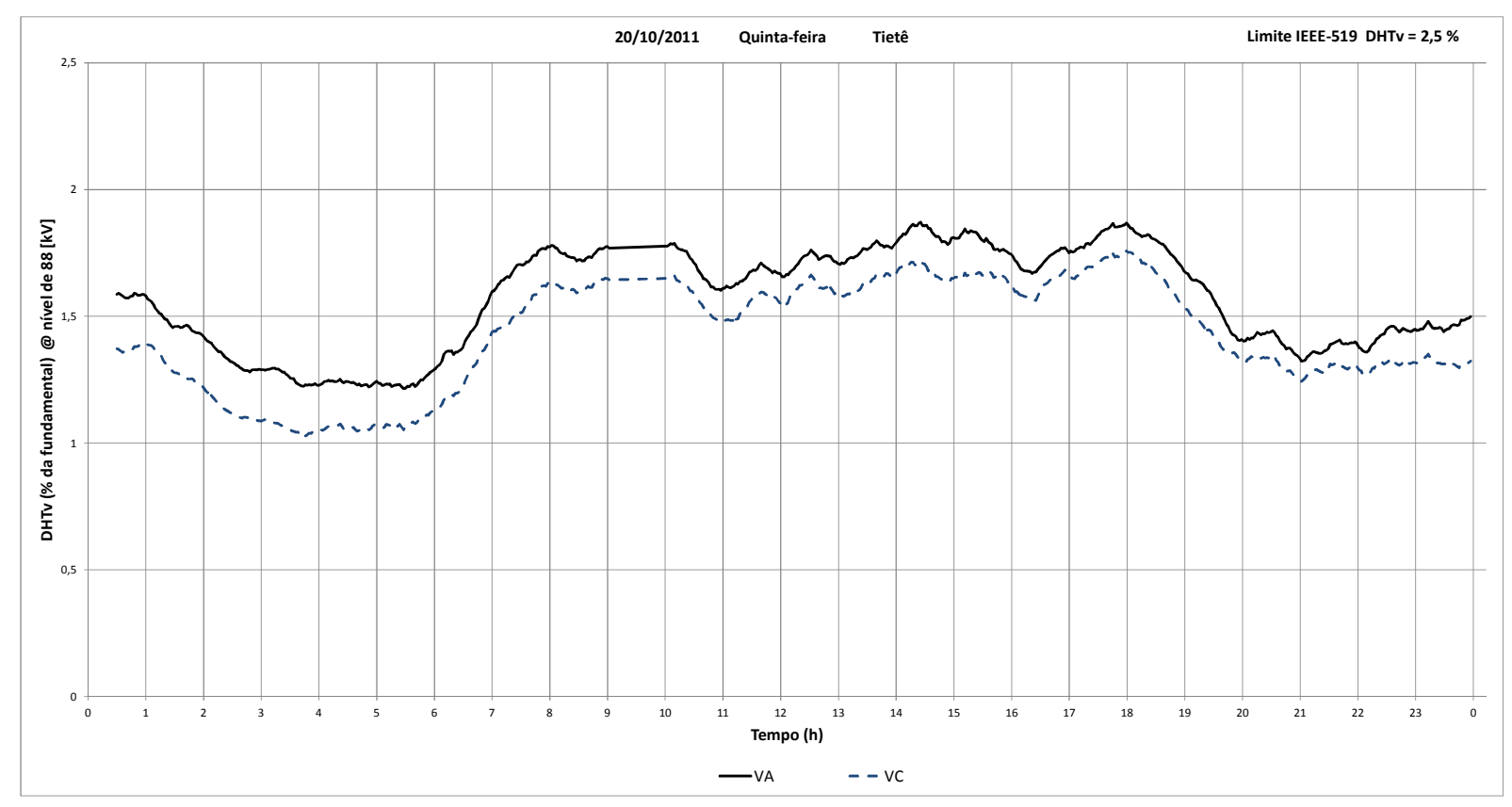

Fig. 4.11 - Registro da DHTv na entrada de Tietê na quinta-feira, 20/10/2011. 


\subsubsection{Análise da distorção de tensão no barramento de $88 \mathrm{kV}$ (Tietê)}

As figuras 4.12 e 4.13 apresentam o espectro harmônico da tensão nos instantes de menor DHTv (3h02) e maior DHTv (18h00), respectivamente.

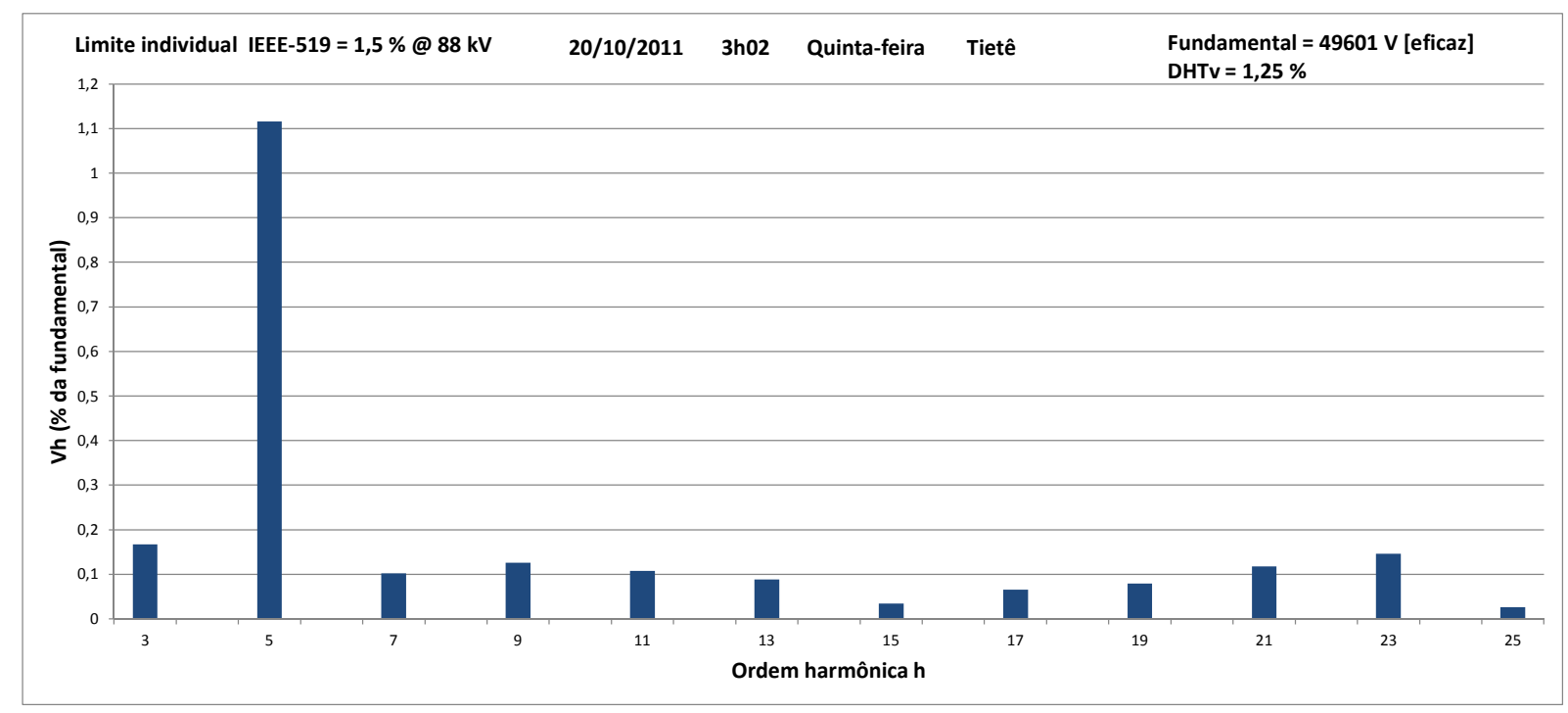

Fig. 4.12 - Espectro da tensão do registro no instante de menor DHTv em Tietê.

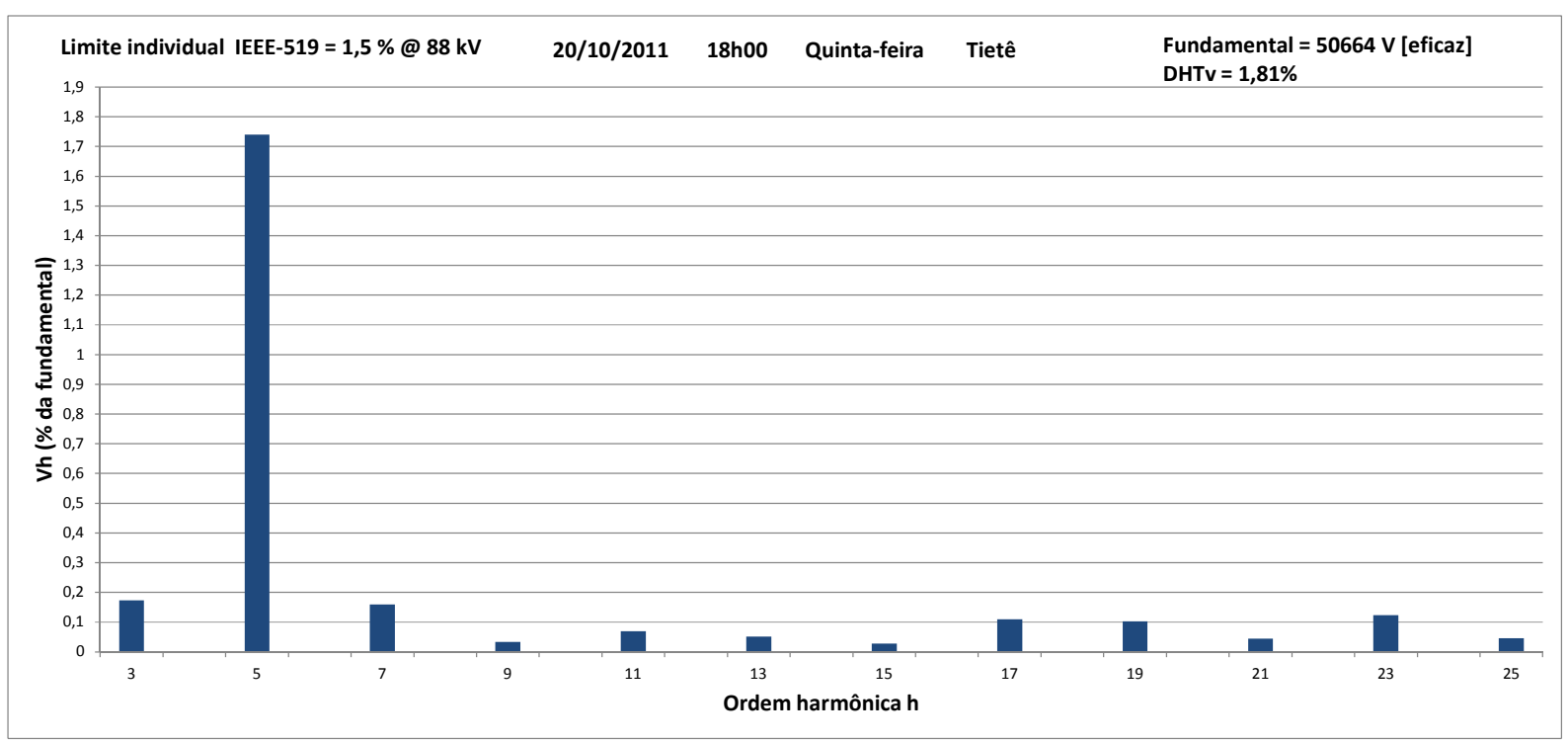

Fig. 4.13 - Espectro da tensão do registro no instante de maior DHTv em Tietê.

Nota-se que a tensão apresenta uma amplitude de quinta harmônica uma ordem de grandeza acima das outras componentes. No entanto, esta medição não permite avaliar se a $5^{\text {a }}$ harmônica provém apenas do sistema ferroviário, pois no ponto de acoplamento entre a subestação Tietê e a concessionária de energia existem outros consumidores que podem estar contribuindo com esta componente harmônica. Os registros na subestação Jaraguá, que alimenta somente os trens, permitirão uma análise mais conclusiva. 
O comportamento das componentes de $5^{\mathrm{a}}$ e $7^{\mathrm{a}}$ harmônicas de tensão durante o dia é mostrado na figura 4.14 .

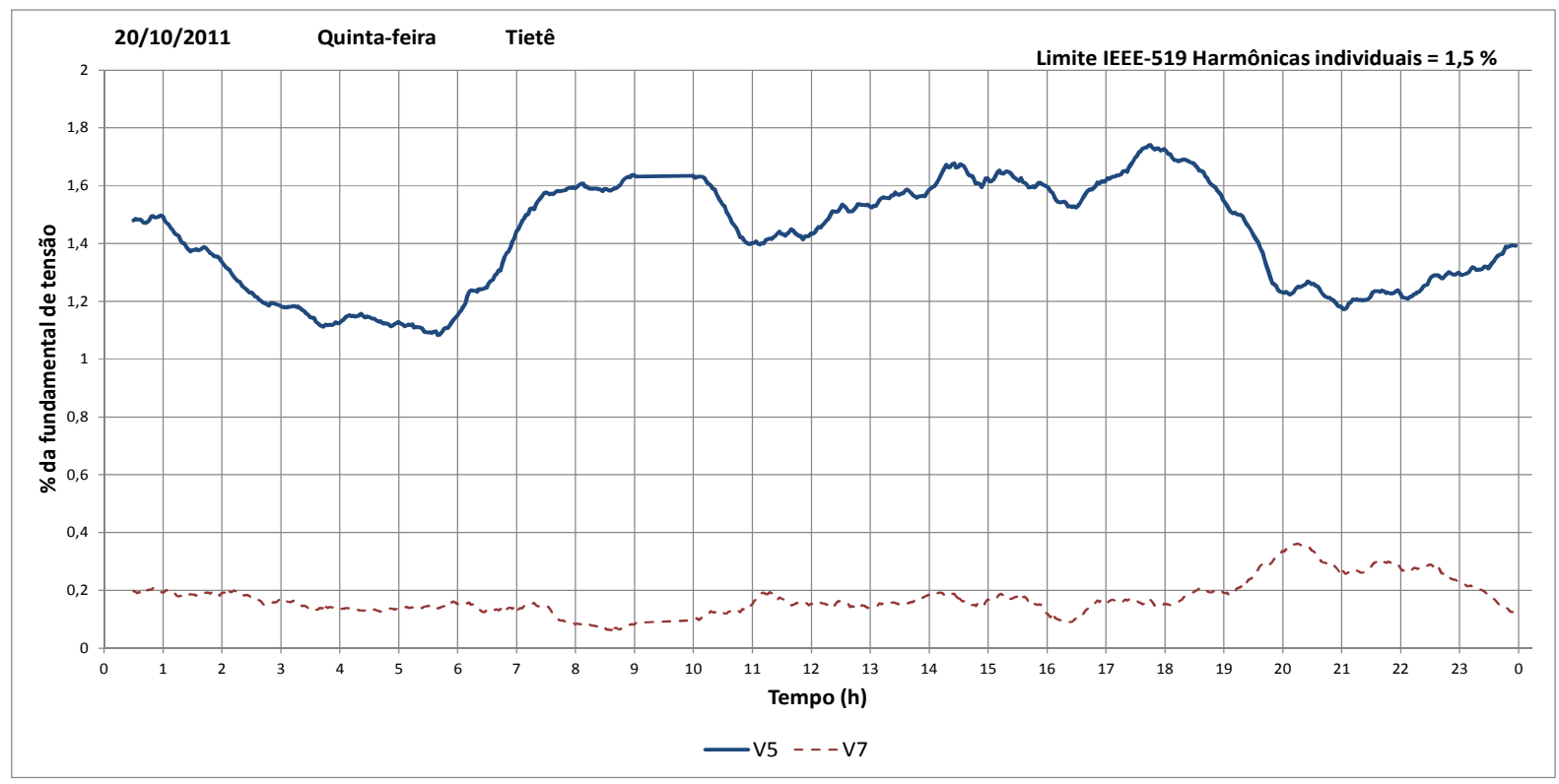

Fig. 4.14 - Registro das harmônicas de tensão de $5^{\mathrm{a}}$ e $7^{\mathrm{a}}$ ordens em Tietê.

Verifica-se que a $5^{\mathrm{a}}$ harmônica de tensão apresenta valores elevados ao longo do dia, inclusive no período das 2 h00 às 4 h00 quando não há operação de trens. Apesar disso, a $5^{\mathrm{a}}$ harmônica de tensão encontra-se abaixo do limite de 2\% estabelecido pela IEC 61000-3-6, porém ultrapassa o limite de $1,5 \%$ estabelecido pela IEEE-519 nos períodos entre 7 h30 e $10 \mathrm{~h} 30$ e entre $12 \mathrm{~h} 30$ e $19 \mathrm{~h} 00$.

A figura 4.15 apresenta os registros das harmônicas de tensão de $11^{\mathrm{a}}, 13^{\mathrm{a}}, 23^{\mathrm{a}}$ e $25^{\mathrm{a}}$ ordens.

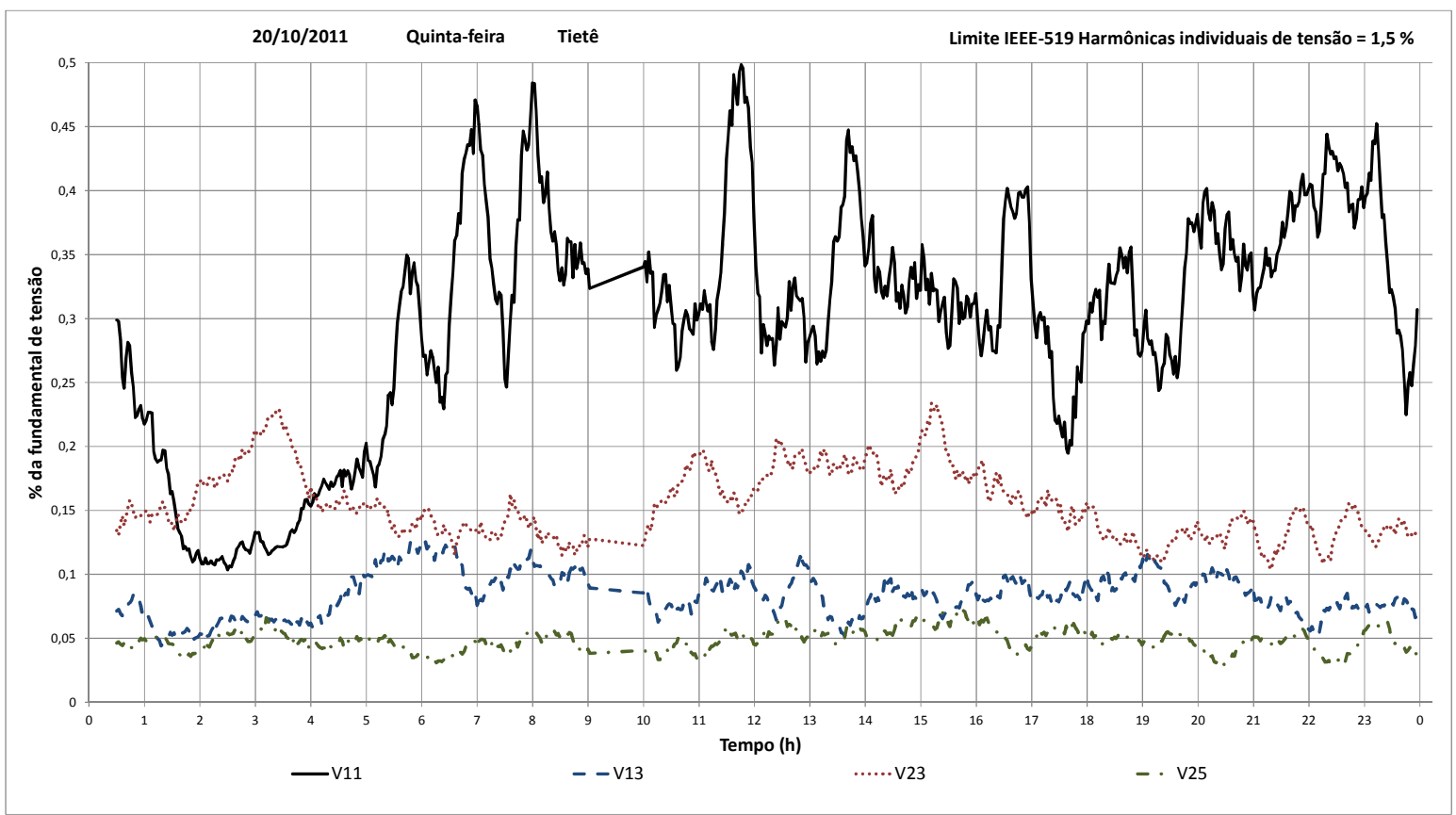

Fig. 4.15 - Registro das harmônicas de tensão de ordens 11, 13, 23 e 25 em Tietê. 
Nota-se que a amplitude destas harmônicas, normalizada pela componente fundamental, está abaixo de $1 \%$, ou seja, abaixo dos limites estabelecidos pela IEEE-519 (inferior a 1,5\%) e IEC 61000-3-6. Vale ressaltar que a IEC 61000-3-6 estabelece limites diferenciados para cada uma das componentes analisadas, ou seja, $1,5 \%$ para as $11^{\mathrm{a}}$ e $13^{\mathrm{a}}$ harmônicas e $0,8 \%$ para as $23^{\mathrm{a}}$ e $25^{\mathrm{a}}$ harmônicas e assim por diante.

\subsubsection{Análise da distorção de corrente no barramento de $88 \mathrm{kV}$ (Tietê)}

A figura 4.16 apresenta os registros temporais das componentes de $5^{\mathrm{a}}$ e $7^{\mathrm{a}}$ harmônicas de corrente em relação à componente fundamental. Nota-se que ambas apresentam um perfil semelhante, o que sugere que provenham de uma mesma fonte. Convém notar que no período compreendido entre $2 \mathrm{~h} 00$ e $4 \mathrm{~h} 00$, o valor percentual é elevado, mas a corrente total é praticamente nula, conforme mostra o registro da figura 4.10, devido à ausência de operação de trens nesse período.

Entre $10 \mathrm{~h} 00$ e $16 \mathrm{~h} 00$ nota-se um aumento na amplitude das componentes harmônicas de $5^{\mathrm{a}}$ e $7^{\mathrm{a}}$ ordens de corrente, porém não se observa nenhum reflexo na tensão do barramento. Este comportamento se repete somente na sexta-feira, 21/10/2011, conforme mostram os registros de $5^{\mathrm{a}}$ e $7^{\mathrm{a}}$ harmônicas de corrente para os demais dias (vide apêndice E).

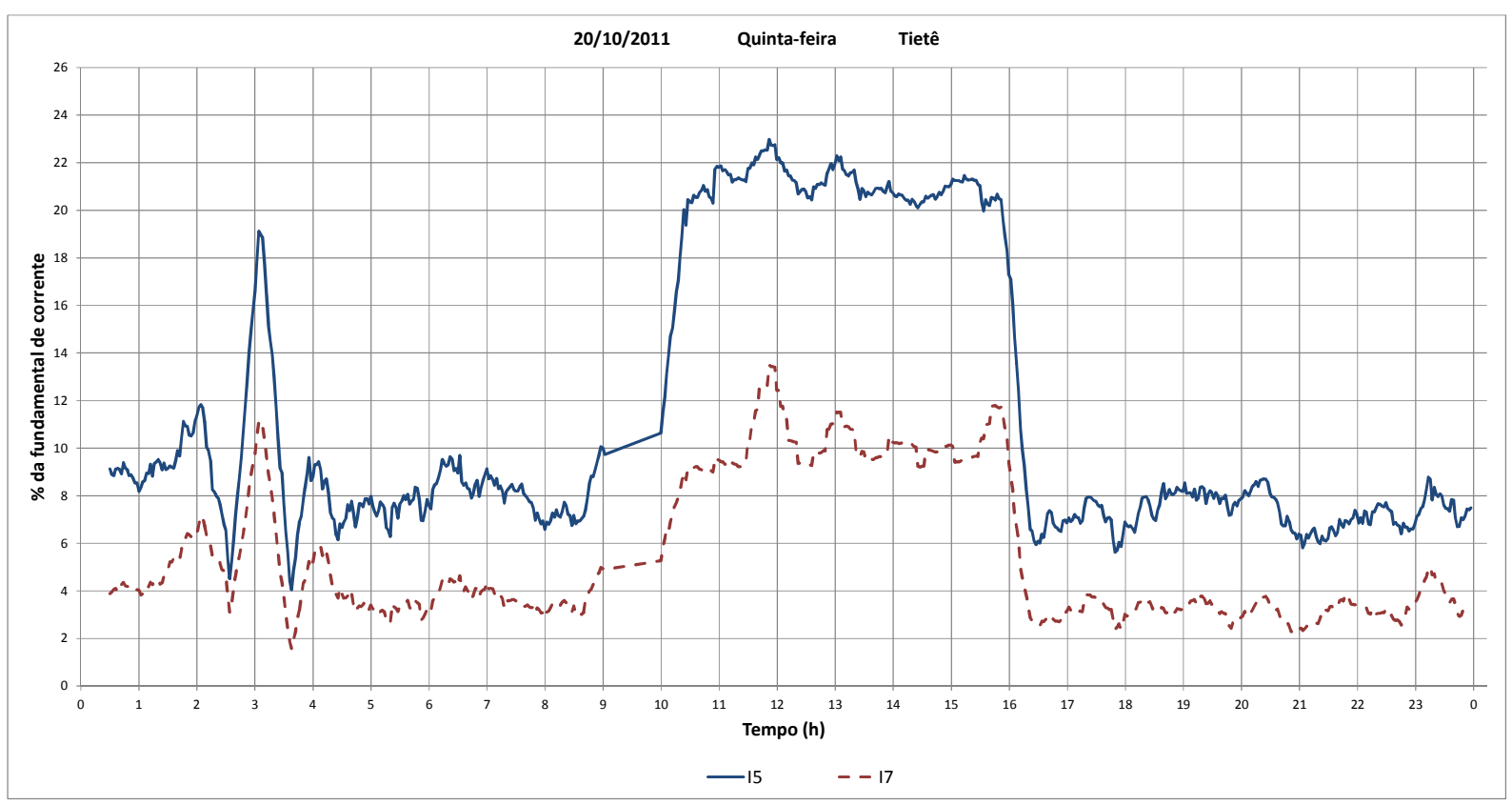

Fig. 4.16 - Registro das harmônicas de corrente de $5^{\mathrm{a}}$ e $7^{\mathrm{a}}$ ordens em Tietê. 
O registro das harmônicas características de corrente até a $25^{\mathrm{a}}$ ordem é apresentado na figura 4.17 .

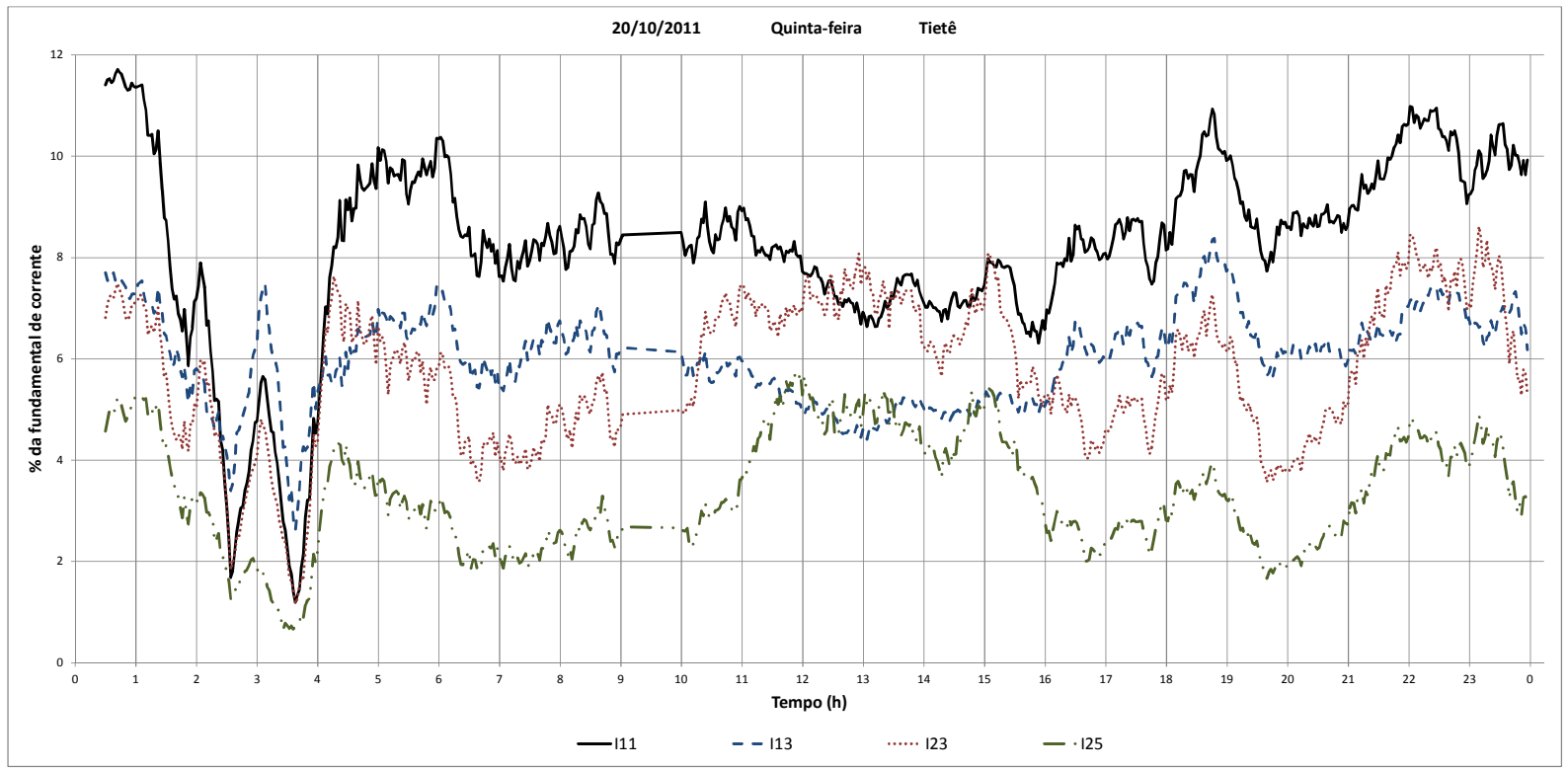

Fig. 4.17 - Registro das harmônicas de corrente de ordens 11, 13, 23 e 25 em Tietê.

Do gráfico da figura 4.17 verifica-se que o comportamento das componentes harmônicas de $11^{\mathrm{a}}$ e $13^{\mathrm{a}}$ ordens é semelhante, o mesmo acontecendo com o par de harmônicas de $23^{\mathrm{a}}$ e $25^{\mathrm{a}}$ ordens. Todas acompanham aproximadamente o comportamento da componente fundamental apresentada no gráfico da figura 4.10.

A figura 4.18 mostra o registro da distorção harmônica total de corrente (DHTi), que segue o comportamento das componentes de $5^{\mathrm{a}}$ e $7^{\mathrm{a}}$ ordens harmônicas (vide figura 4.15).

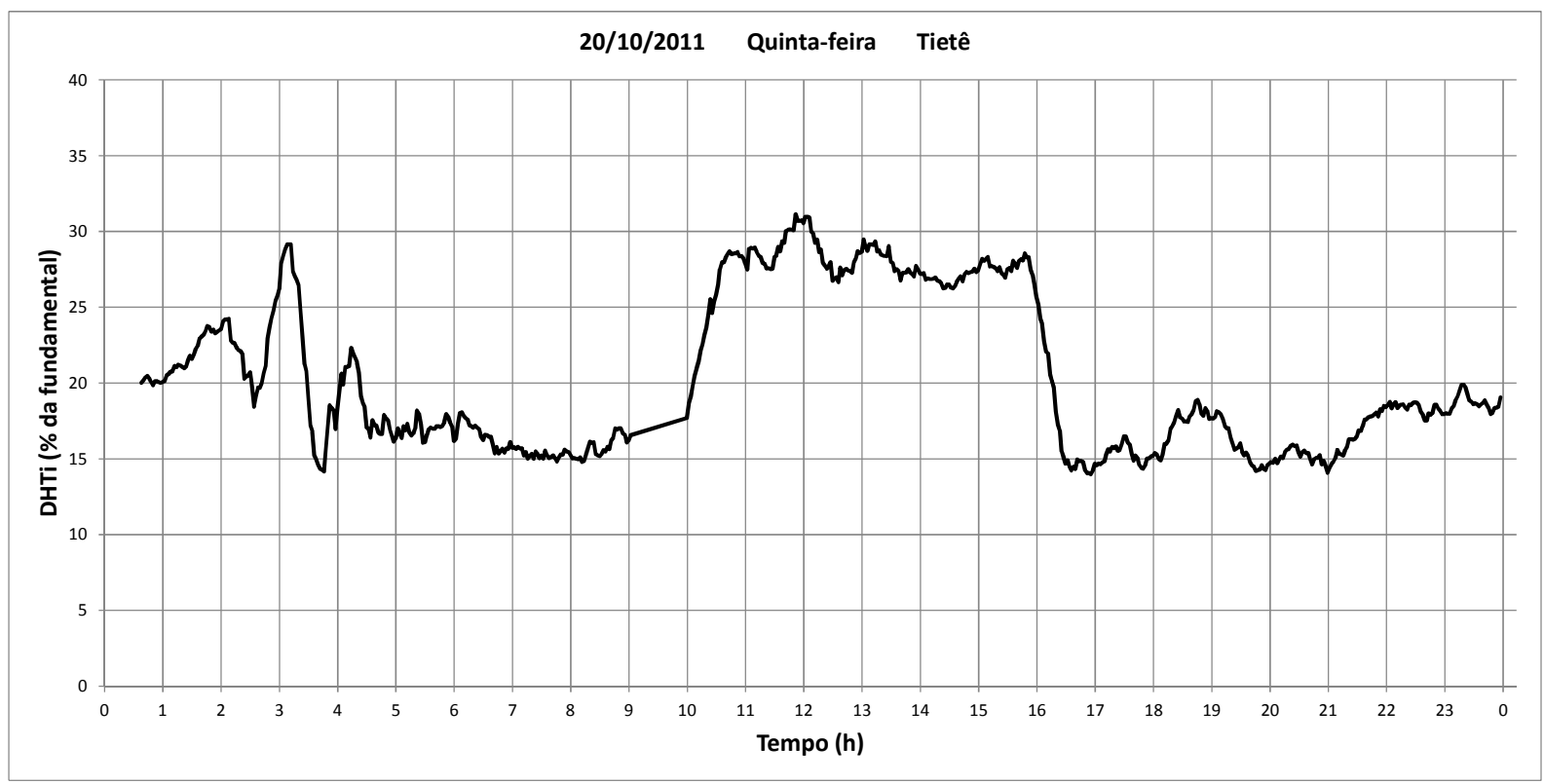

Fig. 4.18 - Registro da DHTi na subestação Tietê. 
As figuras 4.19 a 4.21 apresentam registros da forma de onda da corrente e respectivo espectro, captadas de manhã, à tarde e à noite. Os horários selecionados correspondem a uma amostra de cada um dos três patamares observados na figura 4.18. Os registros das figuras 4.19 e 4.21 são típicos da corrente CA de um retificador de 12 pulsos. O registro da figura 4.20 caracteriza a corrente CA de um retificador de 6 pulsos.
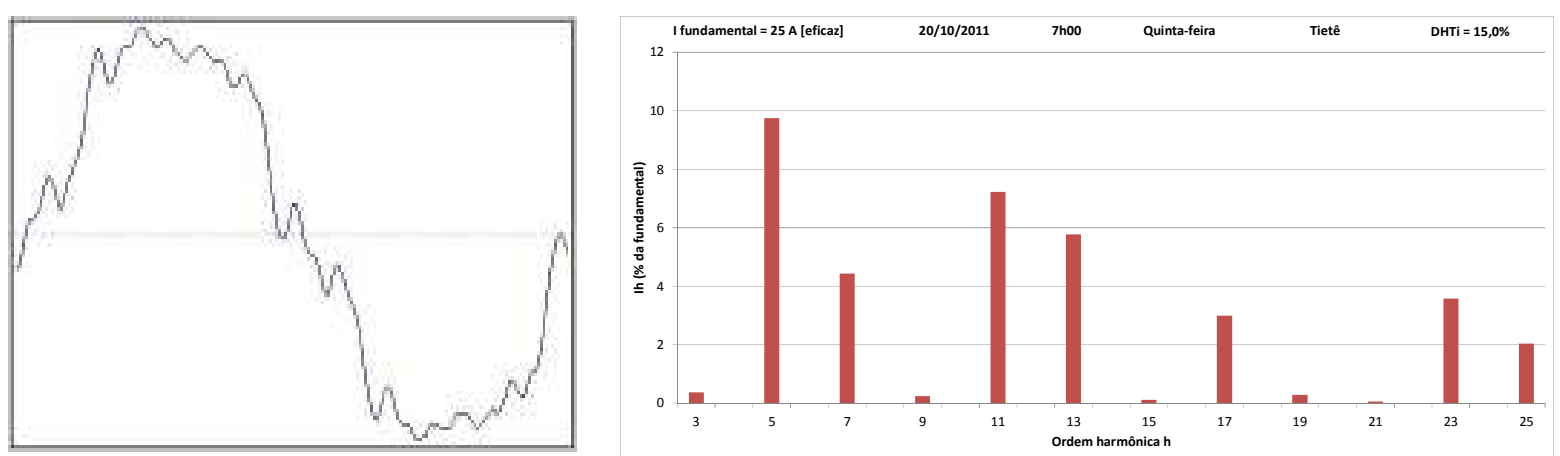

Fig. 4.19 - Forma de onda e espectro da corrente na subestação Tietê às 7h00, 20/10/2011.
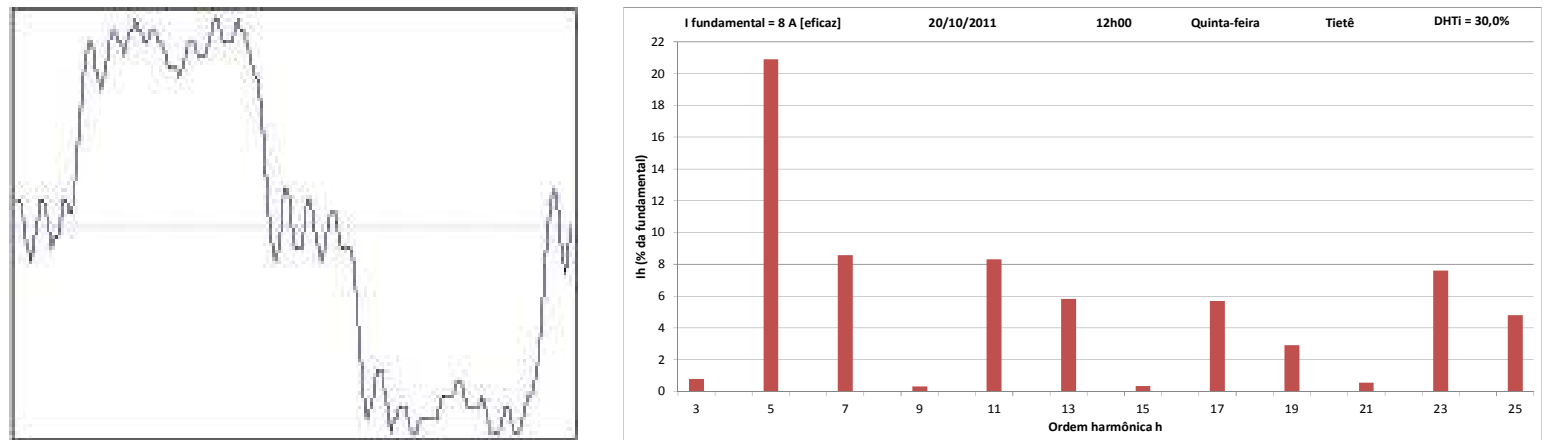

Fig. 4.20 - Forma de onda e espectro da corrente na subestação Tietê às 12h00, 20/10/2011.
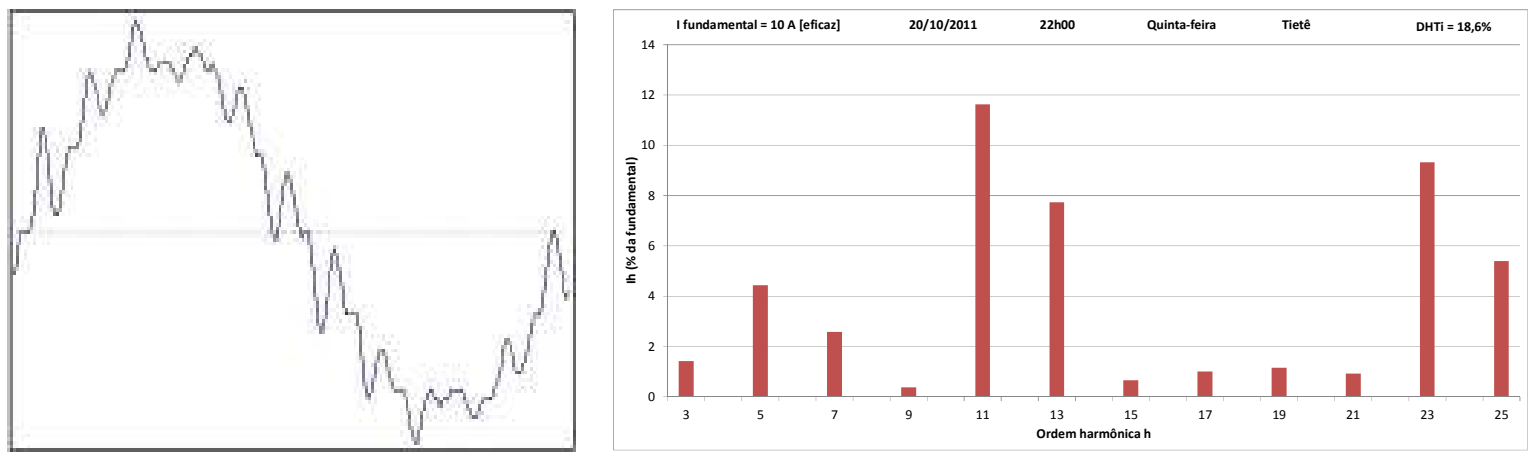

Fig. 4.21 - Forma de onda e espectro da corrente na subestação Tietê às 22h00, 20/10/2011. 
Os níveis de distorção de corrente podem ser caracterizados por um valor de DHT, porém isso pode ser mal interpretado. Uma pequena corrente pode ter um alto valor de DHT e não ser uma ameaça significativa para o sistema. Pode ocorrer de conversores CA-CC apresentarem altos valores de DHT para a corrente de entrada quando operando em condição de carga leve e isto não ser necessariamente um problema devido às magnitudes das correntes harmônicas serem baixas. Para contornar este problema a IEEE-519 recomenda utilizar o índice DTD, apresentado no item 2.1.

Os limites especificados pela IEEE-519 para as harmônicas de corrente dependem da relação entre as correntes de curto-circuito e de carga (Icc/IL), do nível de tensão do barramento e do tipo de retificador utilizado (vide Anexo A).

$\mathrm{Na}$ subestação Tietê, o ponto de acoplamento comum considerado é o primário do transformador de 88/34,5 kV, no qual a corrente de curto-circuito é de 14173 A e a corrente de carga IL é 26 A, obtida pela média das demandas máximas de cada dia. Portanto, a razão Icc/IL é de 14173/26 = 545, valor situado na faixa de 100 a 1000 .

A tabela 4.1 apresenta os limites das componentes harmônicas individuais de corrente e o valor de limite de DTD para a faixa em questão aplicável para retificadores de 12 pulsos.

Tabela 4.1 - Limites de amplitudes de harmônicas de corrente em porcentagem da corrente de carga para sistemas com níveis de tensão de $69 \mathrm{kV}$ a $161 \mathrm{kV}$ e conversores com 12 pulsos.

\begin{tabular}{c|c|c|c|c|c|c|c|c|c}
\hline Icc $_{\mathrm{L}}$ & $\mathrm{I} 5$ & $\mathrm{I} 7$ & $\mathrm{I} 11$ & $\mathrm{I} 13$ & $\mathrm{I} 17$ & $\mathrm{I} 19$ & $\mathrm{I} 23$ & $\mathrm{I} 25$ & DTD \\
\hline $100<1000$ & \multicolumn{2}{|c|}{1,5} & \multicolumn{2}{|c|}{4,0} & \multicolumn{2}{|c|}{0,6} & \multicolumn{2}{|c|}{1,4} & 7,5 \\
\hline
\end{tabular}

Para calcular a distorção total de demanda, cujo resultado é mostrado na figura 4.22, utilizouse a equação a seguir:

$$
\mathrm{DTD}=\mathrm{DHTi} \times\left(\frac{\mathrm{I} 1}{\mathrm{IL}}\right)
$$




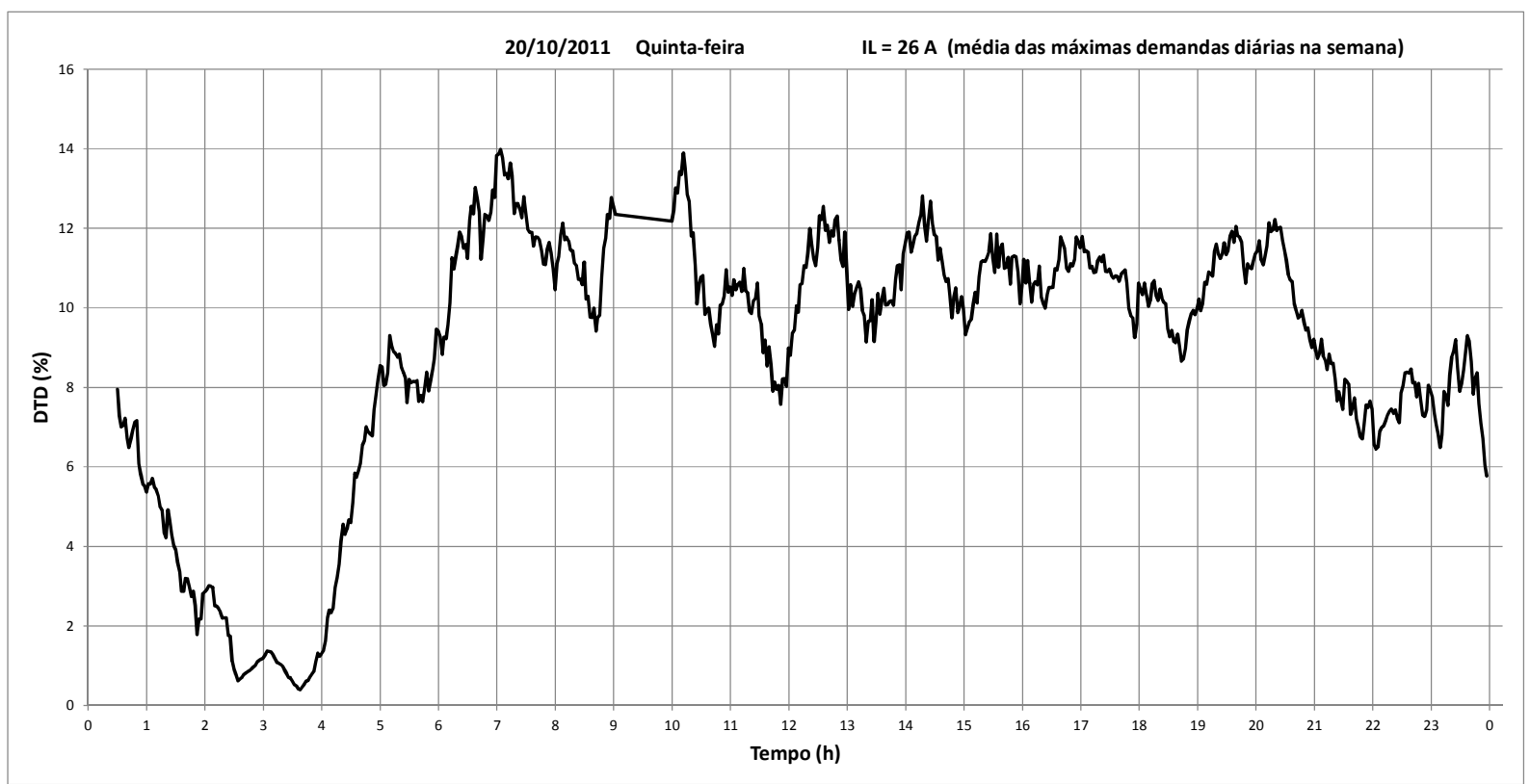

Fig. 4.22 - Registro da DTD na entrada de Tietê.

O gráfico da figura 4.22 mostra que a distorção total de demanda da corrente em porcentagem da corrente de carga entre $5 \mathrm{~h} 00$ e $21 \mathrm{~h} 00$ situa-se entre $8,0 \%$ e $14,0 \%$, ultrapassando o limite especificado pela IEEE-519.

As figuras 4.23 e 4.24 apresentam os registros das componentes harmônicas individuais de corrente em porcentagem da corrente de carga IL em Tietê.

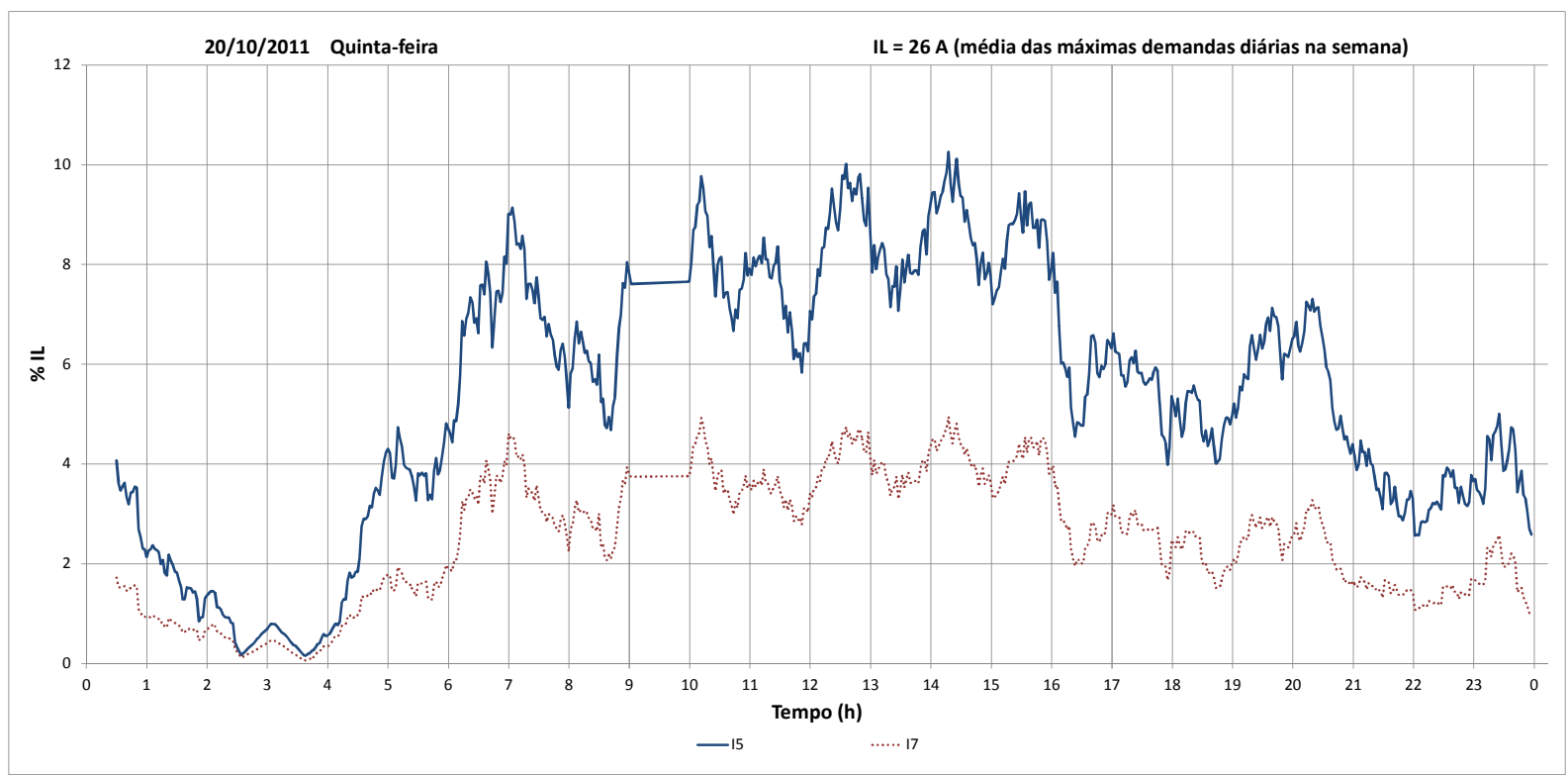

Fig. 4.23 - Registro das componentes harmônicas não-características de corrente de $5^{\mathrm{a}}$ e $7^{\mathrm{a}}$ ordens em porcentagem de IL na entrada de Tietê. 


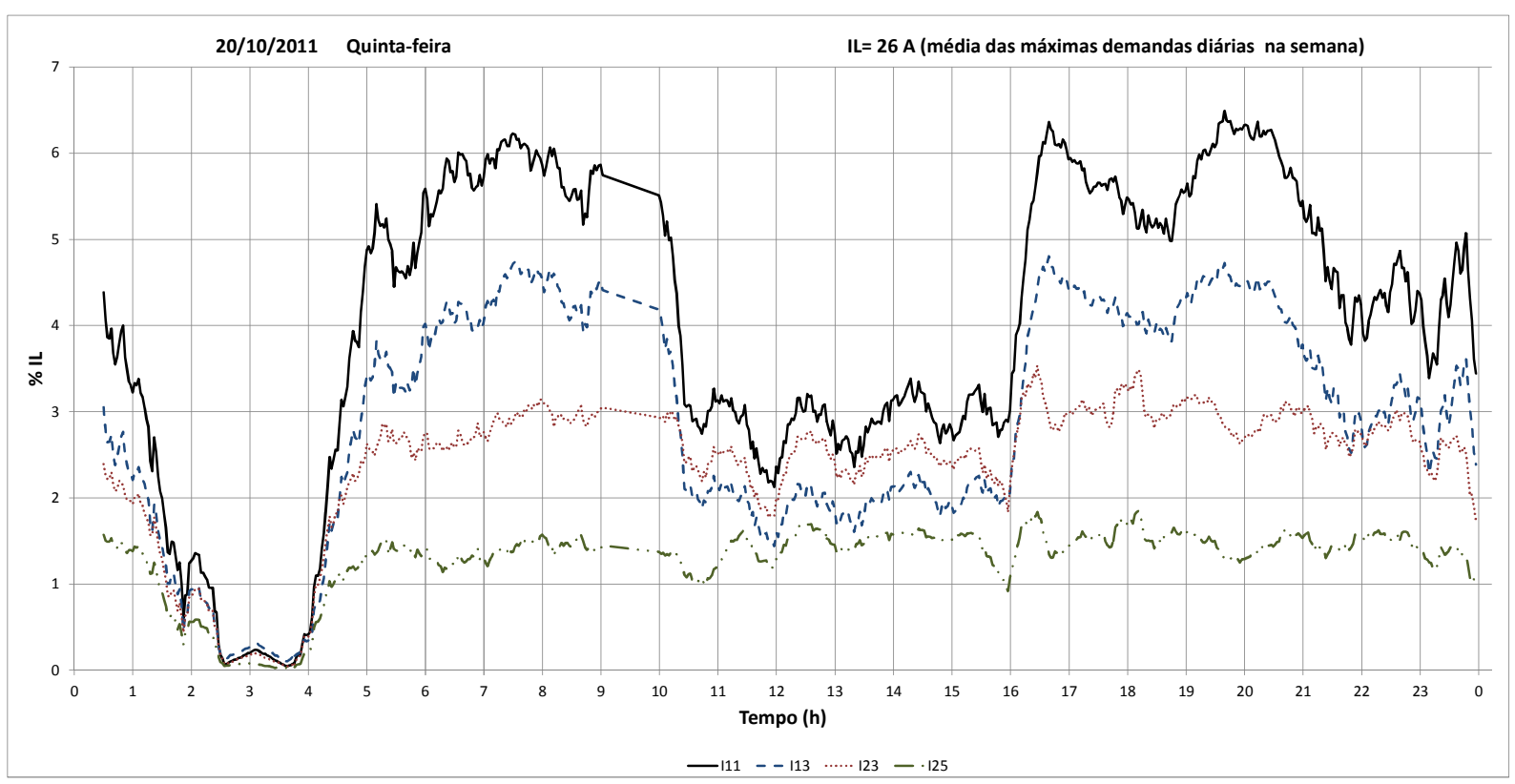

Fig. 4.24 - Registro das componentes harmônicas características de corrente de $11^{\mathrm{a}}, 13^{\mathrm{a}}, 23^{\mathrm{a}} \mathrm{e}$ $25^{\mathrm{a}}$ ordens, em porcentagem de IL, na entrada de Tietê.

O gráfico da figura 4.23 mostra que tanto a $5^{\mathrm{a}}$ quanto a $7^{\mathrm{a}}$ harmônica de corrente ultrapassaram o limite de 1,5\% recomendado pela IEEE-519 para retificadores de 12 pulsos. Essas harmônicas são provenientes do sistema ferroviário, pois a medição de corrente foi feita no primário do transformador de entrada da subestação Tietê. A tabela 4.2 mostra os intervalos de tempo em que a norma IEEE-519 não é atendida para as harmônicas características de corrente até a $25^{\mathrm{a}}$ ordem, normalizadas pela corrente de carga IL, mostradas na figura 4.24 .

Tabela 4.2 - Períodos em que as harmônicas características de corrente ultrapassaram o limite recomendado pela IEEE-519 na subestação Tietê.

\begin{tabular}{|l|l|l|l|l|l|l|l|l|l|l|l|l|l|l|l|l|l|l|l|l|l|l|l|l|}
\hline Tempo & 1 & 2 & 3 & 4 & 5 & 6 & 7 & 8 & 9 & 10 & 11 & 12 & 13 & 14 & 15 & 16 & 17 & 18 & 19 & 20 & 21 & 22 & 23 & 24 \\
\hline $11^{\mathrm{a}}$ & & & & & & & & & & & & & & & & & & & & & & \\
\hline $13^{\mathrm{a}}$ & & & & & & & & & & & & & & & & & & & & & & & \\
\hline $23^{\mathrm{a}}$ & & & & & & & & & & & & & & & & & & & & & & & \\
\hline $25^{\mathrm{a}}$ & & & & & & & & & & & & & & & & & & & & & & & & \\
\hline
\end{tabular}




\subsubsection{Análise do Fator de Potência}

O fator de potência é definido como a relação entre a potência ativa e a potência aparente consumida por um sistema, independentemente das formas de onda de tensão e corrente. Em um sistema com tensões e correntes senoidais o fator de potência é numericamente igual ao cosseno da defasagem entre as ondas de tensão e de corrente fundamentais, $\cos \varphi_{1}$, também chamado de fator de defasagem. Em sistemas com presença de harmônicas, o fator de potência real é o produto do "fator de defasagem" pelo "fator de distorção". O fator de distorção é definido como a relação entre a corrente fundamental $I_{1}$ e a corrente total eficaz, sendo a corrente total eficaz definida como segue:

$$
\mathrm{I}_{\text {total eficaz }}=\sqrt{\sum_{\mathrm{h}=1}^{51} \mathrm{I}_{\mathrm{h}}^{2}}
$$

O fator de defasagem $\left(\cos \varphi_{1}\right)$ ao longo do dia é praticamente constante, como mostra a figura 4.25 .

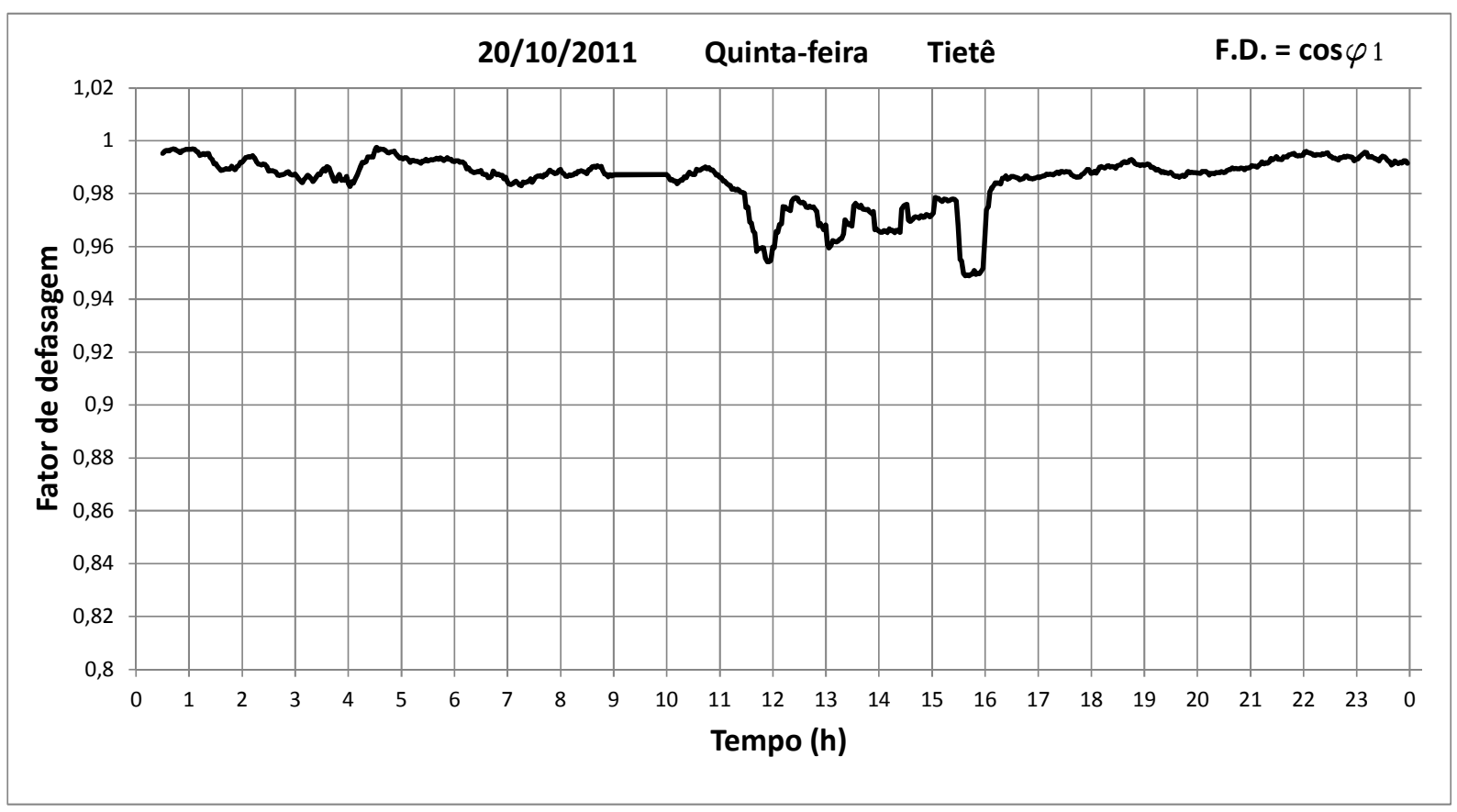

Fig. 4.25 - Registro do fator de defasagem na entrada de Tietê 
O fator de potência real é mostrado na figura 4.26. Verifica-se que o mesmo permaneceu próximo de 0,98 durante todo o dia de operação dos trens, com exceção do horário das $10 \mathrm{~h} 00$ às 16 h00 quando caiu para 0,94 devido ao aumento na distorção harmônica total de corrente neste período, provocado pela elevação das componentes harmônicas de corrente de $5^{\mathrm{a}}$ e $7^{\mathrm{a}}$ ordens (vide figura 4.16).

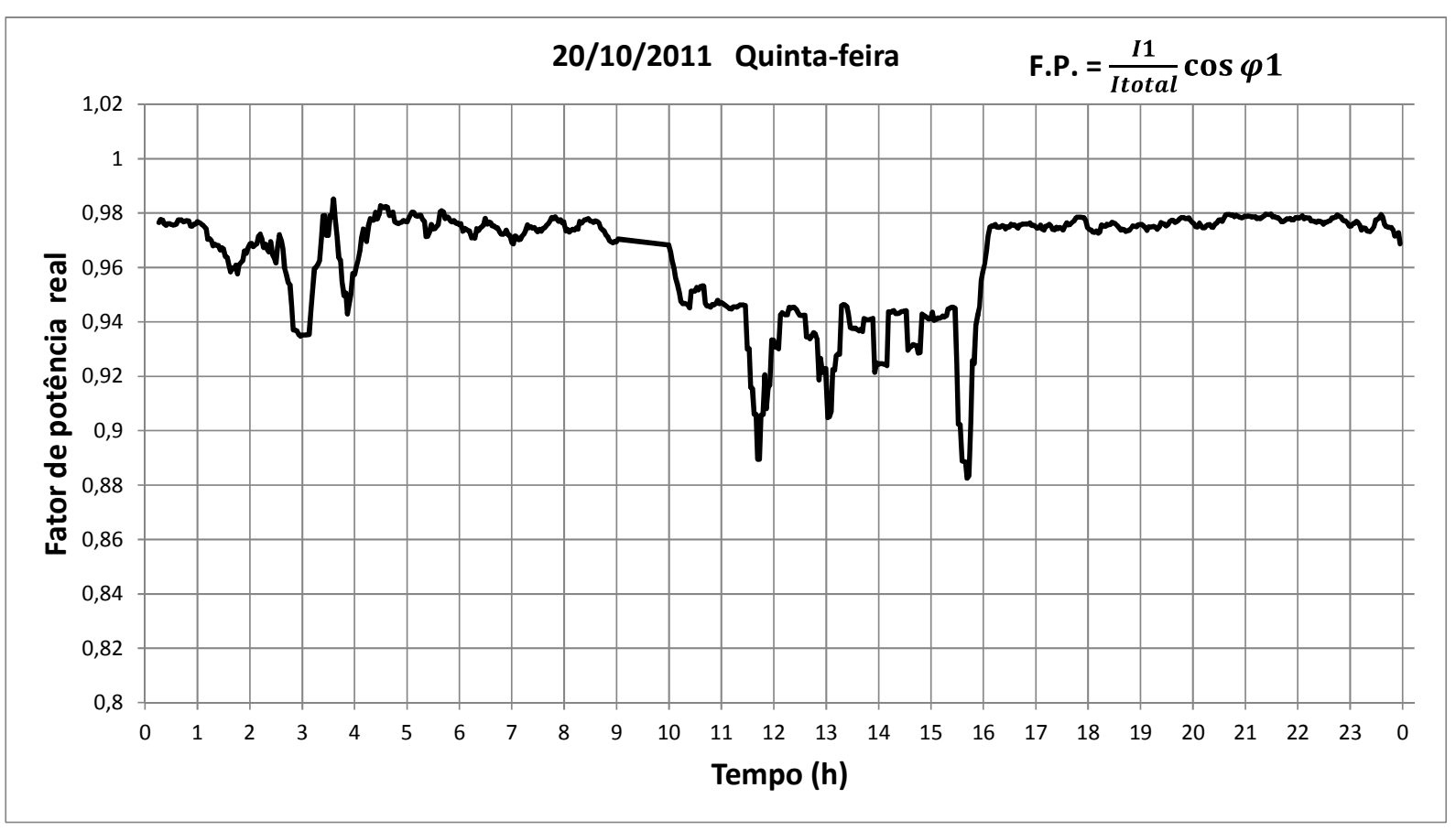

Fig. 4.26 - Registro do fator de potência real na entrada de Tietê. 


\subsubsection{Conclusões parciais de Tietê}

Os registros das medições realizadas em uma semana na subestação Tietê forneceram os seguintes resultados:

Análise da Tensão

- A tensão no ponto de acoplamento comum da concessionária com a CPTM possuía distorção harmônica total abaixo de 2,5\%, respeitando, portanto, os limites especificados pelas normas IEEE-519 e IEC 61000-3-6;

- A componente harmônica de tensão mais significativa no ponto de acoplamento comum era a $5^{\text {a }}$ harmônica, cuja amplitude era uma ordem de grandeza acima das demais componentes. Devido ao fato de não ser esperada uma $5^{\mathrm{a}}$ harmônica de tensão tão elevada nesse ponto de medição, levantou-se a hipótese de que a mesma não fosse devida somente à CPTM, mas também de outros consumidores ligados no mesmo ponto. Por este motivo foram realizadas medições na subestação Jaraguá, que não possui outros consumidores conectados.

Análise da Corrente

- Foi observado um aumento significativo das componentes de $5^{\mathrm{a}}$ e $7^{\mathrm{a}}$ harmônicas de corrente (vide figura 4.16) no período das $10 \mathrm{~h}$ às $16 \mathrm{~h}$ na quinta-feira e na sexta-feira, o mesmo não se verificando nos demais dias da semana. Apesar disso, não houve reflexo nas respectivas componentes harmônicas de tensão (vide figura 4.14).

- A distorção da corrente no ponto de acoplamento comum foi avaliada pela distorção total de demanda e verificou-se que esta ultrapassou o limite da IEEE-519. Apesar disso, o sistema se mostrou capaz de absorver essas harmônicas de corrente, pois a distorção harmônica total de tensão assim como as componentes harmônicas de tensão se manteve abaixo dos limites especificados pelas normas.

Análise do Fator de Potência

- Verificou-se que o fator de distorção influencia significativamente o fator de potência (figura 4.26), principalmente no período entre $10 \mathrm{~h} 00$ e $16 \mathrm{~h} 00$ quando houve um aumento nas amplitudes das harmônicas de corrente de $5^{\mathrm{a}}$ e $7^{\mathrm{a}}$ ordens. 


\subsection{Medições na subestação Jaraguá da CPTM (34,5 kV)}

A subestação Jaraguá alimenta exclusivamente cargas ferroviárias. Portanto, as medições nesta subestação refletem o impacto real provocado pela ferrovia no sistema elétrico.

As medições na subestação Jaraguá foram realizadas na semana de 08 a 16 de fevereiro de 2012. Seguindo a mesma metodologia adotada para as medições da subestação Tietê, optou-se por analisar as medições efetuadas na quinta-feira, 09/02/2012. Os registros das medições de domingo em Jaraguá encontram-se no apêndice D.

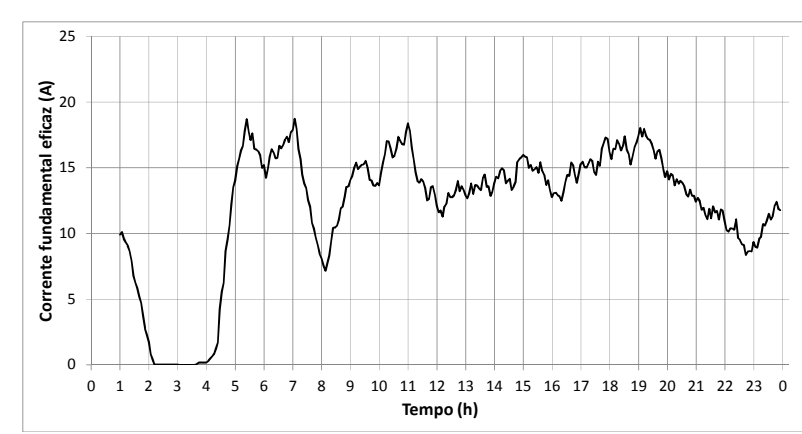

Quinta-feira 09/02/2012

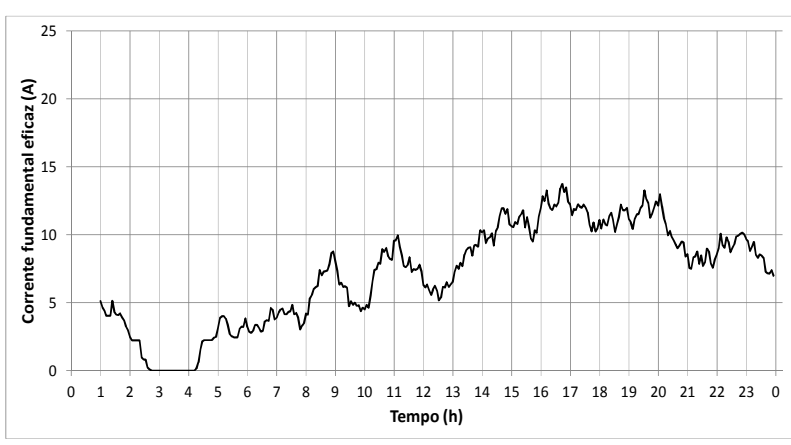

Domingo 12/02/2012

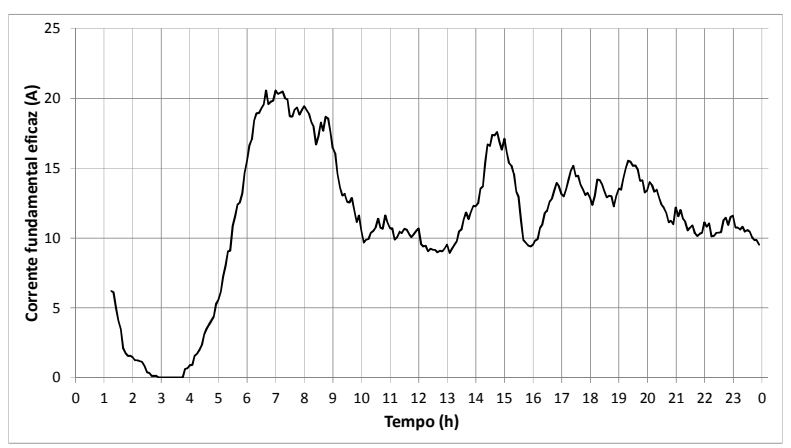

Quarta-feira 15/02/2012

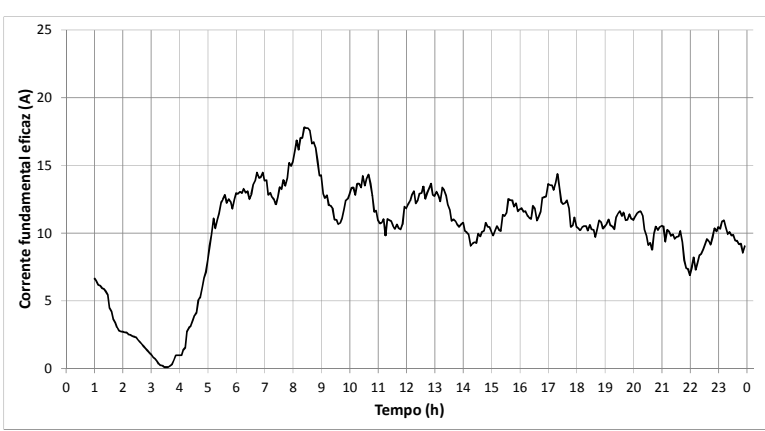

Sábado 11/02/2012

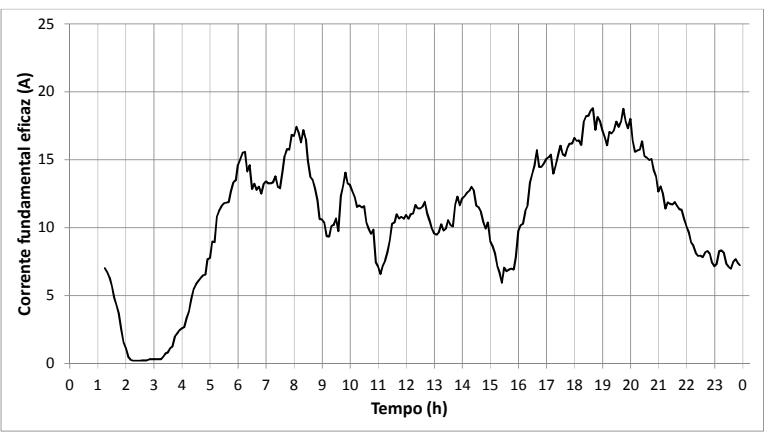

Terça-feira 14/02/2012

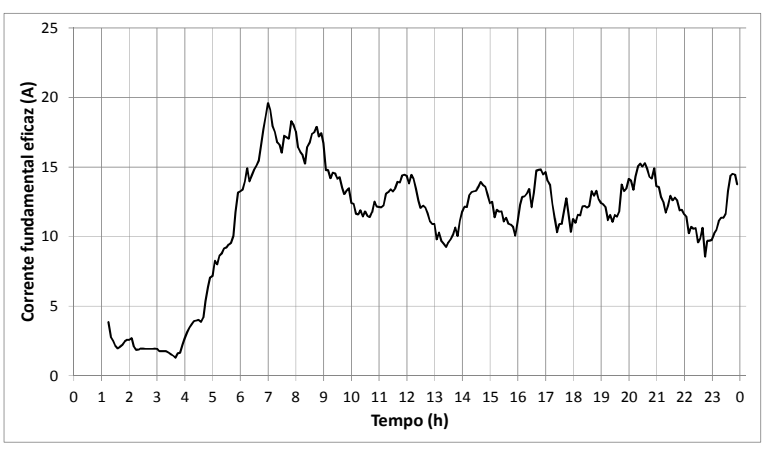

Quinta-feira 16/02/2012

Fig. 4.27 - Registro da corrente CA ao longo da semana de medições em Jaraguá. 
O registro da corrente CA na entrada da subestação Jaraguá em dias úteis, sábado e domingo pode ser visto na figura 4.27. O valor da corrente nominal no barramento de $34,5 \mathrm{kV}$ é $71 \mathrm{~A}$ $\left(\mathrm{S}_{\text {trafo }}=4220 \mathrm{kVA}\right)$. O sistema opera com folga, pois a corrente máxima não ultrapassa $25 \mathrm{~A}$.

A DHTv na entrada de Jaraguá durante a semana de medições é mostrada na figura 4.28. Para a tensão de $34,5 \mathrm{kV}$, os limites recomendados para DHTv pelas normas IEEE-519 e IEC 61000-3-6 são de 5,0\% e 6,5\%, respectivamente. Verifica-se que a DHTv na entrada de Jaraguá oscila entre 5,0\% e 8,0\% na maior parte do tempo durante os dias úteis e sábado. No domingo a DHTv oscila entre $5,0 \%$ e $6 \%$ no horário das $16 \mathrm{~h}$ às $20 \mathrm{~h}$, permanecendo abaixo de $5,0 \%$ no restante do dia.

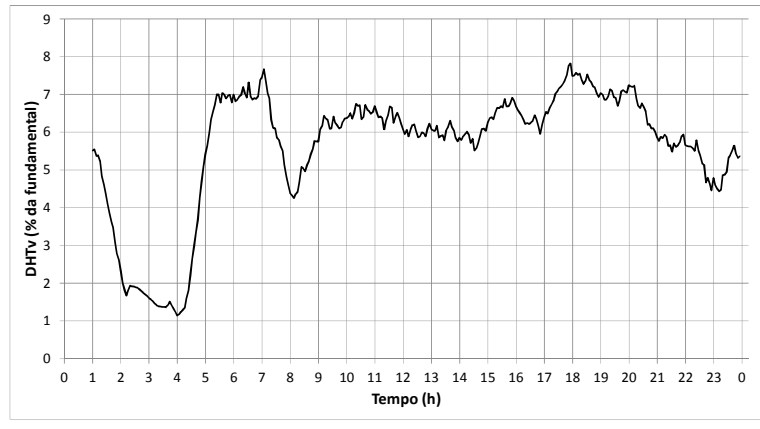

Quinta-feira 09/02/2012

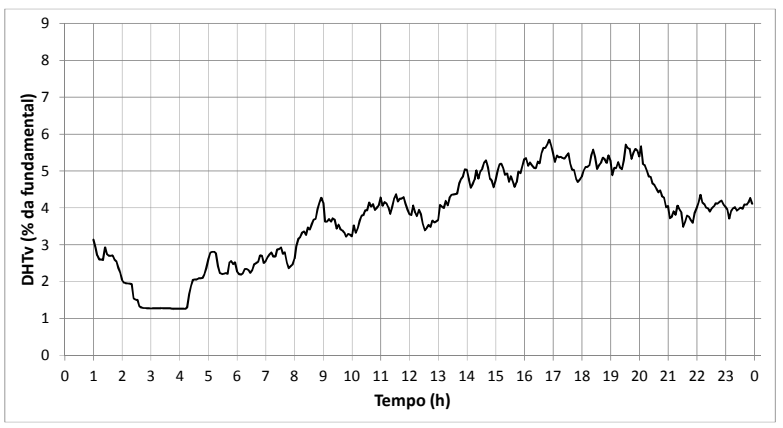

Domingo 12/02/2012

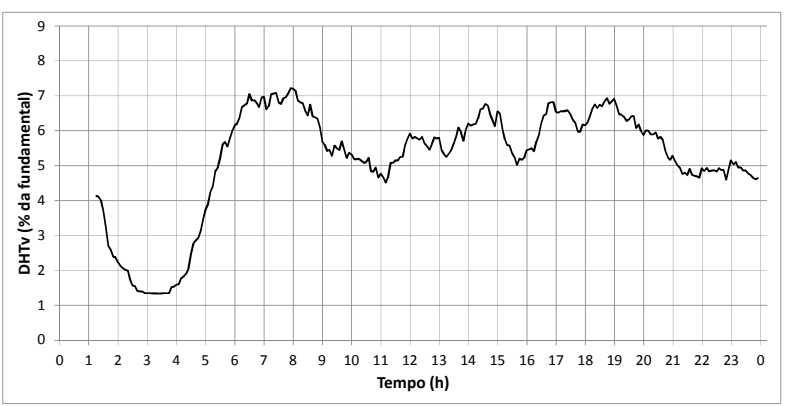

Quarta-feira 15/02/2012

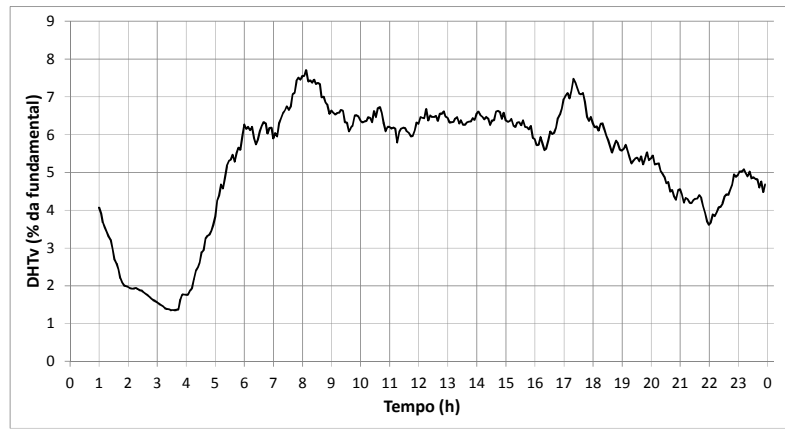

Sábado 11/02/2012

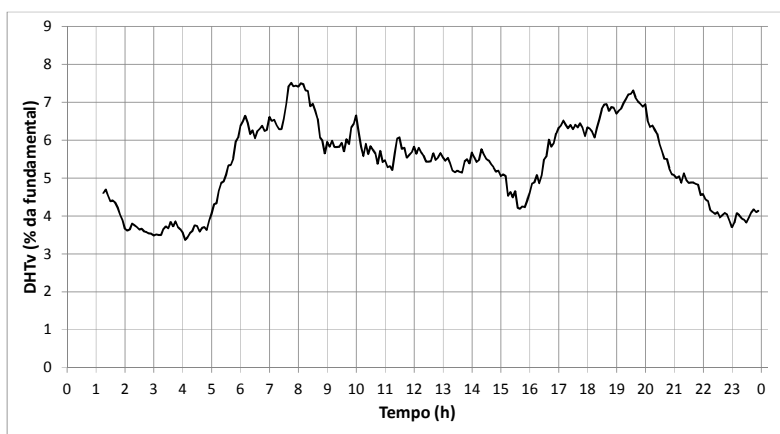

Terça-feira 14/02/2012

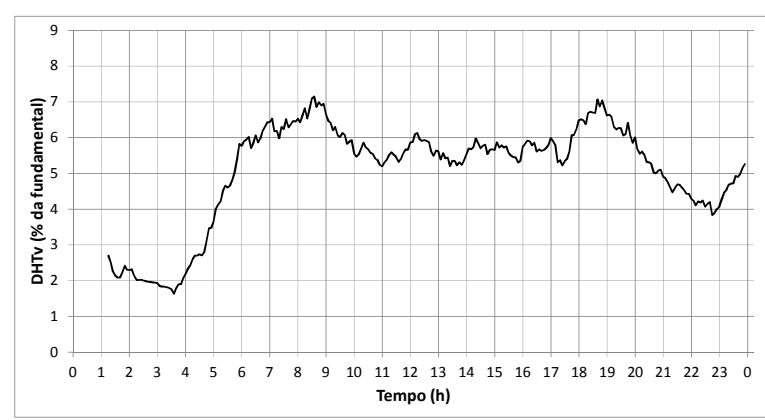

Quinta-feira 16/02/2012

Fig. 4.28 - Registro da DHT de tensão ao longo da semana de medições em Jaraguá. 
As figuras 4.29 e 4.30 apresentam os registros nas três fases de tensão e corrente de entrada da subestação Jaraguá na quinta-feira, dia 09/02/2012. As tensões e correntes estão praticamente equilibradas de forma que nos próximos gráficos serão apresentados somente os registros da fase A.

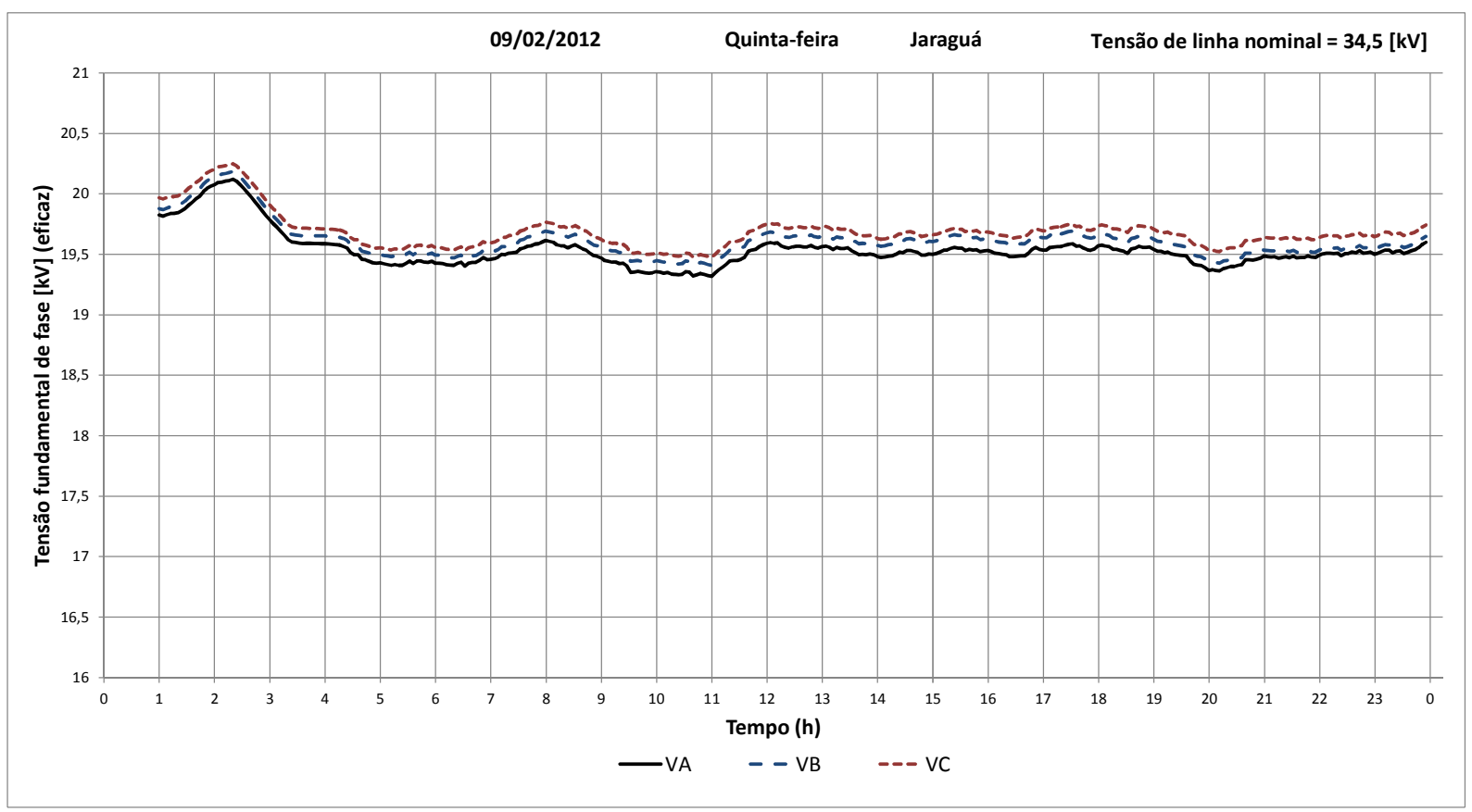

Fig. 4.29 - Registro da tensão na entrada de Jaraguá na quinta-feira, 09/02/2012.

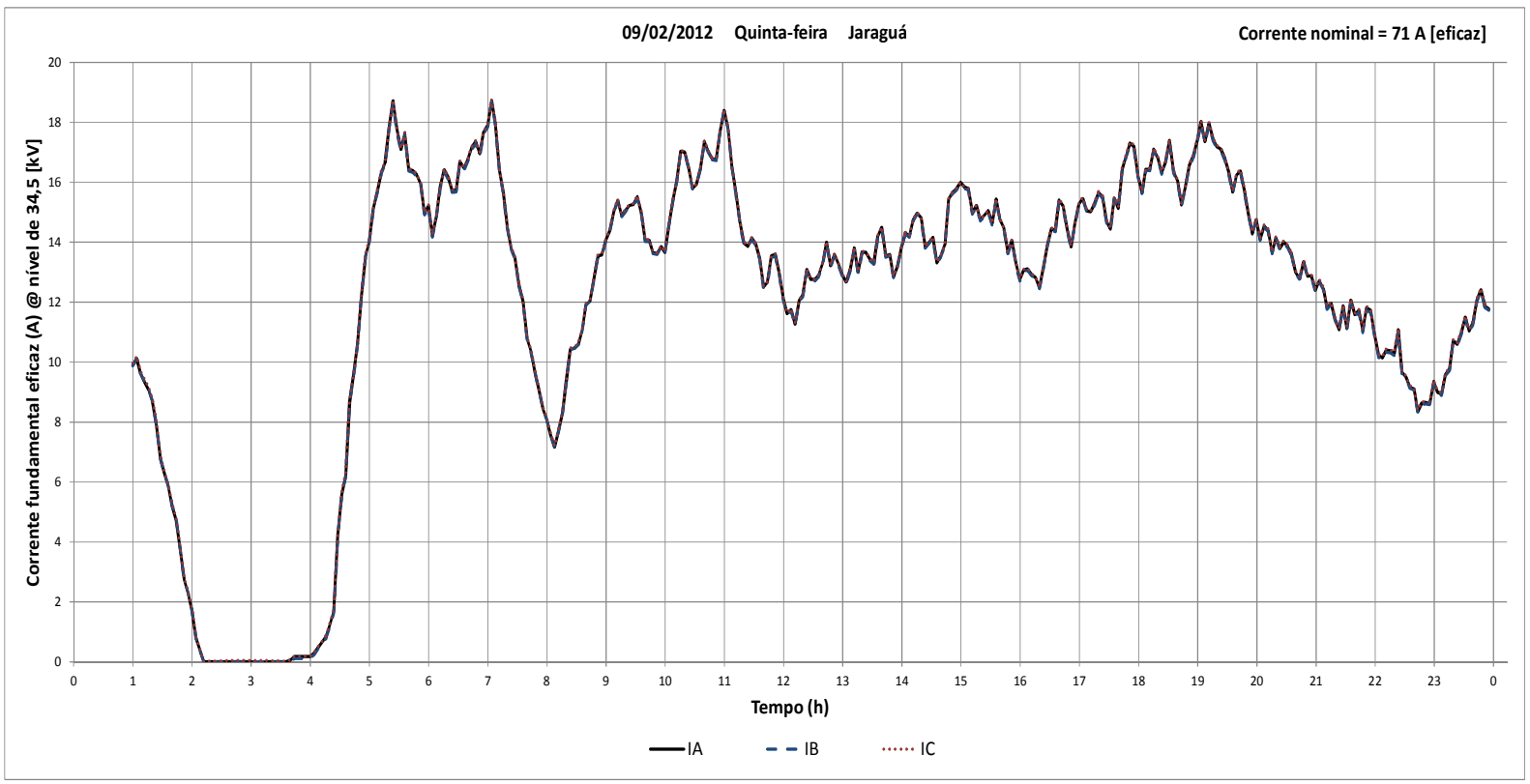

Fig. 4.30 - Registro da componente fundamental da corrente na entrada de Jaraguá. 


\subsubsection{Análise da distorção de tensão no barramento de 34,5 kV (Jaraguá)}

A variação da DHTv em Jaraguá é apresentada na figura 4.31 e os espectros harmônicos da tensão nos instantes de menor DHTv (8h12) e de maior DHTv (17h44) são apresentados nas figuras 4.32 e 4.33 .

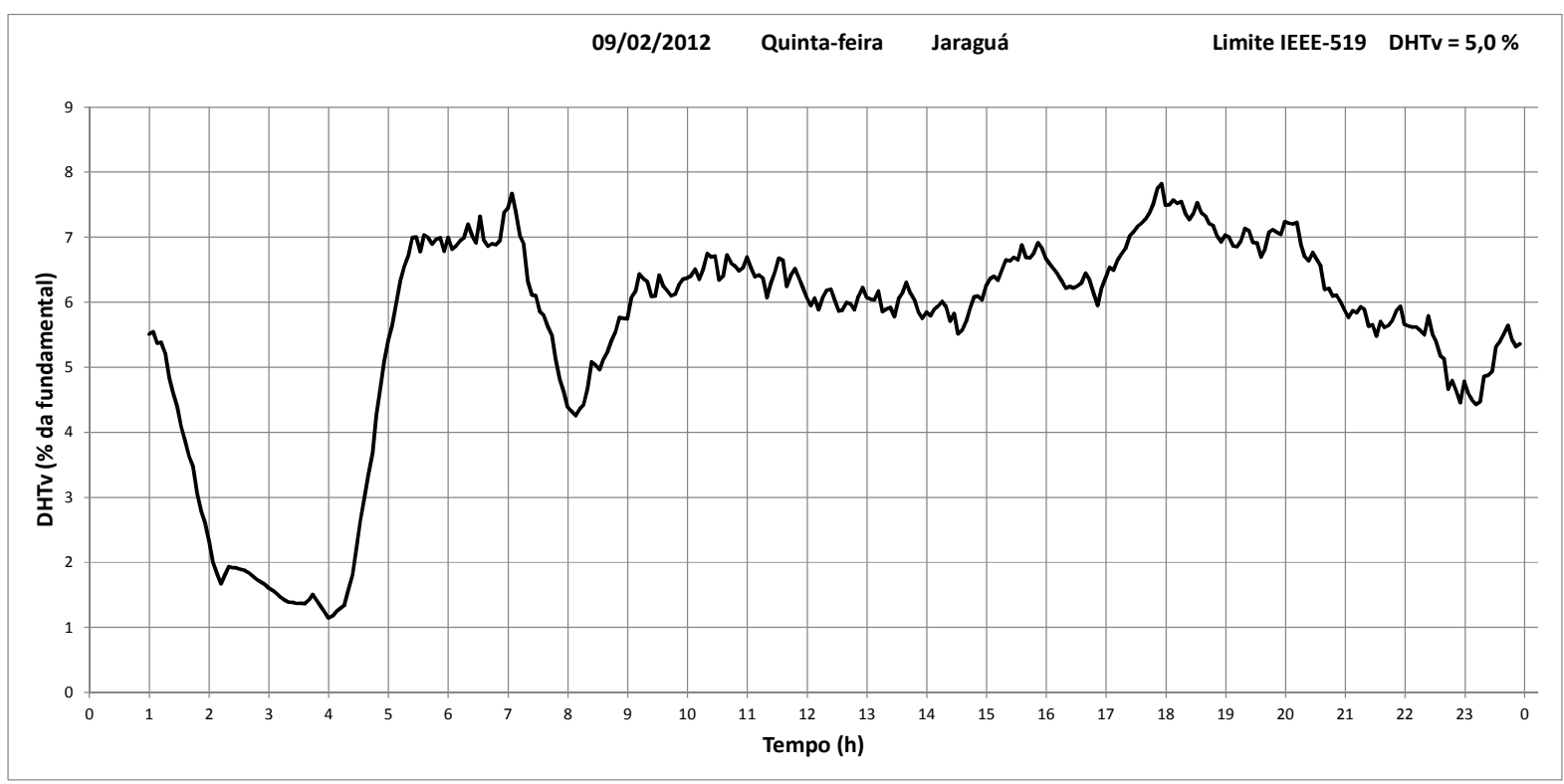

Fig. 4.31 - Registro da DHTv na entrada de Jaraguá.

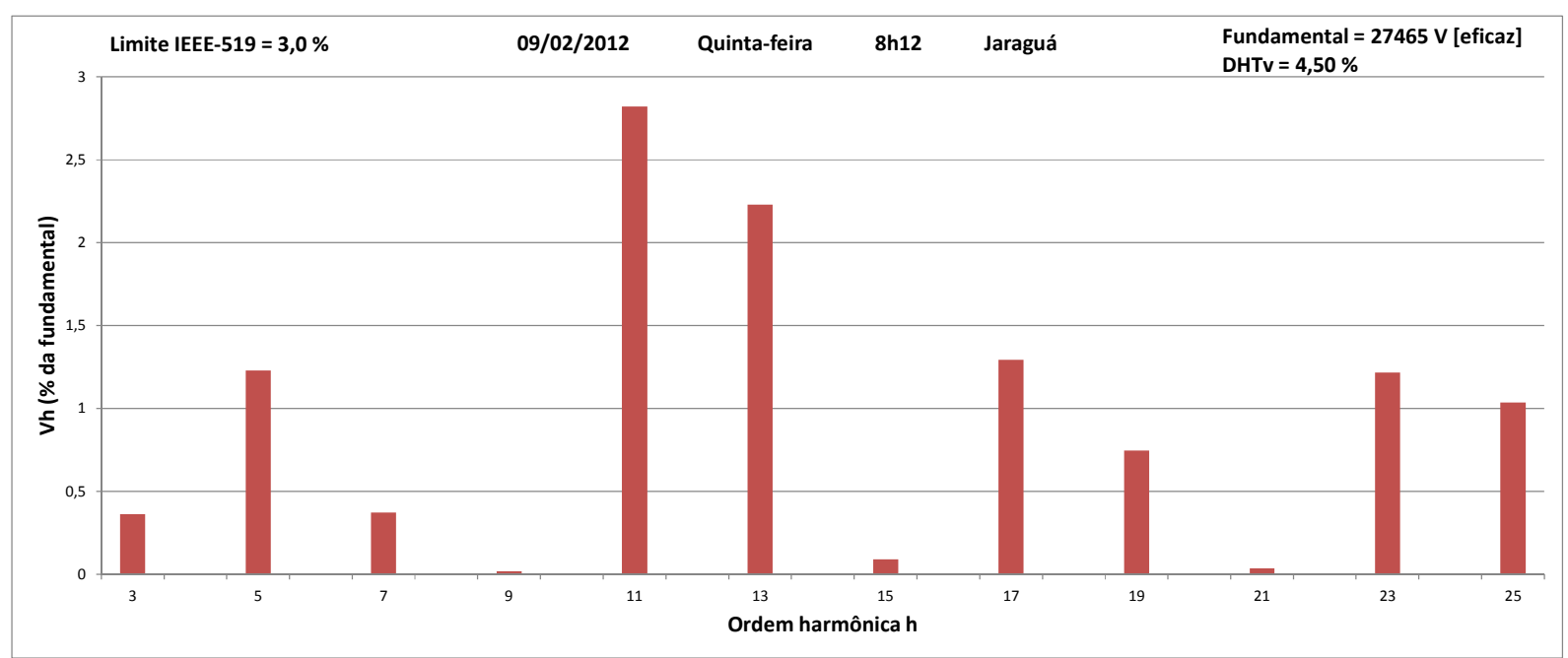

Fig. 4.32 - Espectro da tensão do registro no instante de menor DHTv em Jaraguá. 


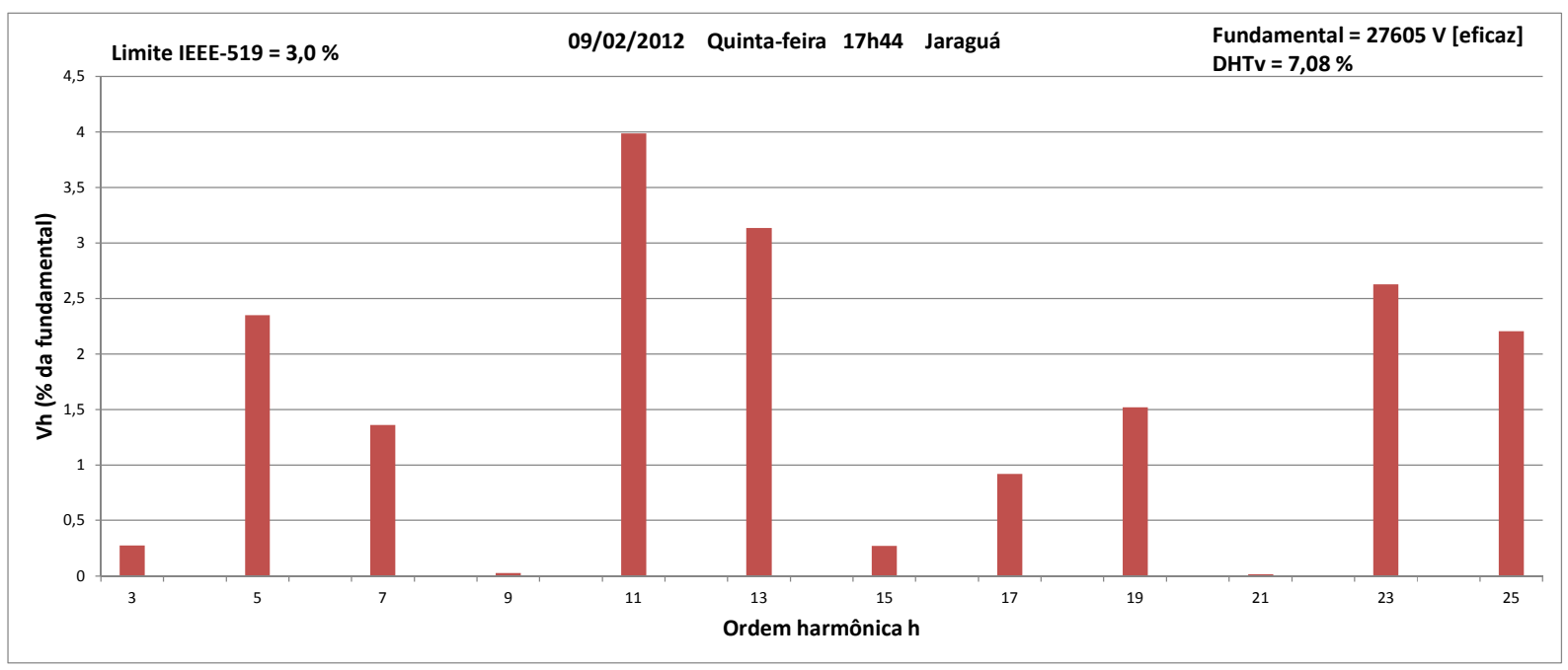

Fig. 4.33 - Espectro da tensão do registro no instante de maior DHTv em Jaraguá.

No espectro da tensão predominam as componentes harmônicas que são características para a corrente CA de um retificador de 12 pulsos.

As figuras 4.34 e 4.35 apresentam os registros das componentes de $5^{\mathrm{a}}$ e $7^{\mathrm{a}}$ harmônicas de tensão e as harmônicas de tensão de ordens $11,13,23$ e 25, respectivamente.

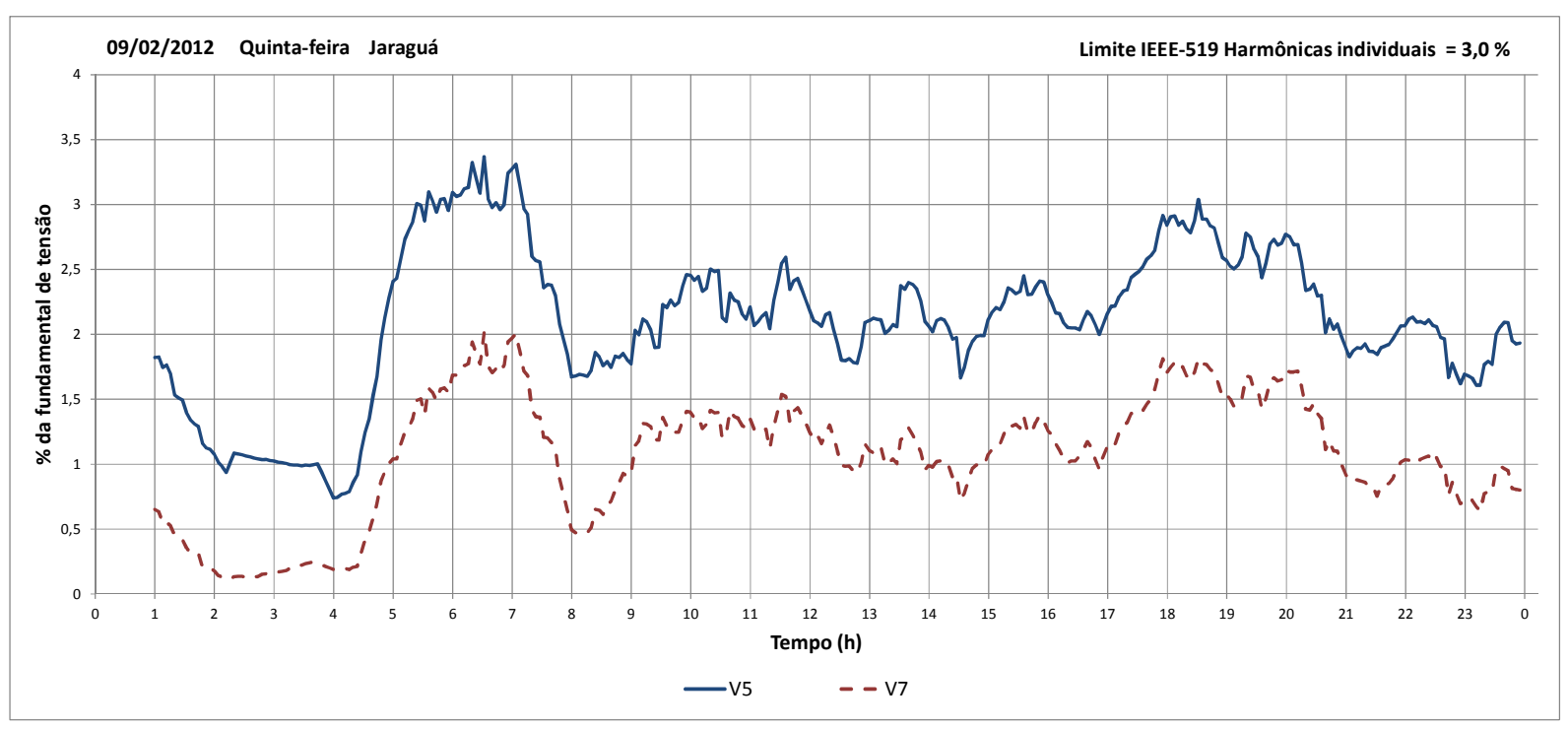

Fig. 4.34 - Registro das harmônicas de tensão de $5^{\mathrm{a}}$ e $7^{\mathrm{a}}$ ordens em Jaraguá.

O sistema atende à IEC 61000-3-6, já que os níveis de $5^{\mathrm{a}}$ e $7^{\mathrm{a}}$ harmônicas são inferiores a $3,25 \%$ e, portanto, abaixo dos limites de $5 \%$ e $4 \%$, respectivamente, estabelecidos pela norma. Porém, no período entre $5 \mathrm{~h} 30$ e $7 \mathrm{~h} 20$ a componente de $5^{\mathrm{a}}$ harmônica ultrapassa em $0,25 \%$ o limite máximo (3\%) estabelecido pela IEEE-519. 


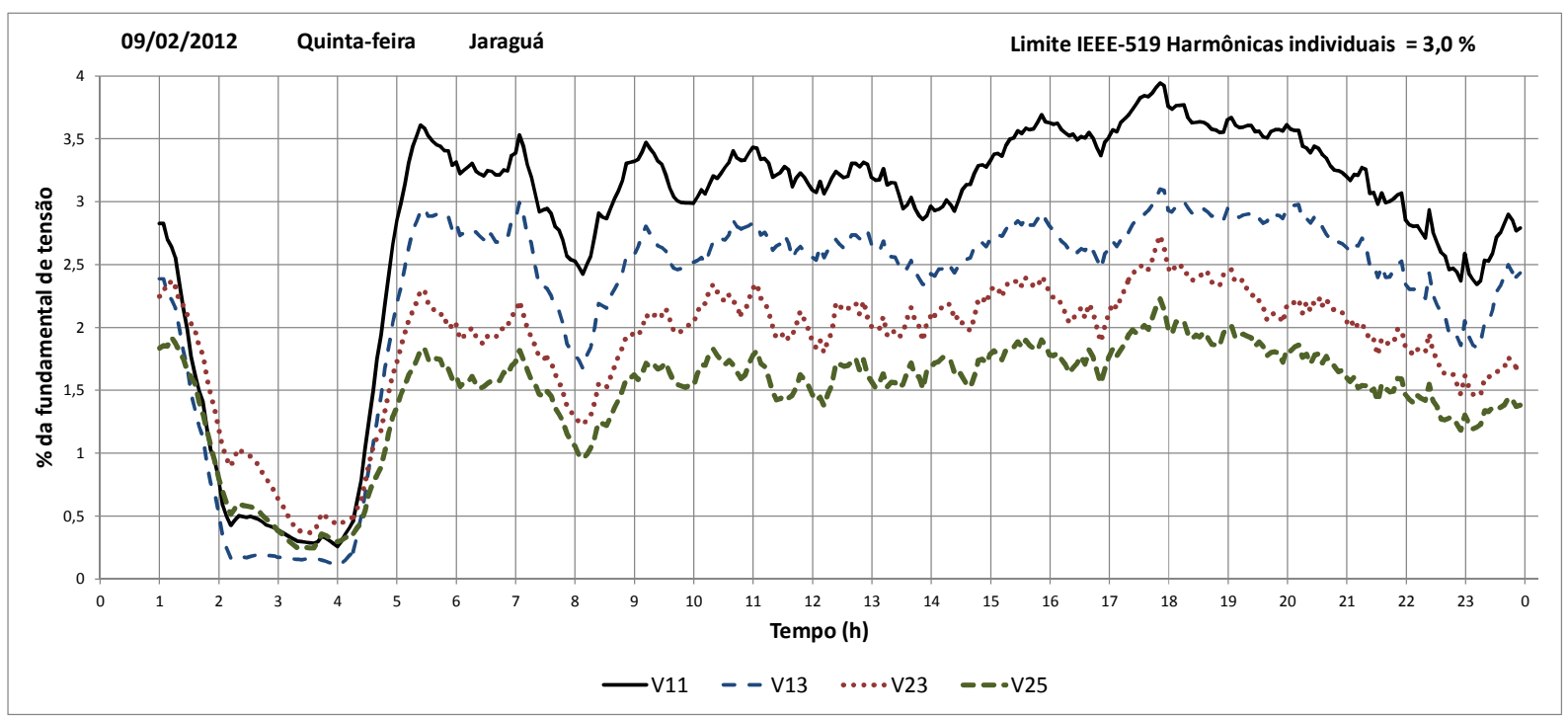

Fig. 4.35 - Registro das harmônicas de tensão de ordens 11, 13, 23 e 25 em Jaraguá.

$\mathrm{Na}$ figura 4.35 observa-se que os perfis das harmônicas são semelhantes, sugerindo que provenham de uma mesma fonte. Além disso, as amplitudes das componentes decrescem da $11^{\mathrm{a}}$ para a $25^{\mathrm{a}}$, em todos os instantes, conforme esperado. Verifica-se que apenas a $11^{\mathrm{a}}$ harmônica de tensão ultrapassou o limite de 3,0\% estabelecido pela IEEE-519, porém, as harmônicas de ordens $11,13,23$ e 25 ultrapassaram, respectivamente, os limites de 3,0\%, $2,5 \%, 1,2 \%$ e $1,1 \%$, especificados pela IEC 61000-3- 6 .

\subsubsection{Análise da distorção de corrente no barramento de 34,5 kV (Jaraguá)}

A figura 4.36 apresenta o registro das harmônicas de corrente de $5^{\mathrm{a}}$ e $7^{\mathrm{a}}$ ordens em Jaraguá.

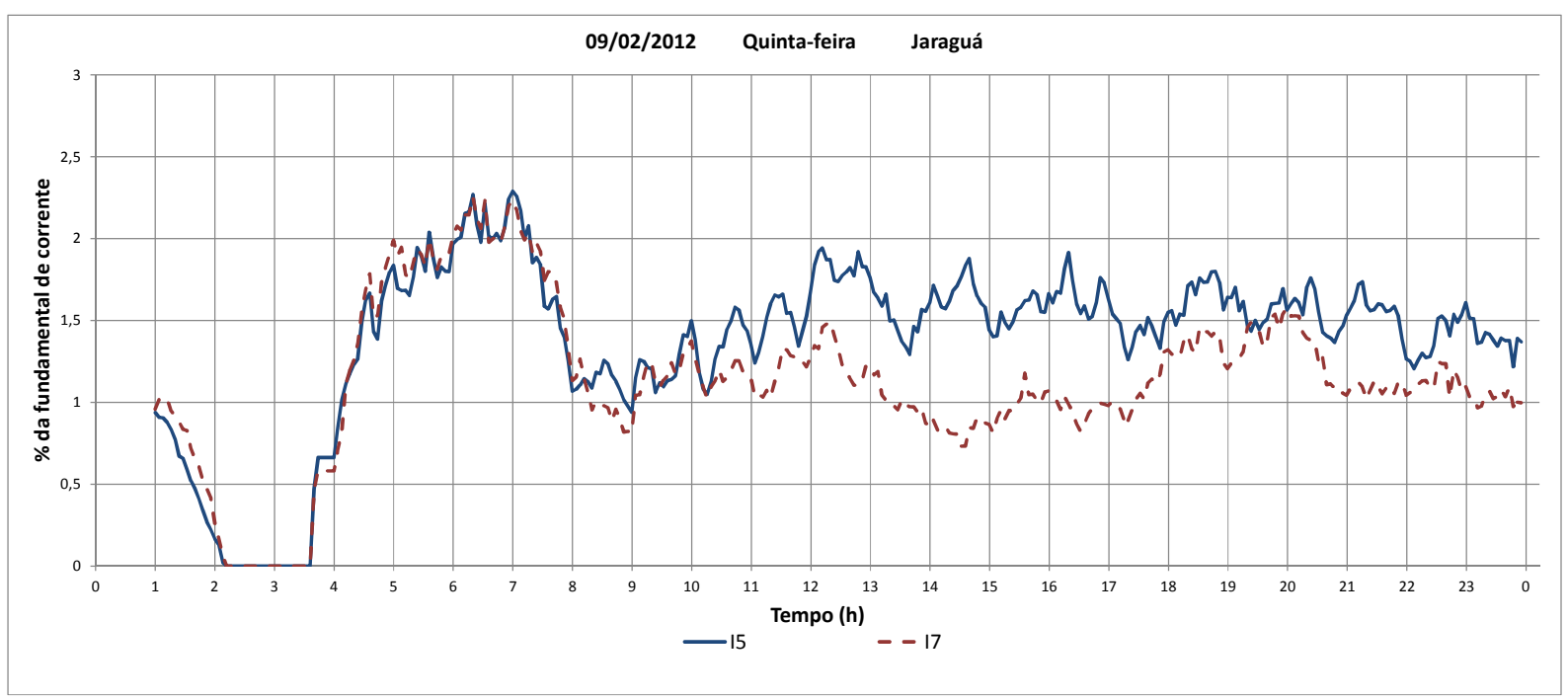

Fig. 4.36 - Registro das harmônicas de corrente de $5^{\mathrm{a}}$ e $7^{\mathrm{a}}$ ordens em Jaraguá. 
Ao contrário do que se verificou na subestação Tietê, as componentes harmônicas de $5^{\mathrm{a}}$ e $7^{\mathrm{a}}$ ordens de tensão (figura 4.34) e correntes (figura 4.36) possuem um perfil semelhante, sugerindo que tenham sido geradas pela mesma carga.

A figura 4.37 apresenta as componentes harmônicas características de corrente. Nota-se a semelhança dos perfis de corrente com os perfis de tensão mostrados na figura 4.35.

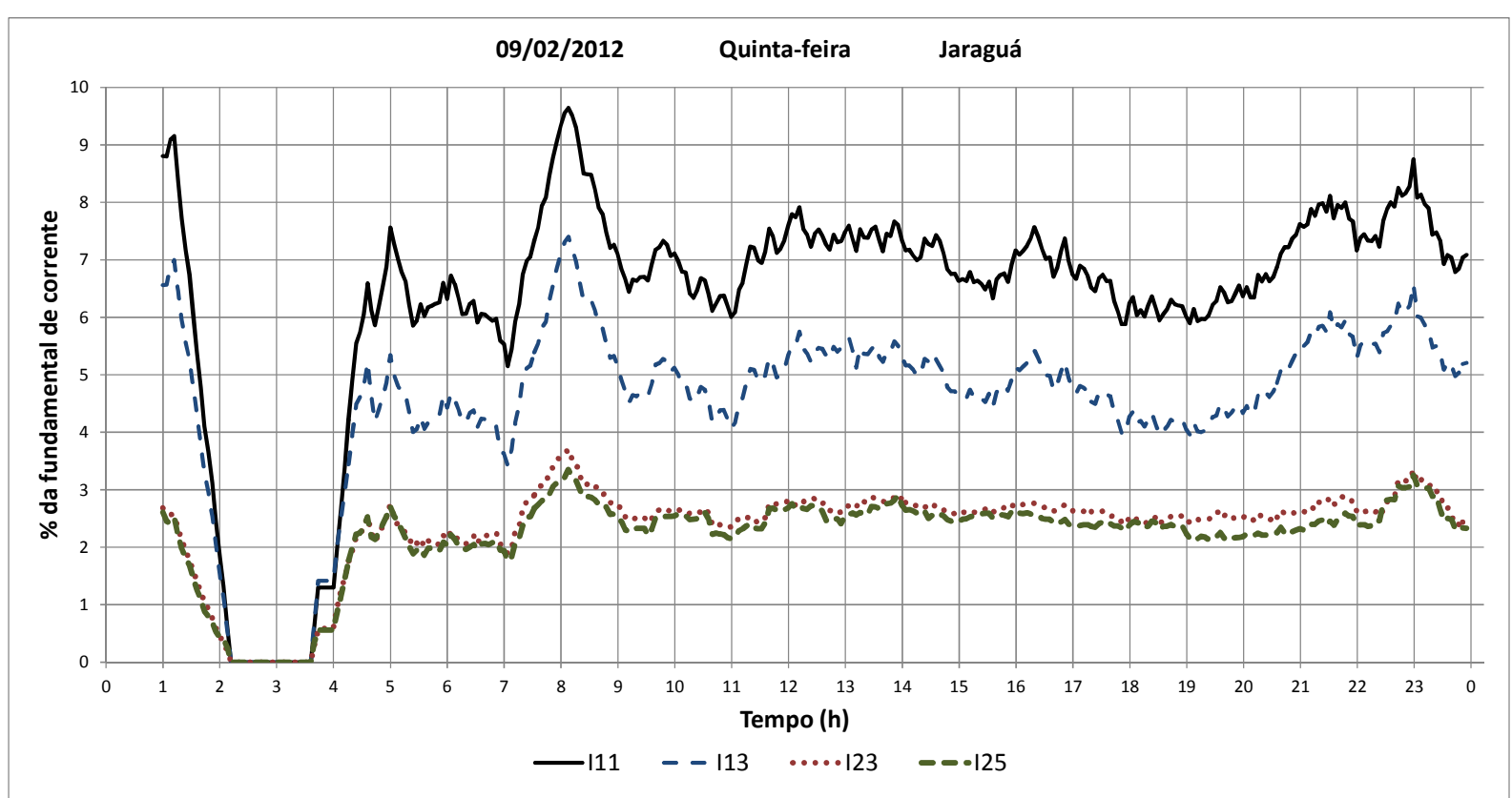

Fig. 4.37 - Registro das harmônicas de corrente de ordens 11, 13, 23 e 25 em Jaraguá.

Essa semelhança já era esperada pelo fato de a carga de Jaraguá ser exclusivamente desta subestação retificadora.

A variação da distorção harmônica total de corrente é mostrada na figura 4.38 .

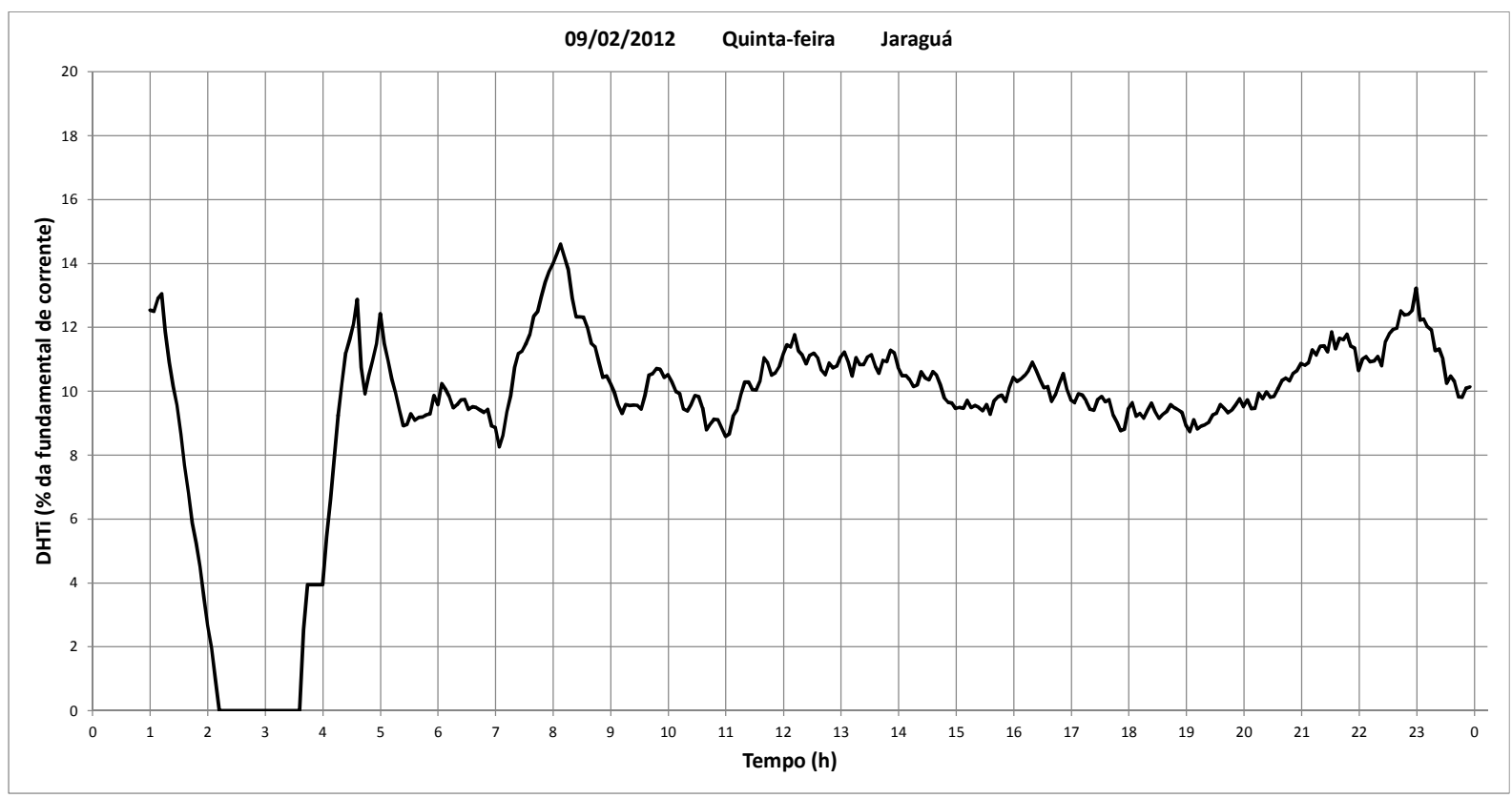

Fig. 4.38 - Registro da DHTi na entrada de Jaraguá. 
As figuras 4.39 a 4.41 apresentam registros da forma de onda da corrente e respectivo espectro, captadas de manhã, à tarde e à noite. O horário selecionado de manhã corresponde à amplitude máxima da $5^{\text {a }}$ harmônica de corrente (figura 4.36) no dia 09/02/2012. Verifica-se em todos os registros uma uniformidade nas formas de onda da corrente e a predominância das harmônicas características de um retificador de 12 pulsos.
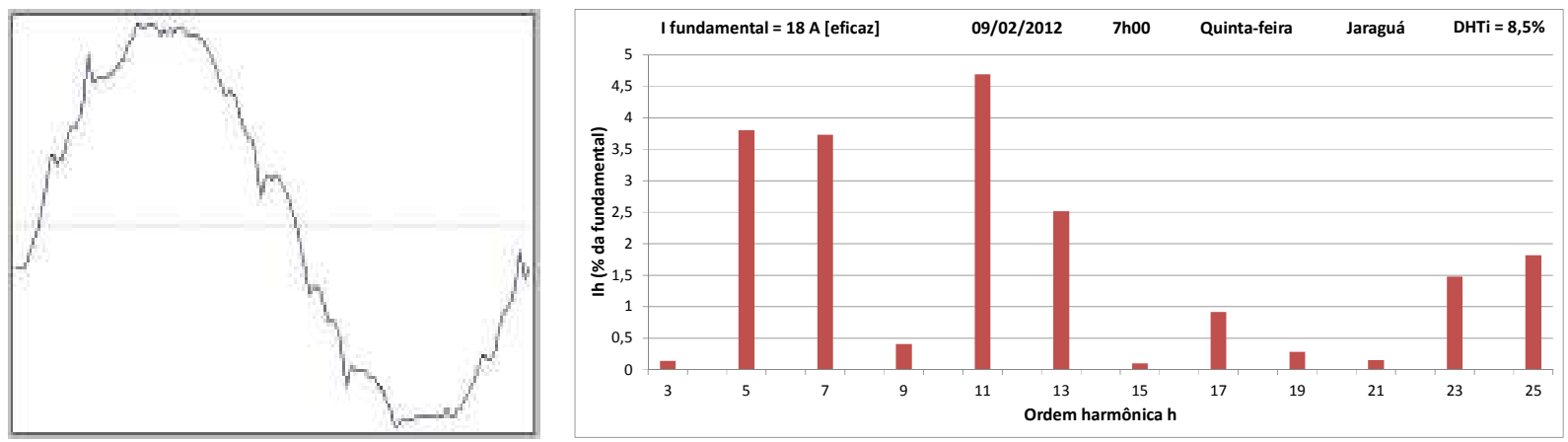

Fig. 4.39 - Forma de onda e espectro da corrente na subestação Jaraguá às 7h00.
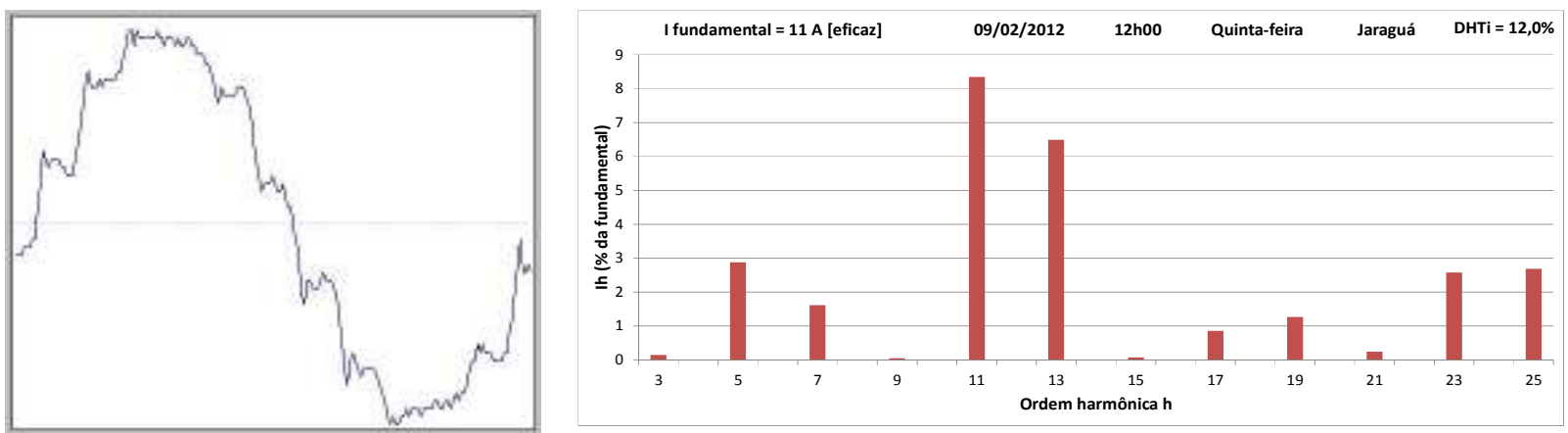

Fig. 4.40 - Forma de onda e espectro da corrente na subestação Jaraguá às $12 \mathrm{~h} 00$.
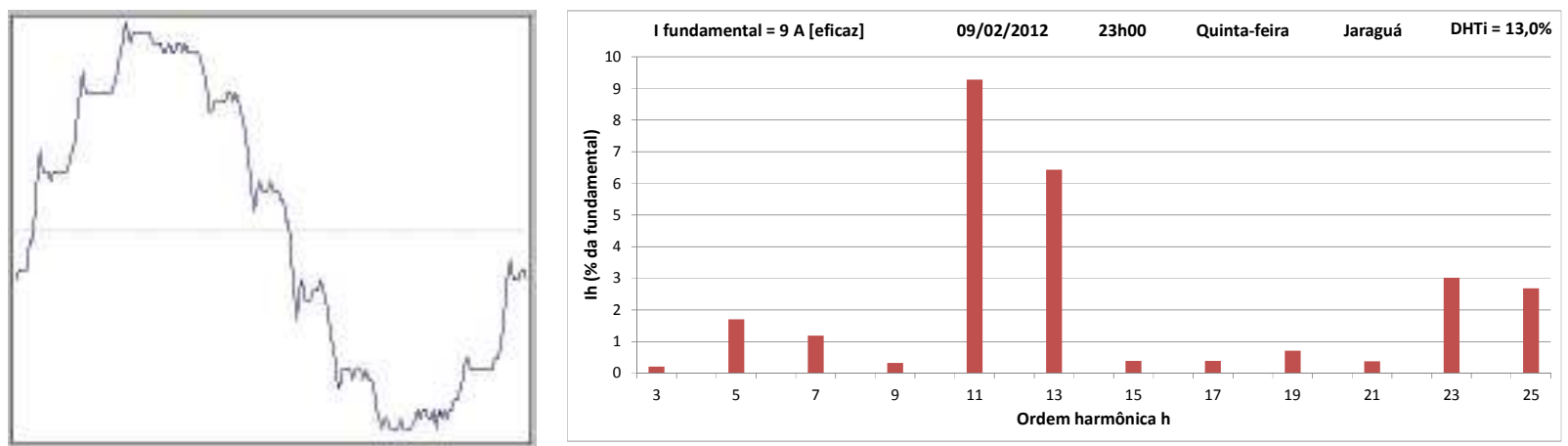

Fig. 4.41 - Forma de onda e espectro da corrente na subestação Jaraguá às 23 h00. 
Conforme mostrado para a subestação Tietê, a avaliação da distorção de corrente é realizada pela IEEE-519 através do índice DTD (Distorção Total de Demanda). A corrente de curtocircuito na entrada da subestação Jaraguá é 1912 A e a corrente de carga é 18 A. A razão Icc/IL é 106, e, portanto, os limites da tabela A1.1 para retificadores de 12 pulsos são os mostrados na tabela 4.3 a seguir.

Tabela 4.3 - Limites de amplitudes de harmônicas de corrente em porcentagem da corrente de carga para sistemas com níveis de tensão de $120 \mathrm{~V}$ a $69 \mathrm{kV}$ e conversores com 12 pulsos.

\begin{tabular}{c|c|c|c|c|c|c|c|c|c}
\hline $\mathrm{Icc} / \mathrm{I}_{\mathrm{L}}$ & $\mathrm{I} 5$ & $\mathrm{I} 7$ & $\mathrm{I} 11$ & $\mathrm{I} 13$ & $\mathrm{I} 17$ & $\mathrm{I} 19$ & $\mathrm{I} 23$ & $\mathrm{I} 25$ & $\mathrm{DTD}$ \\
\hline $100<1000$ & \multicolumn{2}{|c|}{3,0} & \multicolumn{2}{|c|}{7,8} & \multicolumn{2}{|c|}{1,3} & 2,8 & 15,0 \\
\hline
\end{tabular}

O registro da DTD na entrada de Jaraguá para o dia 09/02/2012 é mostrado na figura 4.42. A curva encontra-se abaixo de $9 \%$ em todos os instantes e, portanto, em concordância com o limite de $15,0 \%$ especificado pela IEEE-519.

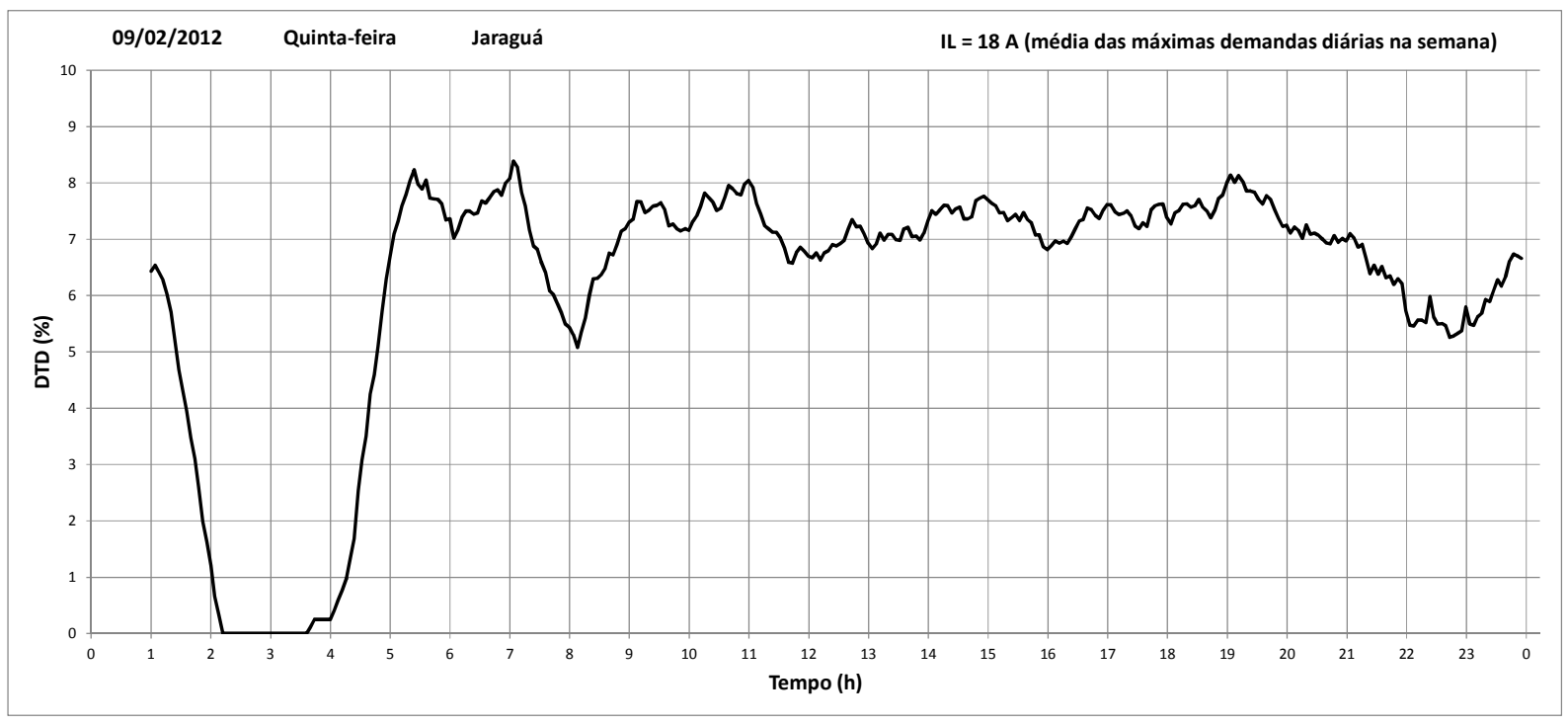

Fig. 4.42 - Registro da DTD na entrada de Jaraguá.

As figuras 4.43 e 4.44 apresentam os registros das componentes harmônicas individuais de corrente em porcentagem da corrente de carga IL em Jaraguá. 


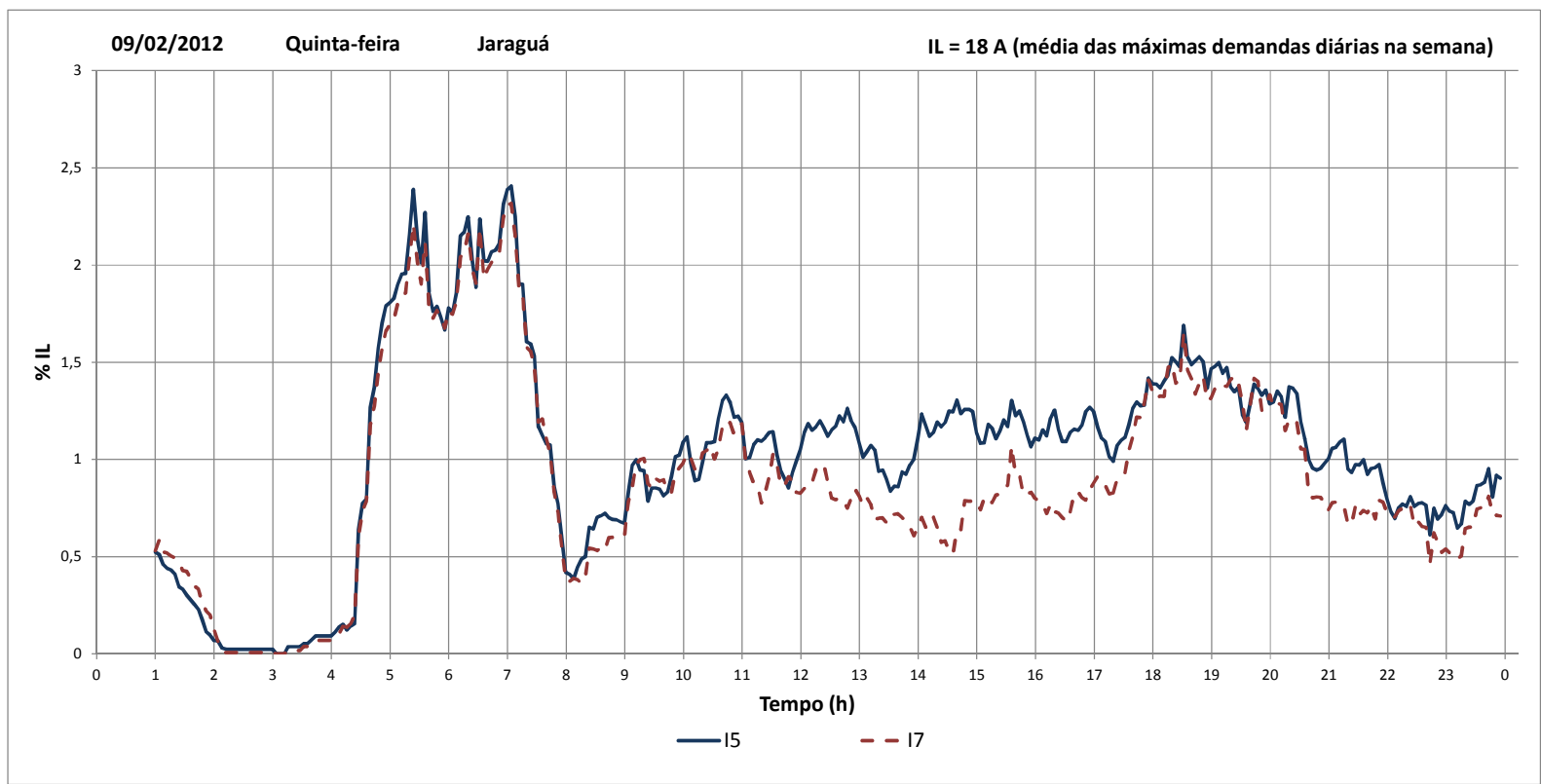

Fig. 4.43 - Registro das componentes harmônicas não-características de corrente de $5^{\mathrm{a}}$ e $7^{\mathrm{a}}$ ordens em porcentagem de IL na entrada de Jaraguá.

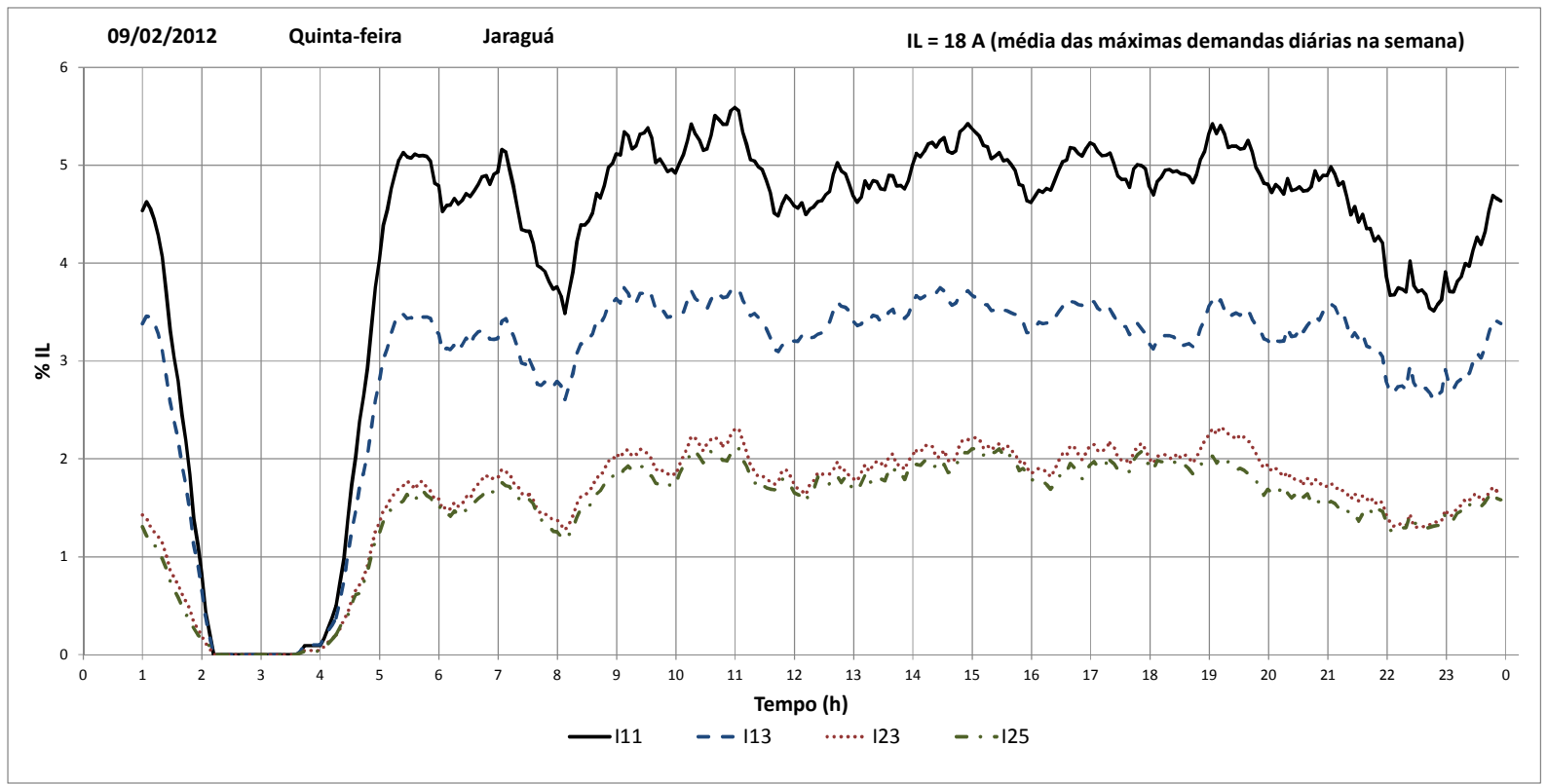

Fig. 4.44 - Registro das componentes harmônicas características de corrente de $11^{\mathrm{a}}, 13^{\mathrm{a}}, 23^{\mathrm{a}} \mathrm{e}$ $25^{\mathrm{a}}$ ordens, em porcentagem de IL, na entrada de Jaraguá.

Verifica-se que as harmônicas de corrente de $5^{\mathrm{a}}$ e $7^{\mathrm{a}}$ ordens encontram-se abaixo do limite de $3,0 \%$ dado na tabela 4.3. As $11^{\mathrm{a}}$ e $13^{\mathrm{a}}$ harmônicas de corrente estão abaixo de $6,0 \%$ e, portanto, atendem o critério de 7,8\% especificado pela IEEE-519. As harmônicas 23 e 25 estão dentro do limite de 2,8\% estabelecido pela IEEE-519. 


\subsubsection{Conclusões parciais de Jaraguá}

Os registros das medições realizadas em uma semana na subestação Jaraguá forneceram os seguintes resultados:

Análise da Tensão

- A DHTv na entrada de Jaraguá oscilou entre 5,0\% e 8,0\% durante os dias úteis e no sábado, e ultrapassou os limites de 5,0\% e 6,5\% recomendados pela IEEE-519 e pela IEC 61000-3-6, respectivamente. No domingo a DHTv oscilou entre 5,0\% e 6\% no horário das $16 \mathrm{~h}$ às $20 \mathrm{~h}$, permanecendo abaixo de $5,0 \%$ no restante do dia.

- O espectro da tensão apresentou predominância das componentes harmônicas que são características para a corrente CA de um retificador de 12 pulsos.

- Verificou-se que apenas a $11^{\text {a }}$ harmônica de tensão ultrapassou o limite de 3,0\% estabelecido pela IEEE-519, porém, as harmônicas de ordens 11, 13, 23 e 25 ultrapassaram, respectivamente, os limites de 3,0\%,2,5\%,1,2\% e 1,1\%, especificados pela IEC 61000-3- 6.

- Observou-se que as componentes harmônicas de tensão apresentaram perfis semelhantes, sugerindo que tivessem origem em uma mesma fonte.

Análise da Corrente

- Ao contrário do observado em Tietê, verificou-se que as componentes harmônicas de corrente apresentaram um perfil semelhante às componentes harmônicas de tensão, o que evidencia o fato de a carga de Jaraguá ser exclusivamente desta subestação.

- Amostras da corrente ao longo do dia mostraram espectros com predominância das harmônicas características de um retificador de 12 pulsos.

- A distorção total de demanda na entrada da subestação Jaraguá esteve abaixo de 9,0\% em todos os instantes da quinta-feira, 09/02/2012, e, portanto, abaixo do limite de 15,0\% especificado pela IEEE-519 para este nível de tensão, corrente de curto-circuito e corrente de carga. As componentes harmônicas de corrente individuais avaliadas também se encontram em conformidade com a norma. 


\subsection{Resultados das simulações}

O modelo do trecho Tietê-Jaraguá da CPTM e os dados técnicos apresentados nos apêndices A e B, respectivamente, foram utilizados para se obter simulações a partir da ferramenta computacional SimPowerSystems 5.1 do software Matlab.

Na simulação foram utilizados os modelos descritos no capítulo 3 e a corrente absorvida pelos trens foi ajustada, de hora em hora, tomando como base os resultados de medição das correntes de entrada em Tietê (figura 4.10) e em Jaraguá (figura 4.30). Foram calculados os valores das harmônicas de tensão e de corrente de $11^{\mathrm{a}}, 13^{\mathrm{a}}, 23^{\mathrm{a}}$ e $25^{\mathrm{a}}$ ordens na entrada da subestação Tietê, e no primário do transformador retificador de 4,22 MVA da subestação Jaraguá.

Em cada figura são sobrepostos os resultados obtidos das medições com os das simulações, para cada componente harmônica, a fim de se verificar a validade do modelo utilizado.

\subsubsection{Harmônicas de tensão em Tietê}

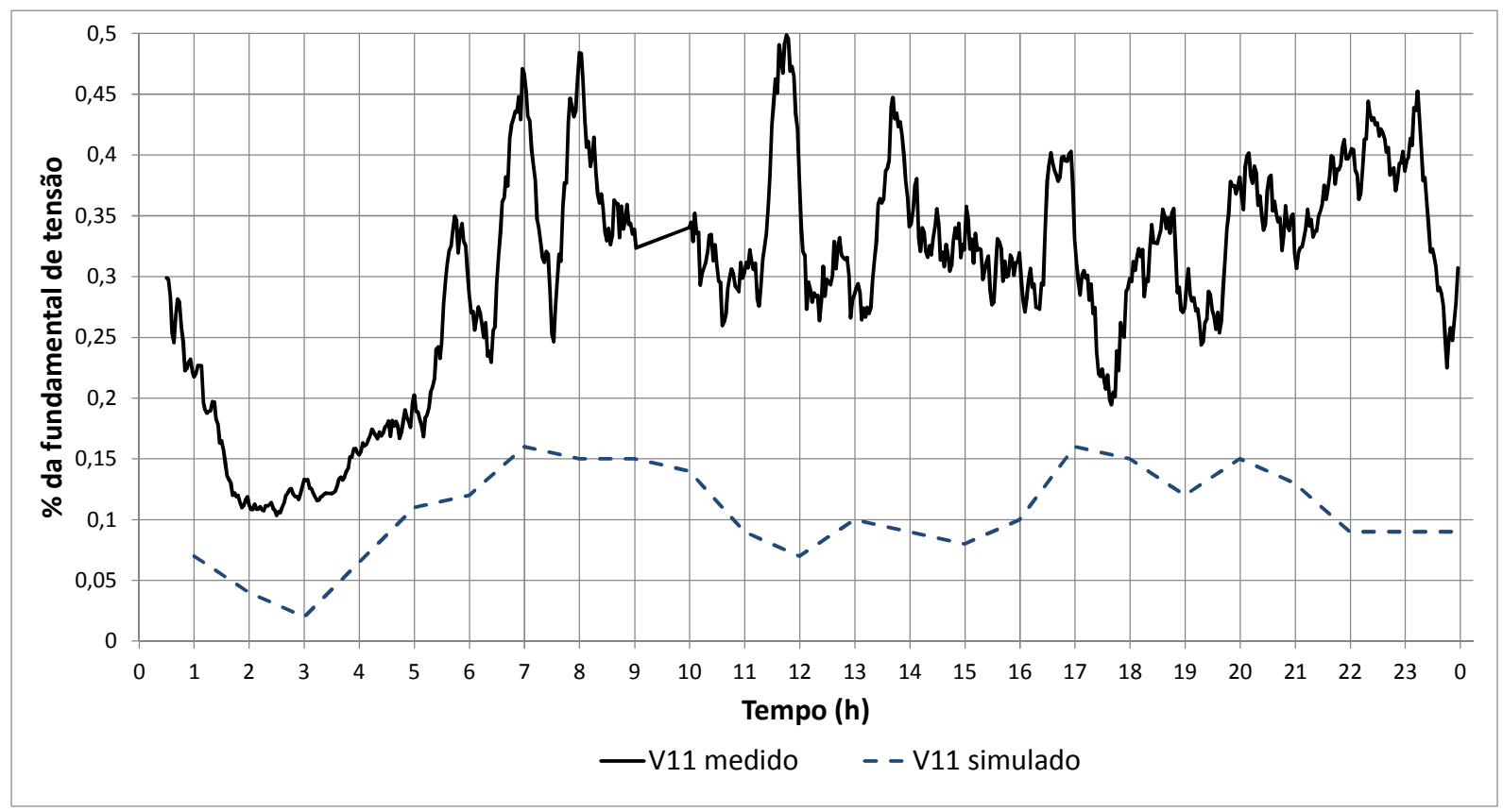

Fig. 4.45 - Resultado das medições e simulações para a $11^{\mathrm{a}}$ harmônica de tensão em Tietê. 


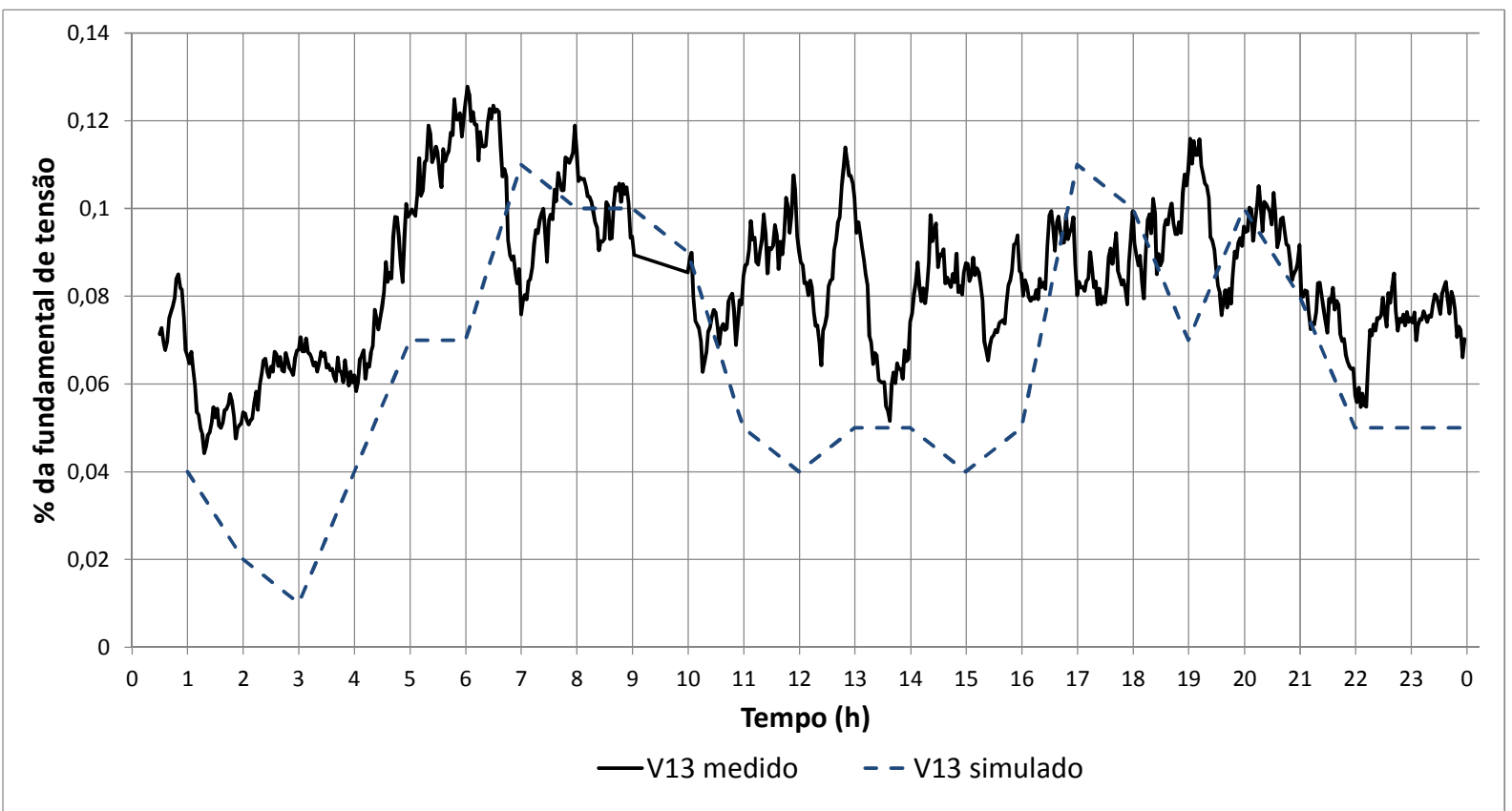

Fig. 4.46 - Resultado das medições e simulações para a 13ª harmônica de tensão em Tietê.

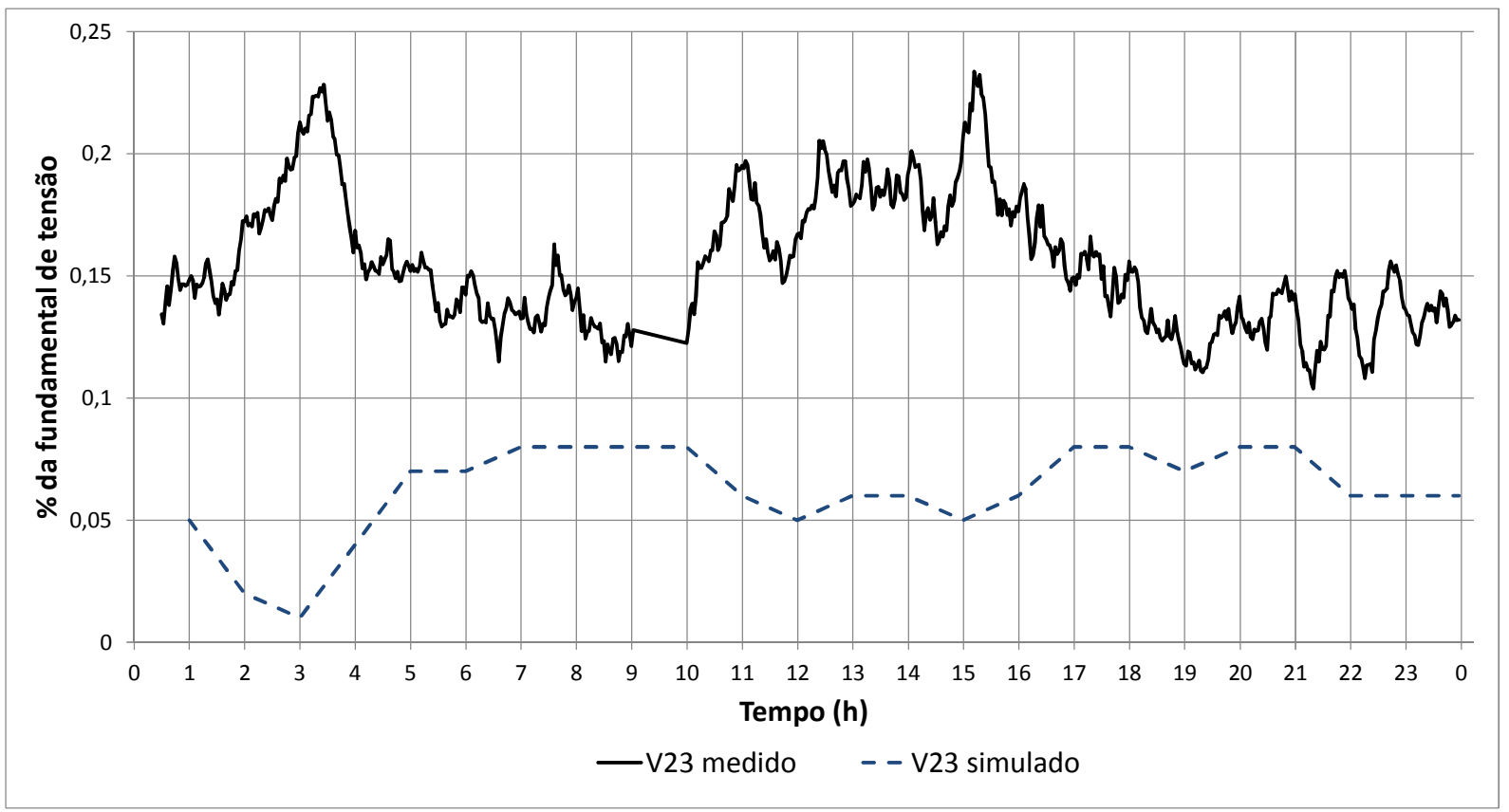

Fig. 4.47 - Resultado das medições e simulações para a $23^{\mathrm{a}}$ harmônica de tensão em Tietê. 


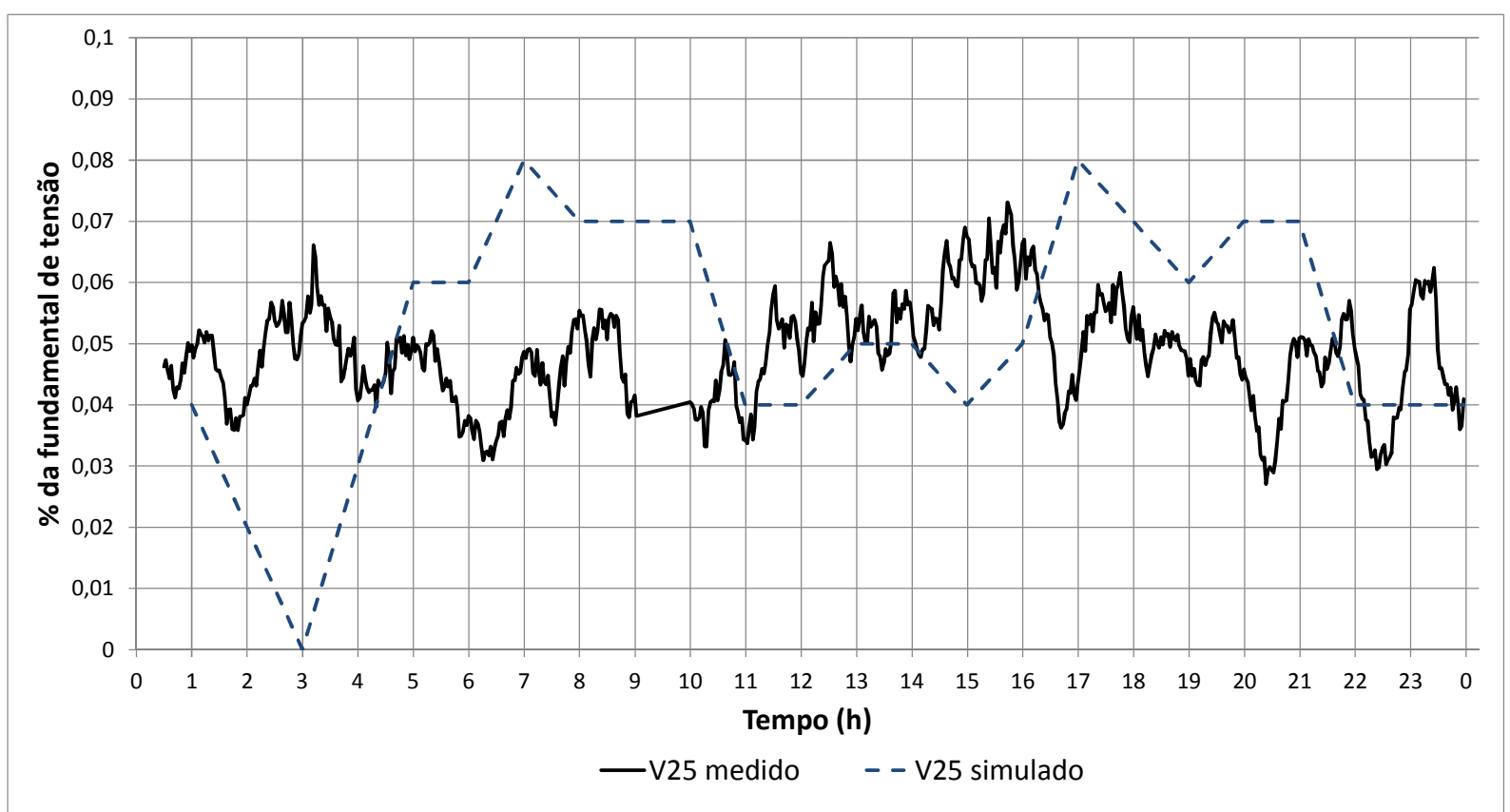

Fig. 4.48 - Resultado das medições e simulações para a $25^{\text {a }}$ harmônica de tensão em Tietê.

As figuras mostram que não há correlação entre os resultados medidos com os simulados para as harmônicas de tensão. Uma possível explicação é o fato de as cargas ligadas à subestação Tietê não serem todas ferroviárias.

\subsubsection{Harmônicas de corrente em Tietê}

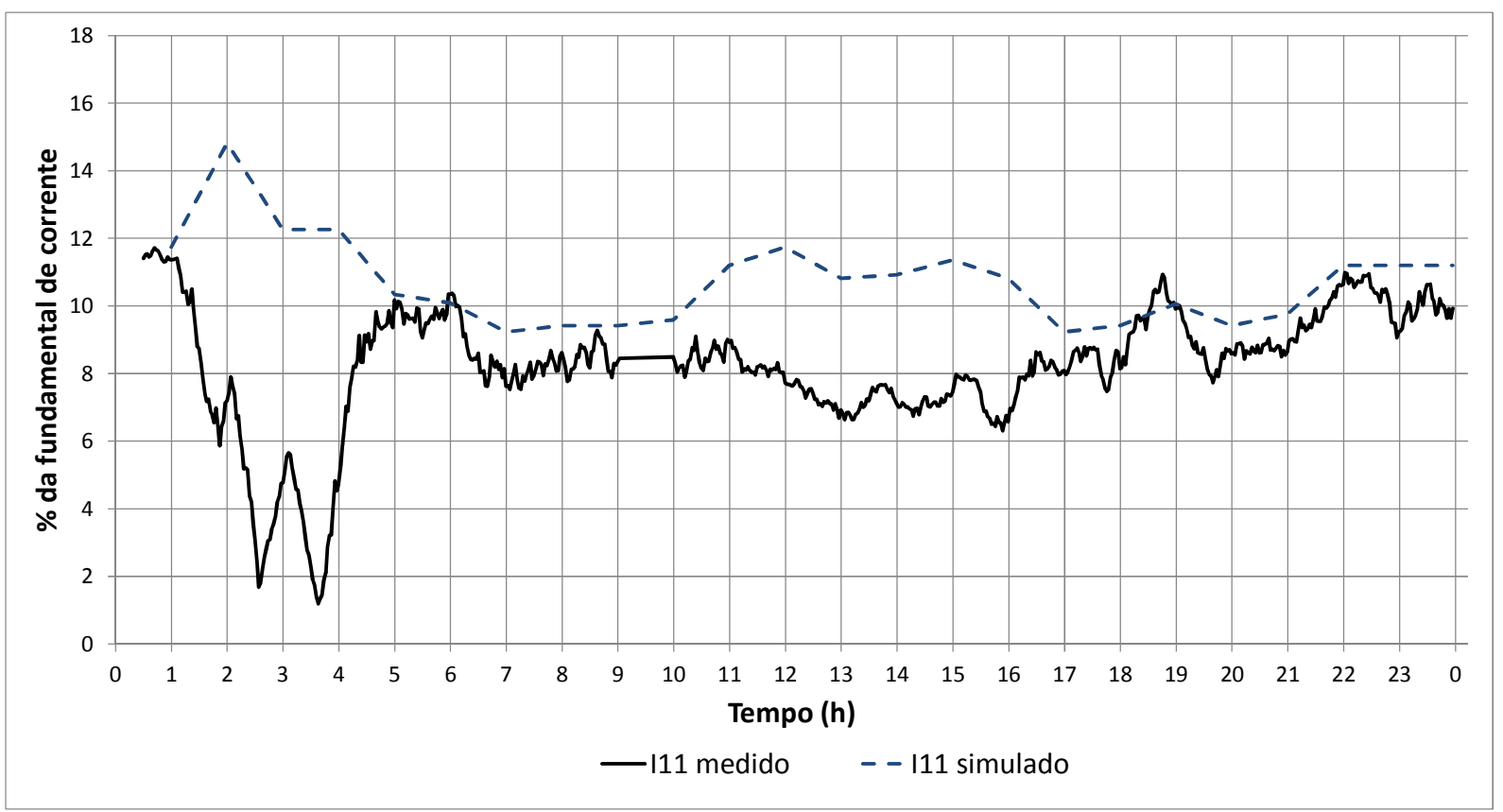

Fig. 4.49 - Resultado das medições e simulações para a $11^{\mathrm{a}}$ harmônica de corrente em Tietê. 


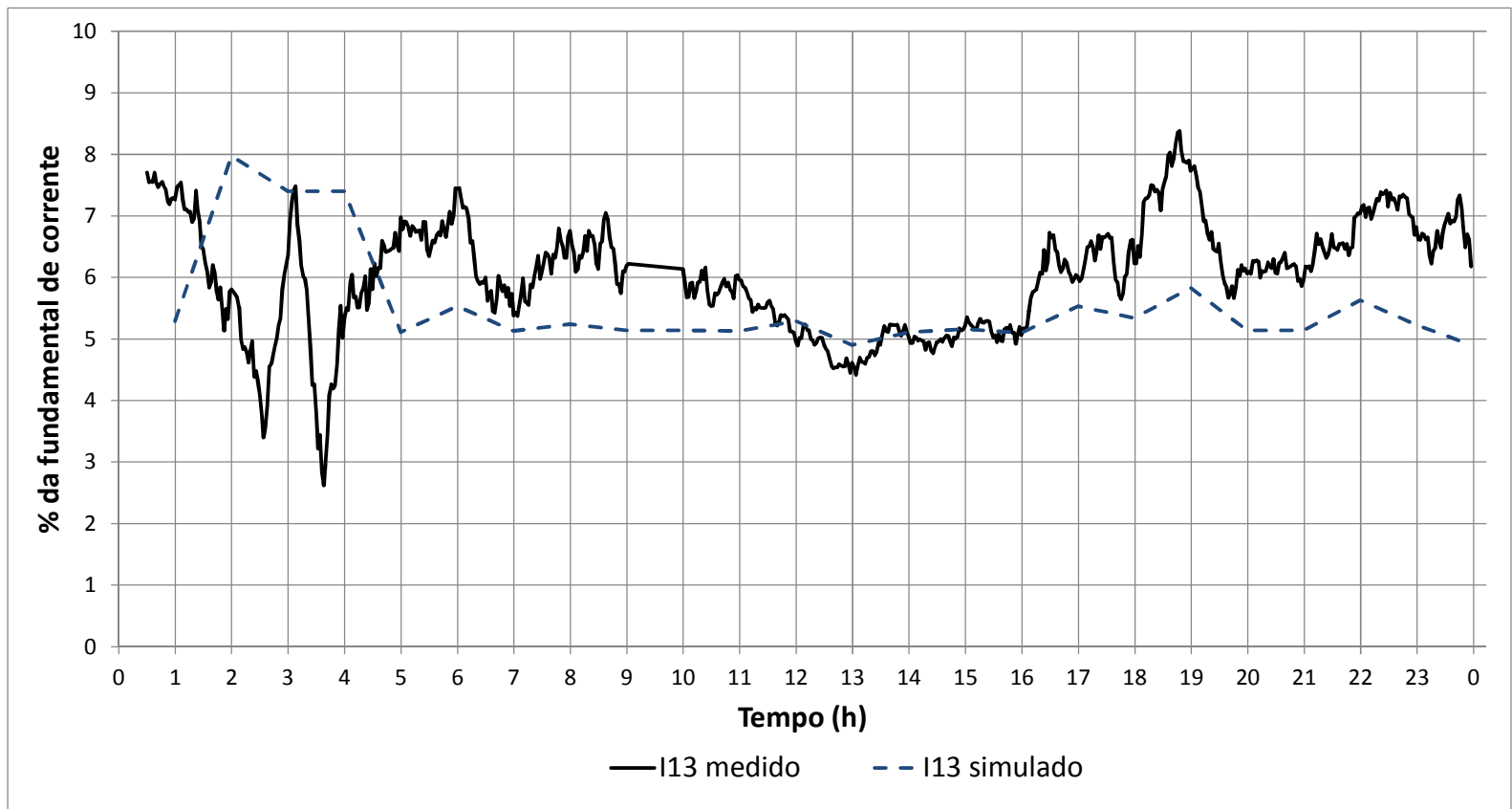

Fig. 4.50 - Resultado das medições e simulações para a $13^{\mathrm{a}}$ harmônica de corrente em Tietê.

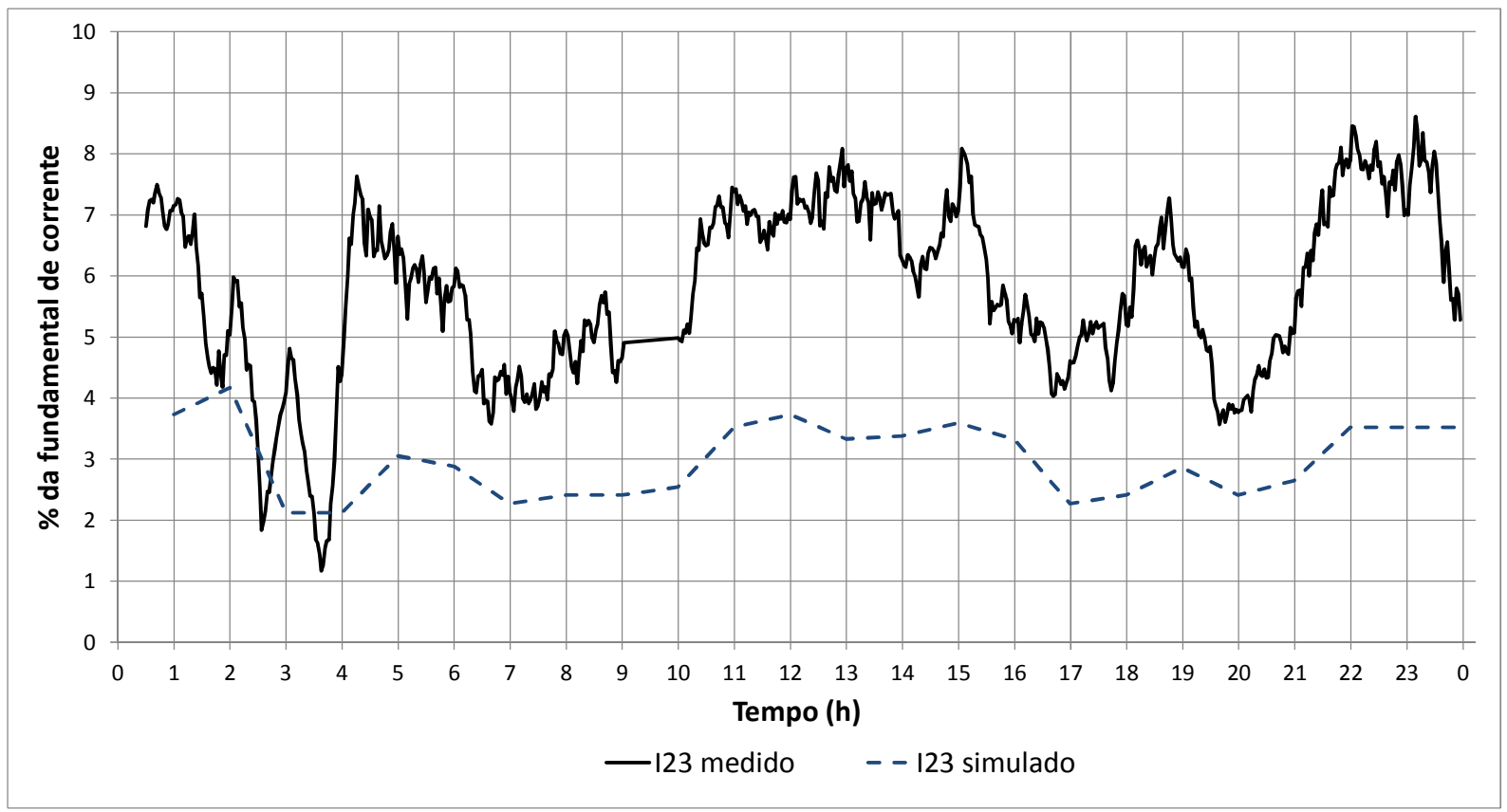

Fig. 4.51 - Resultado das medições e simulações para a 23ª harmônica de corrente em Tietê. 


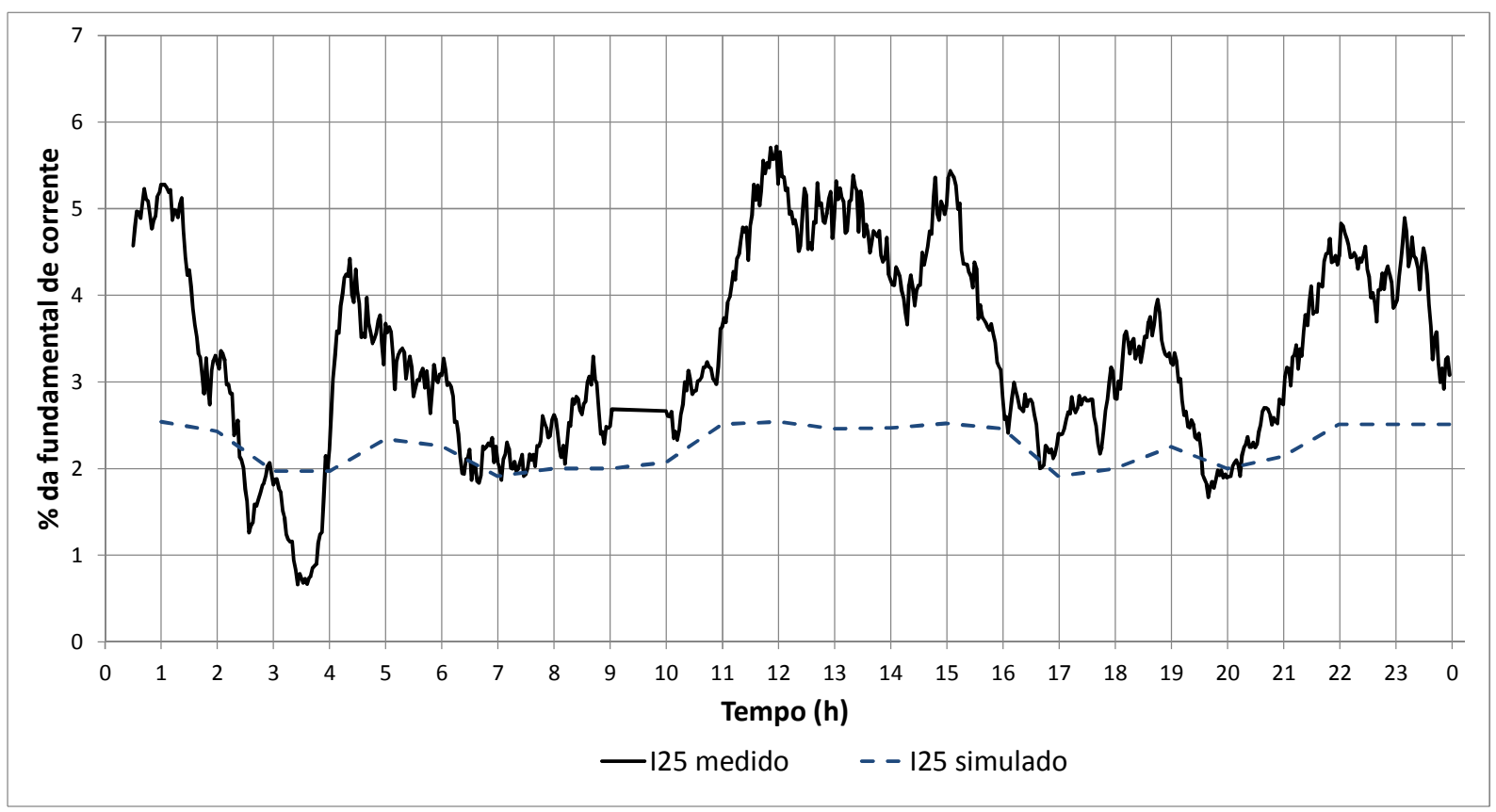

Fig. 4.52 - Resultado das medições e simulações para a 25ª harmônica de corrente em Tietê.

Os resultados apresentados para as harmônicas de corrente mostram uma melhor aderência com os resultados medidos do que os mostrados com as harmônicas de tensão. Nota-se um desvio significativo no período das $10 \mathrm{~h} 00$ às $16 \mathrm{~h} 00$, quando houve um crescimento significativo das harmônicas de $5^{\mathrm{a}}$ e $7^{\mathrm{a}}$ ordens, não contempladas nas simulações.

\subsubsection{Harmônicas de tensão em Jaraguá}

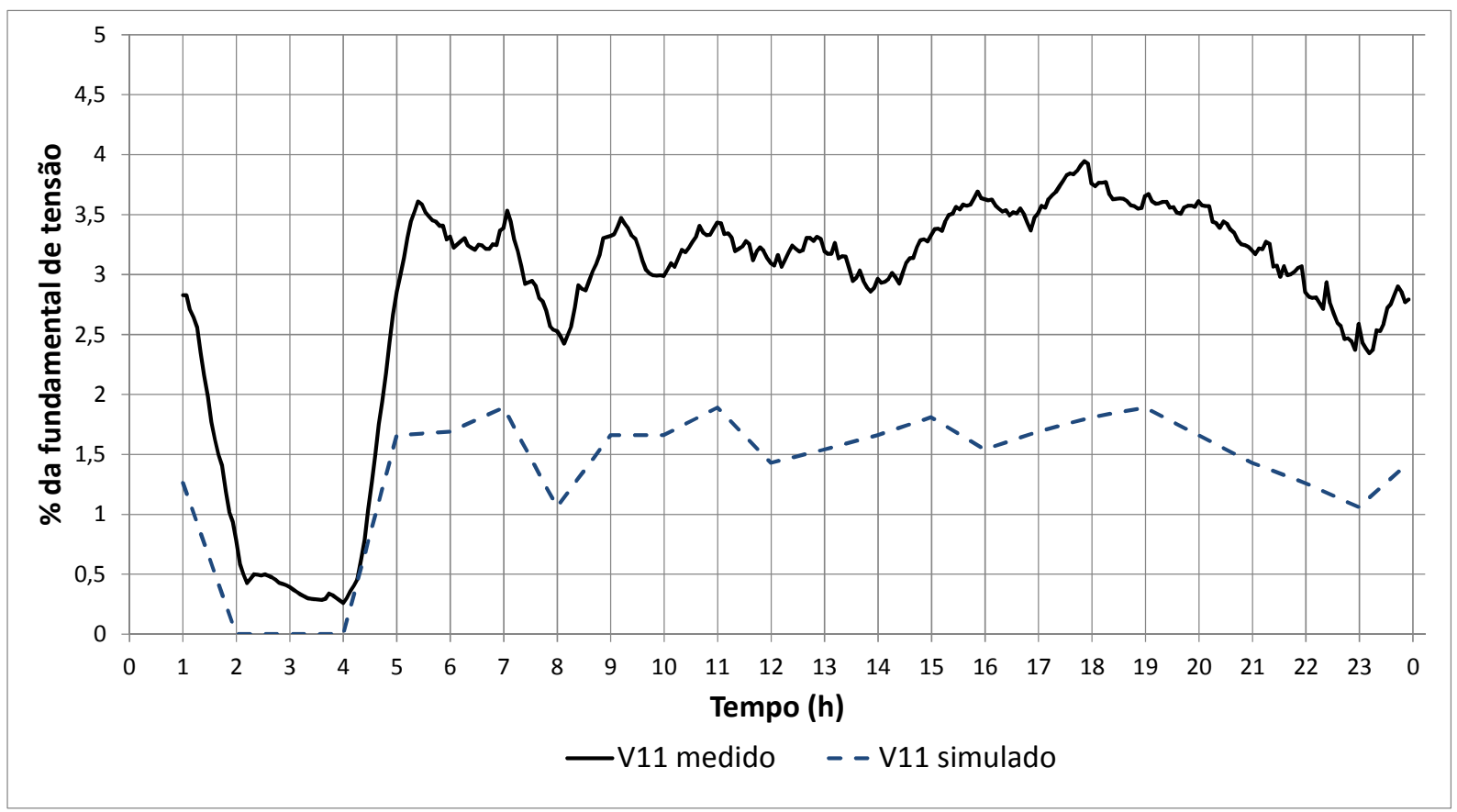

Fig. 4.53 - Resultado das medições e simulações para a $11^{\mathrm{a}}$ harmônica de tensão em Jaraguá. 


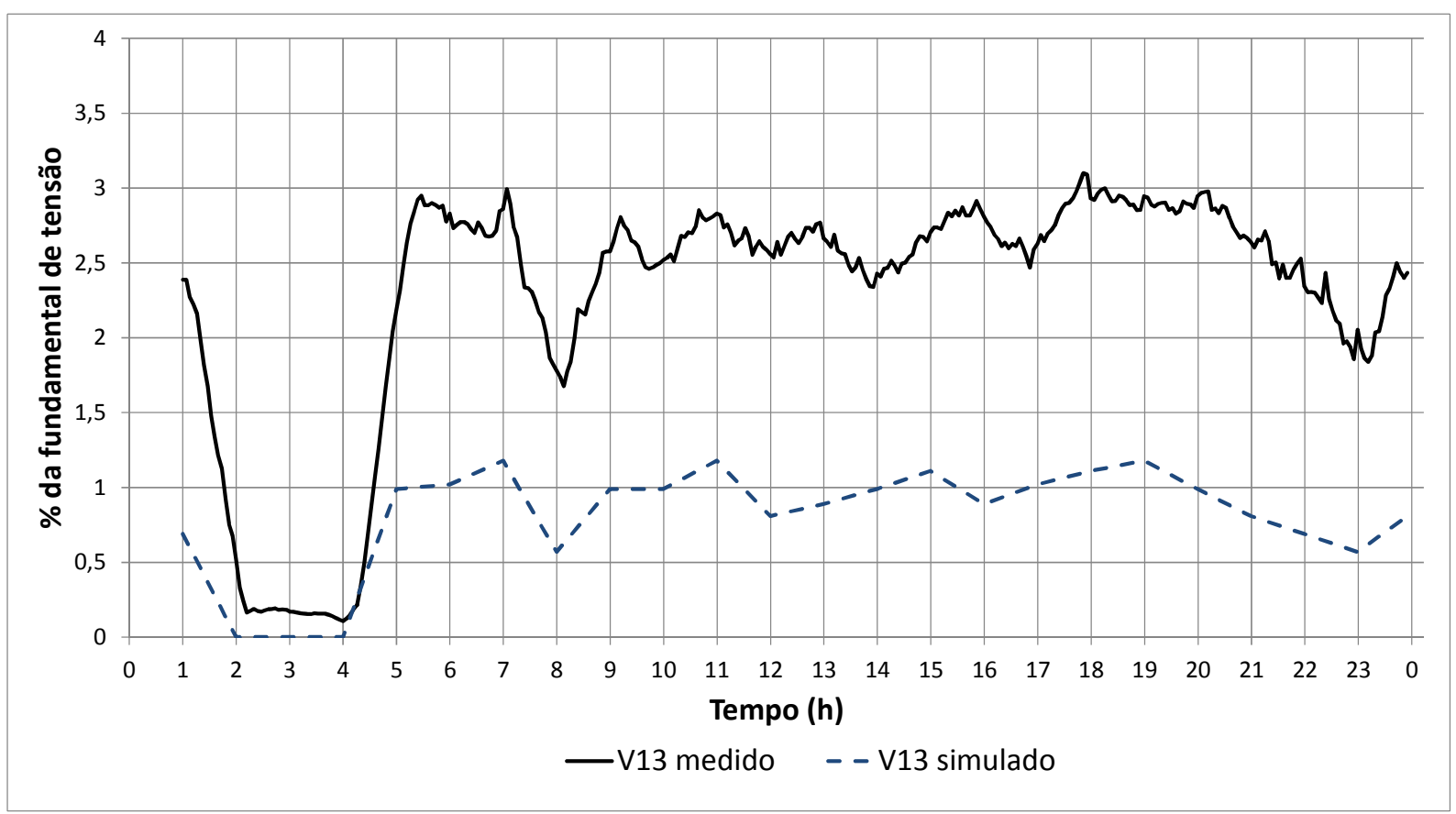

Fig. 4.54 - Resultado das medições e simulações para a 13ª harmônica de tensão em Jaraguá.

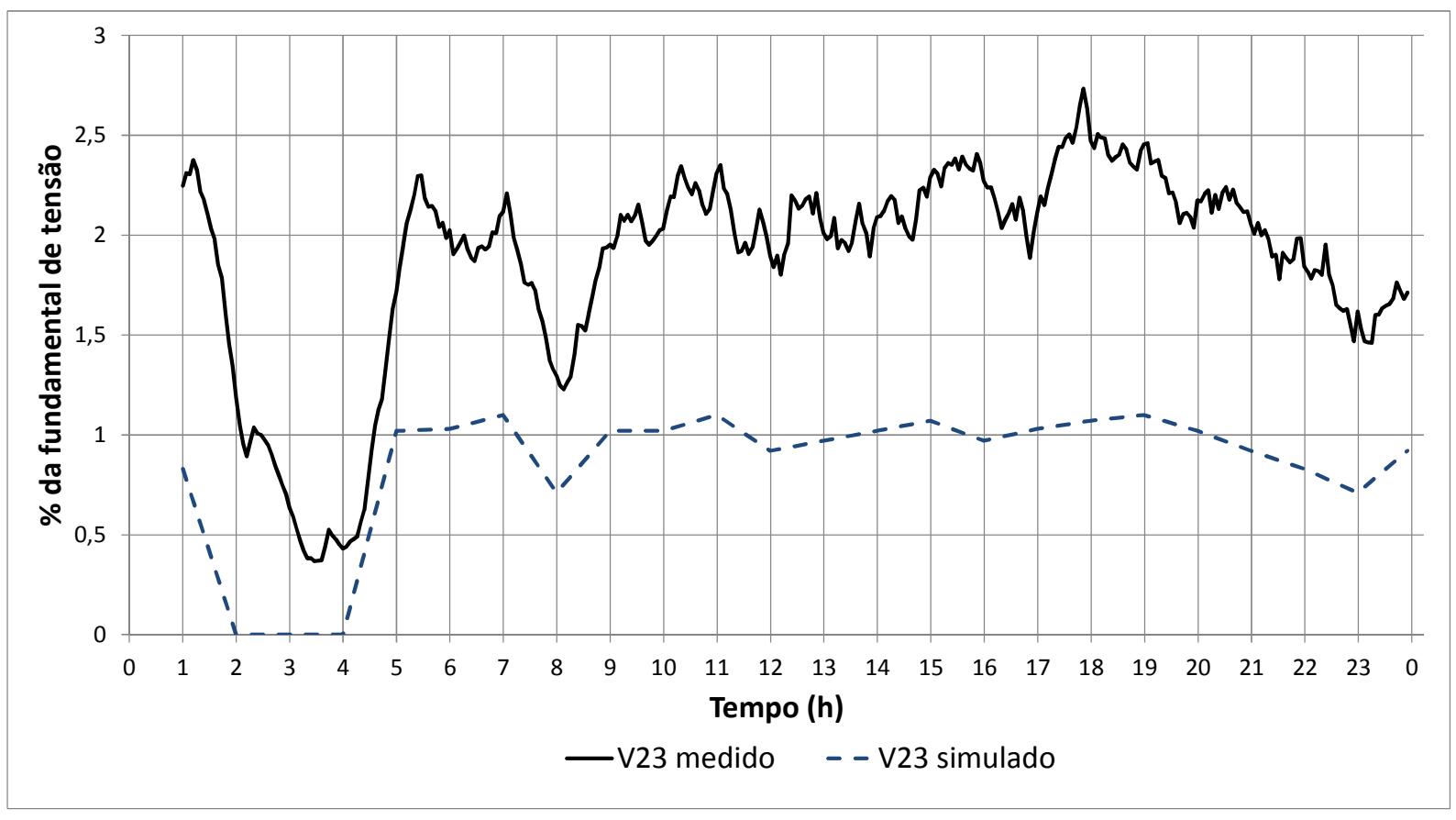

Fig. 4.55 - Resultado das medições e simulações para a $23^{\mathrm{a}}$ harmônica de tensão em Jaraguá. 


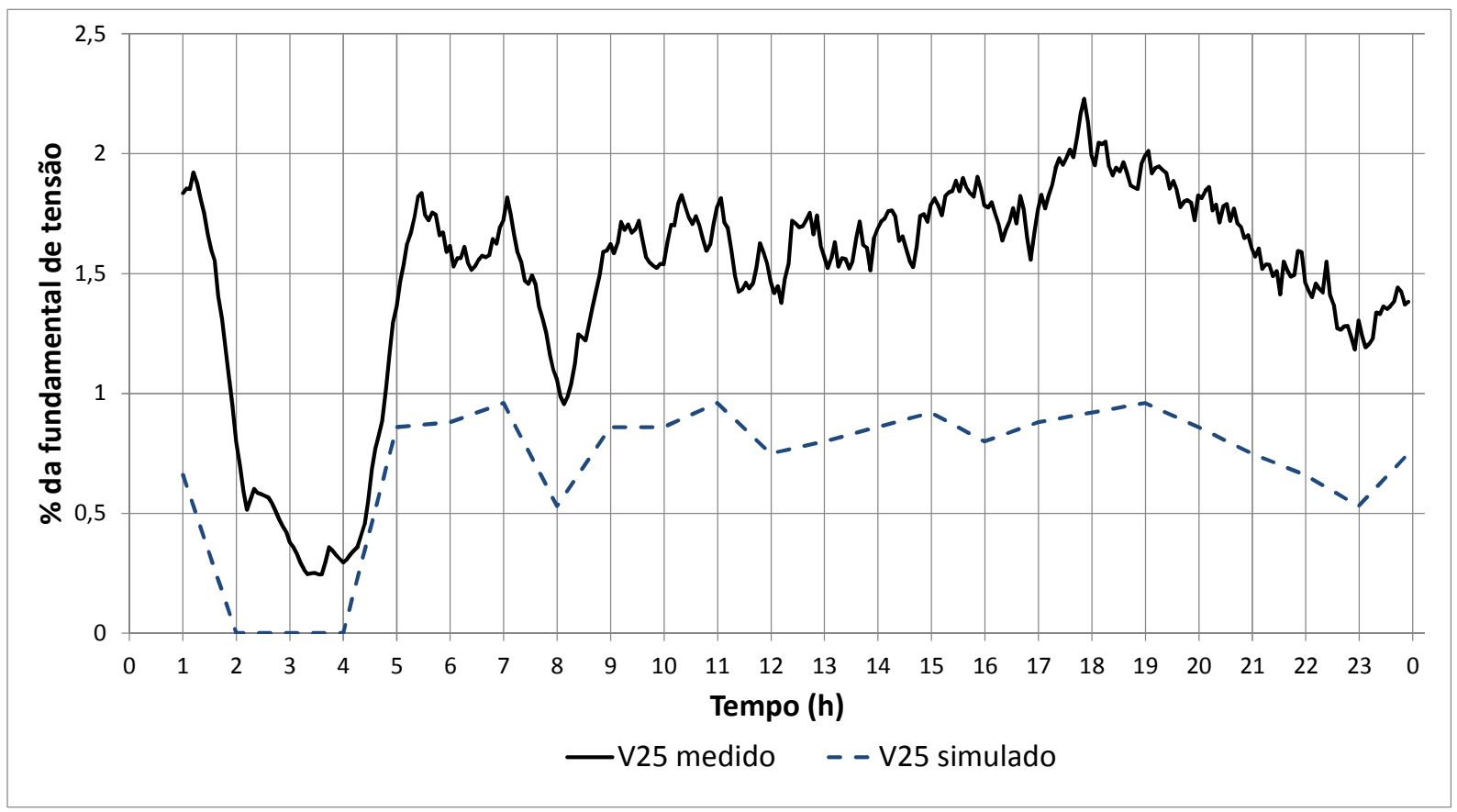

Fig. 4.56 - Resultado das medições e simulações para a $25^{a}$ harmônica de tensão em Jaraguá.

As figuras 4.53 a 4.56 mostram que o perfil dos resultados simulados acompanha os resultados medidos, porém o desvio entre ambos é elevado.

\subsubsection{Harmônicas de corrente em Jaraguá}

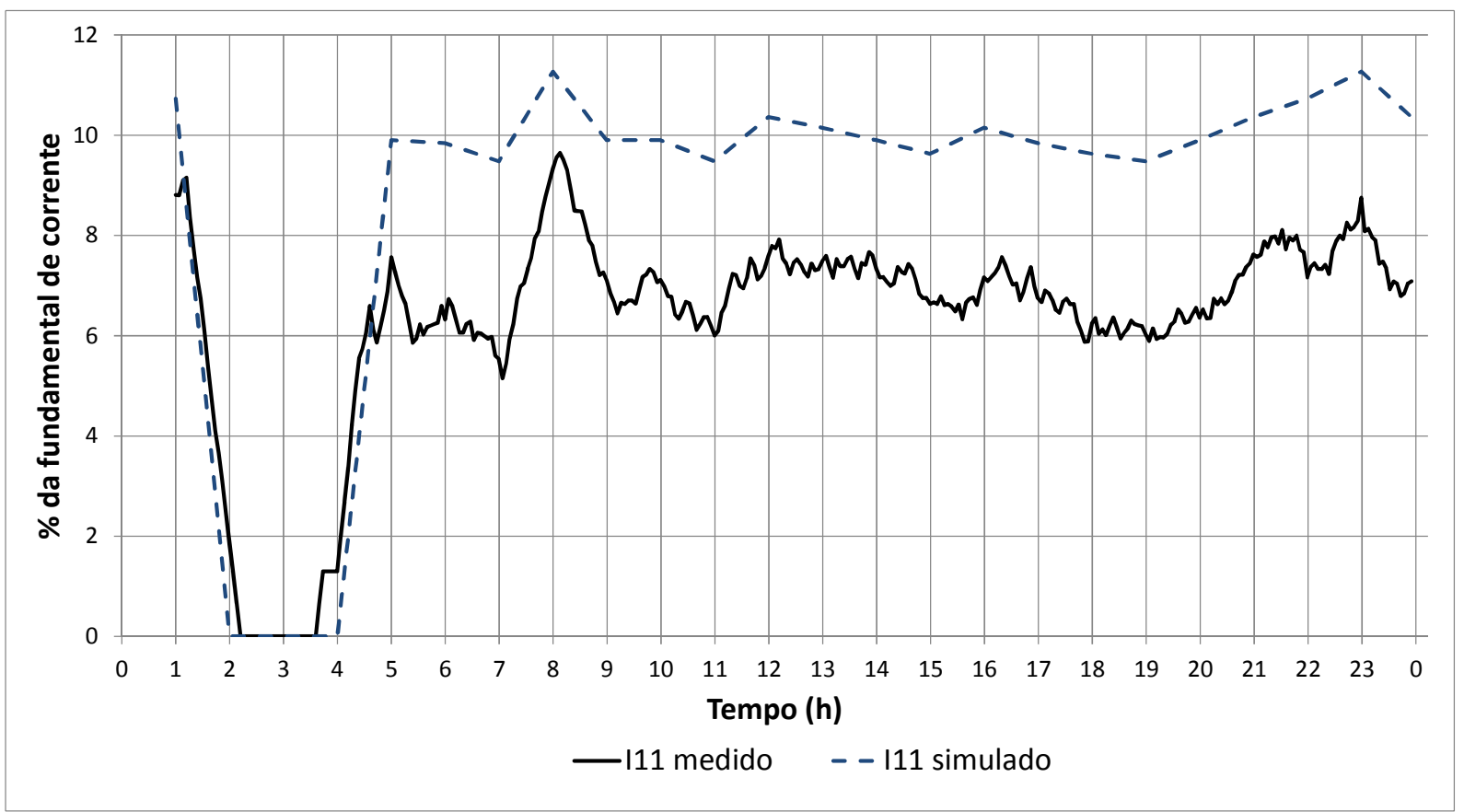

Fig. 4.57 - Resultado das medições e simulações para a $11^{\mathrm{a}}$ harmônica de corrente em Jaraguá. 


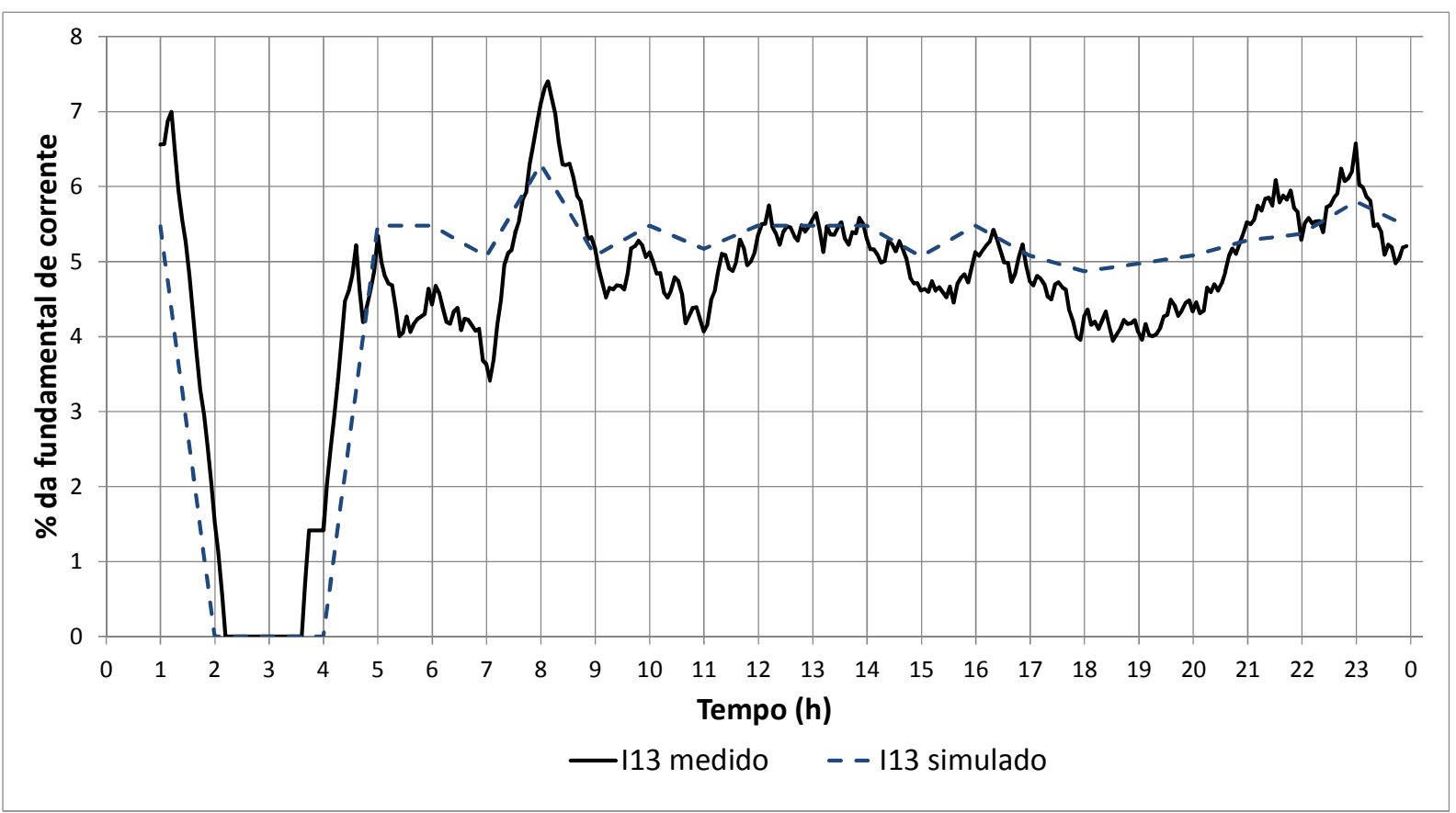

Fig. 4.58 - Resultado das medições e simulações para a $13^{\mathrm{a}}$ harmônica de corrente em Jaraguá.

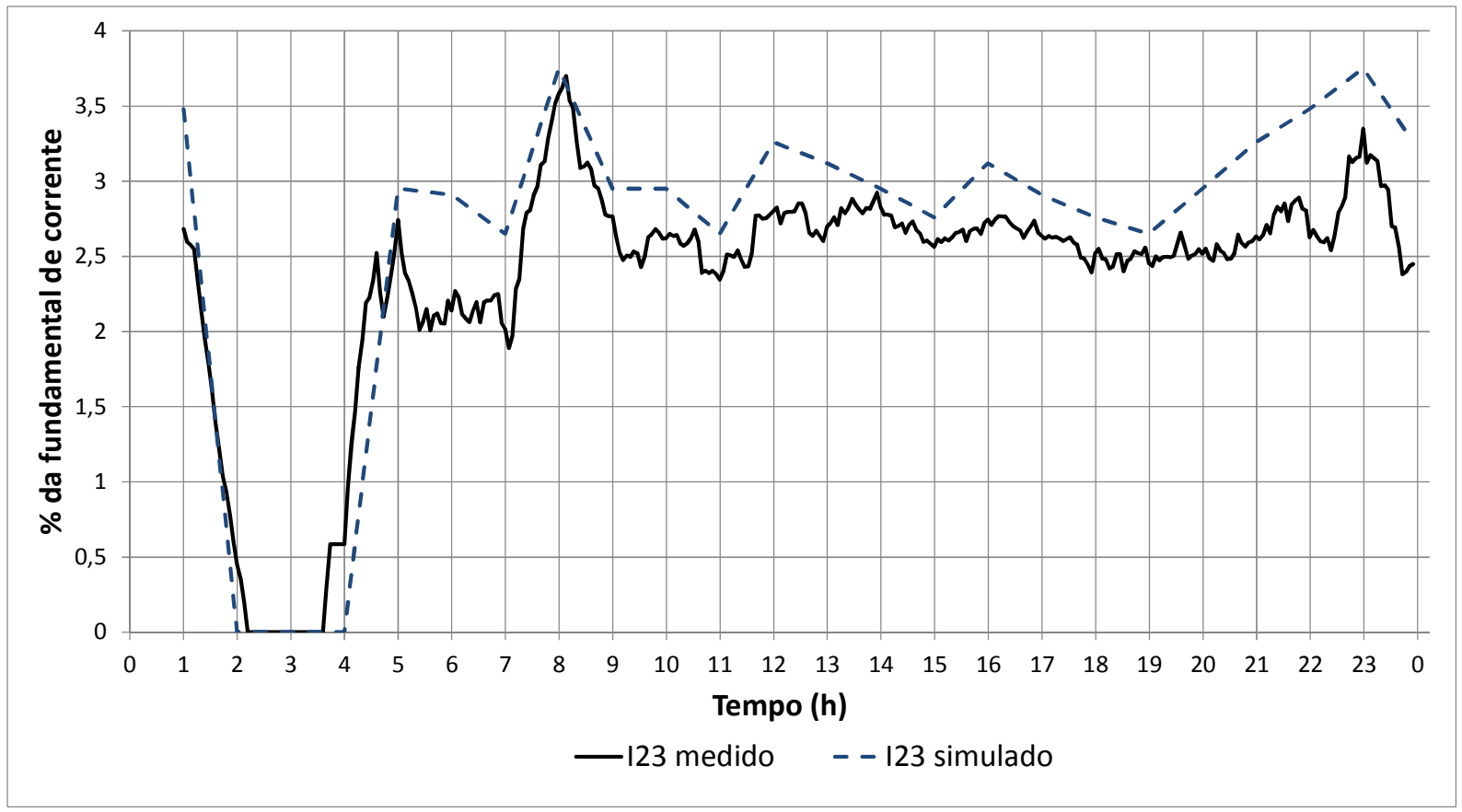

Fig. 4.59 - Resultado das medições e simulações para a $23^{\mathrm{a}}$ harmônica de corrente em Jaraguá. 


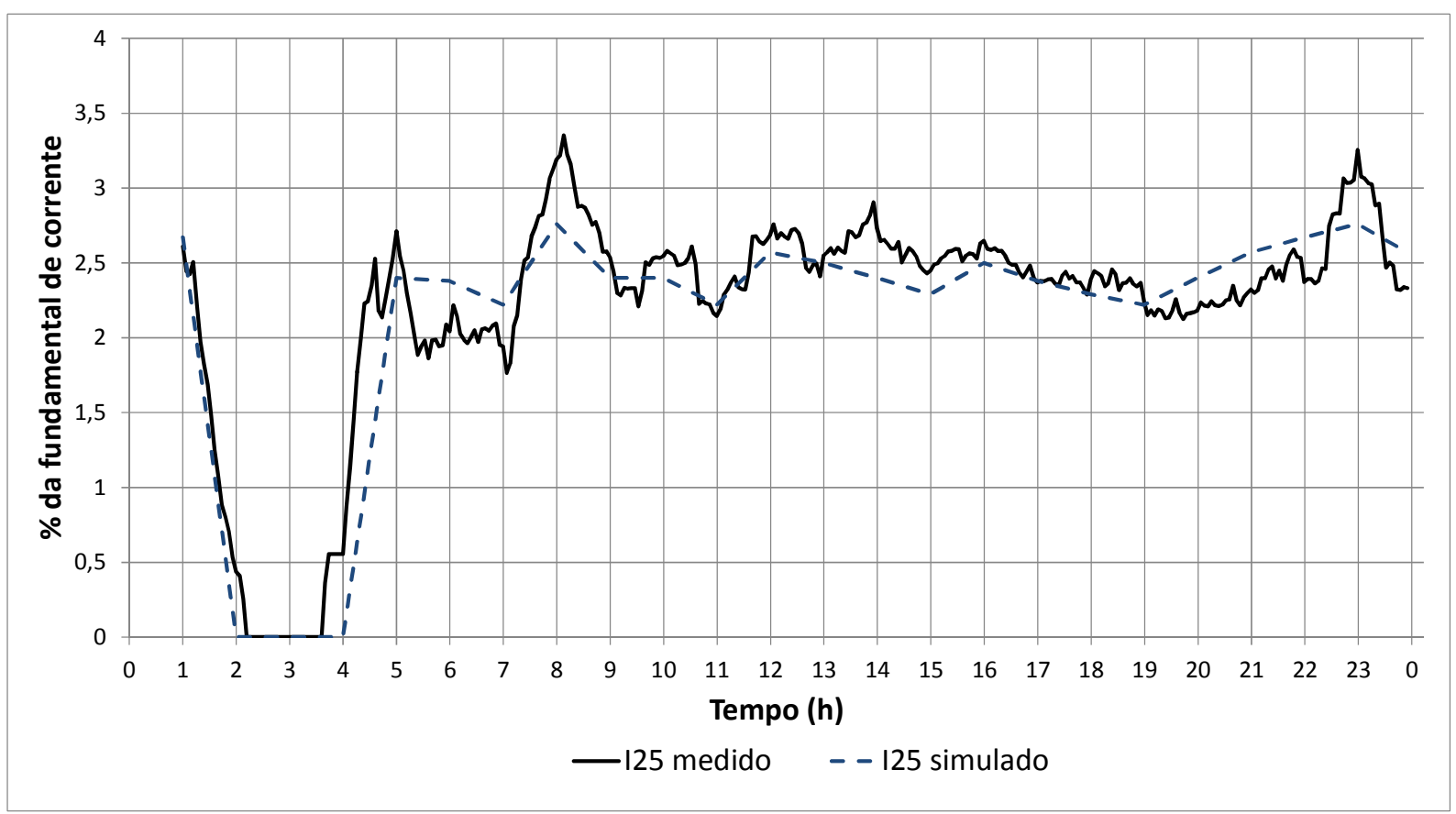

Fig. 4.60 - Resultado das medições e simulações para a $25^{\mathrm{a}}$ harmônica de corrente em Jaraguá.

As figuras 4.57 a 4.60 mostram que há uma boa aderência entre os resultados das simulações e os das medições. A diferença existente entre os valores medidos e simulados é aceitável e provém de limitações da modelagem, uma vez que o modelo utilizado para as simulações é simplificado.

Interessante notar que no caso das harmônicas de corrente de ordens 11 e 23 as curvas com resultados simulados apresentam valores maiores do que os obtidos por medição, enquanto que para as harmônicas de corrente de ordens 13 e 25 as curvas com resultados simulados apresentam valores menores que os correspondentes medidos. 


\section{CAPÍTULO 5 CONCLUSÕES}

Este trabalho abordou o problema da determinação dos níveis de distorção harmônica total e de componentes individuais de harmônicas tanto de tensão quanto de corrente na entrada de subestações retificadoras ferroviárias. Para isso, foram realizadas medições ao longo de uma semana na entrada das subestações Tietê e Jaraguá, ambas da CPTM, além de simulações computacionais em ambiente Matlab e as principais conclusões são indicadas a seguir.

As medições foram inicialmente realizadas na entrada da subestação Tietê $(88 \mathrm{kV})$, por tratarse do ponto de acoplamento comum do sistema ferroviário com a concessionária. Verificou-se que, apesar de não haver filtros de harmônicas na entrada da subestação, a distorção harmônica total de tensão (DHTv) encontrava-se abaixo do limite de 2,5\% em todo o período, atendendo, portanto, às normas IEEE-519 e IEC 61000-3-6 para esse nível de tensão. Chamou a atenção o fato de a $5^{\text {a }}$ harmônica de tensão apresentar amplitude muito elevada, uma ordem de grandeza acima das demais componentes, ultrapassando o limite da IEEE-519 de 1,5\% durante a maior parte do dia, inclusive no horário das 2 h00 às 4 h00 quando não há operação de trens. Por tratar-se de uma componente harmônica de ordem não característica dos retificadores de 12 pulsos utilizados pela CPTM, foi então levantada a hipótese de que a mesma não seria proveniente somente do sistema ferroviário, mas também de outros consumidores ligados ao mesmo ponto. Por esse motivo foram realizadas medições na subestação Jaraguá, que não possui outros consumidores conectados.

A análise das harmônicas de corrente em Tietê mostrou um aumento significativo das componentes de $5^{\mathrm{a}}$ e $7^{\mathrm{a}}$ ordens no período das $10 \mathrm{~h} 00$ às $16 \mathrm{~h} 00$ somente na quinta-feira e na sexta-feira. Neste período observou-se um comportamento típico de um retificador de 6 pulsos. Verificou-se que esse aumento não influenciou as respectivas harmônicas de tensão. As componentes harmônicas de corrente de ordens características 11, 13 e 23 ultrapassaram os limites da norma ao longo do dia, conforme mostrado na tabela 4.2. 
A distorção harmônica total de corrente em Tietê foi avaliada pela distorção total de demanda, que se manteve entre $8,0 \%$ e $14,0 \%$ ao longo do dia, ultrapassando o limite de 7,5\% especificado pela IEEE-519.

O fator de potência na entrada de Tietê foi analisado e verificou-se que o $\cos \varphi$ permaneceu acima de 0,98 ao longo do dia, com exceção do horário das 10 h00 às 16 h00 quando chegou a 0,95, atendendo a legislação brasileira que prevê um fator de potência mínimo de 0,92.

A DHTv na entrada de Jaraguá não atendeu aos limites especificados pelas normas IEEE-519 e IEC 61000-3-6 de 5,0\% e 6,5\%, respectivamente, para o nível de tensão de $34,5 \mathrm{kV}$, oscilando ao longo do dia entre $5,0 \%$ e $8,0 \%$. Verificou-se que o espectro de tensão apresentou predominância das componentes que são características de retificadores de 12 pulsos. Ao contrário de Tietê, observou-se que o perfil ao longo dos dias das componentes harmônicas individuais de tensão era semelhante, sugerindo que tivessem origem em uma mesma fonte, conforme esperado. As amplitudes das harmônicas de tensão de $5^{\mathrm{a}}$ e $7^{\mathrm{a}}$ ordens atenderam às normas ao longo de todo o dia. A amplitude da $11^{\mathrm{a}}$ harmônica de tensão ultrapassou o limite de 3,0\% estabelecido pela IEEE-519, e as amplitudes das harmônicas de tensão de ordens 13, 23 e 25 permaneceram abaixo de 3,0\%. No entanto, essas componentes harmônicas ultrapassaram os limites especificados pela IEC 61000-3-6.

Analisando-se as componentes harmônicas de corrente em Jaraguá, verificou-se que as mesmas apresentaram um perfil semelhante ao perfil das respectivas componentes harmônicas de tensão, evidenciando a característica de Jaraguá alimentar somente cargas ferroviárias. Amostras de corrente ao longo do dia mostraram espectros com predominância das harmônicas características do retificador de 12 pulsos. A análise da distorção total de demanda mostrou que a mesma permaneceu ao longo do dia abaixo de 9,0\%, atendendo ao limite de 15,0\% especificado pela IEEE-519 para as condições dessa subestação. As componentes harmônicas individuais de corrente também atenderam aos critérios da IEEE. 
O modelo de simulação construído no ambiente Simpowersystems do Matlab somente é capaz de calcular as harmônicas de ordens características do retificador de 12 pulsos, por tratar-se de um modelo simplificado. Os resultados obtidos se mostraram eficientes para as harmônicas de corrente tanto em Tietê quanto em Jaraguá, apresentando boa aderência entre os resultados medidos e os simulados. Com relação às harmônicas de tensão na entrada de Tietê não houve correlação apreciável, e a explicação provável é que há cargas que não são ferroviárias ligadas nesse ponto. Quanto às harmônicas de tensão na entrada de Jaraguá, verificou-se que o perfil dos resultados simulados acompanha os resultados medidos, porém apresenta um desvio elevado entre eles. O refinamento da modelagem através do ajuste das impedâncias dos transformadores e dos cabos das linhas de transmissão, acrescentando uma componente capacitiva, pode ser realizado futuramente a fim de se buscar uma melhoria na aderência dos resultados simulados com as medições e garantir uma melhor reprodução da realidade. 


\section{REFERÊNCIAS BIBLIOGRÁFICAS}

AGÊNCIA NACIONAL DE ENERGIA ELÉTRICA - ANEEL, Procedimentos de Distribuição de Energia Elétrica no Sistema Elétrico Nacional - PRODIST, módulo 8, 06/09/2011 Resolução Normativa no 444/2010.

BARTON,T. H. Rectifiers, cycloconverters, and AC controllers. Oxford, England: Oxford Science Publications, 1994.

BIANCHI, G. Some data concerning railway electrification in Italy, Journal of the I.E.E., v. 69, n. 411, p. 325 - 359, Mar.1931.

CAPASSO, A. Power quality concern in railway electrification studies, In: Proceedings International Conference on Harmonics and Quality of Power 8 ${ }^{\text {th }}$, v. 2, 14-16, p. 647 652, Out. 1998.

CARSON, J. R. Wave propagation in overhead wires with ground return. Bell System Technical Journal, n. 5, p. 539-554, October, 1926.

DE CASTRO, F. E. B.; ALOUCHE, P.L. Planejamento e dimensionamento da eletrificação em sistemas de transporte de massa. Engenharia - Revista do Instituto de Engenharia, n. 431, p. 52-60, 1981.

DUGAN,R.C.,et al. Electrical Power Systems Quality. 2.ed. McGraw-Hill, 2003.

GOLDEMBERG, C. et al. Thyristor controlled rectifiers for subway substations, Power Electronics Specialists Conference, p. 2244 - 2250, 2005.

HILL, R. J. Electric railway traction, Part 3, Traction power supplies, Power engineering journal, p. 275-279, Fev. 1994.

IEEE STANDARD 519:1992. IEEE Recommended Practices and Requirements for Harmonic Control in Electrical Power Systems, 1992.

IEC 61000-3-6 :2008. Limits - Assessment of emission limits for the connection of distorting installations to MV, HV and EHV power systems, 2008. 
KIEßLING, F.; PUSCMANN, R.; SCHMIEDER, A. Contact lines for electric railways: planning, design, implementation. 1.ed. Munich: Publicis Kommunikations Agentur, 2001.

LIN, G. et al. Analysis of adverse effects on the public power grid brought by traction powersupply system, IEEE Electrical Power \& Energy Conference, p. 1-7, Oct. 2008.

LO, E. W. C.; LAI, T.M. Harmonic Analysis of EMUs in Railway Systems, International Conference on Power Electronics Systems and Applications proceedings, $1^{\text {th }}$, Hong Kong, p. 142-146, Nov. 2004.

MARKVARDT, K. G. Power Supply for Electric Railways, Moscow: Transport, 1958. $528 \mathrm{p}$.

MATLAB/ Simpowersystems 5.1 - 7.8.0 R2009a. The Mathworks Inc.

PRUDENZI, A. et al. Experimental assessment of energy saving due to trains regenerative braking in an electrified subway line, IEEE Transactions on Power Delivery, v. 13 , p.1536 - 1542, Oct. 1998.

PRUDENZI, A. Estimation of electrical traction load harmonic impact on distribution networks, Power Engineering Society General Meeting, IEEE, v. 2, p. 1166-1171, 13-17, Jul. 2003.

PINATO, P.; ZANINELLI, D. Harmonic disturbances in electric traction system overhead lines, v. 2, p. 748-753, Harmonics and Quality of Power, IEEE, 2002.

RADLEY,W.G.; WHITEHEAD,S. Recent Investigations on Telephone Interference, Journal I.E.E., v. 74, p. 201-222, 1934.

TOLEDO, E. D. et al. Tração elétrica, Ed. Nobel, v. 2, 1988.

WAGNER, C. F.; EVANS, R. D. Symmetrical components as applied to the analysis of unbalanced electrical circuits. 1.ed. New York: McGraw-Hill, 1933. 437p.

WAKILEH, G. J. Power Systems Harmonics, Springer, 2001. 
APÊNDICE A

MODELO DA REDE ELÉTRICA EM MATLAB

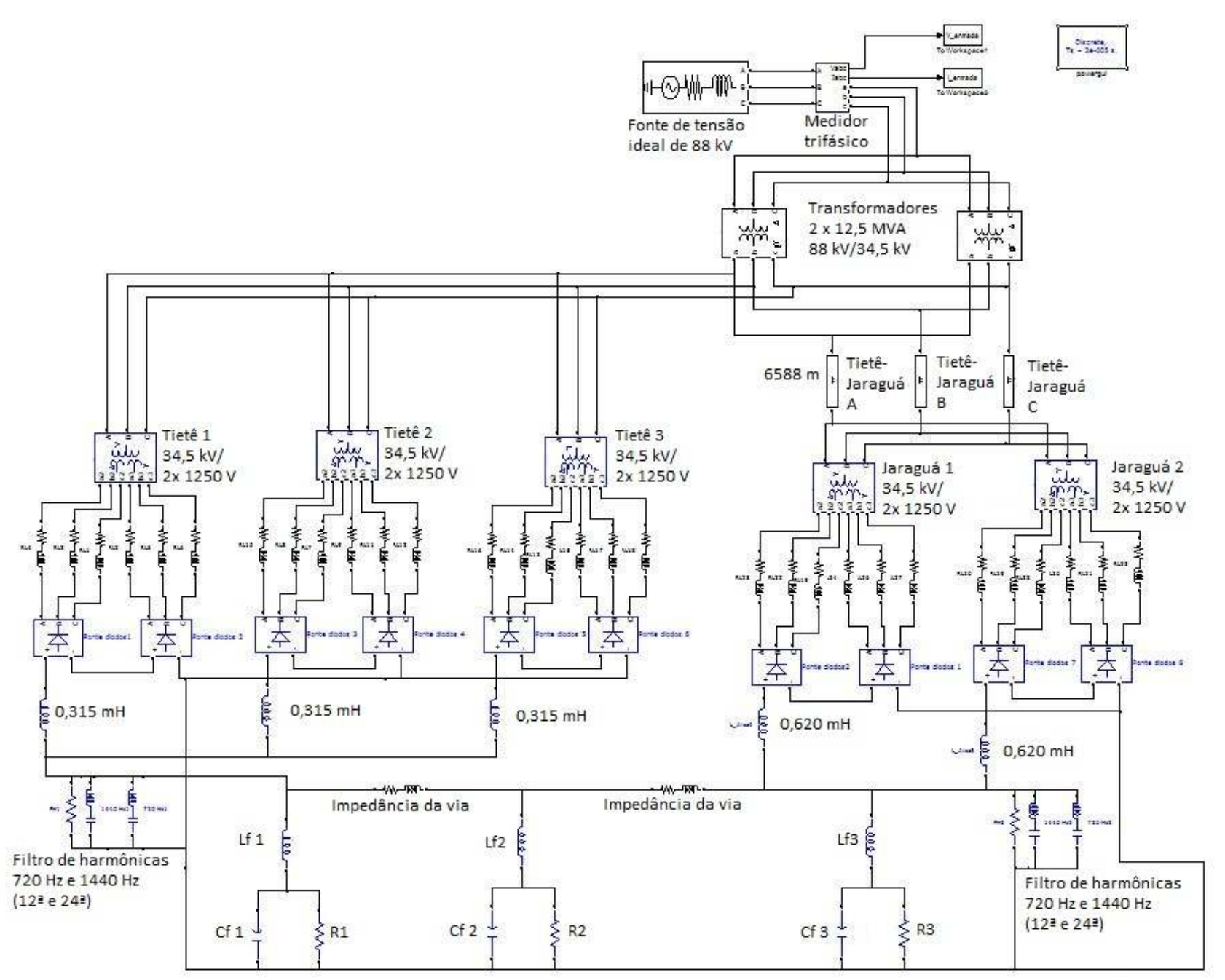




\section{APÊNDICE B \\ DADOS DE ENTRADA PARA AS SIMULAÇÕES}

\begin{tabular}{|c|c|}
\hline Potência de curto-circuito trifásico na subestação Tietê & $\begin{array}{l}2160,3 \text { MVA } \\
X / R=10,20 \\
84,40 \text { graus }\end{array}$ \\
\hline Potência de curto-circuito trifásico na subestação Jaraguá & $114,3 \mathrm{MVA}$ \\
\hline Tensão nominal da concessionária de energia elétrica & $88 \mathrm{kV}$ \\
\hline Corrente de curto-circuito lado $88 \mathrm{kV}$ & $14173 \mathrm{~A}$ \\
\hline Corrente de curto-circuito lado $34,5 \mathrm{kV}$ & $36152 \mathrm{~A}$ \\
\hline Impedância de curto-circuito referida ao lado $88 \mathrm{kV}$ & $\begin{array}{l}\mathrm{Z}=3,5848 \Omega \\
\mathrm{R}=0,3498 \Omega \\
\mathrm{X}=3,5677 \Omega \\
\mathrm{L}=9,4636 \mathrm{mH}\end{array}$ \\
\hline Impedância de curto-circuito referida ao lado $34,5 \mathrm{kV}$ & $\begin{array}{l}\mathrm{Z}=550,9 \mathrm{~m} \Omega \\
\mathrm{R}=53,8 \mathrm{~m} \Omega \\
X=548,3 \mathrm{~m} \Omega \\
\mathrm{L}=1,455 \mathrm{mH}\end{array}$ \\
\hline Transformador de potência Tietê & $\begin{array}{l}12,5 \mathrm{MVA} \\
88 / 36 \mathrm{kV} \\
\mathrm{Zcc}=12,5 \% \\
\mathrm{X} / \mathrm{R}=16,69 \\
\text { Ligação Dyn1 aterrado }\end{array}$ \\
\hline $\begin{array}{l}\text { Impedância do transformador de potência de Tietê referido ao } \\
\text { lado de } 34,5 \mathrm{kV}\end{array}$ & $\begin{array}{l}\mathrm{Z}=11,90 \Omega \\
\mathrm{R}=711,9 \mathrm{~m} \Omega \\
\mathrm{X}=11,88 \Omega \\
\mathrm{L}=31,5 \mathrm{mH}\end{array}$ \\
\hline Transformador retificador Tietê & $\begin{array}{l}4220 \mathrm{kVA} \text { (primário) } \\
2110 \mathrm{kVA} \text { (secundário 1) } \\
2110 \mathrm{kVA} \text { (secundário 2) } \\
34,5 \mathrm{kV} / 2 \times 1,25 \mathrm{kV} \\
\mathrm{ZCC}=6,33 \% \\
\mathrm{X} / \mathrm{R}=11,07 \\
\text { Ligação Yy0d1 }\end{array}$ \\
\hline Transformador retificador Jaraguá & $\begin{array}{l}4220 \mathrm{kVA} \text { (primário) } \\
2110 \mathrm{kVA} \text { (secundário 1) } \\
2110 \mathrm{kVA} \text { (secundário 2) } \\
34,5 \mathrm{kV} / 2 \times 1,25 \mathrm{kV} \\
\mathrm{ZCC}=6,33 \% \\
\mathrm{X} / \mathrm{R}=11,07 \\
\text { Ligação Yy0d1 }\end{array}$ \\
\hline
\end{tabular}




\begin{tabular}{|c|c|}
\hline Cabos entre Transformador retificador e retificador & $\begin{array}{l}3 \times 400 \mathrm{~mm}^{2} \\
\mathrm{Rca}=0,066 \Omega / \mathrm{km} \\
\mathrm{XL}=0,107 \Omega / \mathrm{km}\end{array}$ \\
\hline $\begin{array}{l}\text { Equivalente da linha entre } \text { Transformador retificador e } \\
\text { retificador (Distância }=35 \mathrm{~m})\end{array}$ & $\begin{array}{l}\mathrm{R}=0,00231 / 3 \Omega \\
\mathrm{L}=9,934 / 3 \mu \mathrm{H}\end{array}$ \\
\hline $\begin{array}{l}\text { Indutância de alisamento Tietê } \\
\text { Indutância de alisamento Jaraguá }\end{array}$ & $\begin{array}{l}0,315 \mathrm{mH} \\
0,620 \mathrm{mH}\end{array}$ \\
\hline Filtro de harmônicas Tietê e Jaraguá 720 Hz & $\begin{array}{l}\mathrm{R}=50 \mathrm{k} \Omega \\
\mathrm{L}=1,22 \mathrm{mH} \\
\mathrm{C}=40 \mu \mathrm{F}\end{array}$ \\
\hline Filtro de harmônicas Tietê e Jaraguá $1440 \mathrm{~Hz}$ & $\begin{array}{l}\mathrm{R}=50 \mathrm{k} \Omega \\
\mathrm{L}=1,22 \mathrm{mH} \\
\mathrm{C}=10 \mu \mathrm{F}\end{array}$ \\
\hline Retificador - Resistência de Snubber & $\mathrm{Rs}=10 \Omega$ \\
\hline Retificador - Capacitância de Snubber & $\mathrm{Cs}=0,68 \mu \mathrm{F}$ \\
\hline Retificador - Resistência interna do diodo & Ron $=0,4 \mathrm{~m} \Omega$ \\
\hline Retificador - Tensão de condução direta do diodo & $\mathrm{Vf}=2,5 \mathrm{~V}$ \\
\hline Tensão nominal do retificador & $3281 \mathrm{~V}$ \\
\hline Corrente nominal do retificador & $1219 \mathrm{~A}$ \\
\hline Tensão de saída em vazio & $3375 \mathrm{~V}$ \\
\hline Conexão & $\begin{array}{l}2 \text { pontes Graetz trifásicas } \\
\text { série, montagem } \\
\text { EN60146 }\end{array}$ \\
\hline $\begin{array}{l}\text { Impedância do circuito da via Tietê-Jaraguá } \\
1 \text { cabo mensageiro de cobre com secção } 253 \mathrm{~mm}^{2} \\
1 \text { fio de contato único de cobre com secção } 180 \mathrm{~mm}^{2} \\
\text { Resistividade do cobre }=0,017745 \Omega . \mathrm{mm}^{2} / \mathrm{m} \\
2 \text { trilhos em paralelo: } \mathrm{Z}=0,01 \Omega / \mathrm{km}\end{array}$ & $\mathrm{Z}=5,759 \mathrm{e}-5+\mathrm{j} 7,2970 \mathrm{e}-4 \Omega / \mathrm{m}$ \\
\hline $\begin{array}{l}\text { Impedância equivalente da via Tietê-Jaraguá } \\
\text { Distância }=6588 / 2 \mathrm{~m}\end{array}$ & $\begin{array}{l}\mathrm{Z}=0,1952+\mathrm{j} 2,474 \Omega \\
\mathrm{R}=0,1929 \Omega \\
\mathrm{L}=6,56 \mathrm{mH}\end{array}$ \\
\hline Filtro L-C da Carga & $\begin{array}{l}\mathrm{L}=3,75 \mathrm{mH} \\
\mathrm{C}=26,8 \mathrm{mF}\end{array}$ \\
\hline
\end{tabular}




\section{APÊNDICE C MEDIÇÕES AOS DOMINGOS}

\section{C.1 Medições no domingo dia 23/10/2011 na subestação Tietê}

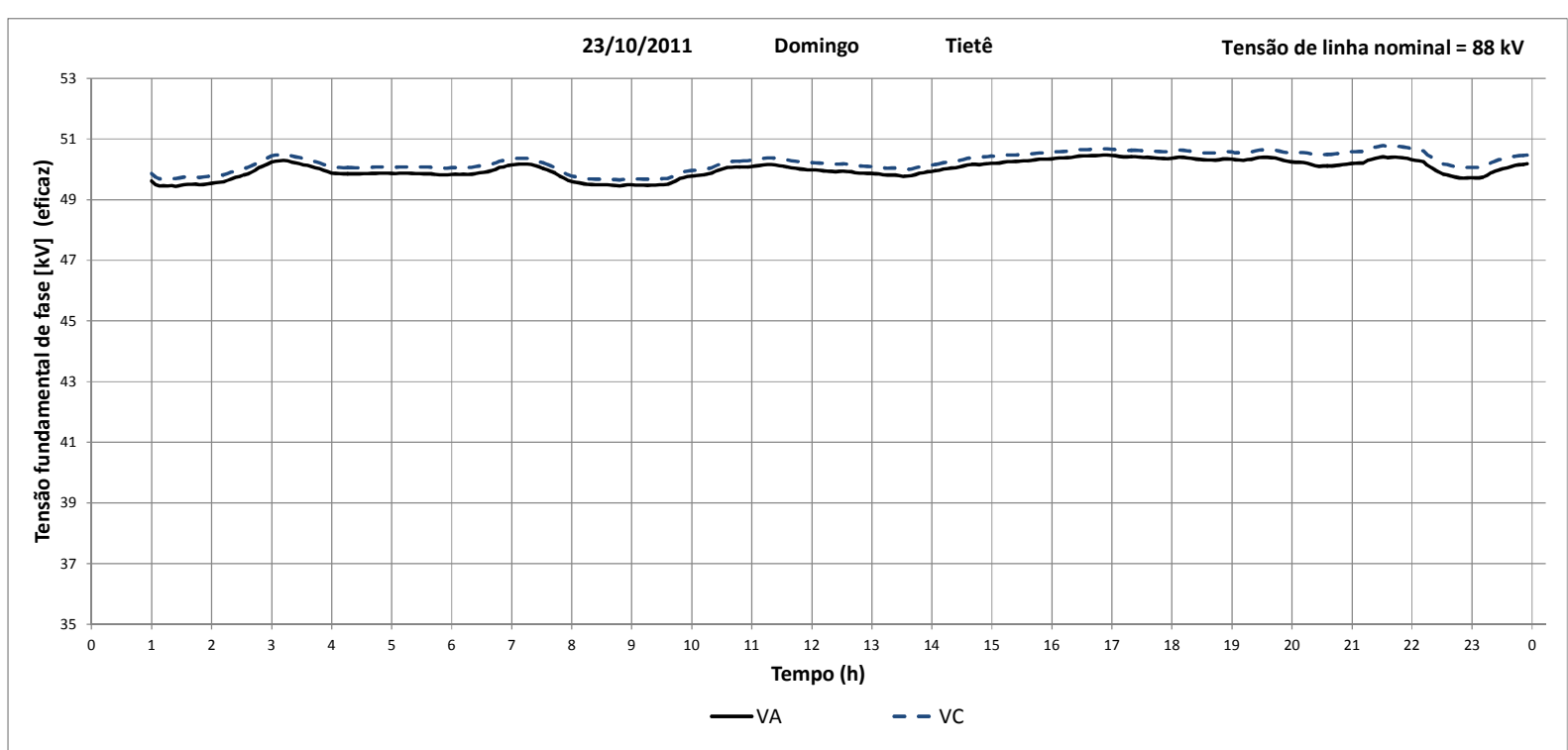

Fig. C.1 - Registro da tensão de entrada em Tietê no domingo, 23/10/2011.

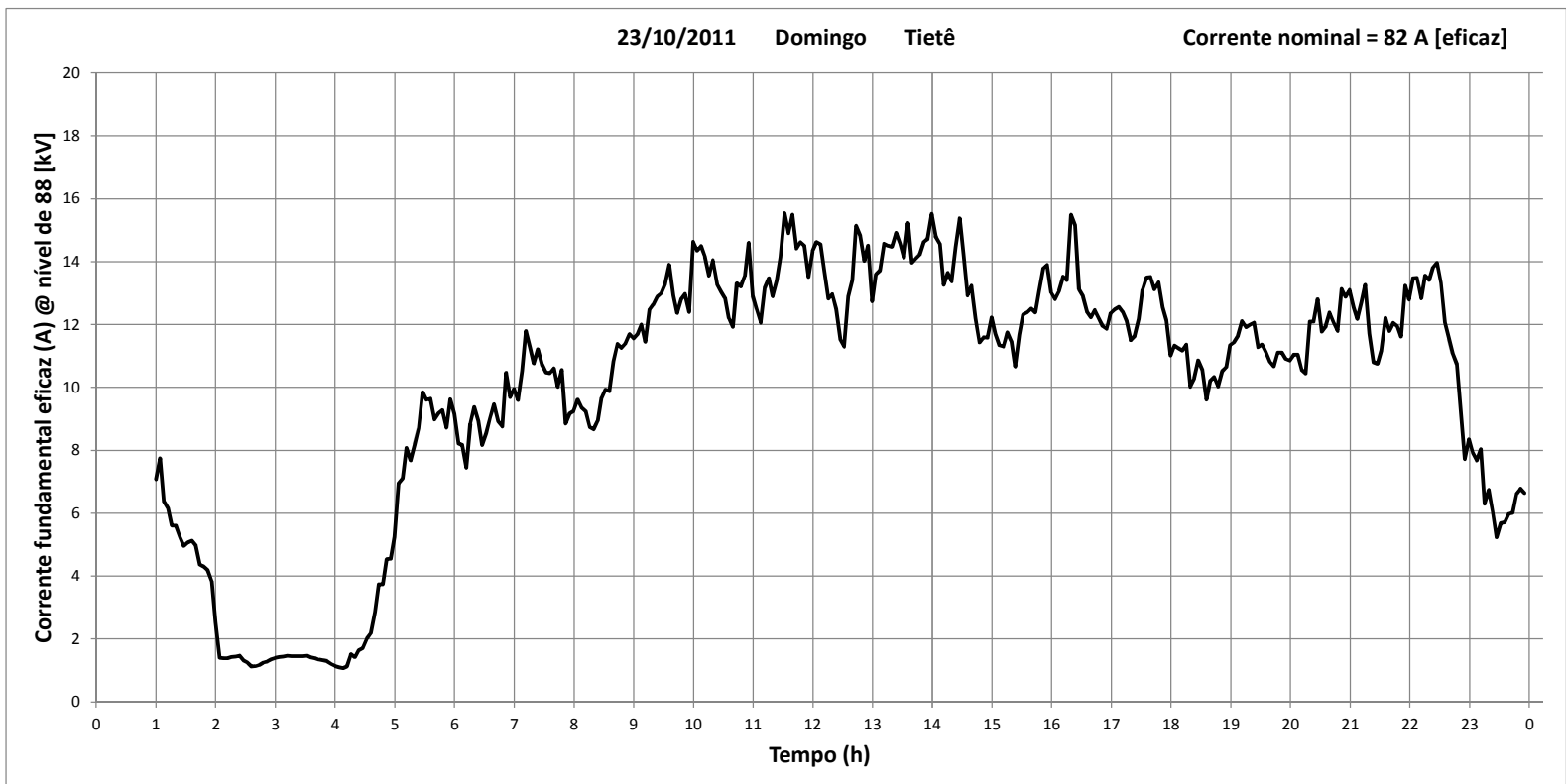

Fig. C.2 - Registro da corrente de entrada em Tietê no domingo, 23/10/2011. 


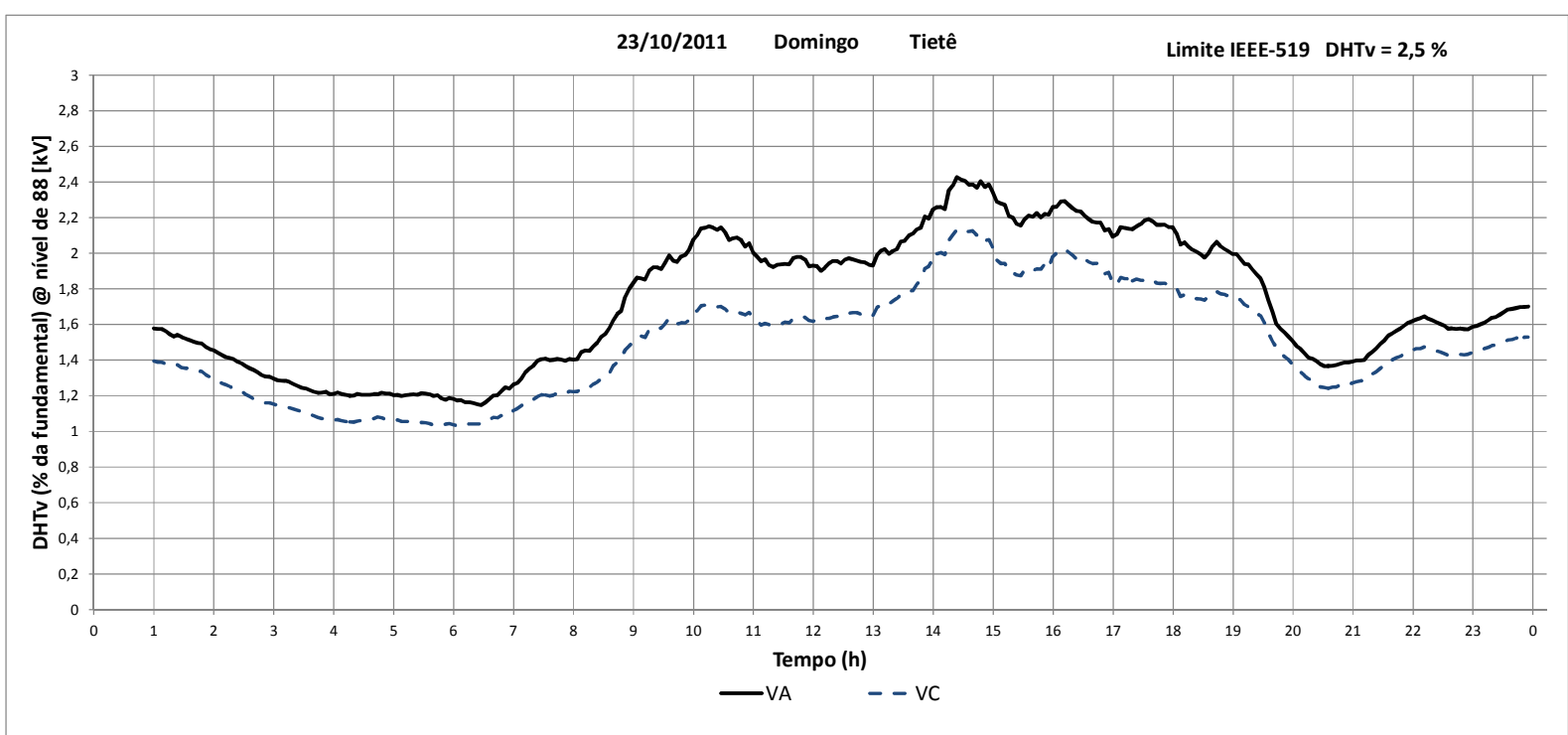

Fig. C.3 - Registro da DHTv na entrada de Tietê no domingo, 23/10/2011.

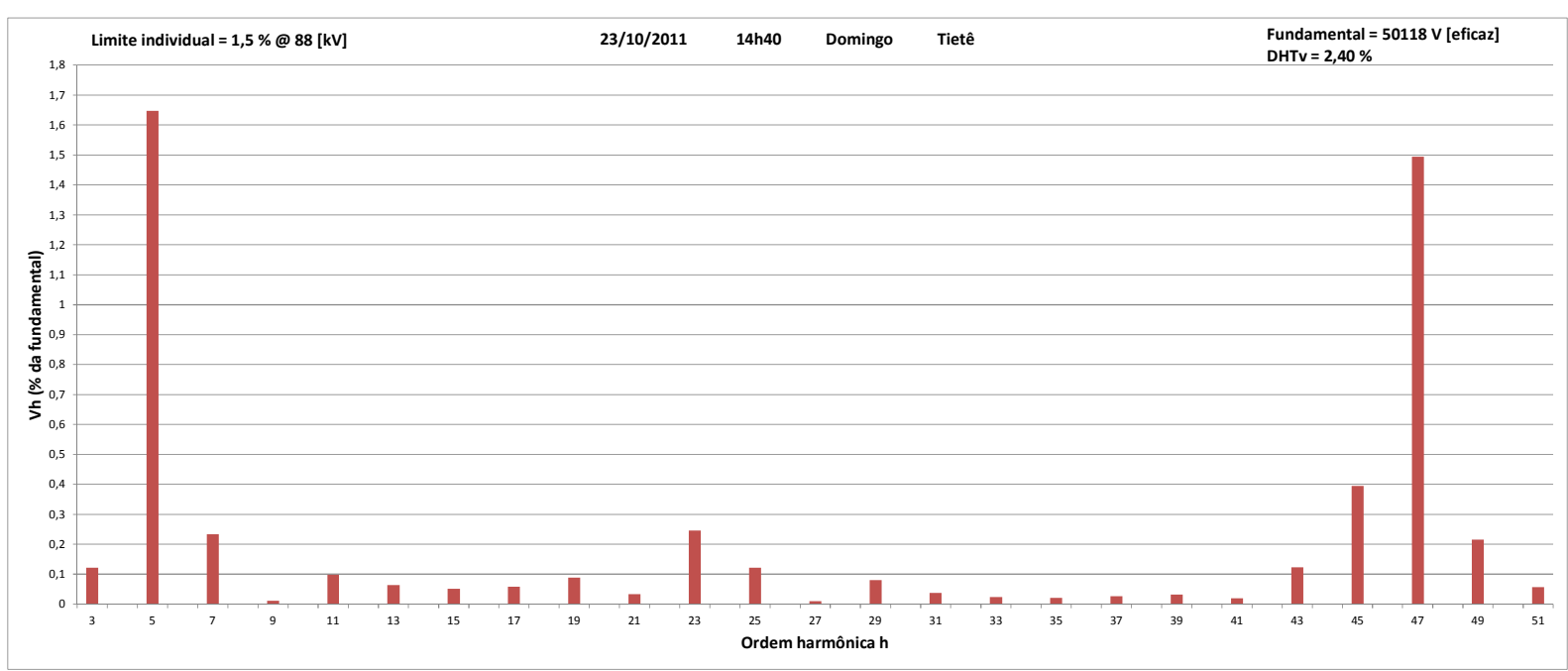

Fig. C.4 - Espectro de tensão do registro no instante de maior DHTv em Tietê no domingo, 23/10/2011.

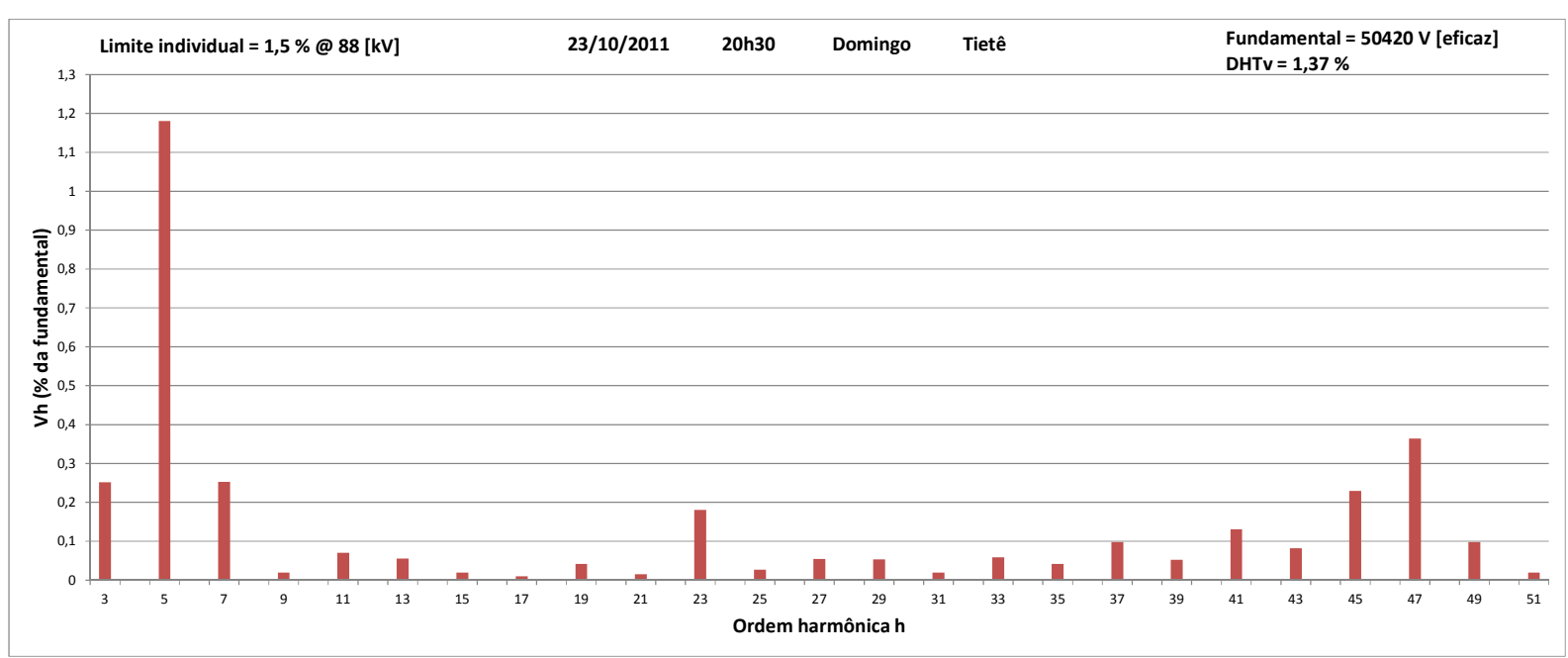

Fig. C.5 - Espectro de tensão do registro no instante de menor DHTv em Tietê no domingo, $23 / 10 / 2011$. 


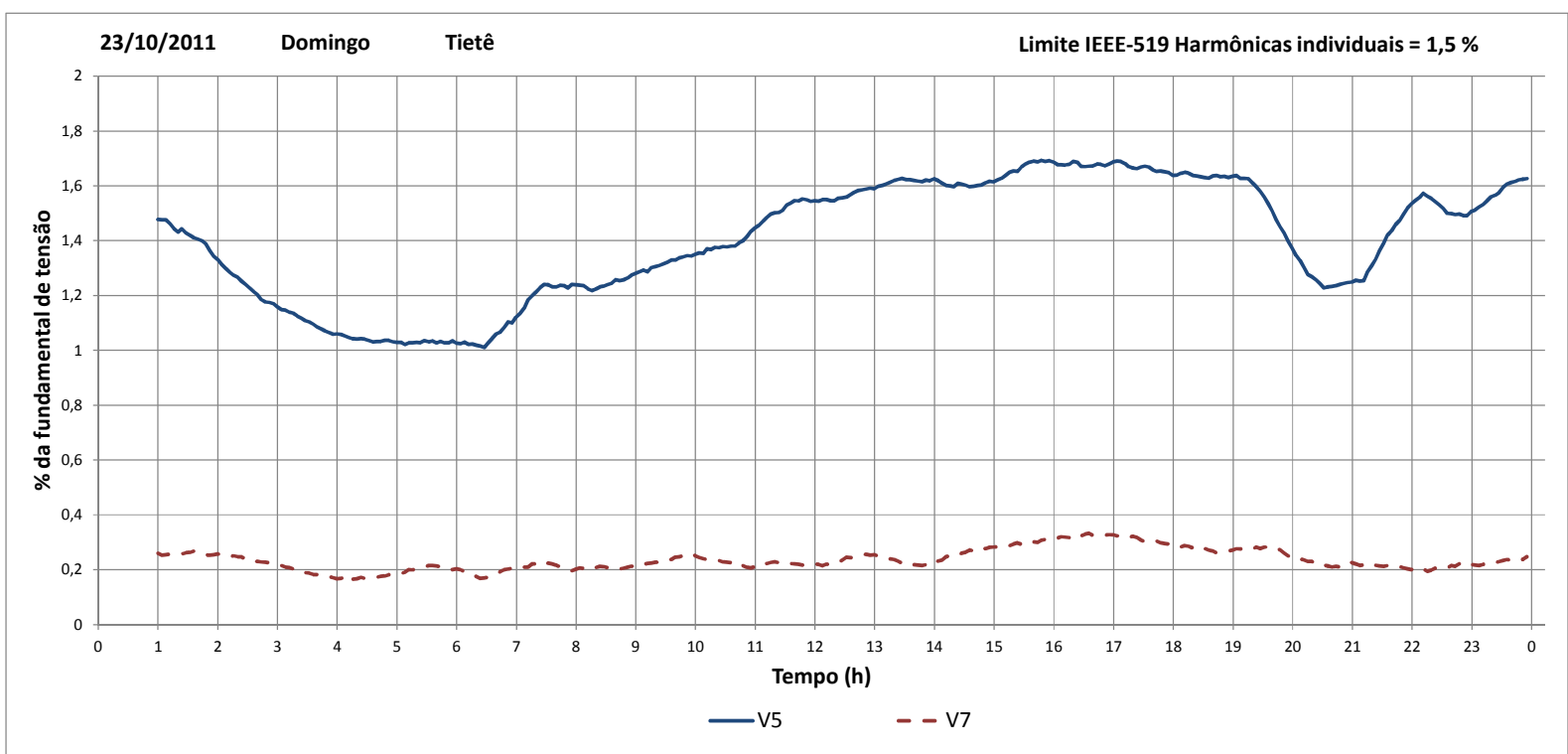

Fig. C.6 - Registro das harmônicas de tensão de $5^{\mathrm{a}}$ e $7^{\mathrm{a}}$ ordens em Tietê no domingo, $23 / 10 / 2011$.

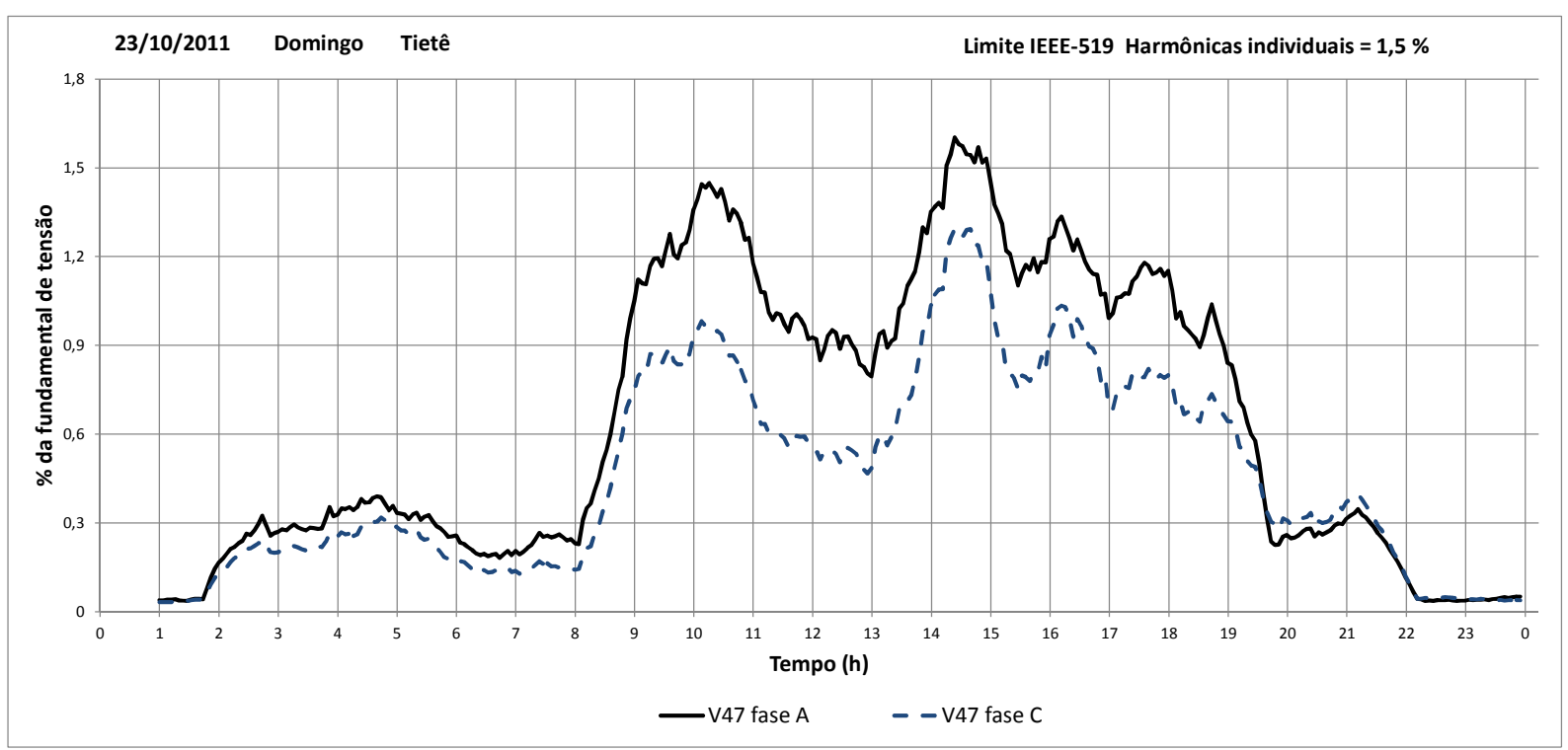

Fig. C.7 - Registro da 47ª harmônica de tensão em Tietê no domingo, 23/10/2011. 


\section{C.2 Medições no domingo dia 12/02/2012 na Subestação Jaraguá}

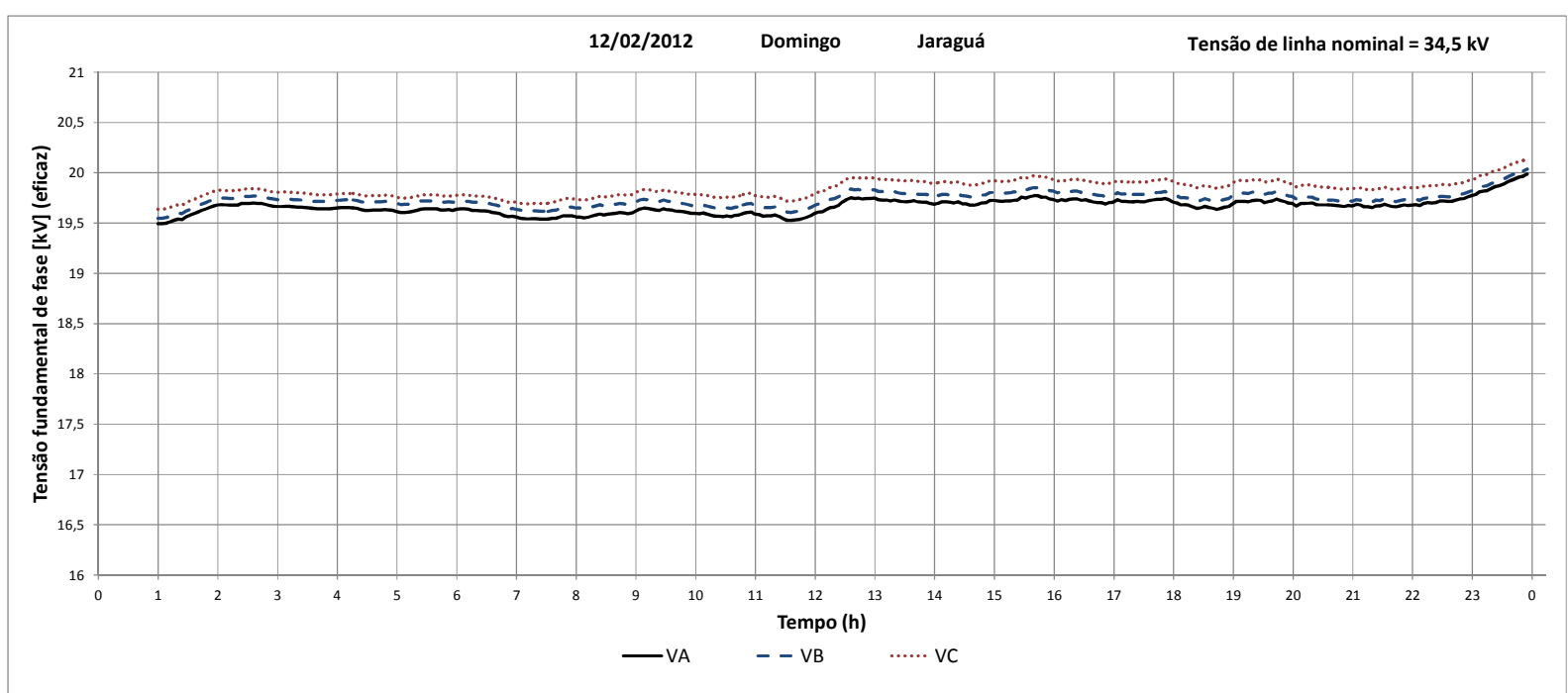

Fig. C.8 - Registro da tensão de entrada em Jaraguá no domingo, 12/02/2012.

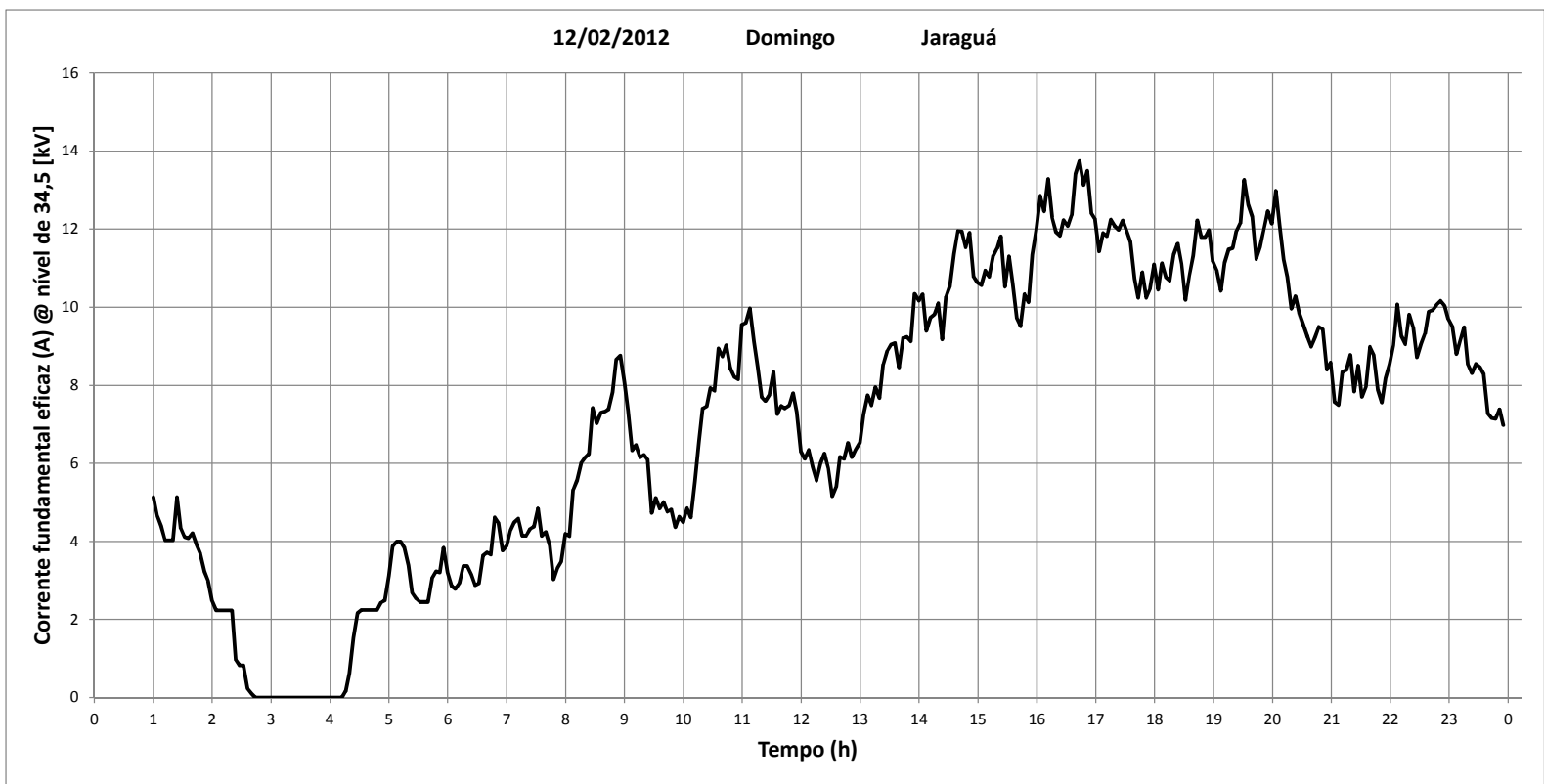

Fig. C.9 - Registro da corrente de entrada em Jaraguá no domingo, 12/02/2012. 


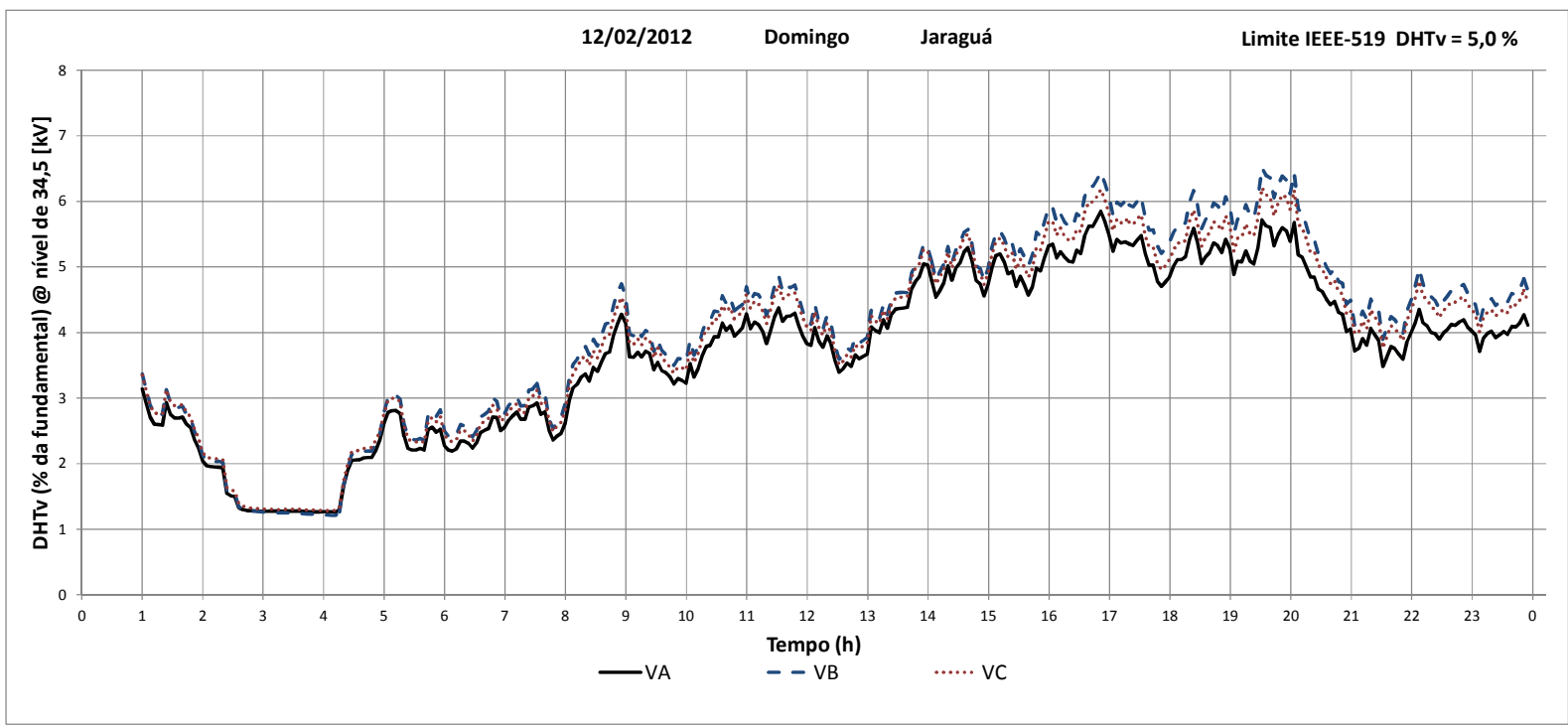

Fig. C.10 - Registro da DHTv na entrada de Jaraguá no domingo, 12/02/2012.

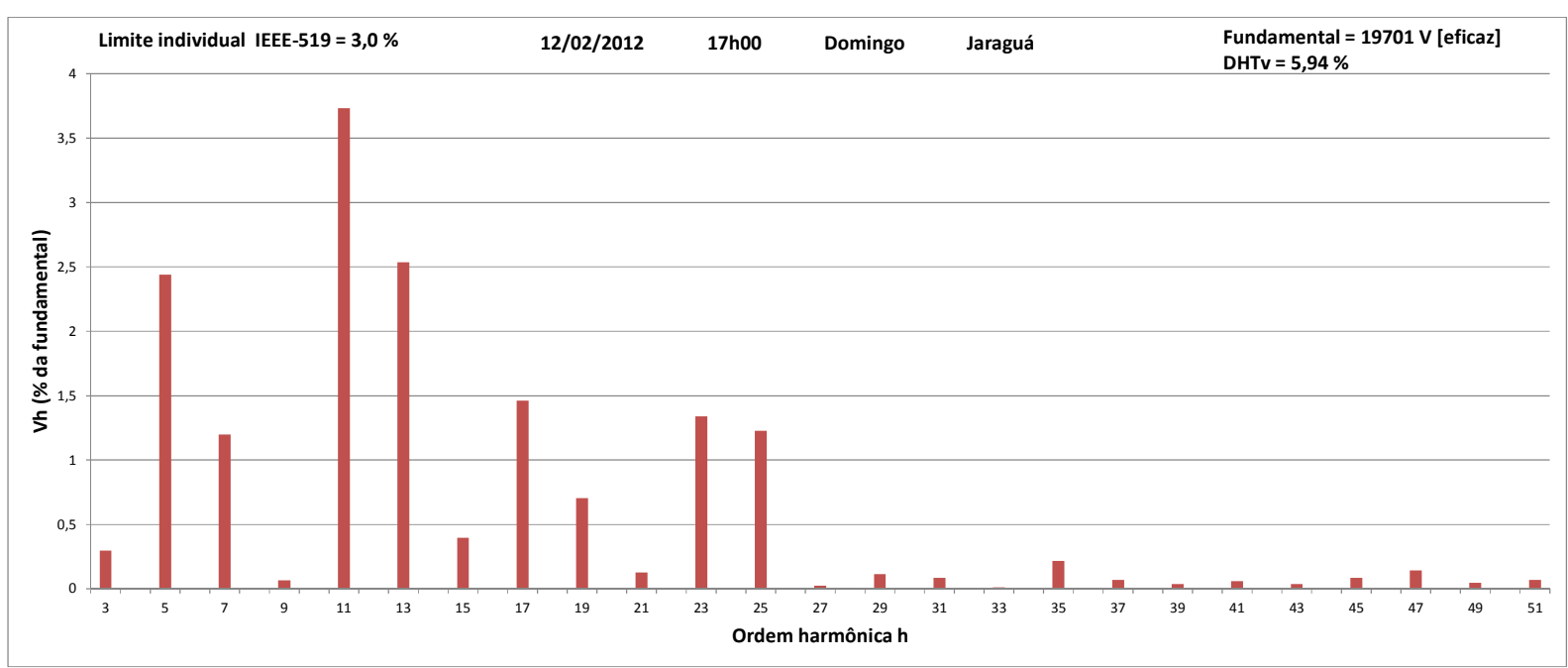

Fig. C.11 - Espectro de tensão do registro no instante de maior DHTv em Jaraguá no domingo, $12 / 02 / 2012$.

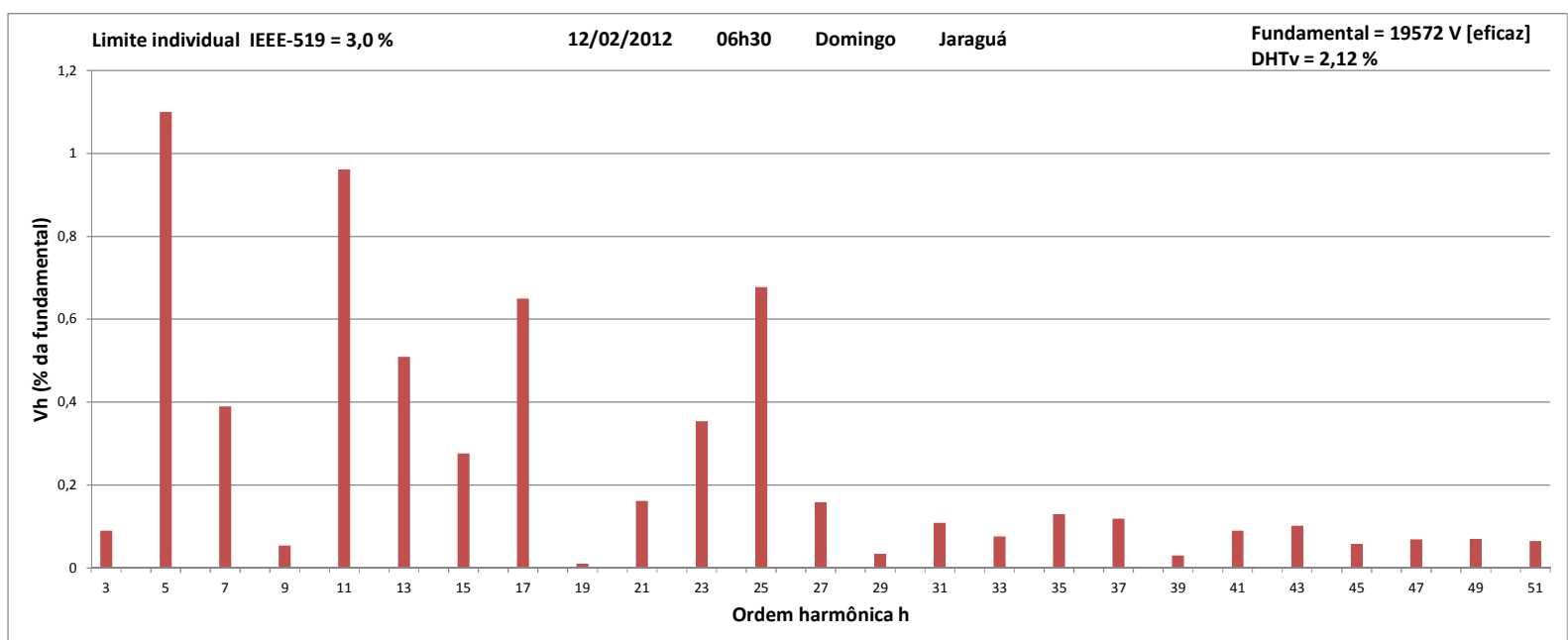

Fig. C.12 - Espectro de tensão do registro no instante de menor DHT de tensão em Jaraguá no domingo, $12 / 02 / 2012$. 


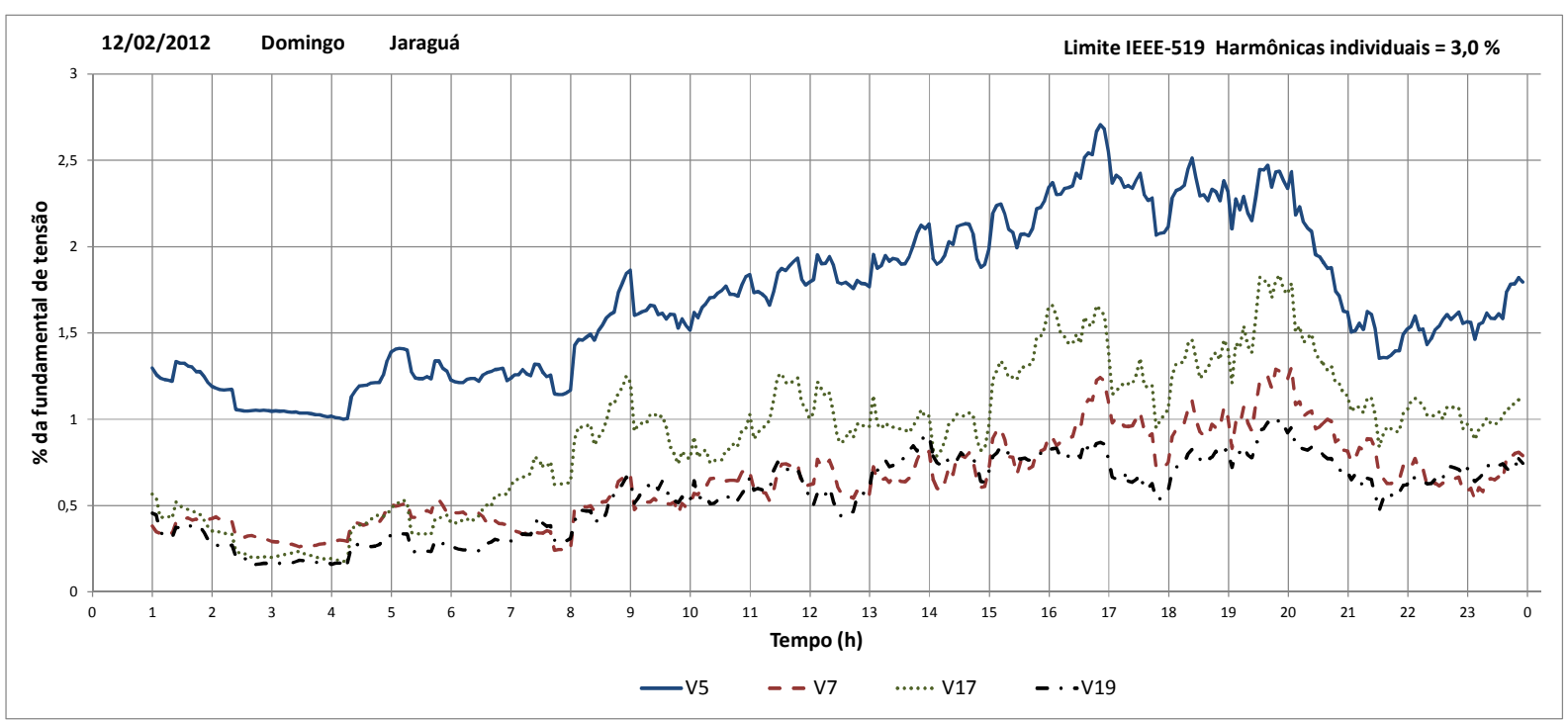

Fig. C.13 - Registro das harmônicas de tensão de ordens 5, 7, 17 e 19 em Jaraguá no domingo, $12 / 02 / 2012$.

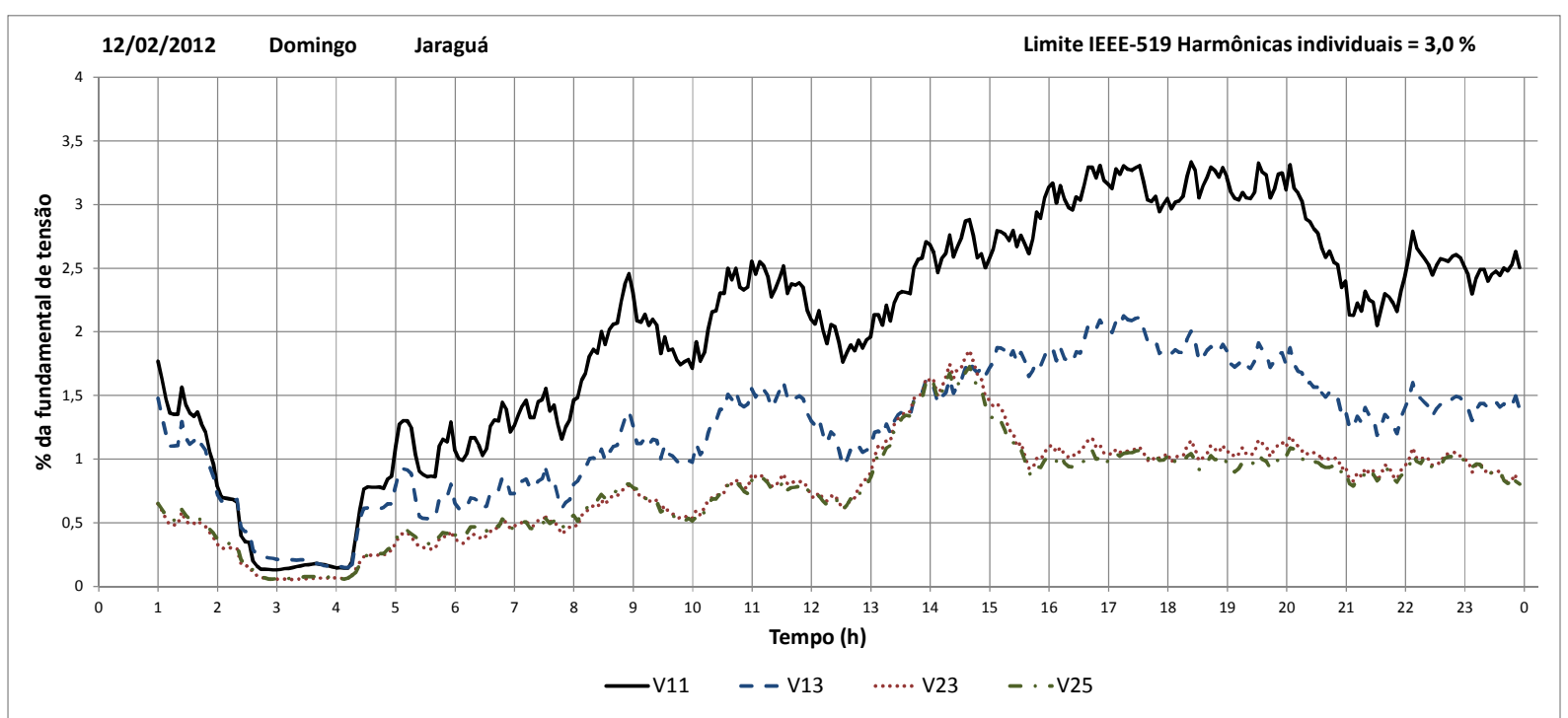

Fig. C.14 - Registro das harmônicas de tensão de ordens 11, 13, 23 e 25 em Jaraguá no domingo, $12 / 02 / 2012$. 


\section{APÊNDICE D \\ REGISTRO DAS MEDIÇÕES DE $5^{\text {a }}$ E $7^{\text {a }}$ HARMÔNICAS}

D.1 Harmônicas de corrente de $5^{\mathrm{a}}$ e $7^{\mathrm{a}}$ ordens em Tietê

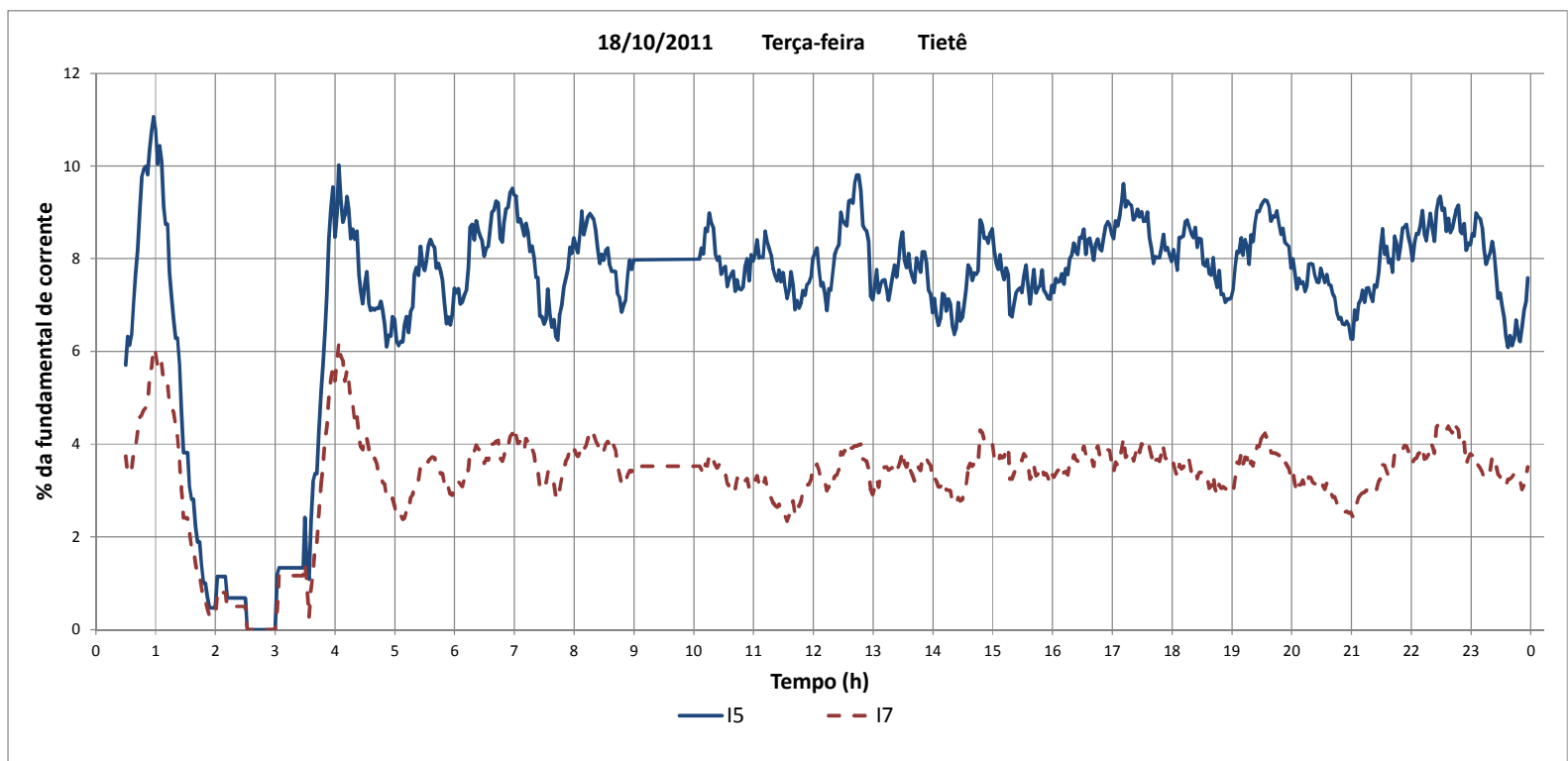

Fig. D.1 - Registro das harmônicas de corrente de $5^{\mathrm{a}}$ e $7^{\mathrm{a}}$ ordens em Tietê na terça-feira, $18 / 10 / 2011$.

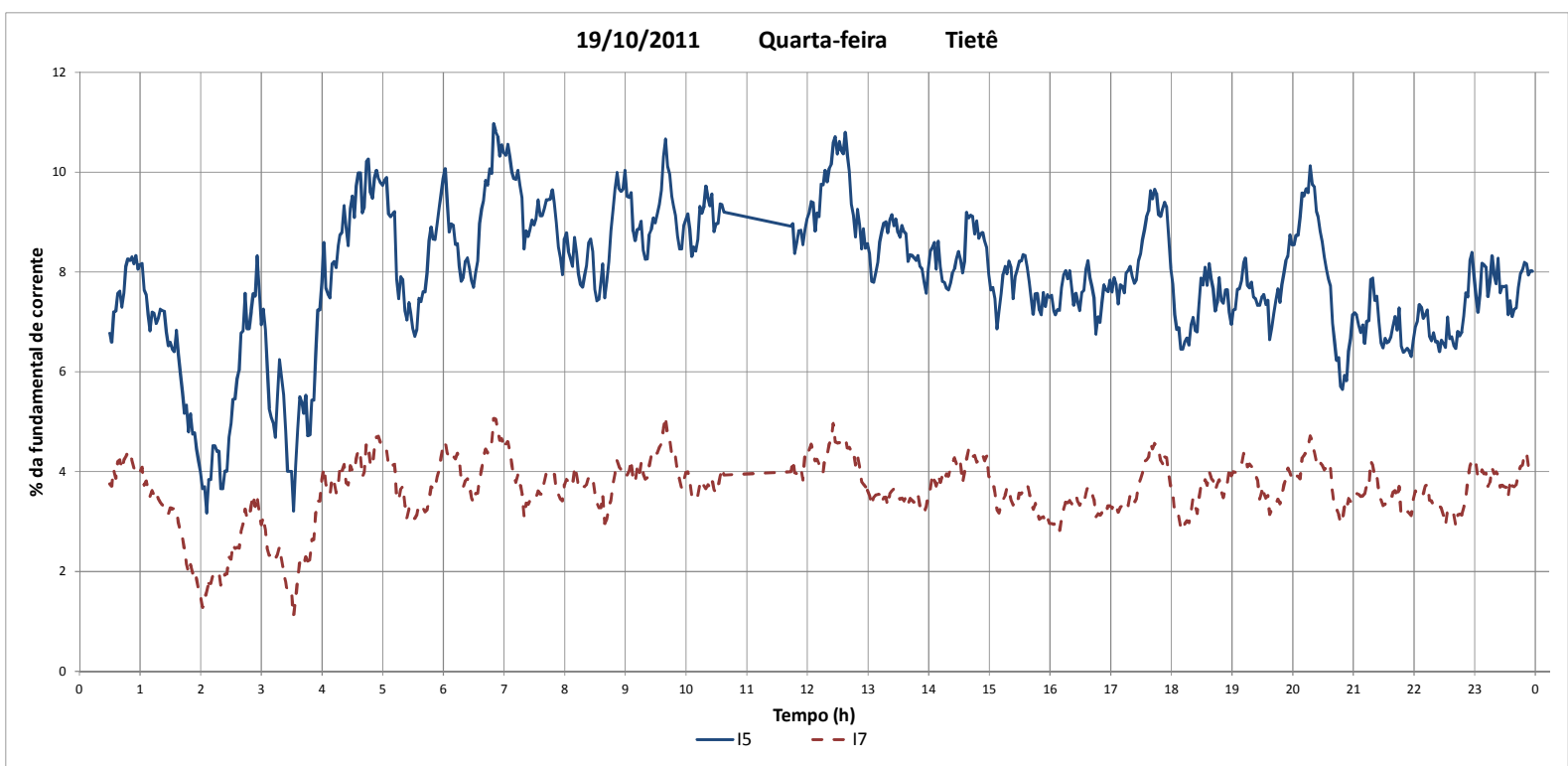

Fig. D. 2 - Registro das harmônicas de corrente de $5^{\mathrm{a}}$ e $7^{\mathrm{a}}$ ordens em Tietê na quarta-feira, 19/10/2011. 


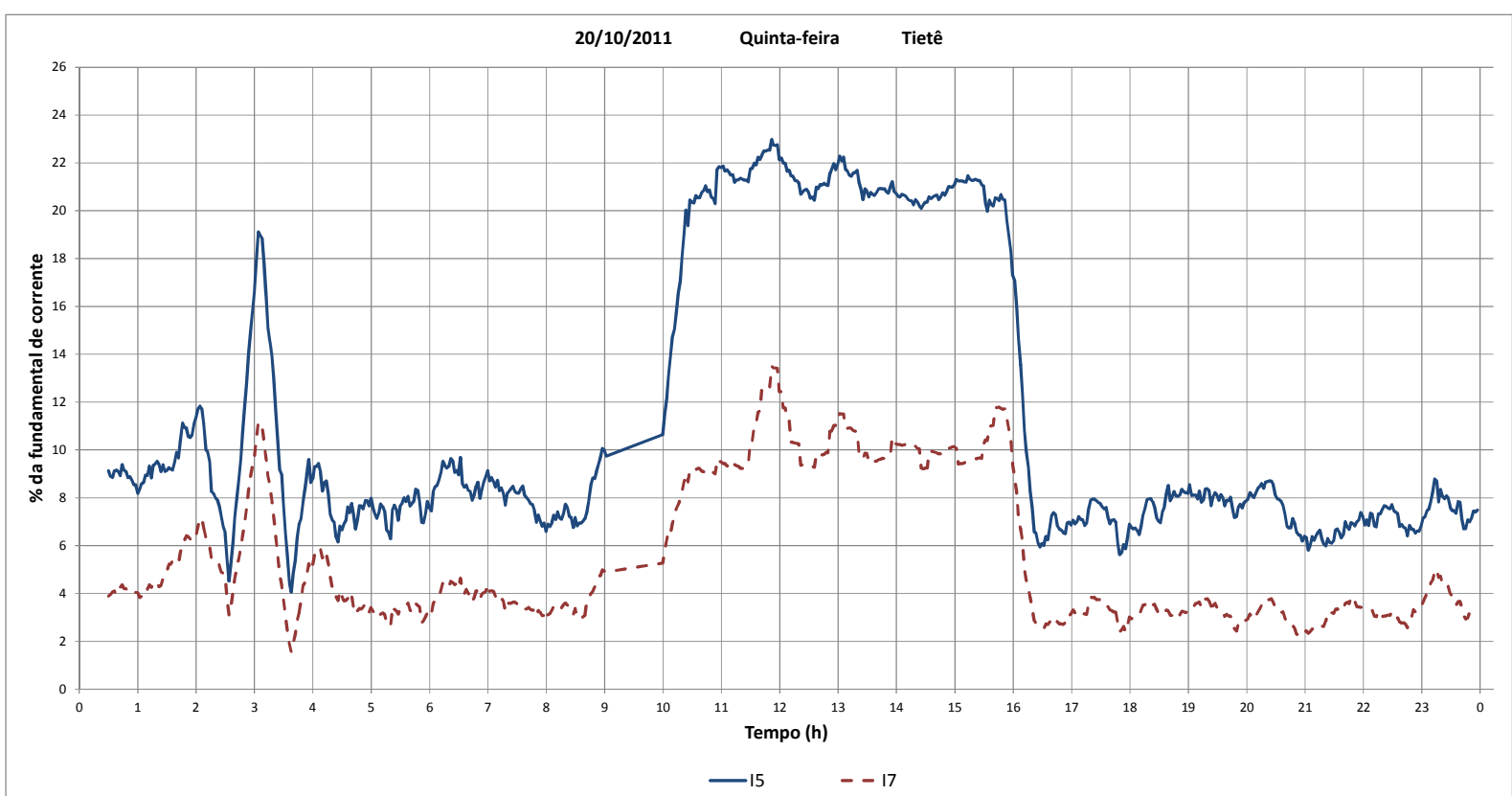

Fig. D.3 - Registro das harmônicas de corrente de $5^{\mathrm{a}}$ e $7^{\mathrm{a}}$ ordens em Tietê na quinta-feira, 20/10/2011.

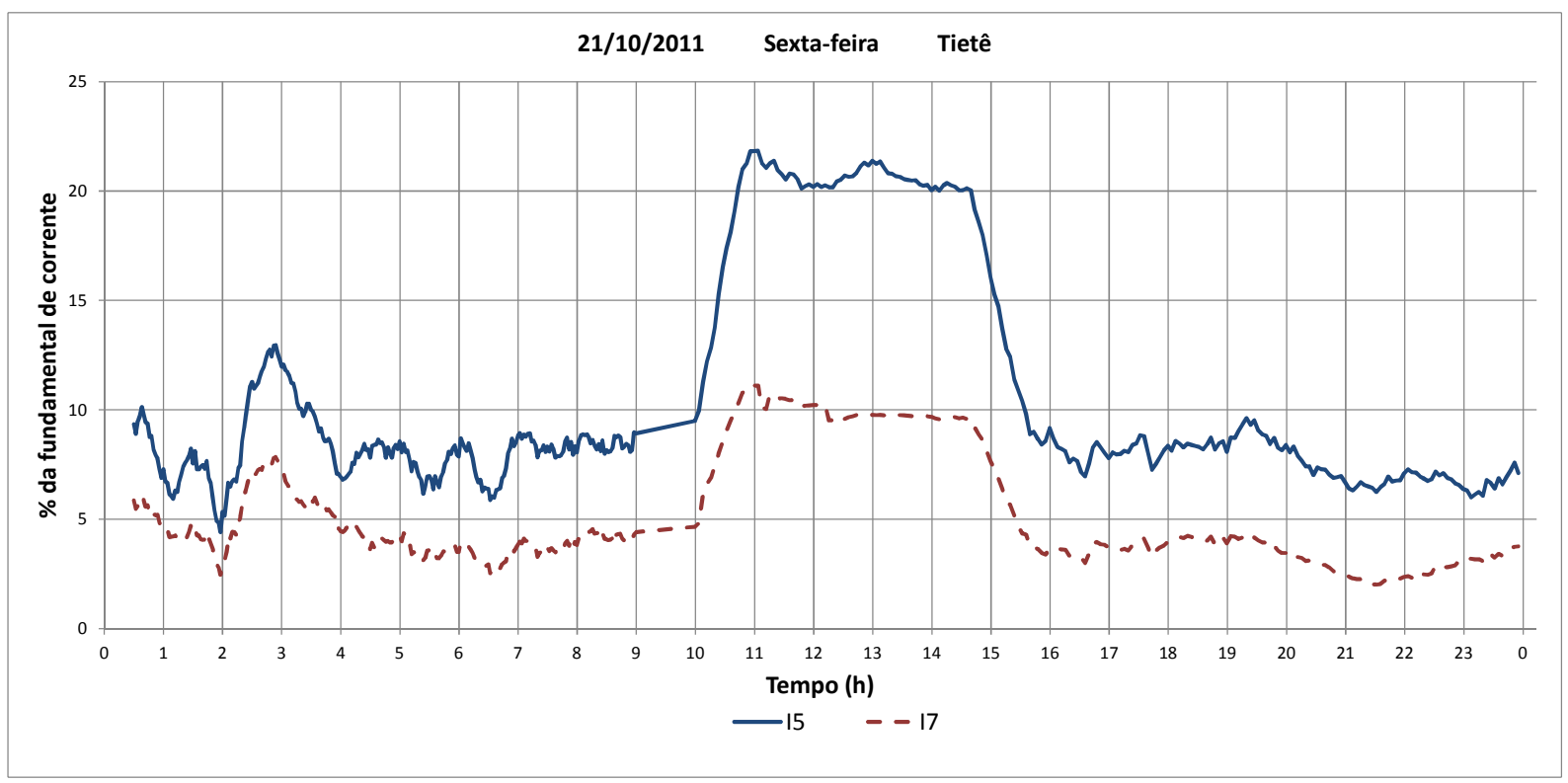

Fig. D. 4 - Registro das harmônicas de corrente de $5^{\mathrm{a}}$ e $7^{\mathrm{a}}$ ordens em Tietê na sexta-feira, 21/10/2011. 


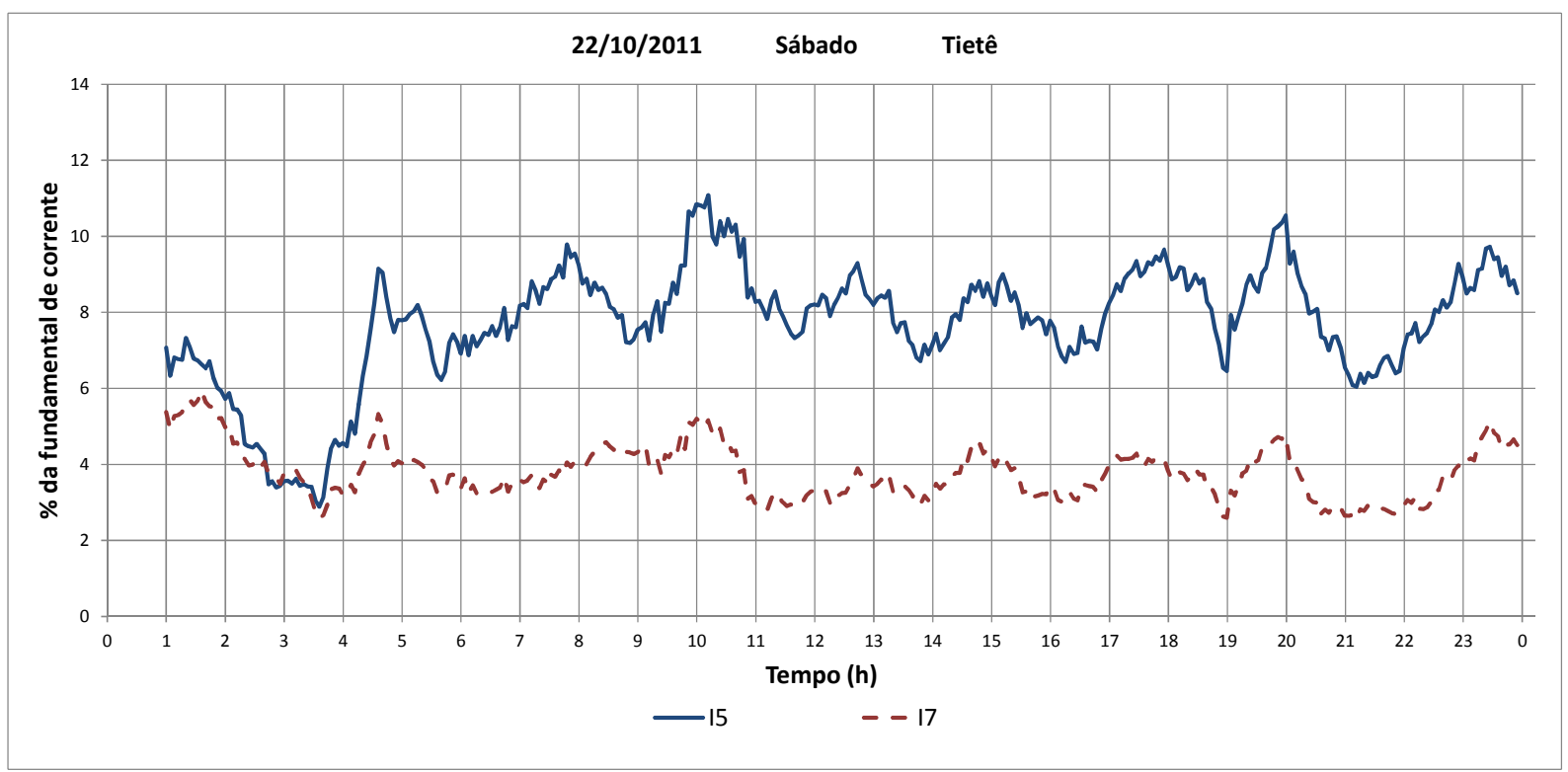

Fig. D.5 - Registro das harmônicas de corrente de $5^{\mathrm{a}}$ e $7^{\mathrm{a}}$ ordens em Tietê no sábado, $22 / 10 / 2011$.

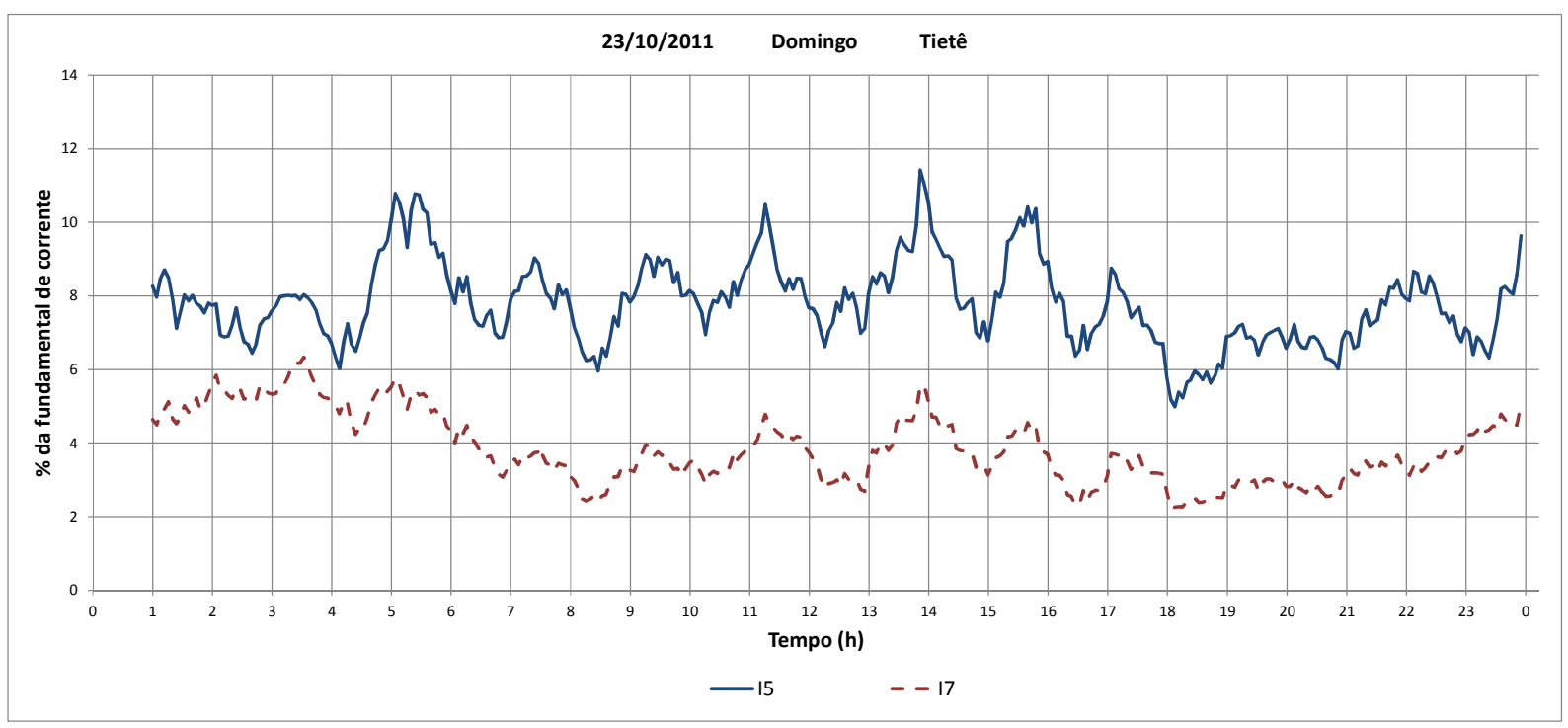

Fig. D.6 - Registro das harmônicas de corrente de $5^{\mathrm{a}}$ e $7^{\mathrm{a}}$ ordens em Tietê no domingo, $23 / 10 / 2011$. 


\section{D.2 Harmônicas de tensão de $5^{a}$ e $7^{\mathrm{a}}$ ordens em Tietê}

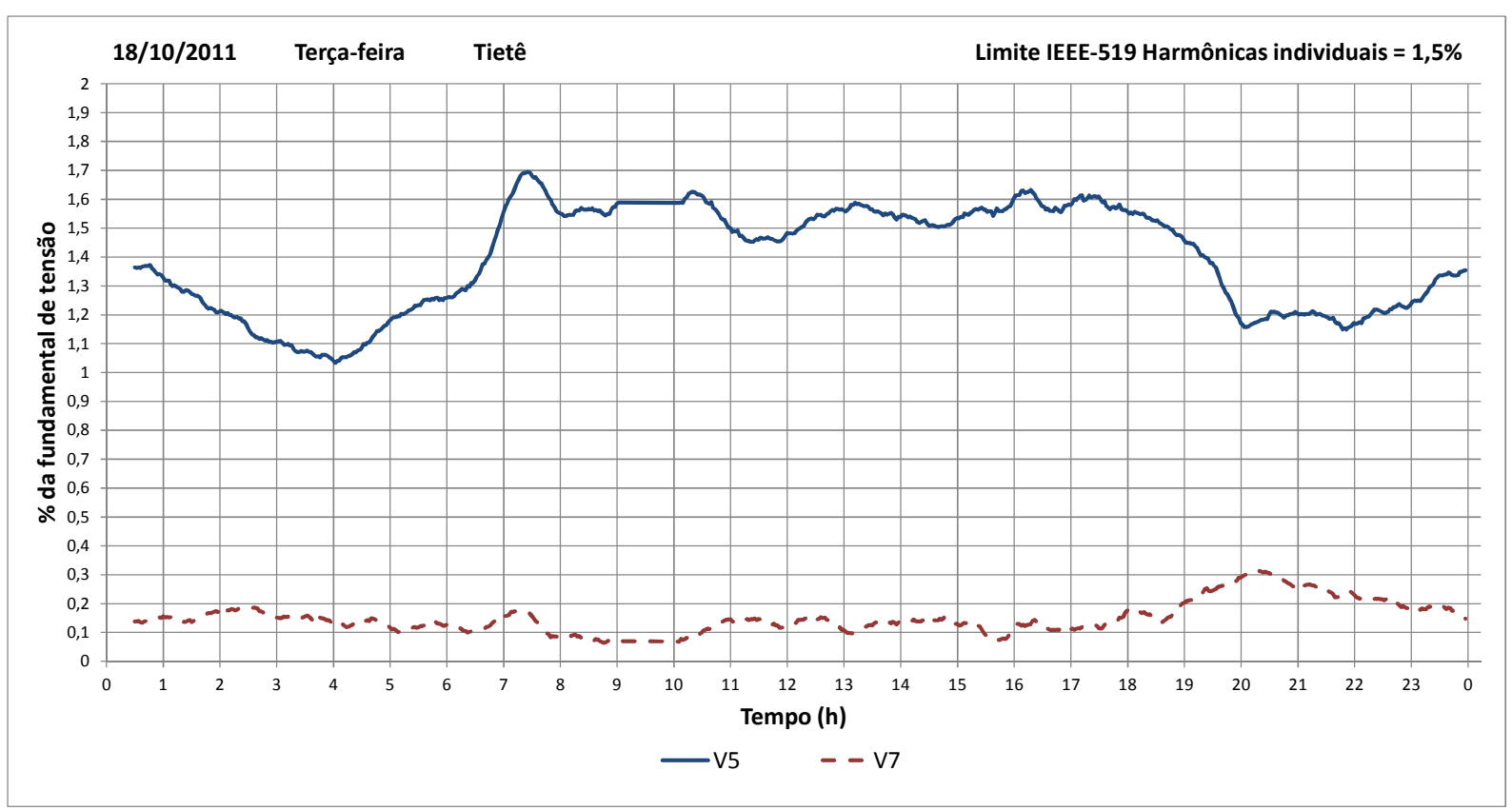

Fig. D.7 - Registro das harmônicas de tensão de $5^{\mathrm{a}}$ e $7^{\mathrm{a}}$ ordens em Tietê na terça-feira, $18 / 10 / 2011$.

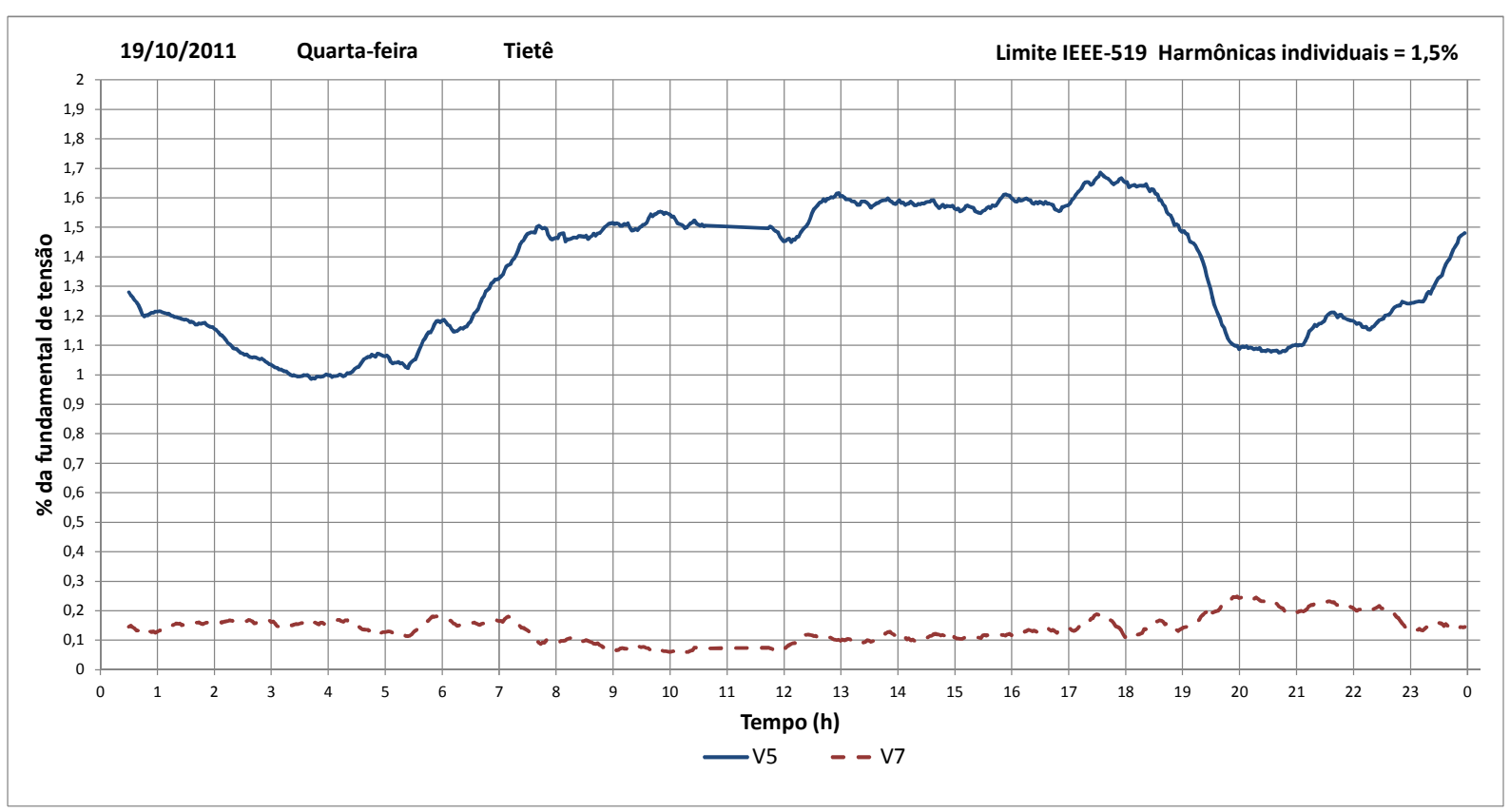

Fig. D.8 - Registro das harmônicas de tensão de $5^{\mathrm{a}}$ e $7^{\mathrm{a}}$ ordens em Tietê na quarta-feira, $19 / 10 / 2011$. 


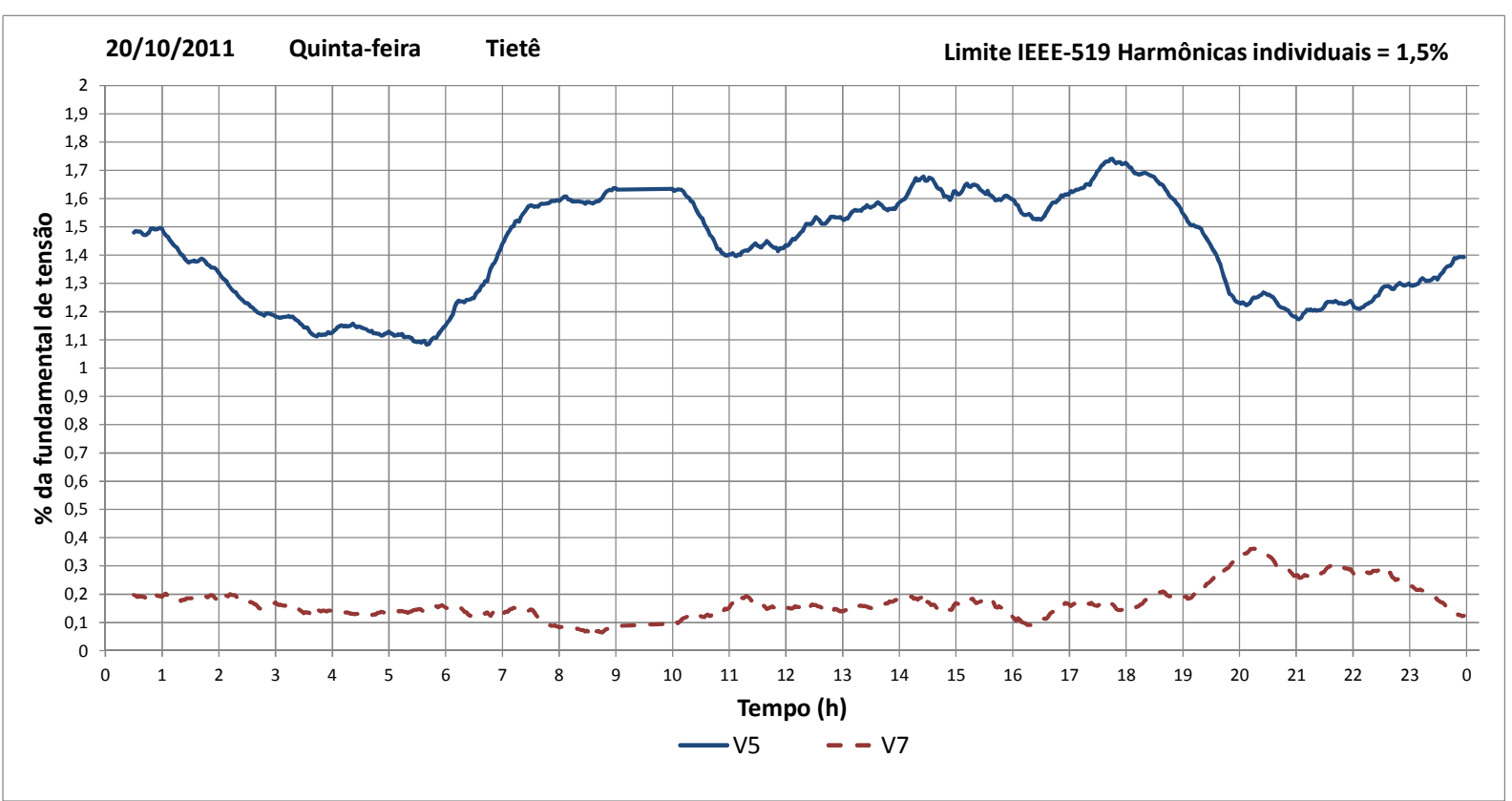

Fig. D.9 - Registro das harmônicas de tensão de $5^{\mathrm{a}}$ e $7^{\mathrm{a}}$ ordens em Tietê na quinta-feira, 20/10/2011.

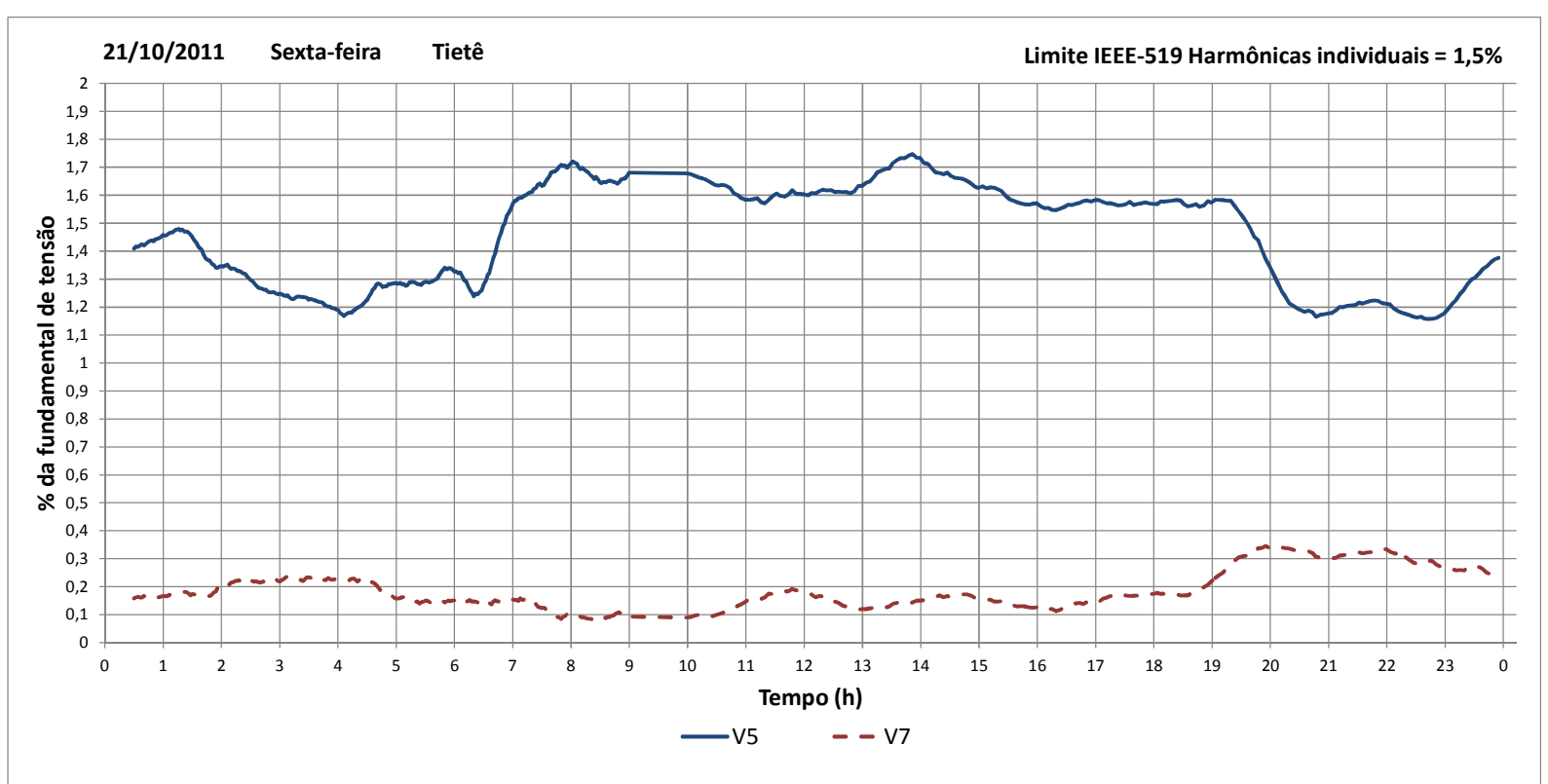

Fig. D.10 - Registro das harmônicas de tensão de $5^{\mathrm{a}}$ e $7^{\mathrm{a}}$ ordens em Tietê na sexta-feira, $21 / 10 / 2011$. 


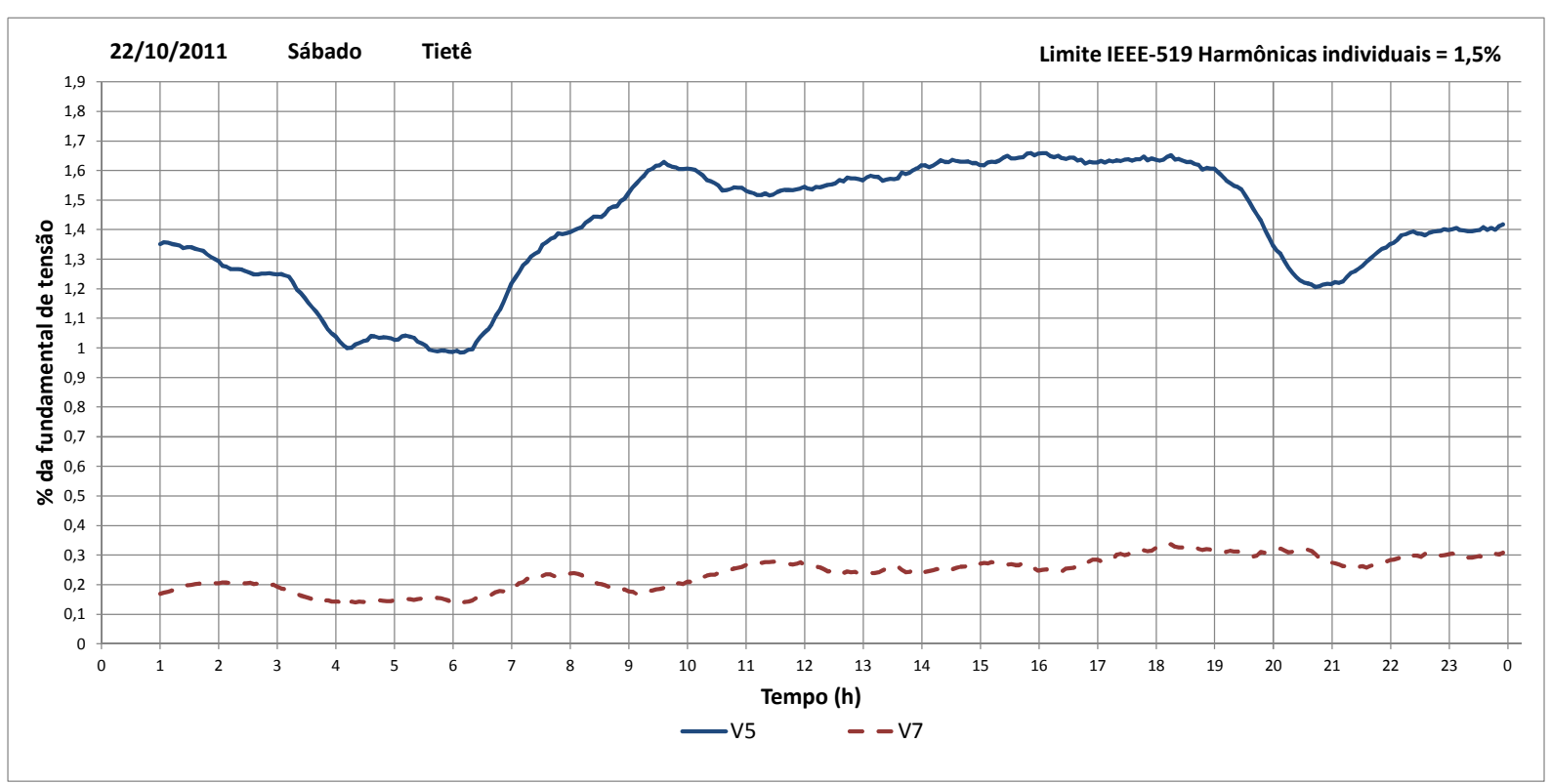

Fig. D.11 - Registro das harmônicas de tensão de $5^{\mathrm{a}}$ e $7^{\mathrm{a}}$ ordens em Tietê no sábado, $22 / 10 / 2011$.

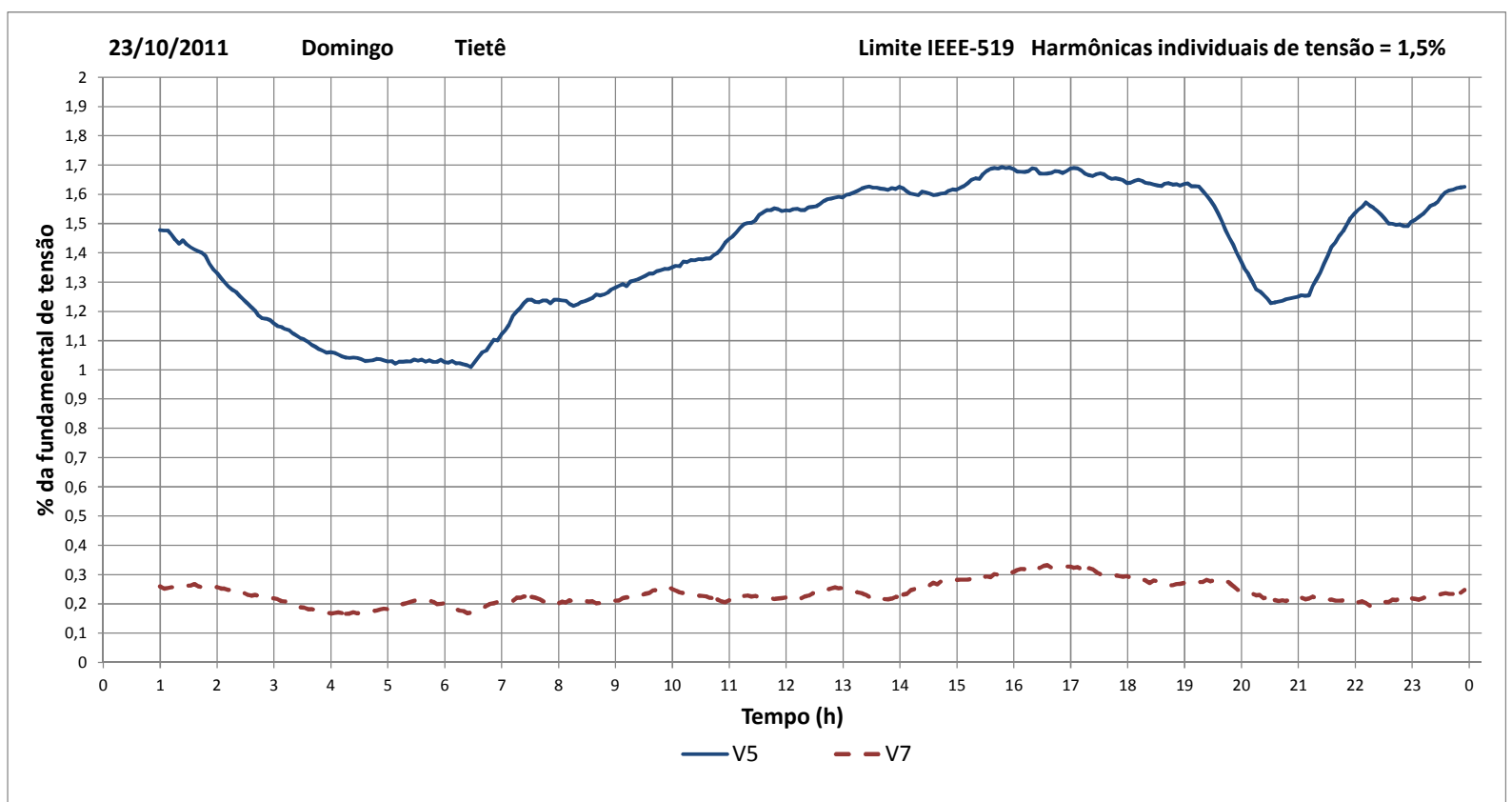

Fig. D. 12 - Registro das harmônicas de tensão de $5^{\mathrm{a}}$ e $7^{\mathrm{a}}$ ordens em Tietê no domingo, $23 / 10 / 2011$. 
D.3 Harmônicas de corrente de $5^{\mathrm{a}}$ e $7^{\mathrm{a}}$ ordens em Jaraguá

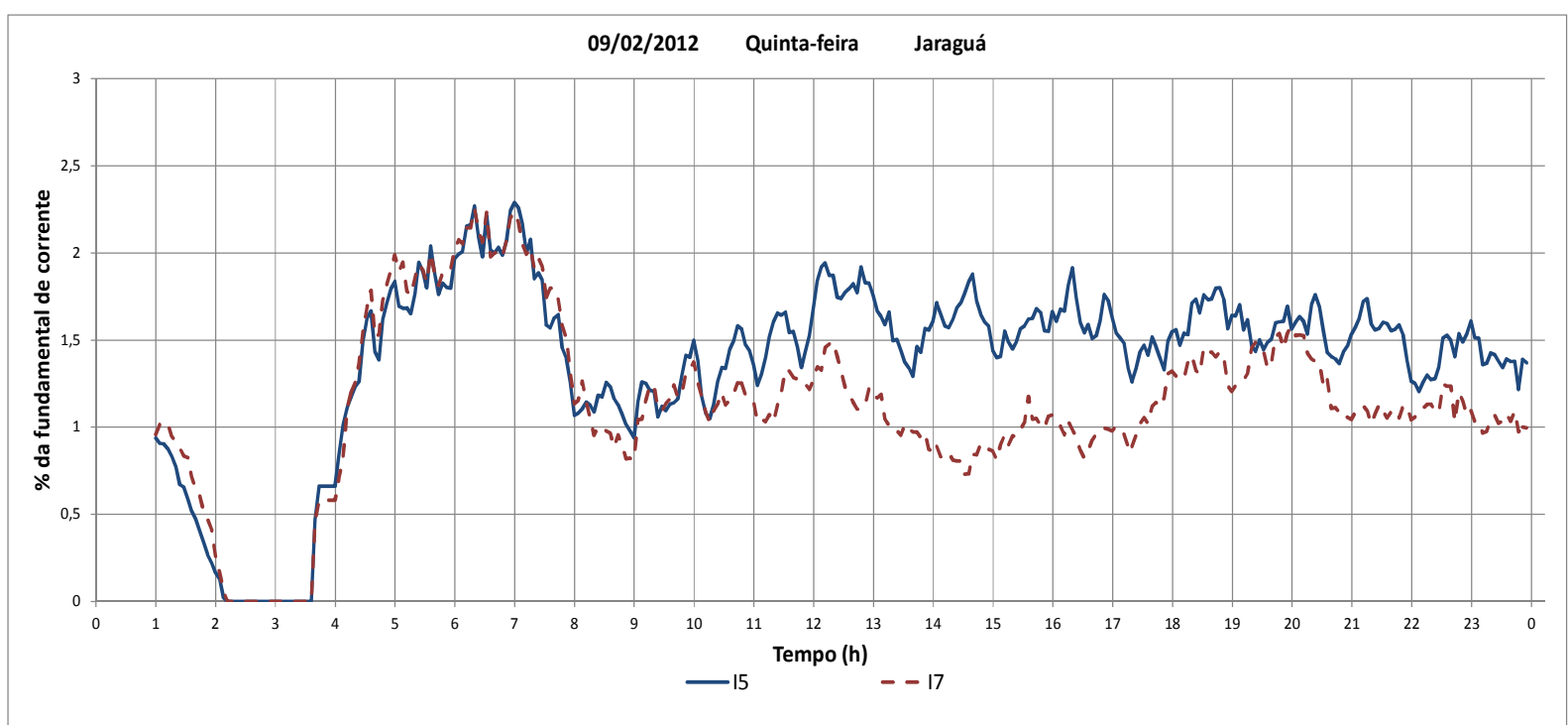

Fig. D.13 - Registro das harmônicas de corrente de $5^{\mathrm{a}}$ e $7^{\mathrm{a}}$ ordens em Jaraguá na quinta-feira, $09 / 02 / 2012$.

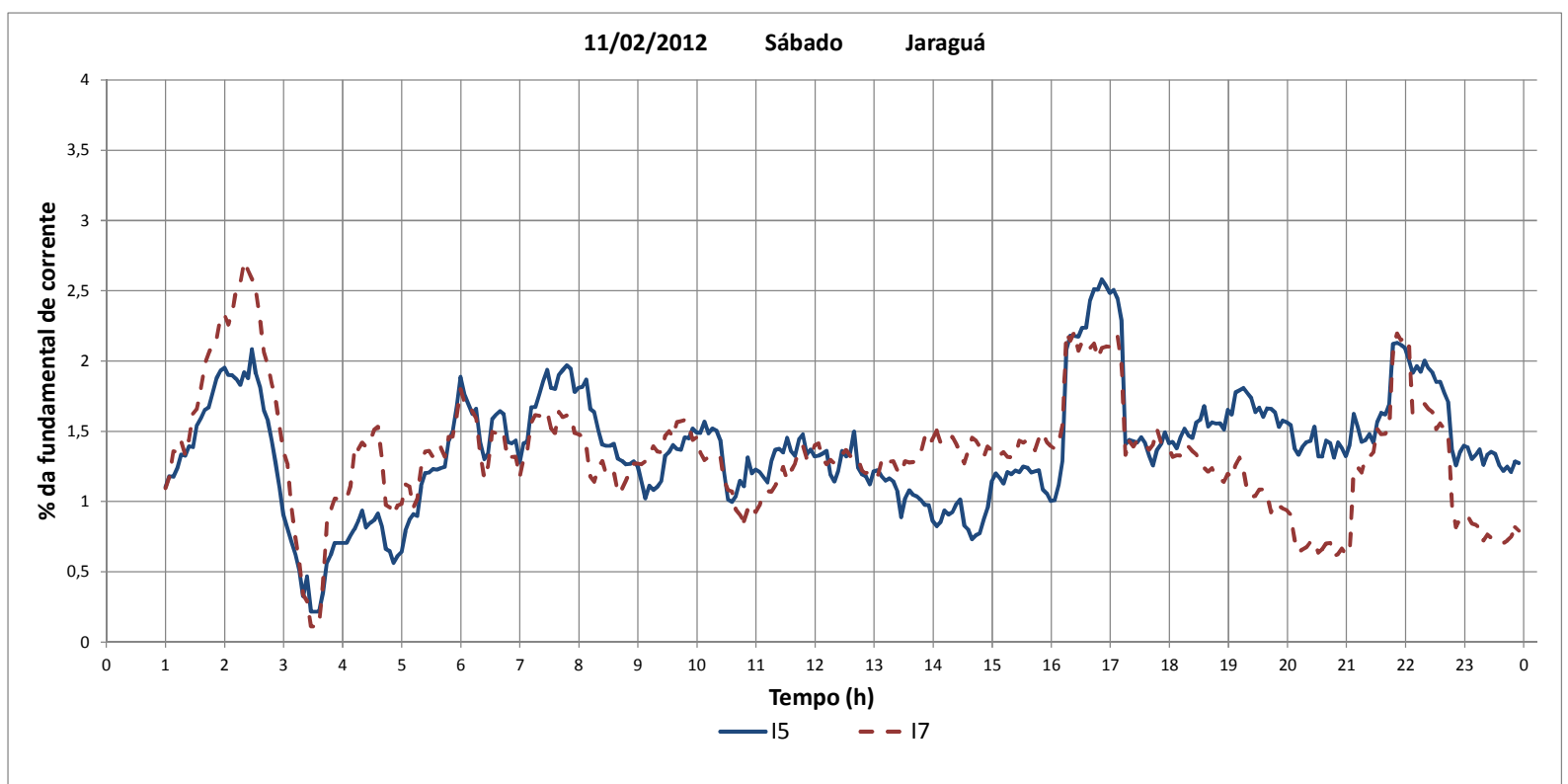

Fig. D.14 - Registro das harmônicas de corrente de $5^{\mathrm{a}}$ e $7^{\mathrm{a}}$ ordens em Jaraguá no sábado, $11 / 02 / 2012$. 


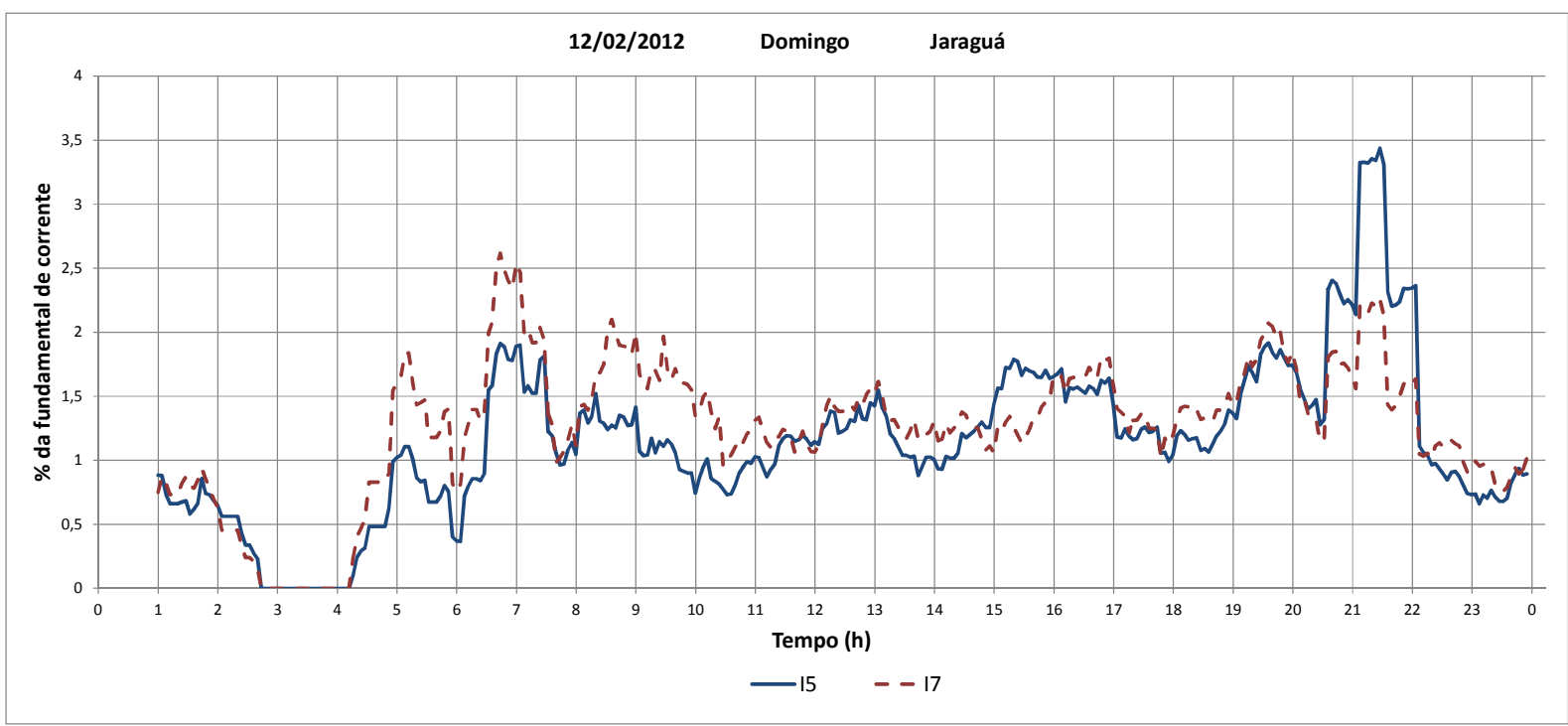

Fig. D.15 - Registro das harmônicas de corrente de $5^{\mathrm{a}}$ e $7^{\mathrm{a}}$ ordens em Jaraguá no domingo, $12 / 02 / 2012$.

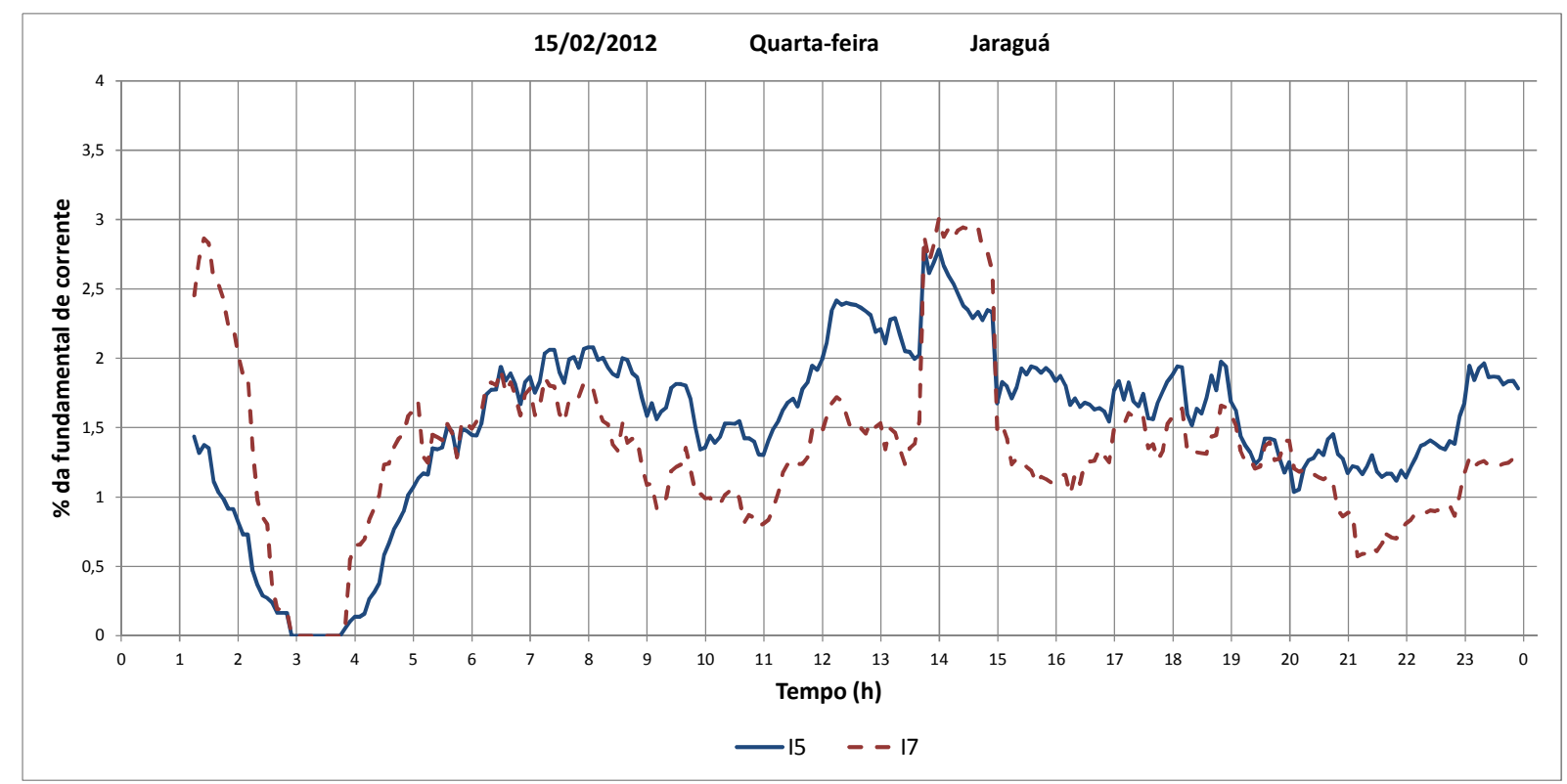

Fig. D.16 - Registro das harmônicas de corrente de $5^{\mathrm{a}}$ e $7^{\mathrm{a}}$ ordens em Jaraguá na quarta-feira, $15 / 02 / 2012$. 


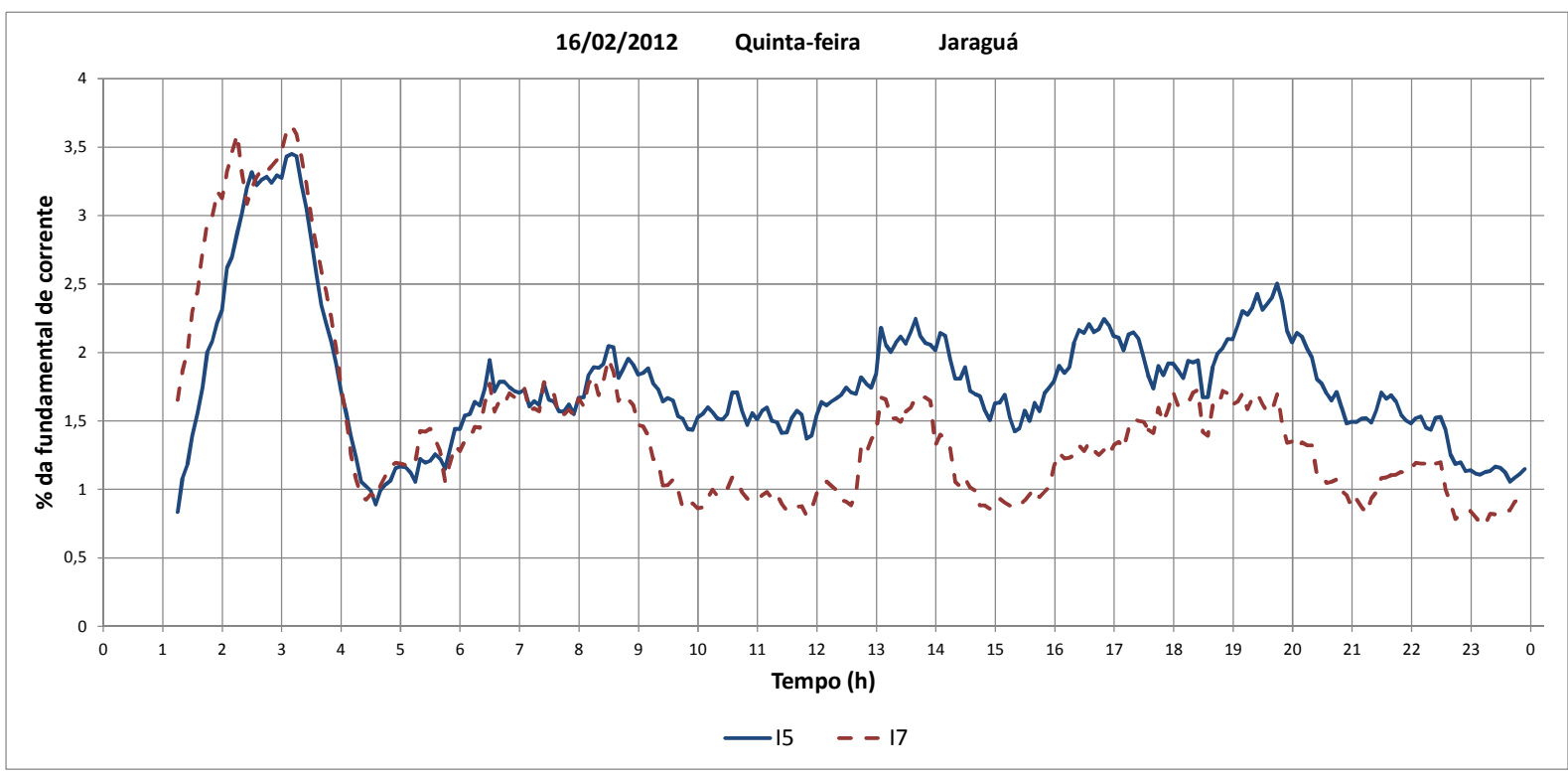

Fig. D. 17 - Registro das harmônicas de corrente de $5^{\mathrm{a}}$ e $7^{\mathrm{a}}$ ordens em Jaraguá na quinta-feira, $16 / 02 / 2012$.

\section{D.4 Harmônicas de tensão de $5^{\mathrm{a}}$ e $7^{\mathrm{a}}$ ordens em Jaraguá}

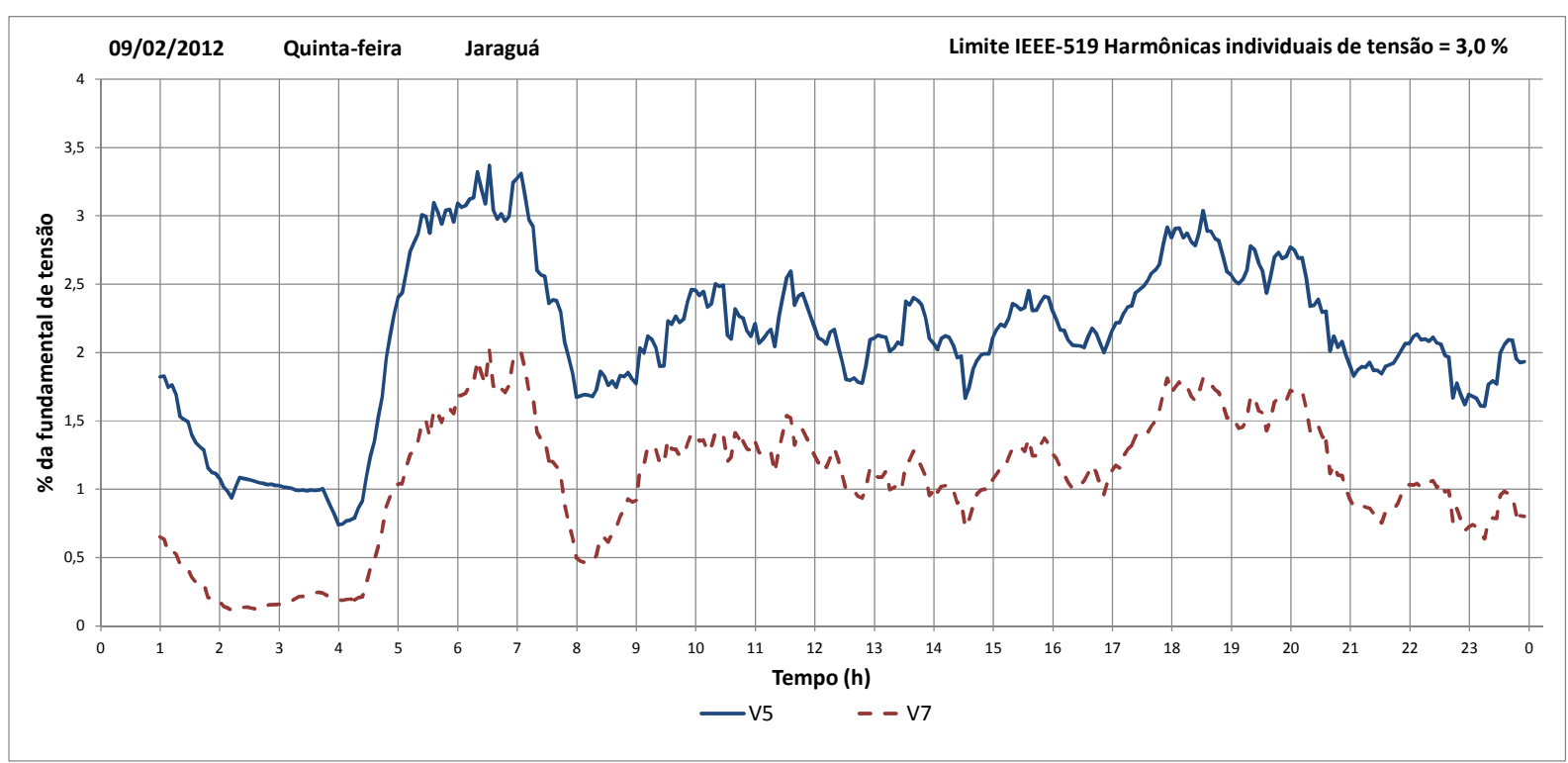

Fig. D.18 - Registro das harmônicas de tensão de $5^{\mathrm{a}}$ e $7^{\mathrm{a}}$ ordens em Jaraguá na quinta-feira, 09/02/2012. 


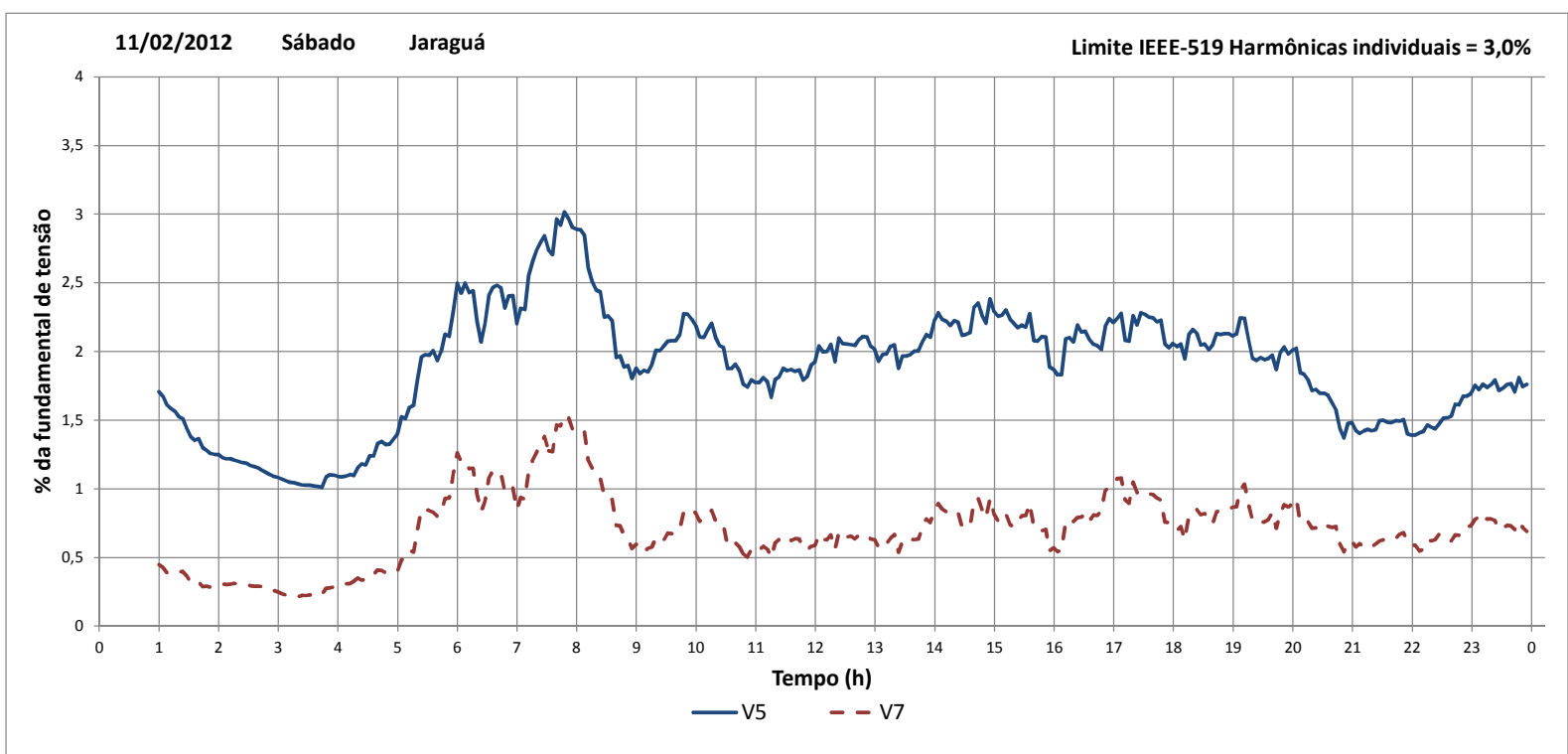

Fig. D.19 - Registro das harmônicas de tensão de $5^{\mathrm{a}}$ e $7^{\mathrm{a}}$ ordens em Jaraguá no sábado, $11 / 02 / 2012$.

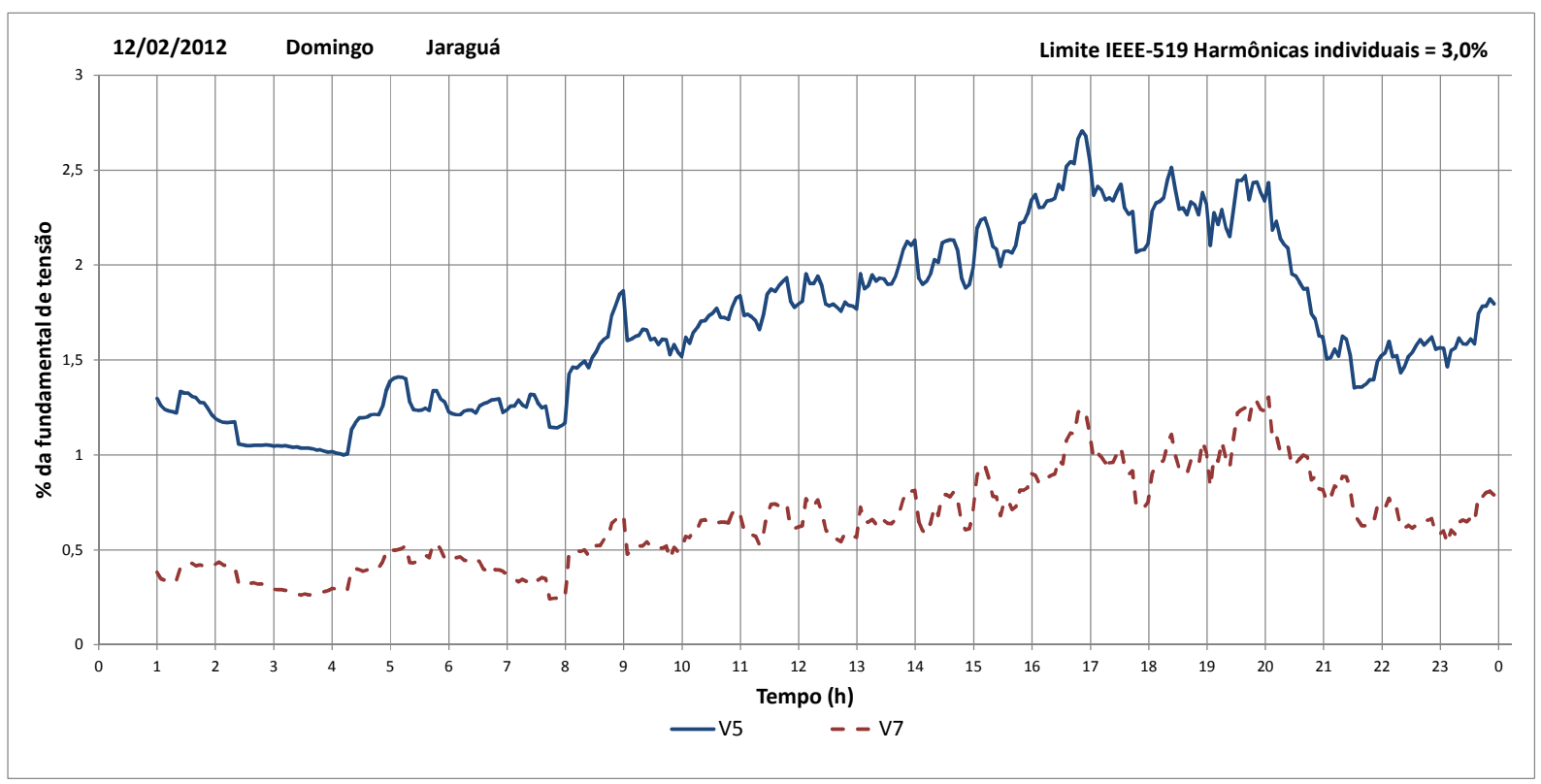

Fig. D.20 - Registro das harmônicas de tensão de $5^{\mathrm{a}}$ e $7^{\mathrm{a}}$ ordens em Jaraguá no domingo, $12 / 02 / 2012$. 


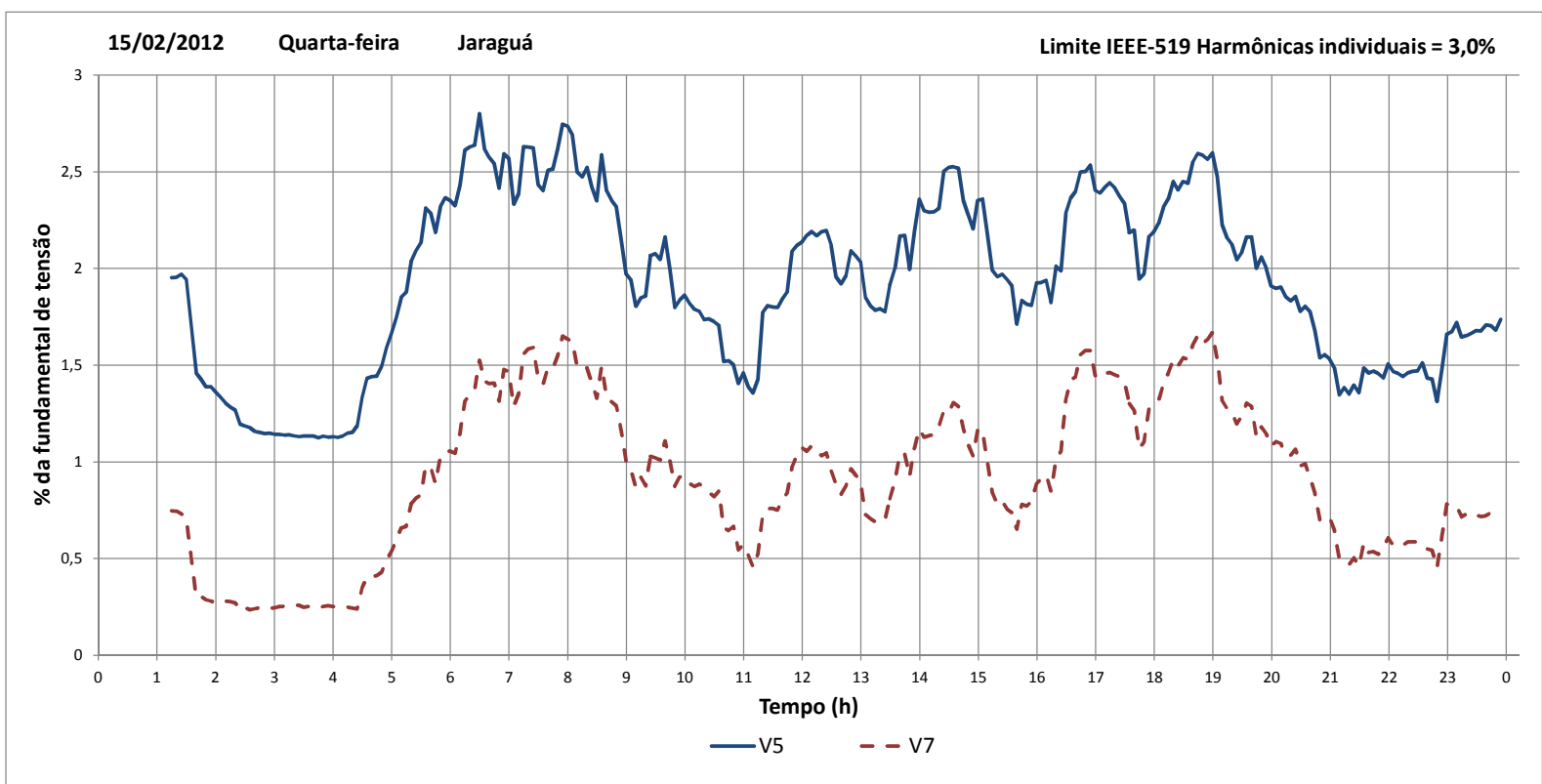

Fig. D.21 - Registro das harmônicas de tensão de $5^{\mathrm{a}}$ e $7^{\mathrm{a}}$ ordens em Jaraguá na quarta-feira, $15 / 02 / 2012$.

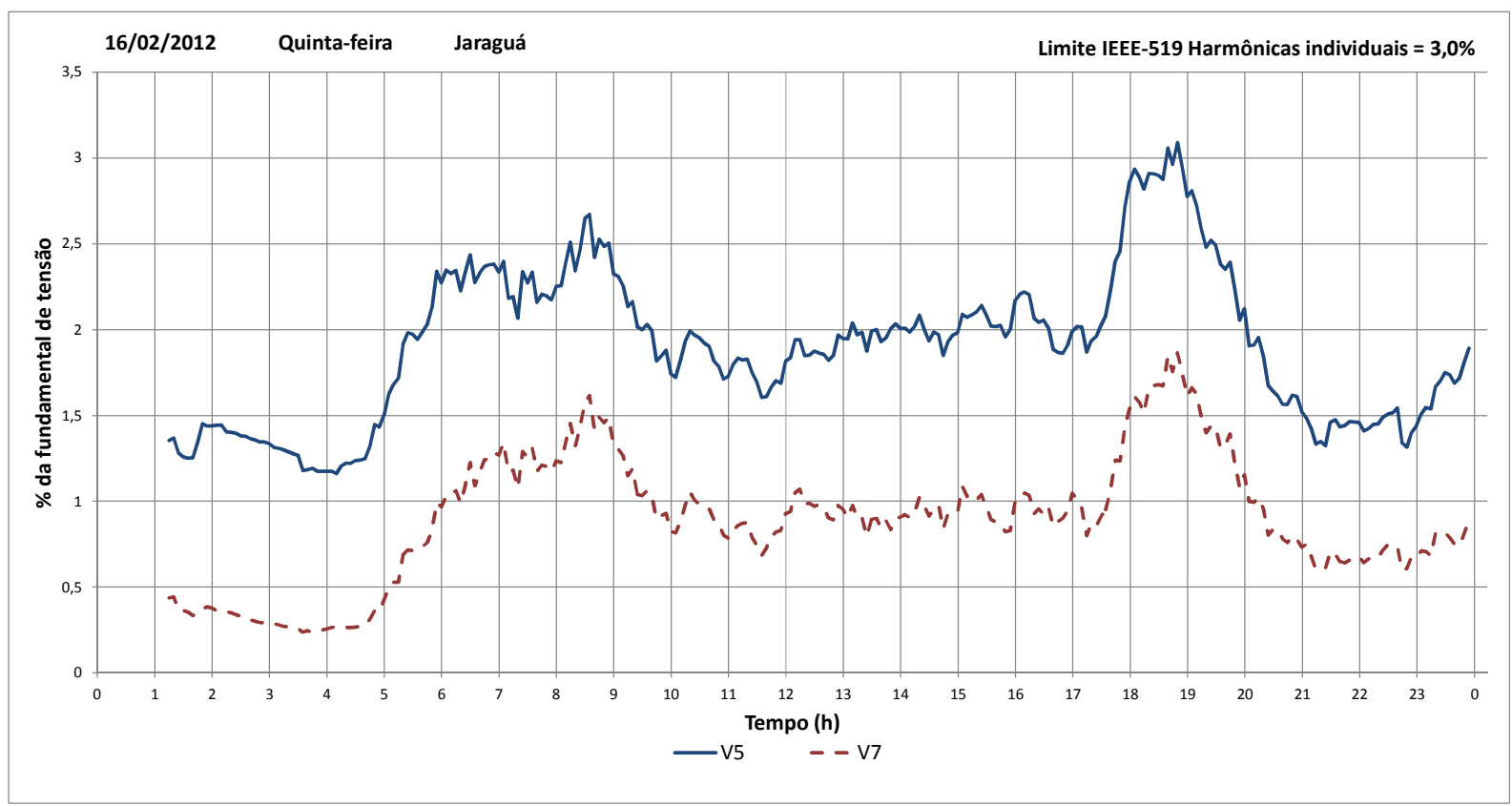

Fig. D.22 - Registro das harmônicas de tensão de $5^{\mathrm{a}}$ e $7^{\mathrm{a}}$ ordens em Jaraguá na quinta-feira, $16 / 02 / 2012$. 


\section{ANEXO A - NORMAS E RECOMENDAÇÕES PARA CONTEÚDO HARMÔNICO EM REDES CA}

\section{A.1. IEEE-519:1992}

A IEEE-519:1992 - "Práticas e requisitos para controle de harmônicas no sistema elétrico de potência" é uma recomendação e, mesmo não tendo valor normativo, é utilizada para esta finalidade por diversas concessionárias no Brasil. Foi elaborada pelo IEEE, para descrever os principais fenômenos causadores de distorção harmônica e recomendar métodos de medição e limites de distorção harmônica. Os limites diferem de acordo com o nível de tensão e com a potência de curto-circuito no ponto de acoplamento comum (PAC). Quanto maior a relação entre a corrente de curto-circuito (Icc) e a corrente de carga, maiores serão as distorções de corrente admissíveis, uma vez que seu impacto na tensão no PAC será menor. Para níveis de tensão mais elevados as exigências de distorção de corrente são mais severas.

Tabela A1.1 - Limites de Distorção da Corrente - Distribuição $\left(120 \mathrm{~V} \leq \mathrm{V}_{\mathrm{Nom}} \leq 69 \mathrm{kV}\right)$

\begin{tabular}{l|l|l|l|l|l|l}
\hline \multicolumn{6}{l}{ Máxima componente de corrente harmônica em \% da corrente de carga $\mathrm{I}_{\mathrm{L}}$} \\
\hline Icc/I $\mathrm{L}$ & $<11$ & $11 \leq \mathrm{n}<17$ & $17 \leq \mathrm{n}<23$ & $23 \leq \mathrm{n}<35$ & $35<\mathrm{n}$ & DTD $(\%)$ \\
\hline$<20$ & 4,0 & 2,0 & 1,5 & 0,6 & 0,3 & 5,0 \\
\hline $20<50$ & 7,0 & 3,5 & 2,5 & 1,0 & 0,5 & 8,0 \\
\hline $50<100$ & 10,0 & 4,5 & 4,0 & 1,5 & 0,7 & 12,0 \\
\hline $100<1000$ & 12,0 & 5,5 & 5,0 & 2,0 & 1,0 & 15,0 \\
\hline$>1000$ & 15,0 & 7,0 & 6,0 & 2,5 & 1,4 & 20,0 \\
\hline
\end{tabular}

Tabela A1.2 - Limites de Distorção da Corrente - Subtransmissão $\left(69 \mathrm{kV}<\mathrm{V}_{\text {Nom }} \leq 161 \mathrm{kV}\right)$

Máxima componente de corrente harmônica em \% da corrente de carga IL

\begin{tabular}{l|l|l|l|l|l|l}
\hline Icc/IL & $<11$ & $11 \leq \mathrm{n}<17$ & $17 \leq \mathrm{n}<23$ & $23 \leq \mathrm{n}<35$ & $35<\mathrm{n}$ & $\mathrm{DTD}(\%)$ \\
\hline$<20$ & 2,0 & 1,0 & 0,75 & 0,3 & 0,15 & 2,5 \\
\hline $20<50$ & 3,5 & 1,75 & 1,25 & 0,5 & 0,25 & 4,0 \\
\hline $50<100$ & 5,0 & 2,25 & 2,0 & 0,75 & 0,35 & 6,0 \\
\hline $100<1000$ & 6,0 & 2,75 & 2,5 & 1,0 & 0,5 & 7,5 \\
\hline$>1000$ & 7,5 & 3,5 & 3,0 & 1,25 & 0,7 & 10,0 \\
\hline
\end{tabular}


Essas tabelas são aplicáveis para retificadores de 6 pulsos e situações em geral. Contudo, quando são utilizados conversores com número de pulsos (q) maior do que 6, os limites para as harmônicas de ordens características são multiplicados pelo fator $\sqrt{\frac{q}{6}}$ desde que as amplitudes das harmônicas de ordens não características sejam inferiores a $25 \%$ dos limites especificados nas tabelas.

Para os limites de distorção de tensão, os valores mais severos se aplicam para níveis de tensão de distribuição menores. A IEEE - 519 estabelece um limite individual por componente e um limite para a distorção harmônica total.

Tabela A1.3 - Limites de Distorção de Tensão (em porcentagem da componente fundamental de tensão)

\begin{tabular}{c|c|c}
\hline $\begin{array}{c}\text { Tensão nominal no Ponto de } \\
\text { Acoplamento Comum }\end{array}$ & $\begin{array}{c}\text { Distorção de tensão } \\
\text { individual [\%] }\end{array}$ & $\begin{array}{c}\text { Distorção Harmônica Total } \\
\text { de Tensão DHTv [\%] }\end{array}$ \\
\hline $\mathrm{V}_{\mathrm{N}} \leq 69 \mathrm{kV}$ & 3,0 & 5,0 \\
\hline $69 \mathrm{kV}<\mathrm{V}_{\mathrm{N}}<161 \mathrm{kV}$ & 1,5 & 2,5 \\
\hline $\mathrm{V}_{\mathrm{N}} \geq 161 \mathrm{kV}$ & 1,0 & 1,5 \\
\hline
\end{tabular}

\section{A.2. IEC 61000-3-6:2008}

A norma IEC 61000-3-6:2008 estabelece um limite máximo de 6,5\% de distorção harmônica total de tensão para equipamentos conectados às redes de média $\left(1 \mathrm{kV}<\mathrm{V}_{\mathrm{N}} \leq 35 \mathrm{kV}\right)$ e $3,0 \%$ para equipamentos alimentados em alta tensão $\left(35 \mathrm{kV}<\mathrm{V}_{\mathrm{N}} \leq 230 \mathrm{kV}\right)$. A tabela A2.1 apresenta os limites para as componentes harmônicas individuais de tensão.

Tabela A2.1 - Níveis de harmônicas de tensão (em porcentagem da componente fundamental de tensão) para sistemas de potência de média e alta tensão.

\begin{tabular}{|c|c|c|c|c|c|}
\hline \multicolumn{3}{|c|}{ Harmônicas ímpares não múltiplas de 3} & \multicolumn{3}{|c|}{ Harmônicas ímpares múltiplas de 3} \\
\hline \multirow[b]{2}{*}{ Ordem h } & \multicolumn{2}{|c|}{ Harmônica de tensão [\%] } & \multirow[b]{2}{*}{ Ordem h } & \multicolumn{2}{|c|}{ Harmônica de tensão [\%] } \\
\hline & $\begin{array}{c}1 \mathrm{kV}<\mathrm{V}_{\mathrm{N}} \\
\leq 35 \mathrm{kV}\end{array}$ & $\begin{array}{c}35 \mathrm{kV}<\mathrm{V}_{\mathrm{N}} \\
\leq 230 \mathrm{kV}\end{array}$ & & $\begin{array}{c}1 \mathrm{kV}<\mathrm{V}_{\mathrm{N}} \\
\leq 35 \mathrm{kV}\end{array}$ & $\begin{array}{c}35 \mathrm{kV}<\mathrm{V}_{\mathrm{N}} \\
\leq 230 \mathrm{kV}\end{array}$ \\
\hline 5 & 5 & 2 & 3 & 4 & 2 \\
\hline 7 & 4 & 2 & 9 & 1,2 & 1 \\
\hline 11 & 3 & 1,5 & 15 & 0,3 & 0,3 \\
\hline 13 & 2,5 & 1,5 & 21 & 0,2 & 0,2 \\
\hline $17 \leq \mathrm{h} \leq 49$ & $1,9 * \frac{17}{h}-0,2$ & $1,2 * \frac{17}{h}$ & $21<\mathrm{h}<45$ & 0,2 & 0,2 \\
\hline
\end{tabular}




\section{A.3. ANEEL - Agência Nacional de Energia Elétrica}

A atual regulamentação brasileira estabelece que o mínimo fator de potência $(\cos \varphi)$ das unidades consumidoras deve ser de 0,92. Esse limite é determinado pelo Artigo $\mathrm{n}^{\mathrm{o}} 95$ da Resolução ANEEL n ${ }^{\circ} 414$ de 09 de setembro de 2010. O consumo de reativos indutivos entre $6 \mathrm{~h} 00$ e $24 \mathrm{~h} 00$ e reativos capacitivos entre 0 h00 e 6 h00 além do permitido é cobrado do consumidor. No Brasil não há regulamentação dos limites de distorções harmônicas nas instalações elétricas.

A ANEEL elaborou um documento em módulos chamado de Procedimentos de Distribuição de Energia Elétrica no Sistema Elétrico Nacional (PRODIST), que estabelece em seu módulo 8 os procedimentos relativos à qualidade da energia elétrica, tanto do produto, como do serviço prestado que devem ser observados pelos consumidores com instalações conectadas em qualquer classe de tensão de distribuição.

Embora não exista regulamentação específica, existem valores de referência para as distorções harmônicas totais que devem ser iguais ou inferiores aos valores fornecidos na tabela A3.1. No cálculo da distorção total devem ser consideradas as harmônicas até a $25^{\mathrm{a}}$ ordem. Além disso, também devem ser atendidos os valores limites para as componentes harmônicas individuais de tensão indicadas na tabela A3.2.

Tabela A3.1 - Valores de referência para distorções harmônicas totais de tensão (em porcentagem da componente fundamental de tensão)

\begin{tabular}{c|c}
\hline Tensão Nominal do Barramento & $\begin{array}{c}\text { Distorção Harmônica Total de Tensão } \\
\text { DHTv [\%] }\end{array}$ \\
\hline $\mathrm{V}_{\mathrm{N}} \leq 1 \mathrm{kV}$ & 10 \\
\hline $1 \mathrm{kV}<\mathrm{V}_{\mathrm{N}} \leq 13,8 \mathrm{kV}$ & 8 \\
\hline $13,8 \mathrm{kV}<\mathrm{V}_{\mathrm{N}} \leq 69 \mathrm{kV}$ & 6 \\
\hline $69 \mathrm{kV}<\mathrm{V}_{\mathrm{N}} \leq 138 \mathrm{kV}$ & 3 \\
\hline
\end{tabular}


Tabela A3.2 - Limites máximos para componentes harmônicas individuais de tensão (em porcentagem da tensão fundamental)

\begin{tabular}{|c|c|c|c|}
\hline \multicolumn{2}{|c|}{ Ordem h } & \multicolumn{2}{|c|}{ Harmônicas de tensão [\%] } \\
\hline & & $13,8 \mathrm{kV}<\mathrm{V}_{\mathrm{N}} \leq 69 \mathrm{kV}$ & $69 \mathrm{kV}<\mathrm{V}_{\mathrm{N}} \leq 138 \mathrm{kV}$ \\
\hline \multirow{9}{*}{$\begin{array}{l}\text { Ímpares não } \\
\text { múltiplas de } 3\end{array}$} & 5 & 4,5 & 2,5 \\
\hline & 7 & 4 & 2 \\
\hline & 11 & 3 & 1,5 \\
\hline & 13 & 2,5 & 1,5 \\
\hline & 17 & 1,5 & 1 \\
\hline & 19 & 1,5 & 1 \\
\hline & 23 & 1,5 & 1 \\
\hline & 25 & 1,5 & 1 \\
\hline & $>25$ & 1 & 0,5 \\
\hline \multirow{5}{*}{$\begin{array}{c}\text { Ímpares múltiplas } \\
\text { de } 3\end{array}$} & 3 & 4 & 2 \\
\hline & 9 & 1,5 & 1 \\
\hline & 15 & 0,5 & 0,5 \\
\hline & 21 & 0,5 & 0,5 \\
\hline & $>21$ & 0,5 & 0,5 \\
\hline \multirow{7}{*}{ Pares } & 2 & 1,5 & 1 \\
\hline & 4 & 1 & 0,5 \\
\hline & 6 & 0,5 & 0,5 \\
\hline & 8 & 0,5 & 0,5 \\
\hline & 10 & 0,5 & 0,5 \\
\hline & 12 & 0,5 & 0,5 \\
\hline & $>12$ & 0,5 & 0,5 \\
\hline
\end{tabular}

